South Asia Development Matters
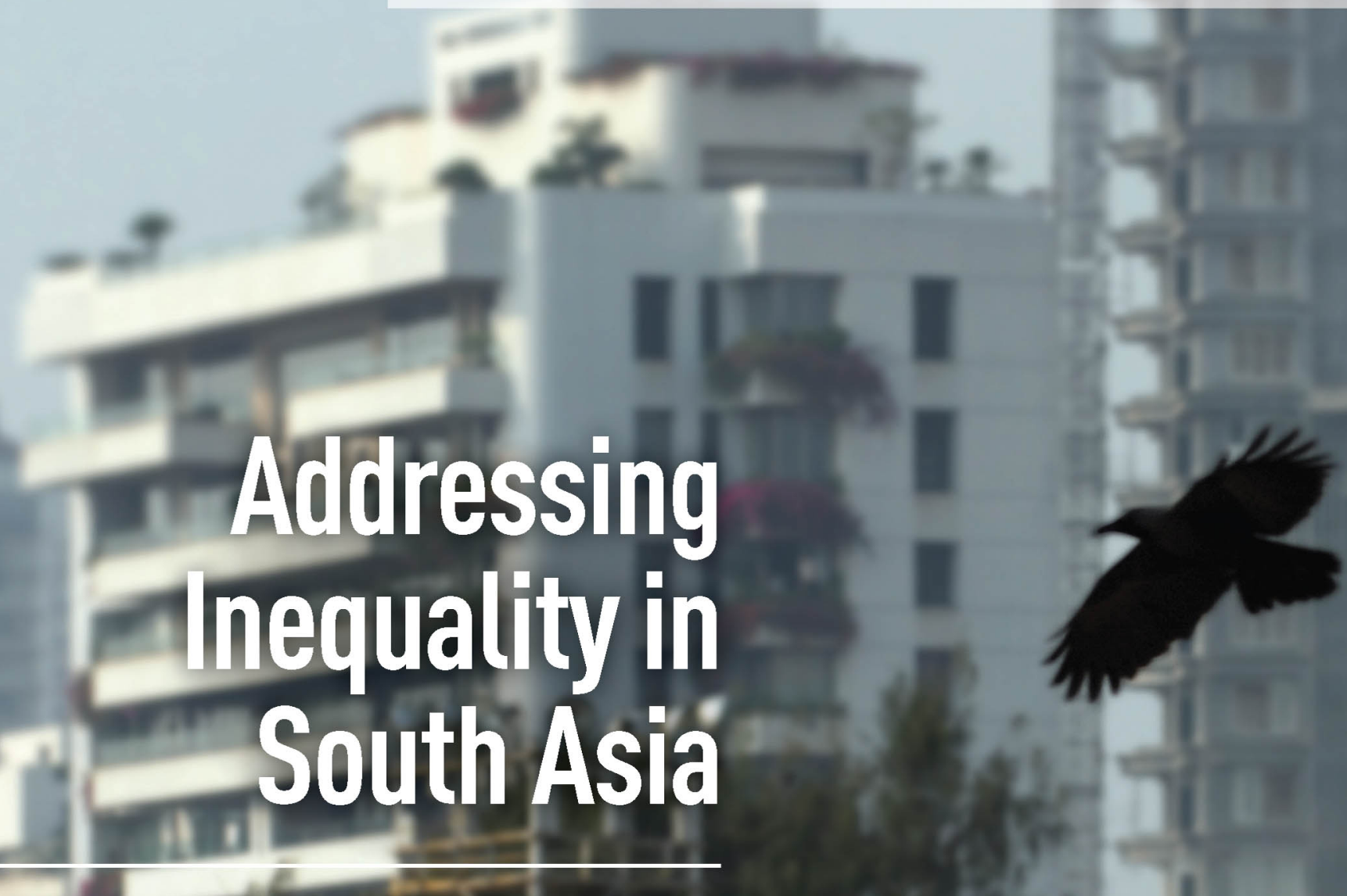

Martín Rama, Tara Béteille, Yue Li, Pradeep K. Mitra, and John Lincoln Newman

(4) WORLD BANK GROUP
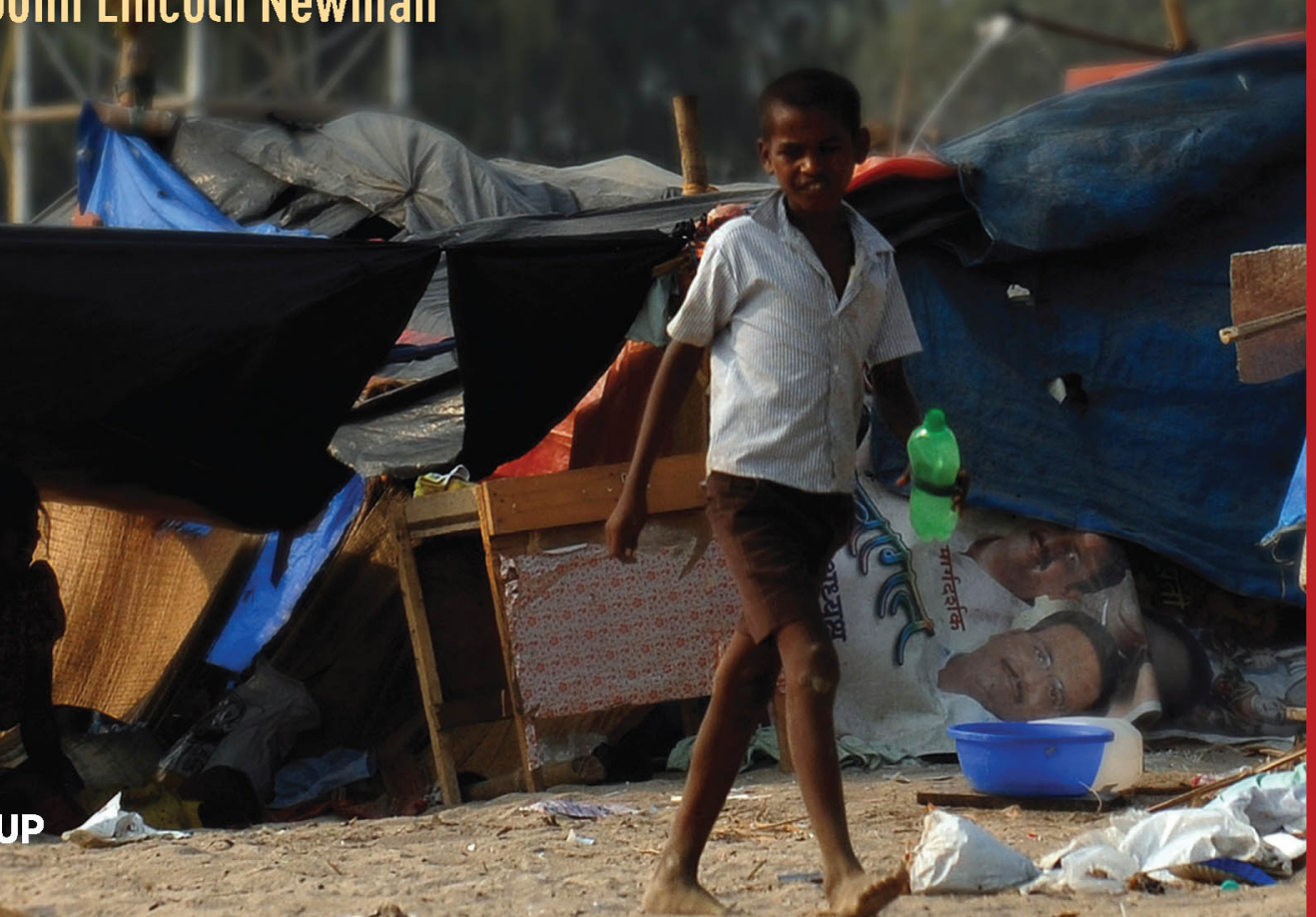

Addressing Inequality in South Asia 



\section{Addressing Inequality in South Asia}

Martín Rama, Tara Béteille, Yue Li, Pradeep K. Mitra, and John Lincoln Newman 
(C) 2015 International Bank for Reconstruction and Development / The World Bank

1818 H Street NW, Washington DC 20433

Telephone: 202-473-1000; Internet: www.worldbank.org

Some rights reserved

\section{4}

This work is a product of the staff of The World Bank with external contributions. The findings, interpretations, and conclusions expressed in this work do not necessarily reflect the views of The World Bank, its Board of Executive Directors, or the governments they represent. The World Bank does not guarantee the accuracy of the data included in this work. The boundaries, colors, denominations, and other information shown on any map in this work do not imply any judgment on the part of The World Bank concerning the legal status of any territory or the endorsement or acceptance of such boundaries.

Nothing herein shall constitute or be considered to be a limitation upon or waiver of the privileges and immunities of The World Bank, all of which are specifically reserved.

\section{Rights and Permissions}

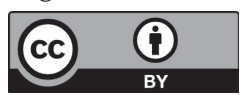

This work is available under the Creative Commons Attribution 3.0 IGO license (CC BY 3.0 IGO) http:// creativecommons.org/licenses/by/3.0/igo. Under the Creative Commons Attribution license, you are free to copy, distribute, transmit, and adapt this work, including for commercial purposes, under the following conditions:

Attribution-Please cite the work as follows: Rama, Martín, Tara Béteille, Yue Li, Pradeep K. Mitra, and John Lincoln Newman. 2015. Addressing Inequality in South Asia. South Asia Development Matters. Washington, DC: World Bank. doi: 10.1596/978-1-4648-0022-1. License: Creative Commons Attribution CC BY 3.0 IGO

Translations-If you create a translation of this work, please add the following disclaimer along with the attribution: This translation was not created by The World Bank and should not be considered an official World Bank translation. The World Bank shall not be liable for any content or error in this translation.

Adaptations - If you create an adaptation of this work, please add the following disclaimer along with the attribution: This is an adaptation of an original work by The World Bank. Views and opinions expressed in the adaptation are the sole responsibility of the author or authors of the adaptation and are not endorsed by The World Bank.

Third-party content-The World Bank does not necessarily own each component of the content contained within the work. The World Bank therefore does not warrant that the use of any third-partyowned individual component or part contained in the work will not infringe on the rights of those third parties. The risk of claims resulting from such infringement rests solely with you. If you wish to re-use a component of the work, it is your responsibility to determine whether permission is needed for that re-use and to obtain permission from the copyright owner. Examples of components can include, but are not limited to, tables, figures, or images.

All queries on rights and licenses should be addressed to the Publishing and Knowledge Division, The World Bank, 1818 H Street NW, Washington, DC 20433, USA; fax: 202-522-2625; e-mail: pubrights@worldbank.org.

ISBN (paper): 978-1-4648-0022-1

ISBN (electronic): 978-1-4648-0023-8

DOI: $10.1596 / 978-1-4648-0022-1$

Cover photo: (C) Chris Stowers / Panos Pictures. Used with the permission of Chris Stowers / Panos Pictures. Further permission required for reuse.

Cover design: Critical Stages

Library of Congress Cataloging-in-Publication Data has been requested. 


\section{Contents}

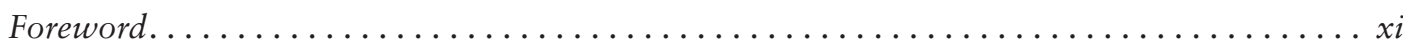

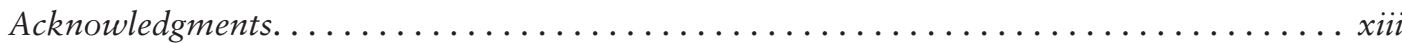

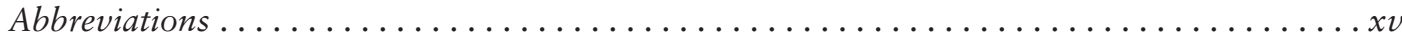

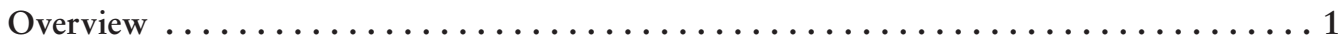

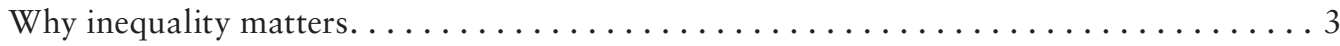

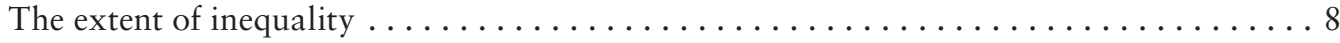

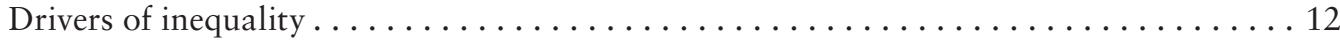

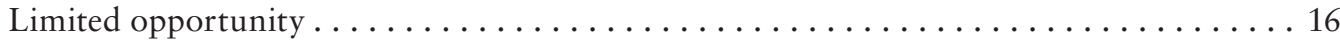

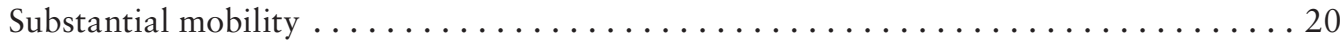

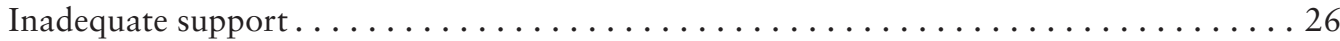

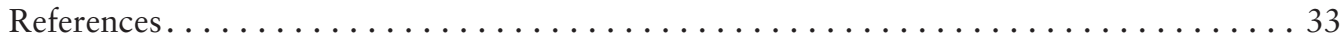

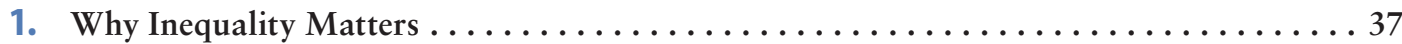

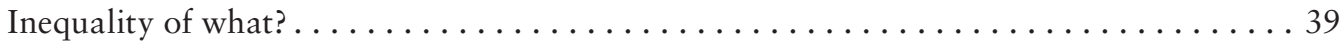

Opportunities versus outcomes . . . . . . . . . . . . . . . . . . . . 39

Monetary measures of inequality ......................... 42

Multidimensional indicators of inequality ................... 43

Subjective well-being. .............................. 47

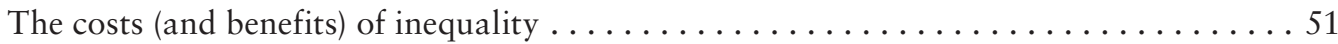

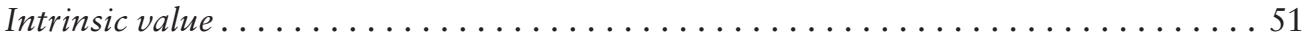

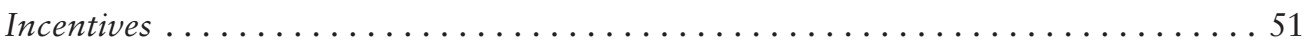

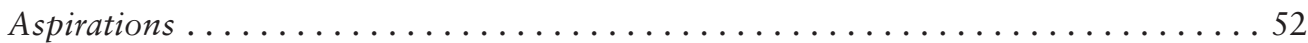

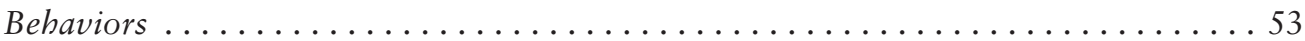

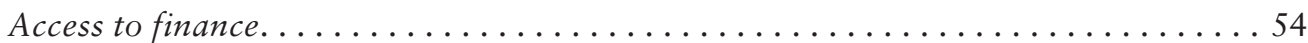

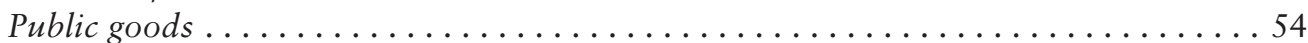

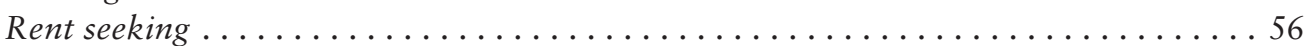

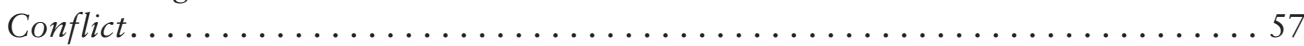


References........................................... 59

Why inequality matters: Main messages and policy implications................60 60

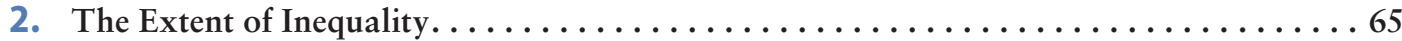

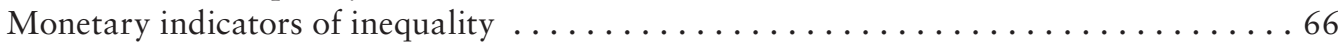

Nonmonetary dimensions of inequality $\ldots \ldots \ldots \ldots \ldots \ldots \ldots \ldots \ldots \ldots \ldots, \ldots \ldots$

Monetary inequality is increasing $\ldots \ldots \ldots \ldots \ldots \ldots \ldots \ldots \ldots \ldots \ldots \ldots \ldots, \ldots \ldots \ldots$

Mixed trends in nonmonetary inequality $\ldots \ldots \ldots \ldots \ldots \ldots \ldots \ldots \ldots \ldots . \ldots \ldots$

What lies behind inequality?.............................. 86

The extent of inequality: Main messages and policy implications ............. 93

References..........................................994

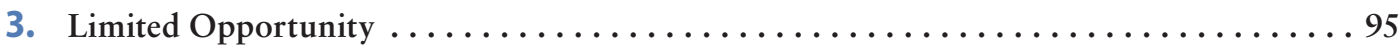

Inequality in access to basic services.......................... 97

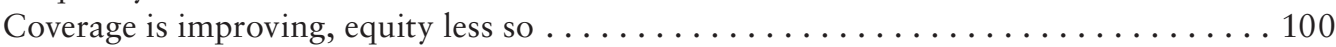

Who is covered? ......................................... 105

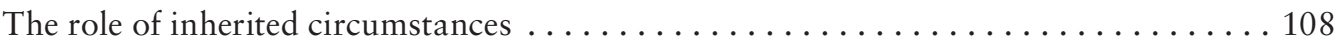

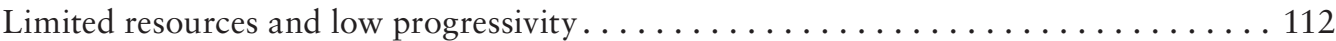

Limited opportunity: Main messages and policy implications ................ 117

References............................................... 117

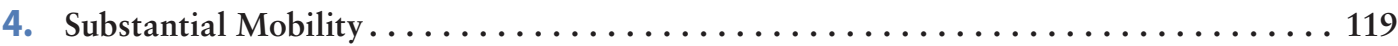

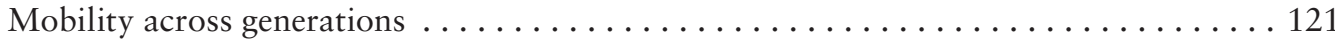

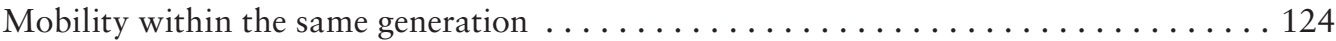

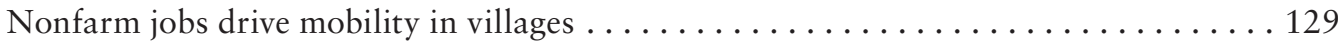

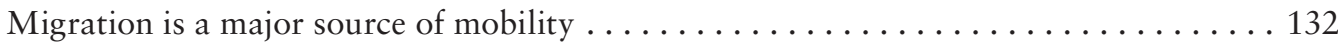

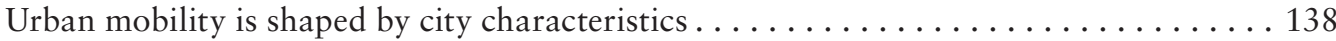

Substantial mobility: Main messages and policy implications ................. 146

References........................................... 147

5. Inadequate Support................................... 151

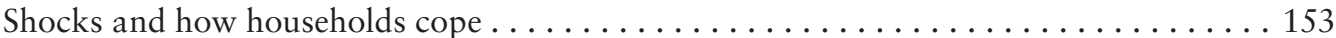

A scorecard for social protection programs . . . . . . . . . . . . . . . . . . 159

The distributional impact of taxes ............................ 164

Wasteful and often regressive subsidies........................... 168

The promise of intergovernmental transfers . . . . . . . . . . . . . . . . . 171

Inadequate support: Main messages and policy implications ................. 173

References ........................................... 174

\section{Boxes}

1.1 Discrimination by teachers pushes children out of school $\ldots \ldots \ldots \ldots \ldots \ldots \ldots 41$

$1.2 \quad$ Standard statistical measures of monetary inequality $\ldots \ldots \ldots \ldots \ldots \ldots \ldots 44$

1.3 Some monetary indicators may underestimate the true extent of inequality $\ldots \ldots \ldots 46$

$1.4 \quad$ Bhutan uses a happiness index to measure well-being $\ldots \ldots \ldots \ldots \ldots \ldots \ldots 50$

2.1 South Asian household surveys used in this report . . . . . . . . . . . . . . . 67

3.1 In demographic transitions, inequality of opportunity increases inequality of outcomes .......................................96

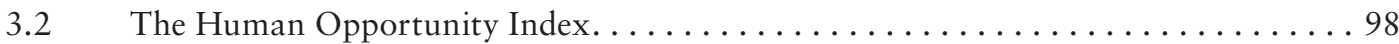

4.1 For a given inequality of opportunity, mobility reduces the inequality of outcomes . . 120

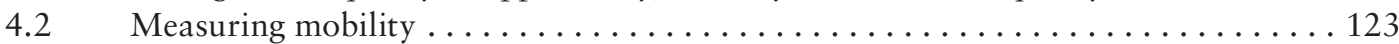

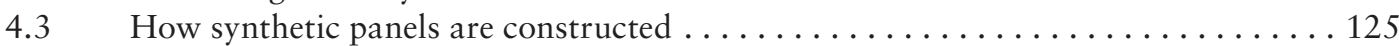


4.4 International migration supports upward mobility in Bangladesh and Nepal . . . . 138

5.1 Support aims at offsetting inequality of outcomes stemming from bad luck . . . . 152

5.2 Bangladesh has a rich and complex social protection architecture. . . . . . . . 160

5.3 The adequacy of social assistance programs has declined in Bangladesh........ 164

\section{Figures}

1 Based on standard monetary indicators, South Asia has moderate levels of inequality . . . 2

2 Billionaire wealth in India is exceptionally large $\ldots \ldots \ldots \ldots \ldots \ldots \ldots \ldots$

3 The health outcomes of the poor are among the worst worldwide.......... 5

$4 \quad$ Returns to education create incentives to study $\ldots \ldots \ldots \ldots \ldots \ldots \ldots \ldots \ldots$

5 Greater inequality reduces the quality of public services when the rich can opt out . . 7

6 Poverty is higher in Indian districts suffering from Naxalite violence . . . . . . . . 8

$7 \quad$ The least wealthy are alarmingly vulnerable $\ldots \ldots \ldots \ldots \ldots \ldots \ldots \ldots$

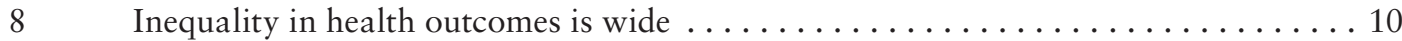

9 Schooling among young adults is highly unequal in some countries in South Asia ... 11

10 Richer countries tend to be more unequal in both South Asia and East Asia...... . 12

11 Monetary inequality is increasing across most of South Asia. . . . . . . . . . 13

12 South Asians do not see an environment conducive to lower inequality. . . . . . . . 14

13 Multiple factors affect household outcomes relative to others in society . . . . . . 15

14 Opportunities in education are better than in health or sanitation, as measured by the HOI. . . . . . . . . . . . . . . . . . . . . . . 17

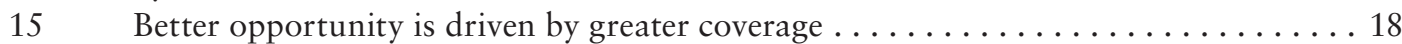

16 Parent's education and location are critically important circumstances. . . . . . . . . 19

17 Considerable occupational mobility exists across generations in India . . . . . . . . 21

18 Occupational mobility is higher for younger generations. . . . . . . . . . . 21

19 Upward mobility in South Asian countries is similar to that in the United States

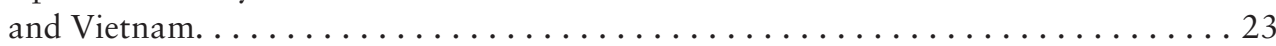
Upward mobility is much stronger in cities than in rural areas . . . . . . . . . 24 The composition of urban employment varies with city size and governance in India. . . 27 In Pakistan, poorer and richer households cope with shocks in different ways . . . . 28 Social assistance is less adequate than social insurance but has greater coverage. . . . 30 Electricity subsidies favor the better-off. . . . . . . . . . . . . . 33 Development spending per person is lower in poorer states and districts. . . . . . 33 Estimates of expenditures differ between household surveys and national accounts . . 45 Monetary and nonmonetary indicators can lead to opposite conclusions . . . . . . 48

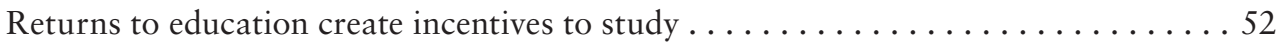
Greater inequality in landholdings is associated with lower asset accumulation

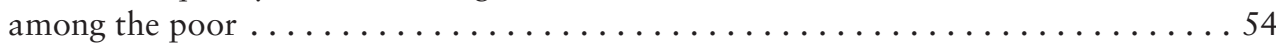

1.5 Greater inequality reduces the quality of public services when the rich can opt out ...55

1.6 Inequality was highest under rent-seeking colonial rule. . . . . . . . . . . 56

1.7 Poverty is higher in Indian districts suffering from Naxalite violence . . . . . . . . 58

2.1 Based on standard monetary indicators, South Asia has moderate levels of inequality . . .69

2.2 Top incomes have been rising in India since the $1980 \mathrm{~s} \ldots \ldots \ldots \ldots \ldots \ldots \ldots$

2.3 The distribution of wealth is more concentrated than that of consumption in India . . .73

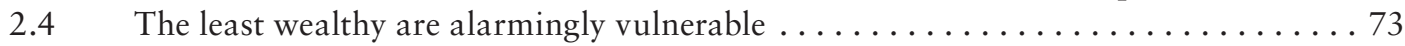

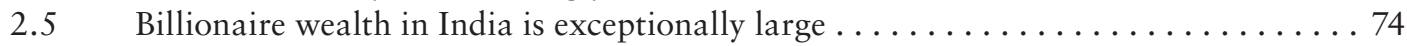

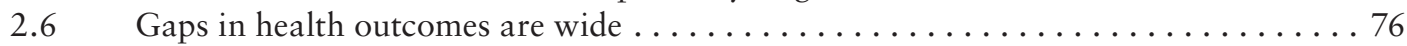

2.7 The health outcomes of the poor are among the worst worldwide $\ldots \ldots \ldots \ldots \ldots 78$

2.8 Schooling among young adults is highly unequal in some countries in South Asia . . 79 
2.9 Gaps in educational attainment are much narrower among children than

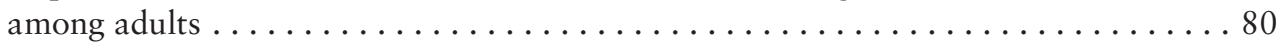

2.10 Among children, similarities in schooling hide disparities in learning in India . . . . 80

2.11 Growth is reducing poverty in South Asia, as it did in East Asia . . . . . . . . . 81

2.12 Richer countries tend to be more unequal in both South Asia and East Asia . . . . . 8 82

2.13 Prosperity has been shared less widely in South and East Asia . . . . . . . . . . 83

2.14 Monetary inequality is increasing across most of South Asia. . . . . . . . . . . 83

2.15 Inequality in health outcomes has remained stable or increased $\ldots \ldots \ldots \ldots \ldots 5$

2.16 Inequality in educational attainment is generally decreasing . . . . . . . . . 86

2.17 Learning outcomes have deteriorated in rural India and rural Pakistan . . . . . . . 87

2.18 The gap in learning outcomes between ethnic groups is declining in Sri Lanka. . . . . 88

2.19 Education explains a growing share of overall inequality $\ldots \ldots \ldots \ldots \ldots \ldots 8$

2.20 The rural-urban divide is becoming a more important source of inequality . . . . 8 89

2.21 Caste is an important correlate of inequality in some Indian states . . . . . . . . . 990

2.22 South Asians do not see an environment conducive to lower inequality. . . . . . . . 91

2.23 Multiple factors affect household outcomes relative to others in society . . . . . . . 992

3.1 The Human Opportunity Index for basic health services is low in most of South Asia . . .99

3.2 The Human Opportunity Index for education is low in Afghanistan and Pakistan . . 101

3.3 The Human Opportunity Index for sanitation is especially low . . . . . . . . . 102

3.4 Opportunities have improved faster in primary education than in health services. . 103

3.5 Better opportunities in health are driven by greater coverage of basic services . . . 103

3.6 Better opportunities in education reflect greater coverage and higher equity in

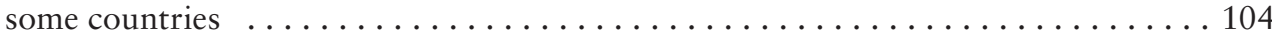

3.7 The coverage of institutional births is lower in rural areas . . . . . . . . . . . 105

3.8 The urban-rural gap in coverage remains large for secondary education . . . . . 106

3.9 Access to electricity is lower in rural areas. . . . . . . . . . . . . . . 107

3.10 In Bangladesh, children of slum dwellers have less access to education . . . . . . . 107

3.11 The coverage of health services is almost the same for boys and girls in South Asia . . 108

3.12 Gender gaps in coverage are small for primary education but large for secondary education . . . . . . . . . . . . . . . . . . . . . . . . . . . . . . . 109

3.13 The coverage of health services differs widely by mother's education . . . . . . . . 110

3.14 Parents' education is highly correlated with children's secondary school attainment . . . 111

3.15 Location and mother's education are critically important circumstances in access to health services . . . . . . . . . . . . . . . . . . . . . . . . . . . . . . 112

3.16 Gender and religion matter for access to education . . . . . . . . . . . . . 113

3.17 Location is a critical circumstance for access to infrastructure services. . . . . . . . . 114

3.18 Limited public resources are spent on health services in South Asia . . . . . . . . . 114

3.19 Spending is progressive only for some health services in Bangladesh . . . . . . . . . 115

3.20 Limited public resources are spent on education services. . . . . . . . . . . . . . 116

3.21 In Bangladesh, education spending is progressive only at the primary level. . . . . . 116

4.1 Considerable occupational mobility exists across generations in India . . . . . . . . 124

4.2 Occupational mobility is higher for younger generations. . . . . . . . . . . . . . . 124

4.3 Consumption grows faster among the poor than among the better-off . . . . . . 126

4.4 Upward mobility in South Asian countries is similar to that of the United States

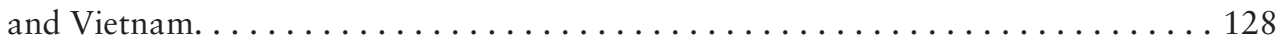

4.5 Upward mobility in India is strong for the Scheduled Castes and Scheduled Tribes. . 128

4.6 Upward mobility is substantial in rural Bangladesh and rural India . . . . . . . . . 129

4.7 Rural India and rural Pakistan have seen a consistent expansion of nonfarm employment . . . . . . . . . . . . . . . . . . . . . . . . . . . . . 130

4.8 Casual rural jobs provide increasingly higher earnings in India $\ldots \ldots \ldots \ldots \ldots 131$ 
4.9 Among men, permanent migration is driven by job aspirations . . . . . . . . 133

4.10 Permanent migrants have higher economic status in India. . . . . . . . . . . . 135

4.11 Seasonal migration is more common among poor and socially disadvantaged groups in India . . . . . . . . . . . . . . . . . . . . . . 135

4.12 Migration provides opportunities for occupational mobility to women in India . . . 137

4.13 Upward mobility is much stronger in cities than in rural areas . . . . . . . . . . 139

4.14 Even self-employment and casual work support upward mobility in urban areas . . 141

4.15 Many informal sector workers are wage earners in urban India . . . . . . . . . . . 141

4.16 South Asian countries are less urban than their peers . . . . . . . . . . . . . . . . 142

4.17 The composition of urban employment varies with city size in India . . . . . . . . . 144

4.18 The composition of urban employment also varies with city governance in India . . 145

5.1 Health-related events and disasters are the most common shocks in Pakistan.... . 155

5.2 Disasters in Pakistan affect rural populations much more than urban populations. . 156

5.3 In Pakistan, poorer and richer households cope with shocks in different ways . . . 158

$5.4 \quad$ Spending on health is mainly out of households' pockets. . . . . . . . . . . 158

5.5 Spending on social protection in South Asia is lower than in other developing

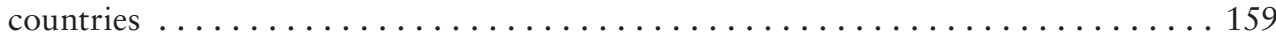

5.6 Absolute spending on social protection is progressive in Bangladesh and Sri Lanka ... 161

5.7 Social assistance is less adequate than social insurance but has greater coverage. . . 163

5.8 Tax revenue is lower than in other countries at a similar development level . . . . 165

5.9 South Asian countries rely less on income taxes and more on trade taxes . . . . . . 166

5.10 In Pakistan, even registered taxpayers fail to file tax returns. . . . . . . . . . 167

5.11 Relative to their means, the poor in Pakistan pay almost as much tax as the

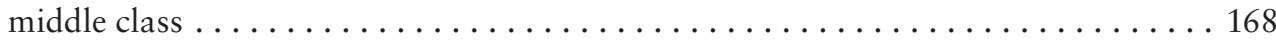

5.12 Much public spending goes into energy subsidies. . . . . . . . . . . . . . 169

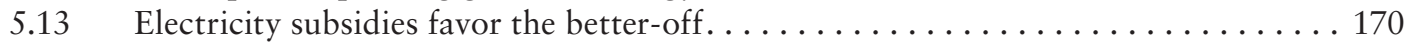

5.14 Intergovernmental transfers benefit poorer states and provinces . . . . . . . . 171

5.15 Development spending per person is lower in poorer states and districts. . . . . . . 172

\section{Maps}

1 Government revenue in South Asia is low compared with the rest of the world. . . . . 31

5.1 Government revenue in South Asia is low compared with the rest of the world.... 165

\section{Tables}

1 Changes in employment status reveal substantial mobility among migrant men

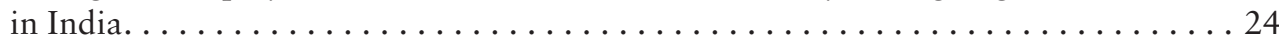

2 Rural jobs allow people to escape poverty; urban jobs are a ticket to the middle class. . . 25

4.1 Occupational mobility has increased more for the most disadvantaged population groups in India . . . . . . . . . . . . . . . . . . . . . . 124

4.2 Upward mobility is considerable among the poor and the vulnerable . . . . . . 127

4.3 Changes in employment status reveal substantial mobility among migrant men in India. . . . . . . . . . . . . . . . . . . . . . . . . . 134

4.4 Rural jobs allow people to escape poverty; urban jobs are a ticket to the middle class . . . . . . . . . . . . . . . . . . . . . . . . . . . . . 140

5.1 Bangladesh suffered 2 of the 10 most deadly natural disasters of recent times . . . 154 



\section{Foreword}

T

he extent of inequality, and what to do about it, are among the most hotly debated issues in economics. Every faith and ideology has normative views on how much inequality is tolerable, or desirable. And to complicate matters, equality along a dimension that matters for some members of society often entails inequality in some respect that others care about. Debates on inequality seem to become more intense in periods of rapid structural transformation, both in advanced economies and in developing countries. As jobs migrate abroad, or people move to cities, or a modern sector emerges, the entire distribution of well-being is shaken. Age-old rankings that seemed cast in stone become compromised, new fortunes are made-sometimes quickly_and the entire social fabric comes under stress.

Those are times when calls for action abound. But they are also times of confusion: on the extent of inequality, on its drivers, and on its implications. Debates are often framed in either-or terms which are not particularly enlightening. Rivers of ink are devoted to discussing whether the government should tackle inequality or boost growth "first," for instance. There is also a tendency to focus on simple, aggregate indicators of inequality which tend to hide as much as they reveal. Indeed, high inequality should be less of a concern in a society with high mobility, where people from disadvantaged backgrounds and their offspring can prosper. Conversely, even apparently low levels of inequality could justify corrective interventions if higher earnings result from connections and rent seeking, rather than from hard work and entrepreneurship.

This report takes a fresh look at inequality in South Asia, one of the most dynamic regions in the world. It does so with a focus on well-being, exploring both monetary and non-monetary dimensions of inequality. The former include income, consumption and wealth. The latter comprise access to basic services in health, education, and infrastructure, as well as subjective assessments.

This combination of perspectives is revealing. In particular, countries in South Asia do not appear to be particularly unequal when focusing on consumption per person, but the region is host to both extravagant wealth at the top and appalling human development outcomes at the bottom. This in itself says something about what is working well-the ability of people to make a living - and what is not working so well-the delivery of basic 
social services and the channeling of support to those in need.

The report also makes an analytical contribution, by providing a clear framework to think about inequality and what to do about it. This framework considers not only opportunity in childhood, but also mobility in adulthood, and support throughout life. The focus on opportunity, dominant in recent applied work on equity, brings warranted attention to the social sectors: access to education, quality of schooling, coverage of health programs... Not surprisingly, this focus has been associated with an emphasis on entitlements and rights-based approaches. But limiting our attention to opportunity also runs the risk of downplaying other very important areas of public policy. The most dramatic structural transformation South Asia is going through is urbanization. The occupational and geographic transitions associated with it are shaping mobility across and within generations. South Asia is also a region characterized by low tax revenue and massive subsidies, affecting the capacity of governments to provide adequate support throughout life.

The combination of a broad range of indicators with a focus on individuals' wellbeing throughout the lifecycle yields important insights. The report confirms that the region still has a way to go if it wants to ensure opportunity in childhood. There has been enormous progress in the coverage of primary school, but the quality of education received by the poor, and access to secondary school for girls, remain important challenges. The same applies to access to health services and sanitation, with rural areas being at a serious disadvantage. A clear agenda for the social sectors can be derived from these analyses.

There are also shortcomings in the support people receive throughout life. The region is home to some remarkable social protection programs, which have attracted worldwide attention. But beyond these targeted interventions, widespread tax avoidance and evasion, combined with regressive subsidies for electricity and fuel, imply that the poor receive relatively little support from the rich. Intergovernmental transfers, channeling resources from rich to poor areas, are progressive; but for now they are not large enough to make a big difference. There is obviously a fiscal agenda out of these findings.

Perhaps the most important new insight from the report concerns mobility in adulthood. Despite South Asia's being a region characterized by high informality and haphazard urbanization, jobs and migration have performed much better than could be expected. Occupational mobility is increasing steadily from one generation to the next. Within the same generation, mobility in earnings - measured by the ability to move out of poverty and into the middle class-is comparable to that of the United States or Vietnam. Importantly, jobs seem to trump caste as the extent of mobility is similar for groups across the entire social spectrum. Nurturing this dynamism should be the highest priority for those who care about addressing inequality. And that involves an agenda for urbanization and private sector development.

Philippe Le Houérou Vice-President for South Asia The World Bank 


\section{Acknowledgments}

This report was prepared by a core team led by Martín Rama and includ( ing Tara Béteille, Yue Li, Pradeep K. Mitra, and John Lincoln Newman. The other members of the team were Gladys López-Acevedo, Cem Mete, and Albertus Voetberg. Important contributions were made by Mehtabul Azam, Olivier Dupriez, Virgilio Galdo, Minh Cong Nguyen, María Florencia Pinto, and Kritika Saxena. Additional research support was provided by Claudia Berg, Bilgehan Gokcen, Rehan Rafay Jamil, Ayesha Raheem, and Amir Sadegh Sadeghi.

Former Regional Vice President for South Asia Isabel Guerrero and Regional Vice President Philippe H. Le Houérou provided overall guidance and invaluable insights during the preparation process.

A set of background papers was commissioned for the report. They were prepared by Luis Alberto Andrés, Yamini Aiyar, Dan Biller, Anirvan Chowdhury, Hai-Anh H. Dang, Ambrish Dongre, Agustin Echenique,
Varun Gauri, Karla Hoff, Shahidur Khandker, Peter Lanjouw, Ghazala Mansuri, Mario Picon, and Vyjayanthi Sankar.

Ravi Kanbur served as an external adviser. Pranab Bardhan, Peter Lanjouw, Julián Messina, and Branko Milanovic were the peer reviewers. They all contributed rich feedback throughout the preparation process.

The production of the report and the logistics supporting it were assured by Neelam Chowdhry, Maya S. Krishnan, and Muhammad Shafiq. Eva Franzuela Cardenas was in charge of resource management.

The World Bank's Publishing and Knowledge Unit was in charge of the design, typesetting, printing, and dissemination of both the hard and soft version of the report. Martha Gottron and Laura Glassman edited the report. Special thanks go to Aziz Gökdemir and Patricia Katayama for coordinating the entire process.

The team also thanks Alex Anthony Ferguson and Gabriela Aguilar Martínez for their guidance on communication. 



\section{Abbreviations}

$\begin{array}{ll}\text { BBS } & \text { Bangladesh Bureau of Statistics } \\ \text { BISP } & \text { Benazir Income Support Programme } \\ \text { BLSS } & \text { Bhutan Living Standards Survey } \\ \text { CIT } & \text { corporate income tax } \\ \text { DHS } & \text { Demographic and Health Survey } \\ \text { DRM } & \text { day reconstruction method } \\ \text { FFE } & \text { Food for Education } \\ \text { GDP } & \text { gross domestic product } \\ \text { GE } & \text { Generalized Entropy (Index) } \\ \text { GNH } & \text { Gross National Happiness } \\ \text { HIES } & \text { Household Income and Expenditure Survey } \\ \text { HOI } & \text { Human Opportunity Index } \\ \text { IHDS } & \text { India Human Development Survey } \\ \text { LFS } & \text { Labor Force Survey } \\ \text { LPG } & \text { liquefied petroleum gas } \\ \text { MGNREG } & \text { Mahatma Gandhi National Rural Employment Guarantee (Act) } \\ \text { MLD } & \text { mean log deviation } \\ \text { NEREC } & \text { National Education Research and Evaluation Centre [Sri Lanka] } \\ \text { NLSS } & \text { Nepal Living Standards Survey } \\ \text { NRVA } & \text { National Risk and Vulnerability Assessment } \\ \text { NSS } & \text { National Sample Survey } \\ \text { PDS } & \text { Public Distribution System [India] } \\ \text { PPP } & \text { purchasing power parity } \\ \text { PSLM } & \text { Pakistan Social and Living Standards Measurement } \\ \text { OECD } & \text { Organisation for Economic Co-operation and Development } \\ \text { UN } & \text { United Nations } \\ \text { VAT } & \text { value added tax } \\ \text { VPA } & \text { Vulnerability and Poverty Assessment } \\ \text { WDI } & \text { World Development Indicators } \\ \text { WHO } & \text { World Health Organization } \\ & \end{array}$





\section{Overview}

F ifty years have passed since the Nobel laureate, poet-turned-plenipotentiary Octavio Paz, saw India, where he was Mexico's ambassador, as "a land of extremes." The poet's muse was his encounter with the profusion of sights and sounds, colors and smells, people and animals that greeted him during his travels on the subcontinent. He described it as "the incredible opulence" of the maharajahs surrounded by what he saw as "equally unbelievable" poverty (Paz 1997). Is that still the case today? And if so, what should be done (and not done) about it?

Despite the enormous progress made on statistical data and analytical tools over these 50 years, assessing whether South Asia remains "a land of extremes" is a significant undertaking. The extent of inequality varies depending on the indicator of individual well-being considered.

The assessment also varies depending on whether attention goes to inequality of opportunity in childhood or to inequality of outcomes in adulthood. Moreover, a static picture that describes the distribution of fortunes at any point in time may miss important insights compared to a more dynamic one that considers mobility throughout the life cycle.
Disentangling what lies behind the "extremes" is even more challenging. What shapes opportunity at birth may be different from what fosters mobility in adulthood. Moreover, inequality can be both good and bad. When differences in fortunes reward hard work and entrepreneurship, they provide incentives for individuals to try their best and in doing so to contribute to everybody's well-being. But when the extremes reflect suppressed aspirations at one end and rent seeking at the other, inequality leads to wasted talent and consolidates institutional arrangements with long-term negative impact on growth and development. Without a clear understanding of the drivers of inequality, policy recommendations on what to do about it could be flawed.

If standard monetary indicators are to be taken at face value, South Asia has modest levels of inequality. Gini coefficients for consumption per capita range between 0.28 and 0.40 depending on the country, much lower than in China, Mexico, or South Africa (figure 1). The share of the poorest 40 percent of households in total consumption also suggests that inequality in South Asian countries is moderate by international standards. 


\section{FIGURE 1 Based on standard monetary indicators, South Asia has moderate levels of inequality}

\section{a. Gini coefficients}

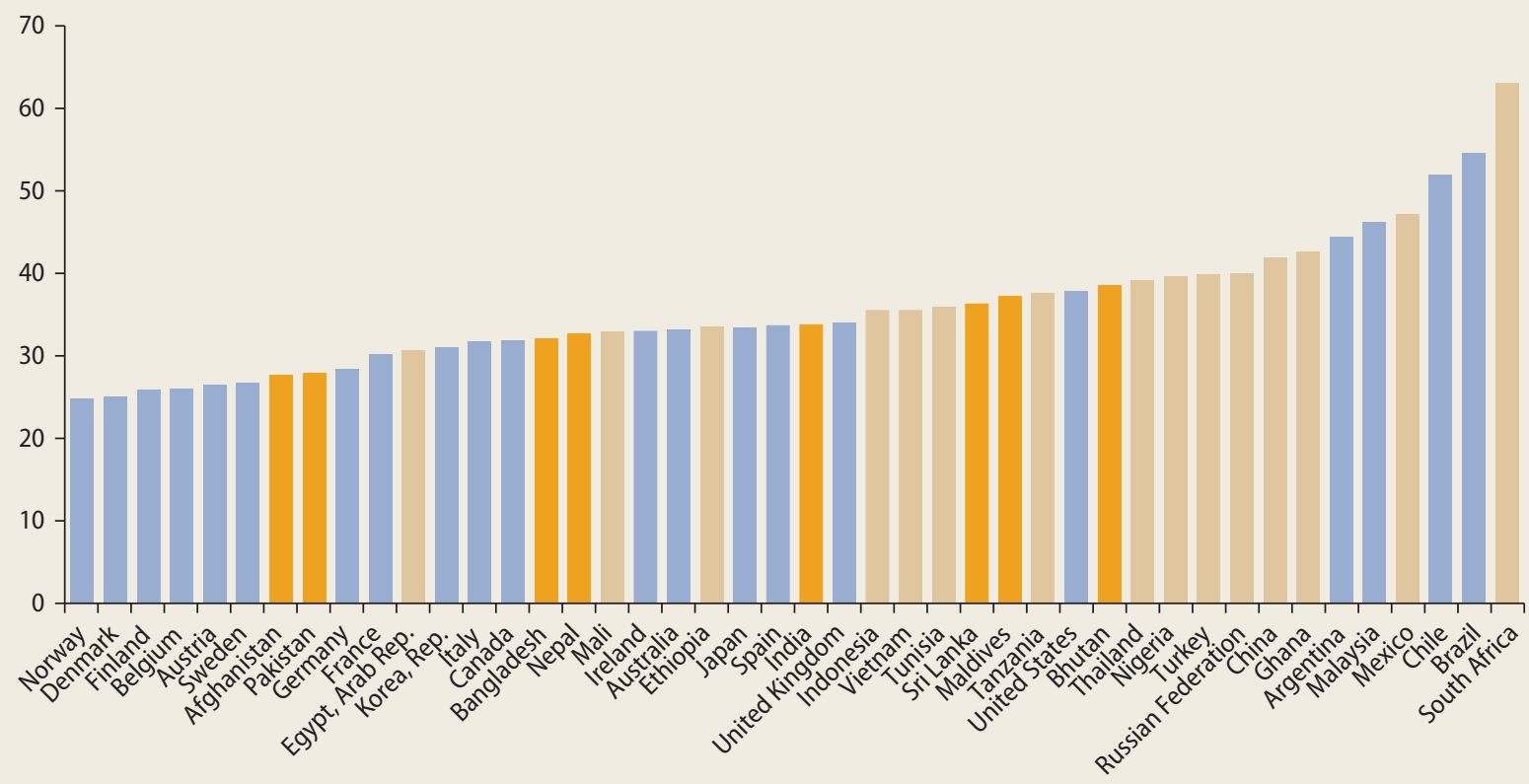

b. Share of the poorest 40 percent

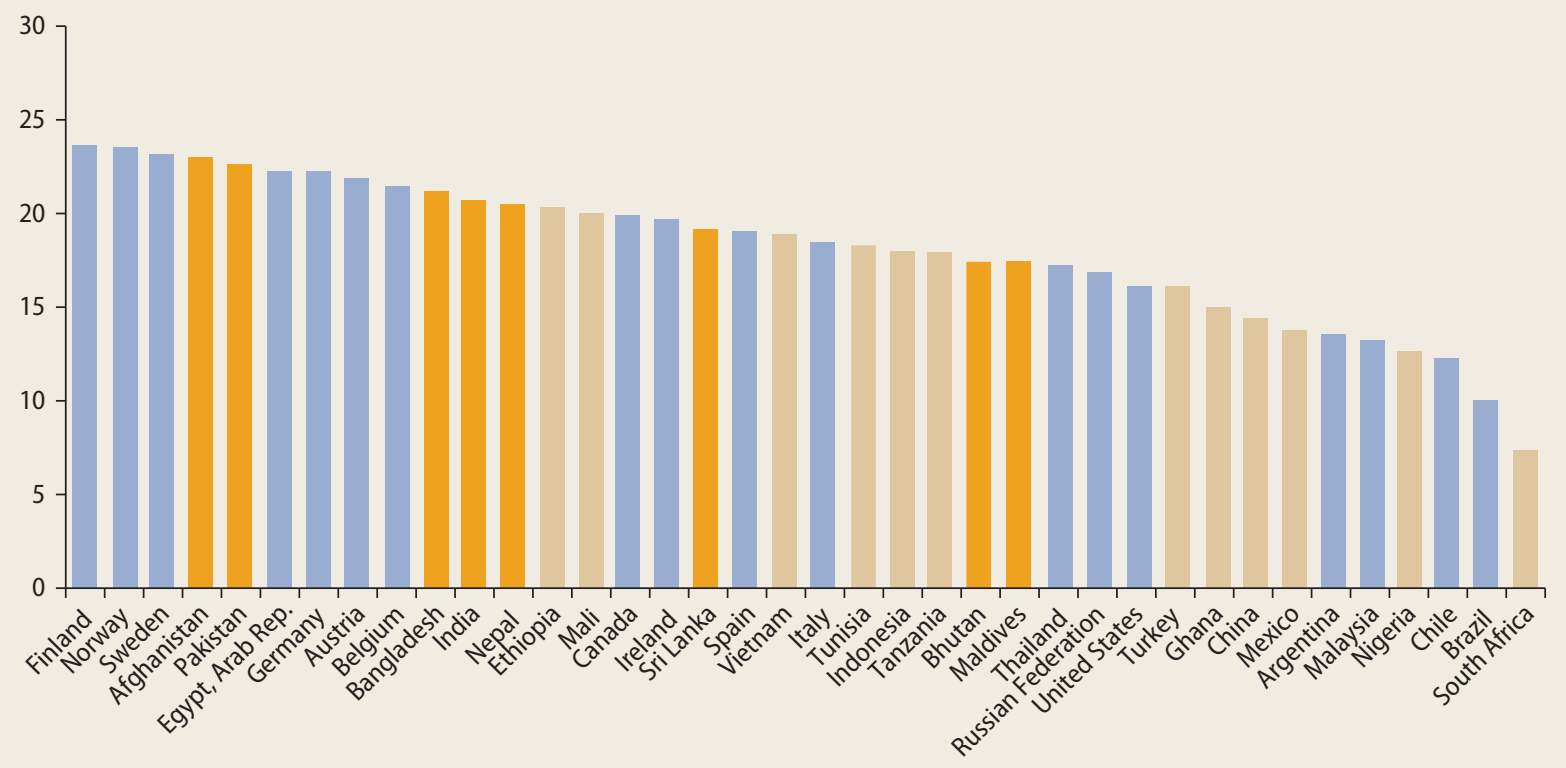

Sources: Based on World Bank's World Development Indicators database, http://data.worldbank.org/data-catalog/world-development-indicators, and the Organisation for Economic Co-operation and Development's (OECD) Income Distribution and Poverty data series, http://stats.oecd.org/Index.aspx?DataSetCode=IDD.

Note: Orange and light brown bars indicate countries where inequality is estimated based on consumption per capita. Light blue bars indicate countries with estimates based on income per capita. 
Arguably, the comparison is tainted by the nature of the monetary indicators considered in different countries. In advanced economies as well as in many Latin American countries, inequality is measured on the basis of income per capita. In South Asian countries, in contrast, most surveys convey information about consumption per capita. Within the same country, income inequality is generally higher than consumption inequality. However, the conclusion that monetary inequality in South Asia is moderate holds even when comparing only countries for which data on consumption per capita are available.

Information on the assets held by the wealthiest offers a complementary perspective on monetary inequality, one in which South Asians at the top are disproportionately rich. In the only two countries in the region with publicly known billionaires, the concentration of billionaire wealth appears to be unusually large in India. According to Forbes magazine (2014), total billionaire wealth amounts to 12 percent of gross domestic product (GDP) in 2012. As such, India is an outlier in the ratio of billionaire wealth to GDP among economies at a similar development level (figure 2).

Nonmonetary indicators of well-being provide a more striking picture than monetary indicators. Despite not being the poorest region in the world, South Asia has some of the worst human development outcomes worldwide, and the comparison is even more dramatic when focusing on the outcomes of the poorest quintile. The share of children under five who are stunted among the poorest quintile is above 50 percent in Bangladesh and Nepal and reaches 60 percent in India (figure 3). India and Pakistan also have some of the highest infant mortality rates and under-five child mortality rates among the poor across all comparators. Of 1,000 children born in India's poorest population quintile, 82 will die within 12 months and 117 within five years. The figures for Pakistan are 94 and 120, respectively.

Joining others in this endeavor, this report takes a positive perspective to assess the extent of inequality. The primary focus of the assessment is inequality of outcomes in relation to both monetary and nonmonetary dimensions of well-being. Inherited circumstances and a variety of shocks affect inequality of outcomes; public policies can offset the contributions of these factors but may instead amplify them. Within a person's life cycle, disparities in opportunity, mobility, and support drive gaps in outcomes. To understand whether something should be done to address inequality in South Asia-and what that should be-this report analyzes the region's performance on these three aspects.

\section{Why inequality matters}

Equality carries an intrinsic value for most of the world's faiths and ideologiesreligious or secular. Every normative theory of social arrangements that has stood the test of time also seems to demand equality of something. However, this report also cares about the ways in which inequality affects social organization and economic performance. In other words, it takes a positive and not just a normative perspective. Seen this way, inequality is neither good nor bad. Some forms of inequality generate costs to society whereas others entail benefits. The issue is to identify the turning point at which the costs of inequality start exceeding its benefits. Doing so in a precise way is clearly out of reach. But economic analysis helps identify the main costs and benefits and aids in getting a sense of their order of magnitude.

Inequality in outcomes profoundly affects how individuals and households behave. At the risk of oversimplifying, some degree of monetary inequality is needed to create incentives for people to study and accumulate human capital, to work instead of taking leisure, to save for the future, and to invest in risky businesses. Returns to education are a clear example of a differentiation in labor earnings that spurs the accumulation of human capital and economic growth but at the same time results in inequality in outcomes. In South Asia, returns are larger the higher the educational attainment of the 
FIGURE 2 Billionaire wealth in India is exceptionally large

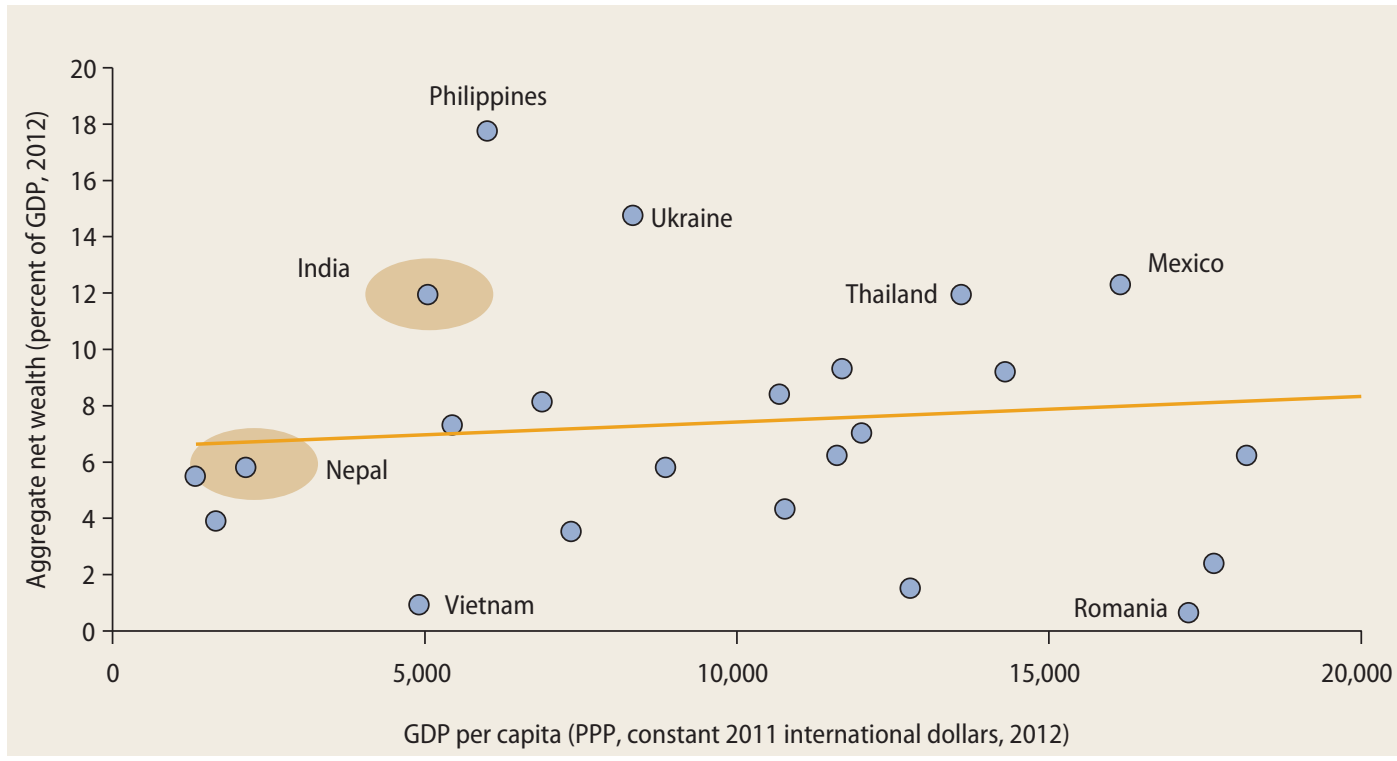

Sources: Based on Forbes magazine's Billionaires database, http://www.forbes.com/billionaires/, and World Bank's WDI database, http://data.worldbank.org /data-catalog/world-development-indicators.

Note: $\mathrm{PPP}=$ purchasing power parity.

person (figure 4). Schooling is of course not the only determinant of labor earnings, and it accounts for only a fraction of earnings variation across individuals. But the relationship between schooling and earnings is robust.

However, incentives may fail to change behavior when economic mobility is lacking. Entrenched inequality of outcomes can significantly undermine individuals' aspirations in youth, affecting their subsequent educational and occupational choices. Confirmatory bias leads people to conform to the stereotype-for example, by discounting the abilities of those who belong to a marginalized group. And entrenched poverty may lead to depression and behavior akin to "learned helplessness" (Hoff 2012).

Effects of this sort have been found to make a substantial difference. In a controlled experiment in India, boys from high and low caste displayed the same ability to solve mazes under monetary incentives, but low-caste boys performed worse if the name and caste of the boys were announced at the beginning of the session. Making caste salient may have evoked in the children memories that changed how they think about themselves and their relationship with others. (Hoff and Pandey 2006, 2012).

The difference can be positive as well. In India, some villages have reserved the position of chief councillor (pradhan) for women. After about seven years of exposure to a female pradhan, the gender gap in aspirations was sharply reduced for teenagers in these villages. Girls were less likely to want to be a housewife, less likely to want their in-laws to determine their occupation, and more likely to want a job that requires more education. The gender gap in educational outcomes was erased in these villages. Because little else changed in terms of actual policy or career opportunities, seeing a woman achieve the position of local head likely provided a role model and affected aspirations, efforts, and educational choices (Beaman and others 2012; Duflo 2012).

Although inequality of outcomes may create incentives to accumulate human and physical capital, it may also affect the capacity of households to borrow for that purpose. If accumulation needs to build on individual or household savings, those at the bottom of the distribution may be unable to increase 


\section{FIGURE 3 The health outcomes of the poor are among the worst worldwide}

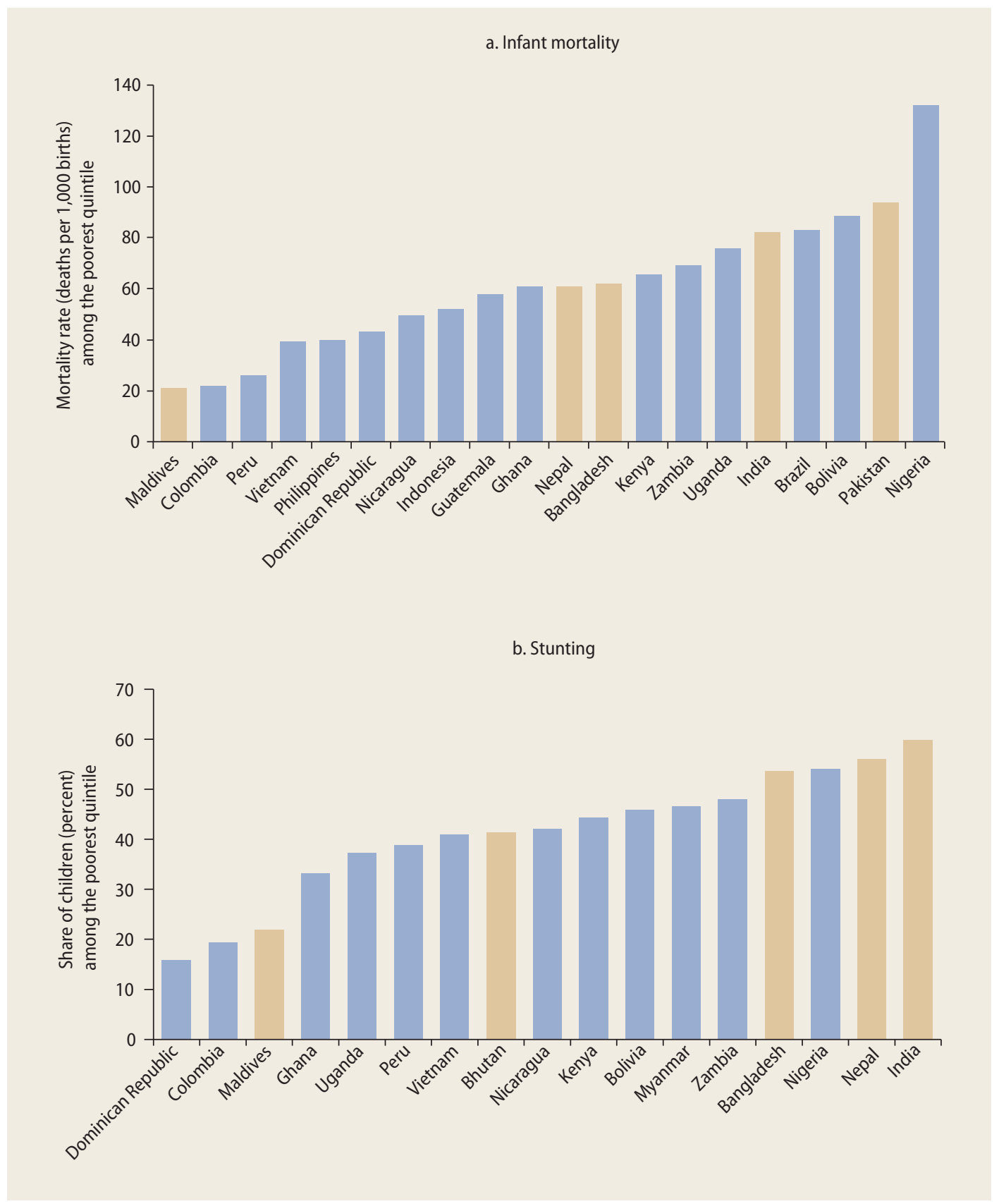

Source: Based on World Bank Health, Nutrition and Population Statistics database, http://datatopics.worldbank.org/hnp/WealthQuintiles.

Note: Infant mortality rate is the number of deaths to children younger than 12 months per 1,000 live births. Stunting is the percentage of children younger than five years of age whose z-scores are two standard deviations or more below World Health Organization (WHO) Child Growth Standards. 
FIGURE 4 Returns to education create incentives to study

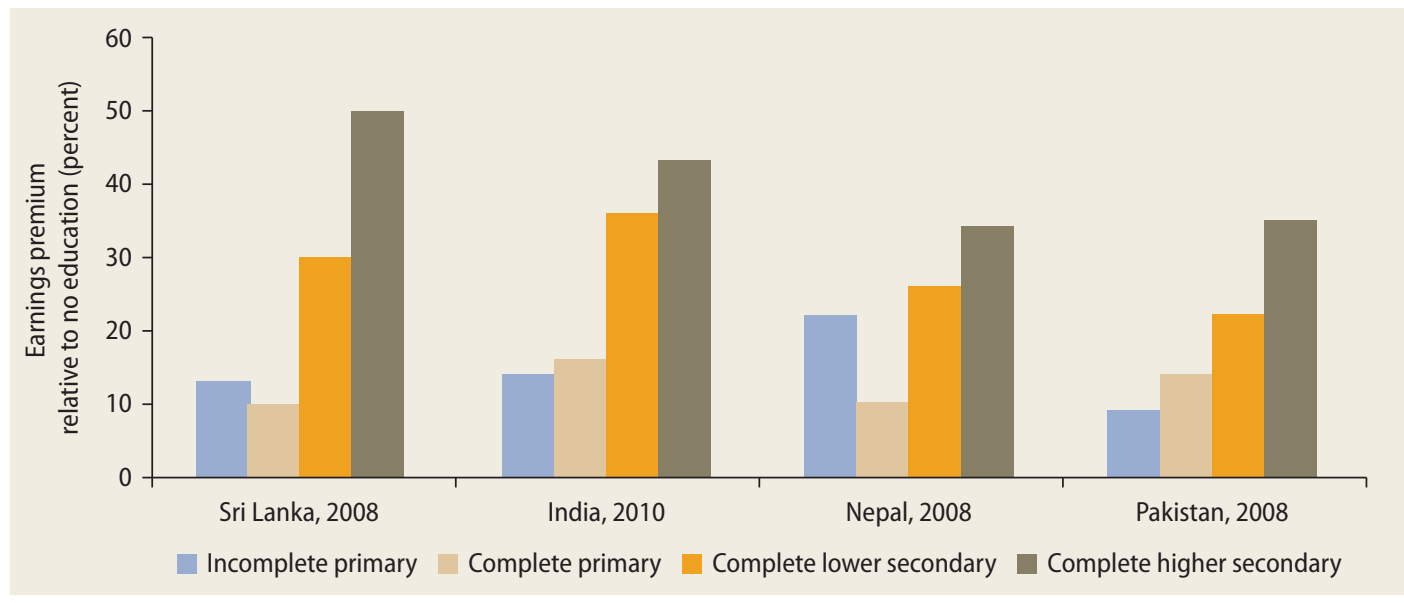

Source: World Bank 2011

their capital significantly, and that in turn may perpetuate inequality. In rural Pakistan, concentration of landholdings is the norm, but the extent of concentration varies from one village to another. Controlling for the initial poverty status and livestock holding of households, the poor are more likely to accumulate livestock in villages with a lower level of land inequality (Mansuri 2013).

The influence of inequality goes beyond individual or household behavior. Inequality also affects the ability of people to act collectively, the institutions they set up, and the ways in which resources are allocated for the benefit of the group. A salient case is the provision of public goods, where inequality can have effects of opposite signs. On the one hand, in a very unequal society, the betteroff typically have more power and are more effective at pulling in resources for the public goods they value. On the other hand, a high degree of inequality makes it more tempting for the better-off to opt out of public services altogether.

In the end, which of the two effects prevails is likely to depend on whether opting out is an option. In Pakistan, land inequality is unambiguously associated with greater access to services in the cases of electricity, drainage, and access to public transport (figure 5). In contrast, the teaching quality in public primary schools is far poorer in the most unequal villages. Notably, this negative impact of land concentration on teaching quality does not extend to private schools. These results imply that service quality and access tend to decline at very high levels of inequality but mainly for services for which the wealthy can move to private providerssuch as schools.

Inequality of outcomes does not generate the right incentives when it rests on rents (Stiglitz 2013). In that case, rather than being encouraged to study or to accumulate, individuals and households divert their efforts toward securing favoritism and protection. Rewarding such behaviors with high returns is costly to economic growth and social development. It leads to a suboptimal allocation of resources in the short term and consolidates institutional arrangements with negative long-term impacts on growth.

For instance, there is no doubt that India has world-class entrepreneurs, commanding admiration for their innovation and management capacity, and many of them operate successfully in highly competitive global markets. At the same time, over a quarter of India's billionaire wealth is estimated to be inherited, 40 percent is based on inheritance, and 60 percent originates from "rent-thick sectors," such as real estate, infrastructure, construction, mining, telecommunications, cement, and media. This does not 


\section{FIGURE 5 Greater inequality reduces the quality of public services when the rich can opt out}

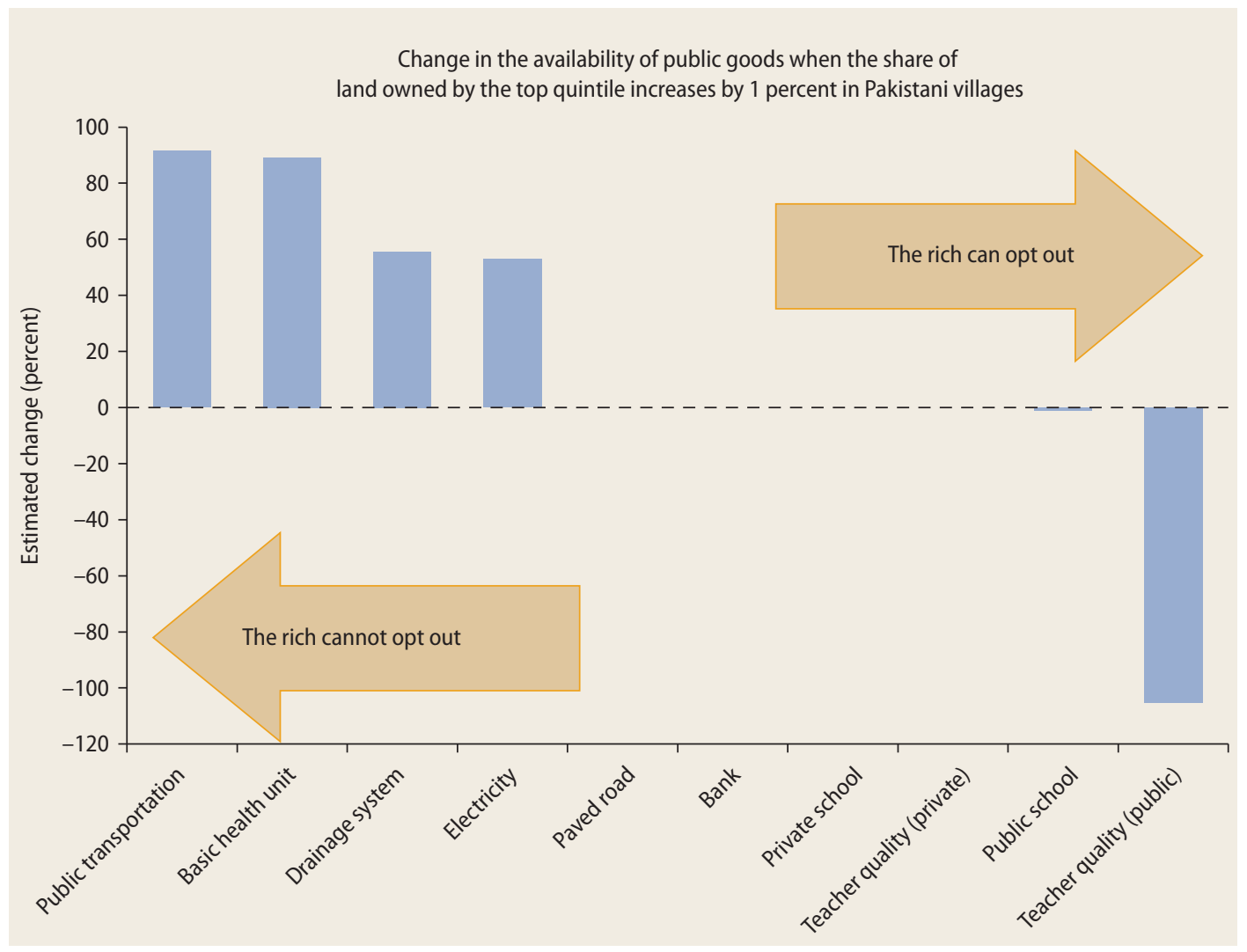

Source: Based on Mansuri 2013 for this report.

imply that wealth was acquired through the exercise of influence, but highlights that the potential for rent extraction exists (Gandhi and Walton 2012).

Some connections also exist between inequality and conflict, though a straightforward relationship would be hard to establish between the two. Inequality may damage trust-the foundation for social cohesion-and thus weaken collective decision making. The problem is particularly salient in management of common resources. Across irrigation communities in south India and in Nepal, inequality is found to make resolving disputes in water allocation more difficult (Bardhan 2005; Lam 1998).

More broadly, inequality affects the economics of conflict (Lichbach 1989). In some cases, conflict reflects a systematic use of violence for economic gain, such as the control of resources, property, occupations, and business activities (Blattman and Miguel 2010; Collier and Hoeffler 2004). In others, economic factors lurk in the background of a conflict that erupts along social and political cleavages (Bardhan 2005; Horowitz 2000). Inequality, especially deprivation, may intensify the grievances felt by certain groups or can reduce the opportunity costs of initiating and joining a violent conflict.

Conflict may take many extreme forms. In South Asia, it is more common in areas characterized by massive deprivation (Iyer 2009). In the case of India, the probability of a district being affected by Naxalites (Maoist rebels) can be linked to the characteristics of the district. With the exception of Jharkhand, poverty incidence of rural areas is higher in districts where Naxalites 
FIGURE 6 Poverty is higher in Indian districts suffering from Naxalite violence

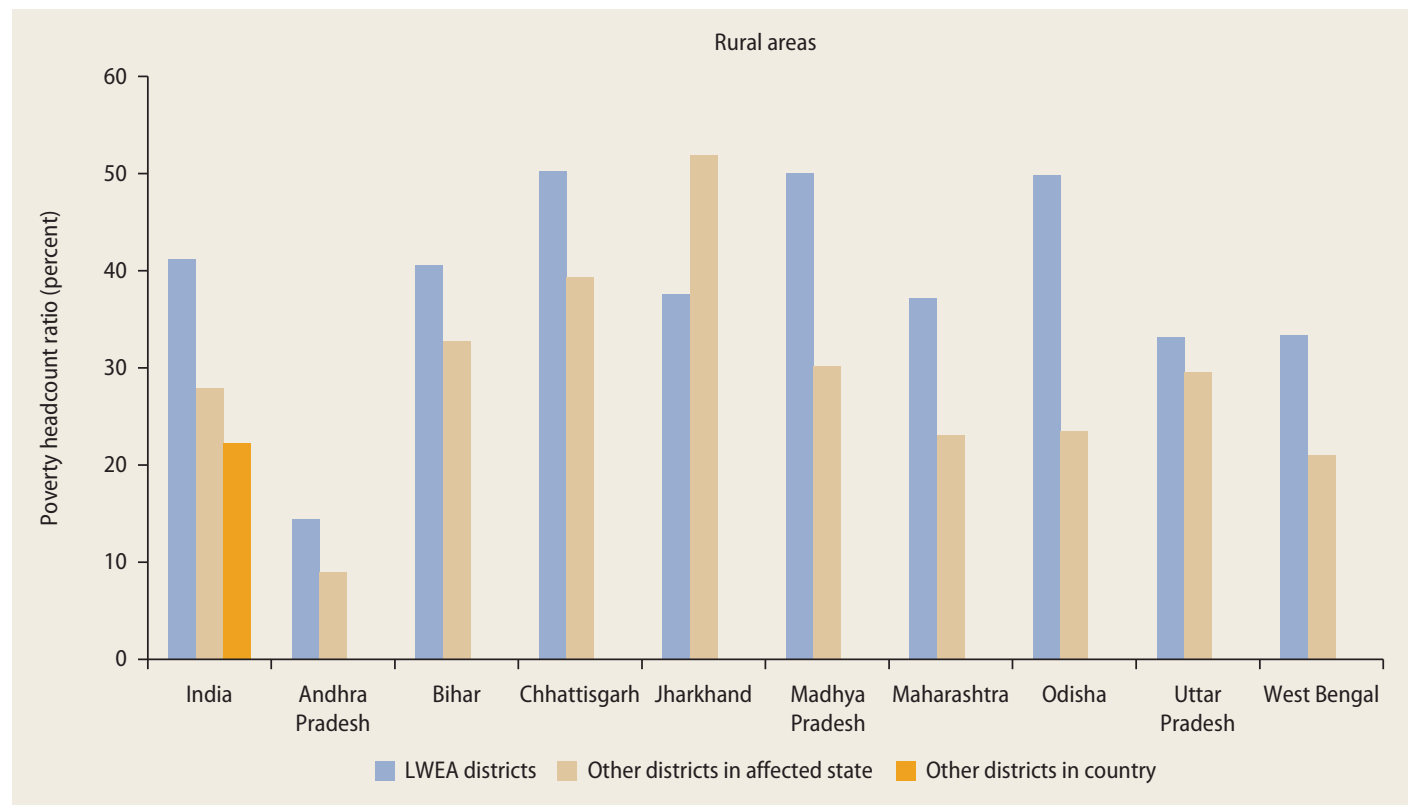

Source: Based on India National Sample Survey (NSS) 2011-12.

Note: LWEA = left-wing-extremism-affected districts. As defined by the Planning Commission in http://pcserver.nic.in/iapmis/state_district_list.aspx, India has 88 such districts. The headcount ratio is based on the national poverty line.

are better implanted (figure 6). In Pakistan, the probability of violent attacks by insurgents, sectarians, and terrorists is found to increase with food insecurity and land inequality (Malik 2009, 2011).

\section{The extent of inequality}

Both monetary and nonmonetary indicators of well-being capture important dimensions of inequality in outcomes. Traditionally, the assessment of inequality is dominated by single-dimensional monetary indicators, represented by either income or consumption, both in cash and in kind. These monetary indicators are generally computed based on individual records from representative household surveys. However, household surveys may not capture well the income or the consumption of the richest members of society. The survey questionnaires usually focus on the relatively basic basket of goods and services purchased by those who live around the poverty line. In so doing, they fail to capture the more diverse and sophisticated ways in which the better-off spend their money-and to remind respondents about them. Richer households also tend to shun surveys of this sort. One indication of underreporting is the size of the discrepancies between levels and growth rates of consumption, as measured by household surveys and by national accounts. Disconnect between the two major data sources is large in several South Asian countries, especially in India.

Individual tax returns can be used to examine the extent of undercounting of the rich in household surveys (Banerjee and Piketty 2005). According to this data source, the income share of India's top 0.01 percent was in the 1.5 percent to 2 percent range, whereas the share of the top 0.1 percent was in the 3 percent to 4.5 percent range. Assuming that the top 1 percent is not captured by household surveys is not enough to account for the full gap but explains 20 percent to 40 percent of it. This fraction is large enough to give credence to the hypothesis that traditional income- or consumption-based monetary indicators are biased downward, probably by a substantial margin. 
The distribution of wealth provides a complementary perspective on monetary inequality in which considerable disparities exist in asset holdings, net worth, and financial vulnerability. In India, at the household level, the Gini coefficient is 0.668 for asset holdings and 0.680 for net worth. As in other countries, the wealth distribution is more concentrated than the distribution of income and especially more concentrated than that of expenditures. But perhaps more striking than the extent of inequality is the vulnerability of the least wealthy. Wealth provides means to smooth consumption in the short run and to raise it in the long run. Wealth also gives a sense of security. For a typical Indian household among the top 10 percent, the net worth could support consumption for more than 23 years. For a typical Indian household in the bottom 10 percent, however, the net worth was sufficient to support consumption for less than three months (figure 7).

Nonmonetary dimensions of inequality capture the dispersion in human capabilities, as reflected, for example, in health and education outcomes. Differences in these outcomes can affect individuals' abilities to do what they would value doing and to convert different means into well-being (Sen 1980, 1992).
Monetary and nonmonetary indicators tend to be correlated, as shown by the fact that health status or educational attainment is typically higher among people who are better off in monetary terms. But the correlation is not perfect because monetary and nonmonetary indicators capture different concepts and can vary independently. Therefore, nonmonetary indicators provide additional information on distribution of well-being, beyond what is provided from monetary indicators of inequality.

Nonmonetary outcomes are also very unevenly distributed in South Asia. A comparison of health status across population quintiles, defined by a wealth index, is revealing in this respect. Gaps in neonatal mortality (death within the first 28 days of life) and in under-five child mortality (death within the first five years of life) between the top and the bottom quintiles are large, especially in India and Pakistan (figure 8). For children who live, the main challenge is to be well nourished. Children belonging to the poorest quintile are more likely to be stunted in every country in the region, although the gap is relatively less glaring in Maldives and Sri Lanka.

Inequality in educational attainment is large as well, although varying widely across

\section{FIGURE 7 The least wealthy are alarmingly vulnerable}

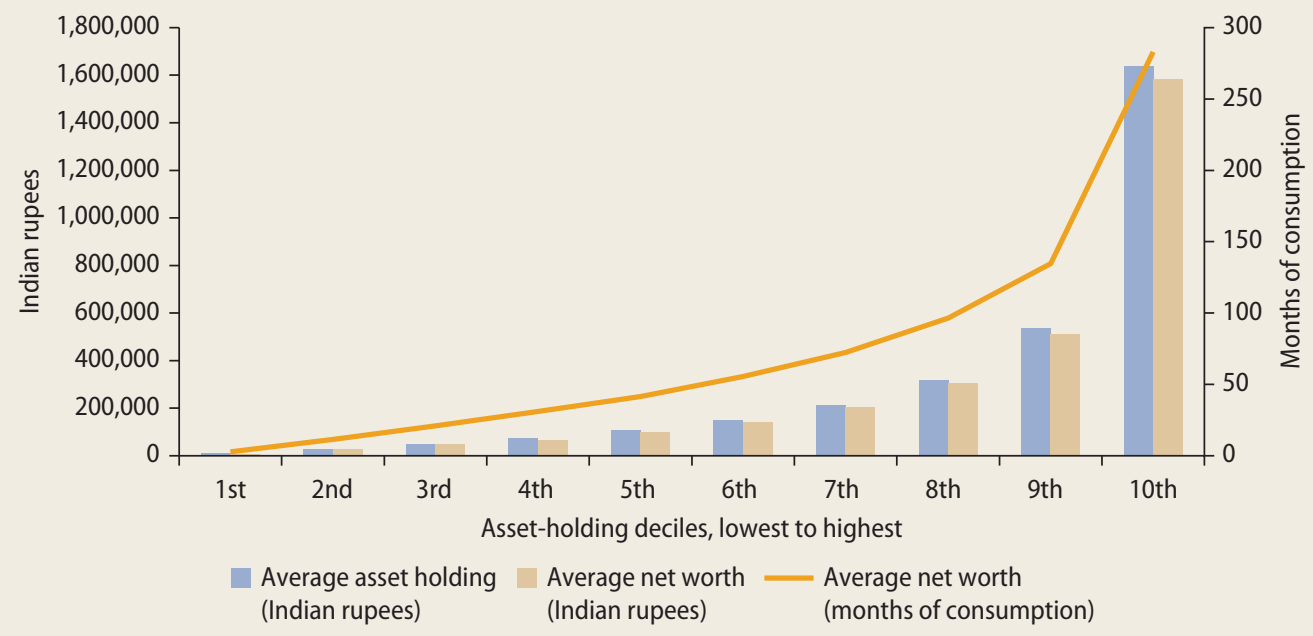




\section{FIGURE 8 Inequality in health outcomes is wide}

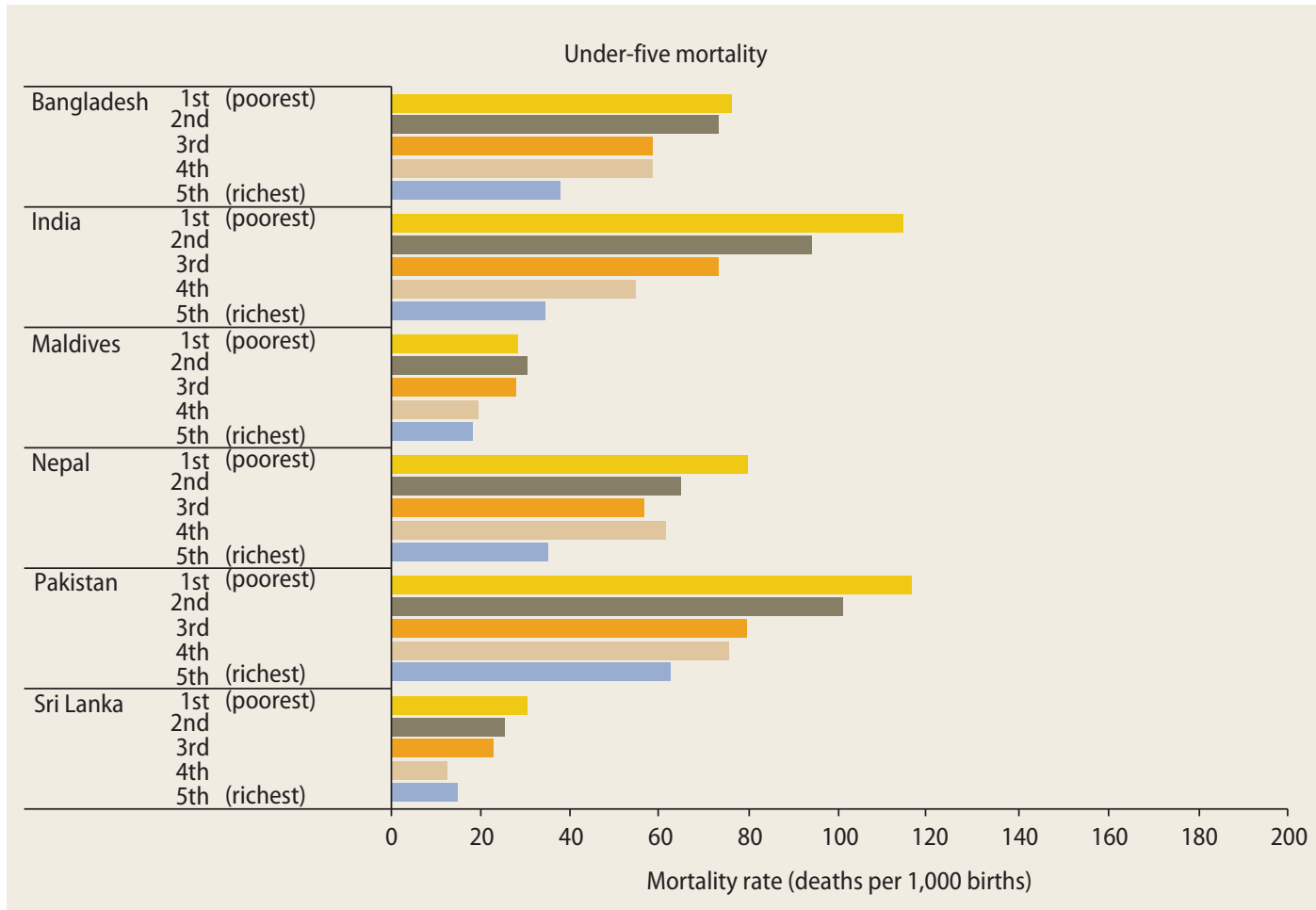

Sources: Based on Demographic and Health Survey (DHS) 2011 for Bangladesh, DHS 2005 for India, DHS 2009 for Maldives, DHS 2011 for Nepal, DHS 2007 for Pakistan, and DHS 2007 for Sri Lanka.

Note: Under-five mortality rate is the number of deaths to children younger than five years per 1,000 live births.

the region. From an international perspective, countries in South Asia seem to lie at both ends of the developing-country range. Among the countries for which comparable data are available, Maldives and Sri Lanka exhibit the lowest gaps in educational attainment among young adults between the population quintiles with the highest and the lowest expenditures per capita (figure 9). At the other end of the spectrum, gaps in Nepal, Afghanistan, and especially Bhutan are larger than in all comparators. However, the international comparison is highly sensitive to the age group considered because educational attainment is expanding rapidly throughout the region. Gaps between children are being eliminated at the primary level.

For the younger South Asian cohorts, inequality in relation to education is increasingly driven by quality rather than by access. Although average performance in systematic learning evaluations is generally low, considerable dispersion occurs in test scores across students from different backgrounds. For India, the inequality in learning outcomes can be seen by comparing test scores of children whose households have both a radio and a TV to those who have neither. The mean test scores for students in the first group are higher across the entire distribution than for those from the second group. Gaps in learning outcomes are large in other countries of the region as well (Dundar and others 2014).

Trends in inequality also vary depending on the indicator considered. In South Asia, inequality in consumption per capita is generally higher in the richer countries, and it has increased over time as countries grew richer. This is consistent with growth being effective at reducing poverty in the region, as it was earlier in East Asia. Moreover, South Asian countries have lower levels of 


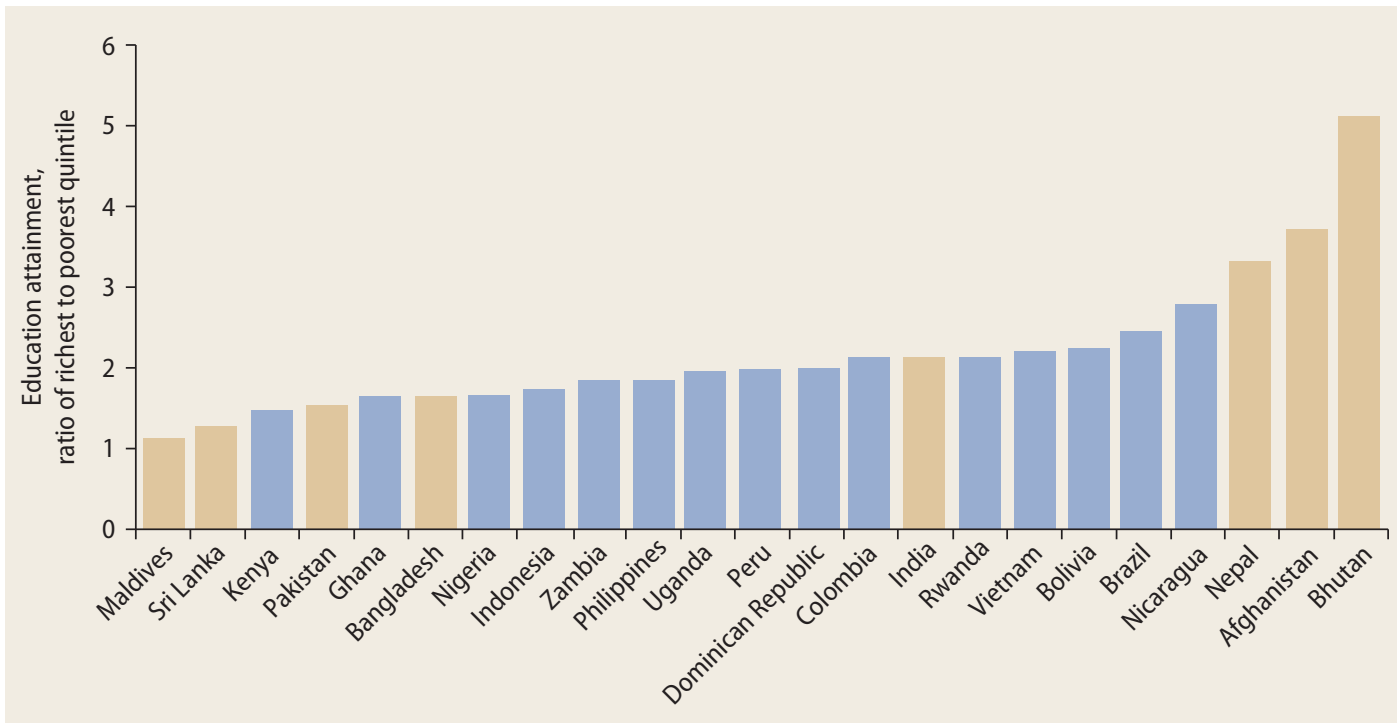

Sources: Based on National Risk and Vulnerability Assessment (NRVA) 2007 for Afghanistan; Household Income and Expenditure Survey (HIES) 2010 for Bangladesh; Bhutan Living Standards Survey (BLSS) 2007 for Bhutan; NSS 2009-10 for India; HIES 2009-10 for Maldives; Nepal Living Standards Survey (NLSS) 2010 for Nepal; Household Integrated Economic Survey (HIES) 2010-11 for Pakistan; HIES 2009-10 for Sri Lanka; and World Bank Education Equality Country Profiles database, http://datatopics.worldbank.org/Education/wDHS/HProfiles.aspx.

Note: Educational attainment is measured in years of schooling. The population considered are 20 to 29 years of age.

inequality than East Asian countries had when they were at similar levels of income per capita. However, in both regions, countries with a higher income per capita are characterized by greater inequality (figure 10).

Of course, no mechanical relationship exists between growth and inequality. A well-known hypothesis in development economics-known as the Kuznets curveis that inequality initially increases as countries grow into middle-income levels and then decreases as they become richer. But the empirical evidence on this relationship is mixed (Milanovic 2011). In addition, the extent of inequality depends on policy choices and not just on some economic fate.

That said, a rigorous statistical analysis of the available microeconomic data across countries suggests that growth has been more propitious to increasing inequality in South Asia than in other regions (Dollar, Kleineberg, and Kraay 2013). For the world as a whole, when average consumption per capita increases by 1 percent, the consumption per capita of the poorest 20 percent of the population increases by 1.057 percent. The corresponding figure for the poorest 40 percent of the population is 1.004 percent. None of these estimates is significantly different from 1.0, meaning that growth is overall neutral with respect to distribution. Breaking the results down by region uncovers some interesting variation, however. For the combined East and South Asia regions, the estimate is substantially lower than 1.0 in both the 1990s and the 2000s (and significantly so in the 1990s).

Consistent with the Kuznets curve hypothesis, monetary indicators of inequality have increased in the poorest countries in the South Asia region in recent years, whereas they have decreased in the richest ones (figure 11). However, the only two countries for which a decrease is observable have a combined population of less than 1 million people in a region accounting for a fourth of mankind. The vast majority of South Asians have experienced an increase in inequality, sometimes at a fast pace. 


\section{FIGURE 10 Richer countries tend to be more unequal in both South Asia and East Asia}
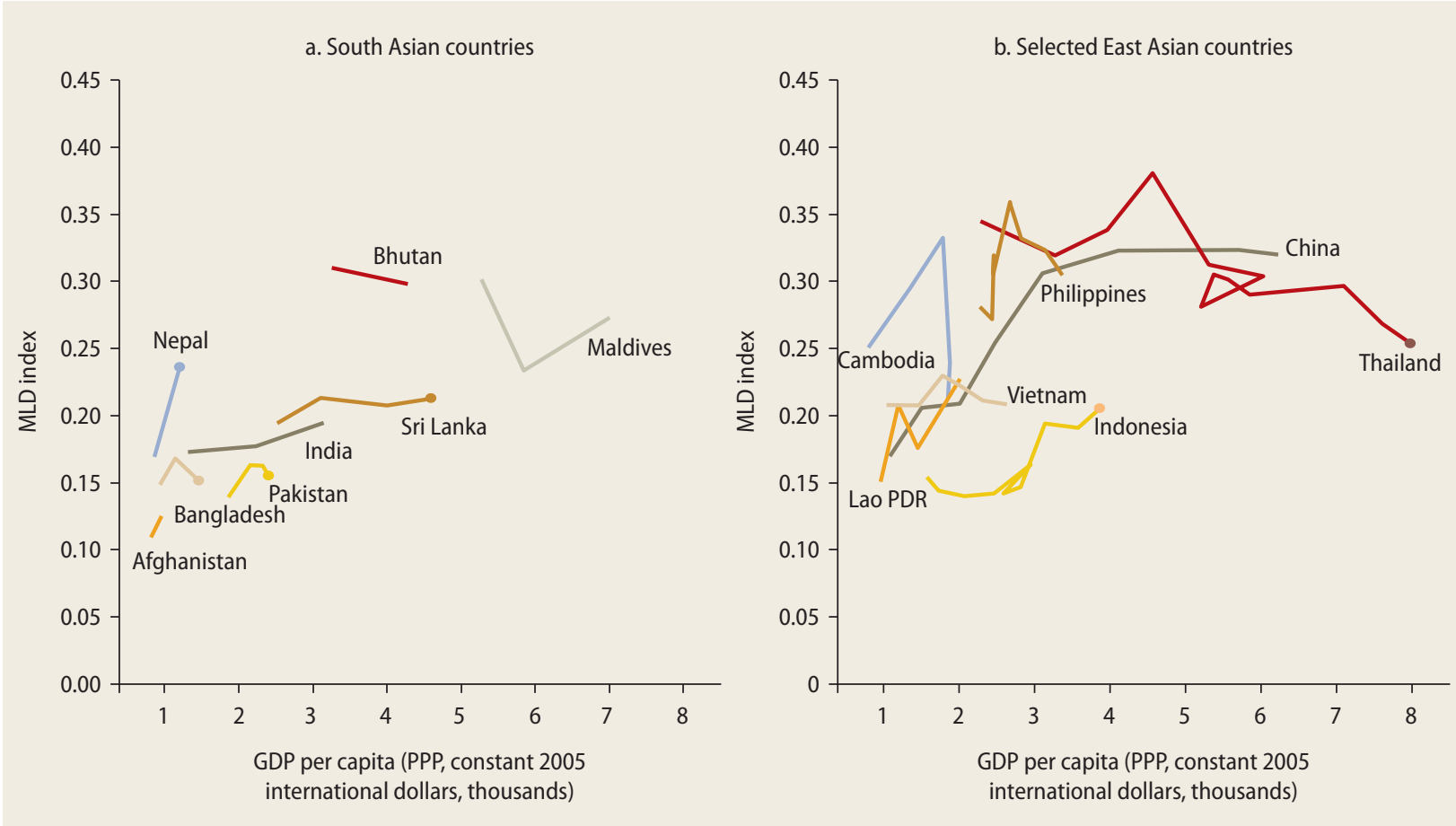

Sources: For South Asia, based on NRVA 2005 and 2007 for Afghanistan; HIES 2000, 2005, and 2010 for Bangladesh; BLSS 2003 and 2007 for Bhutan; NSS 1993-94, 2004-05, and 200910 for India; HIES 2002-03 and 2009-10, and Vulnerability and Poverty Assessment (VPA) 2004 for Maldives; NLSS 1995 and 2010 for Nepal; HIES 2001-02, 2004-05, 2007-08, and 2010-11 for Pakistan (Punjab); and HIES 1995-95, 2002-03, 2006-07, 2009-10 for Sri Lanka. For East Asia, based on the World Bank's World Development Indicators database, http:// data.worldbank.org/data-catalog/world-development-indicators and PovcalNet tool, http://iresearch.worldbank.org/PovcalNet/index.htm: 1994-2009 for Cambodia; 1990-2009 for China; 1984-2010 for Indonesia; 1992-2008 for Lao PDR; 1985-2009 for Philippines; 1981-2010 for Thailand; and 1993-2008 for Vietnam.

Note: MLD = mean log deviation; PPP = purchasing power parity.

Trends in nonmonetary inequality are more mixed. Health outcomes show signs of widening inequality. The ratios between the neonatal and under-five child mortality rates of the population quintiles with the highest and the lowest expenditures per capita have either stayed constant or increased in most countries. Bangladesh had a reduction in inequality in neonatal mortality. All other countries for which data are available at two points in time, on all indicators, show an increase in inequality in health outcomes. The increase is especially marked in the case of stunting.

In contrast, inequality in education outcomes has unambiguously been narrowing. Gaps in educational attainment among children 6 to 11 years of age either have been stable, mainly in countries that have achieved close to universal coverage of primary education, or have decreased. The decline in inequality is remarkable for the population at large (adults 15 to 65 years of age) as well, with the exception of Afghanistan.

\section{Drivers of inequality}

The diversity of the observed trends, depending on the indicator considered, makes relying on a single metric to assess changes in inequality or progress toward shared prosperity difficult. This difficulty comes on top of the measurement issues associated with some of the most common indicators. For instance, lower survey response rates among better-off households and greater underestimation of their expenditures by the available survey instruments may bias standard monetary measures such as the Gini index or the income share of the bottom 40 percent. 
Even in the absence of bias, the story on inequality in South Asia would be different if it were told based on consumption indicators, on wealth indicators, or on health indicators.

At the same time, the diversity of assessments is welcome because it provides useful insights on the drivers of inequality in South Asia. High inequality in health outcomes is suggestive of limited access to basic care among the poor, especially during pregnancy and childhood. High inequality of wealth is to be expected in the presence of sizable rents for the few and not much redistribution toward the many. Moderate inequality in consumption indicators, in contrast, could reflect substantial mobility, allowing households from disadvantaged backgrounds and their offspring to prosper.

A cursory analysis also reveals some strong-and somewhat predictablepatterns of the impact of individual characteristics on inequality. Simple decompositions of consumption inequality between population groups suggest that characteristics such as educational attainment, location, or ethnicity matter considerably. Both education gaps and the rural-urban divide account for a growing share of consumption inequality. The share is smaller in the case of ethnicity, but caste remains relevant in northern and eastern Indian states.

The impact of these individual characteristics on inequality can be mediated by economic structures and public policies. However, opinion polls show that in South Asia, the contribution public policies make is often seen under a negative light. The Gallup World Poll asks respondents about their satisfaction with basic services, their assessment of future well-being, and their views on government efforts to help the poor. The six South Asian countries covered by the Gallup World Poll can be compared to Brazil, a country that has experienced a substantial reduction in inequality in recent years. Moreover, this reduction is generally attributed to policy changes (Barros and others 2010; de Souza 2012; Ferreira, Leite, and Litchfield 2008).
FIGURE 11 Monetary inequality is increasing across most of

South Asia

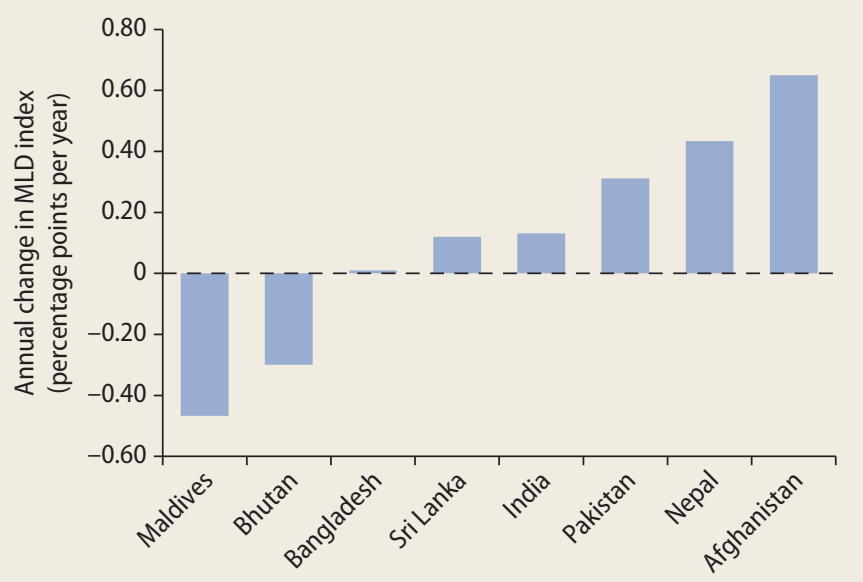

Sources: Based on NRVA 2005 and 2007 for Afghanistan; HIES 2000 and 2010 for Bangladesh; BLSS 2003 and 2007 for Bhutan; NSS 1993-94 and 2009-10 for India; NLSS 1995 and 2010 for Nepal; HIES 2002-03 and 2009-10 for Maldives; HIES 2001-02 and 2010-11 for Pakistan (Punjab); and HIES 1995-95 and 2009-10 for Sri Lanka.

Note: MLD = mean log deviation.

In Brazil, according to the Gallup World Poll, satisfaction with access to public services is higher among poorer population groups, and a negative correlation exists between income per capita and expectations of a better life. Poorer population groups are also more satisfied with government efforts to help them. Taken together, these responses reveal a positive view of equality of opportunity, upward mobility, and targeted support. All of this is at odds with responses to the same questions in South Asian countries (figure 12).

The role played by individual characteristics such as education, location, and caste provides some clues about what lies behind inequality. Opinion polls, in turn, are informative on how public policies may offset or amplify the contribution from inherited circumstances.

A simple conceptualization of how these different variables come into play involves a person's life cycle (figure 13). Circumstances at birth, such as gender and caste, shape the options available to individuals, especially in relation to the accumulation of human capital. As people age and enter the labor force, 


\section{FIGURE 12 South Asians do not see an environment conducive to lower inequality}

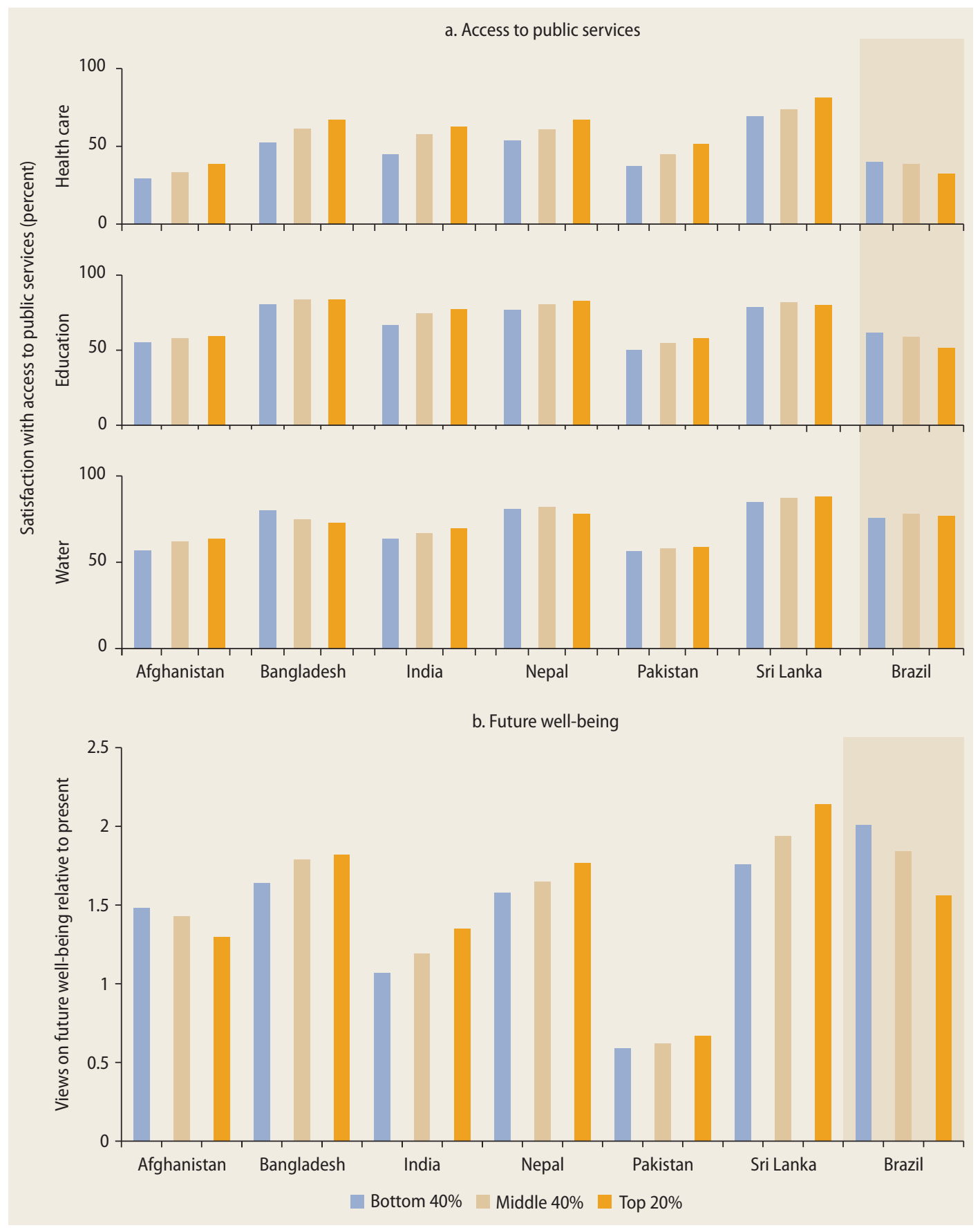

(continues next page) 


\section{FIGURE 12 South Asians do not see an environment conducive to lower inequality (continued)}

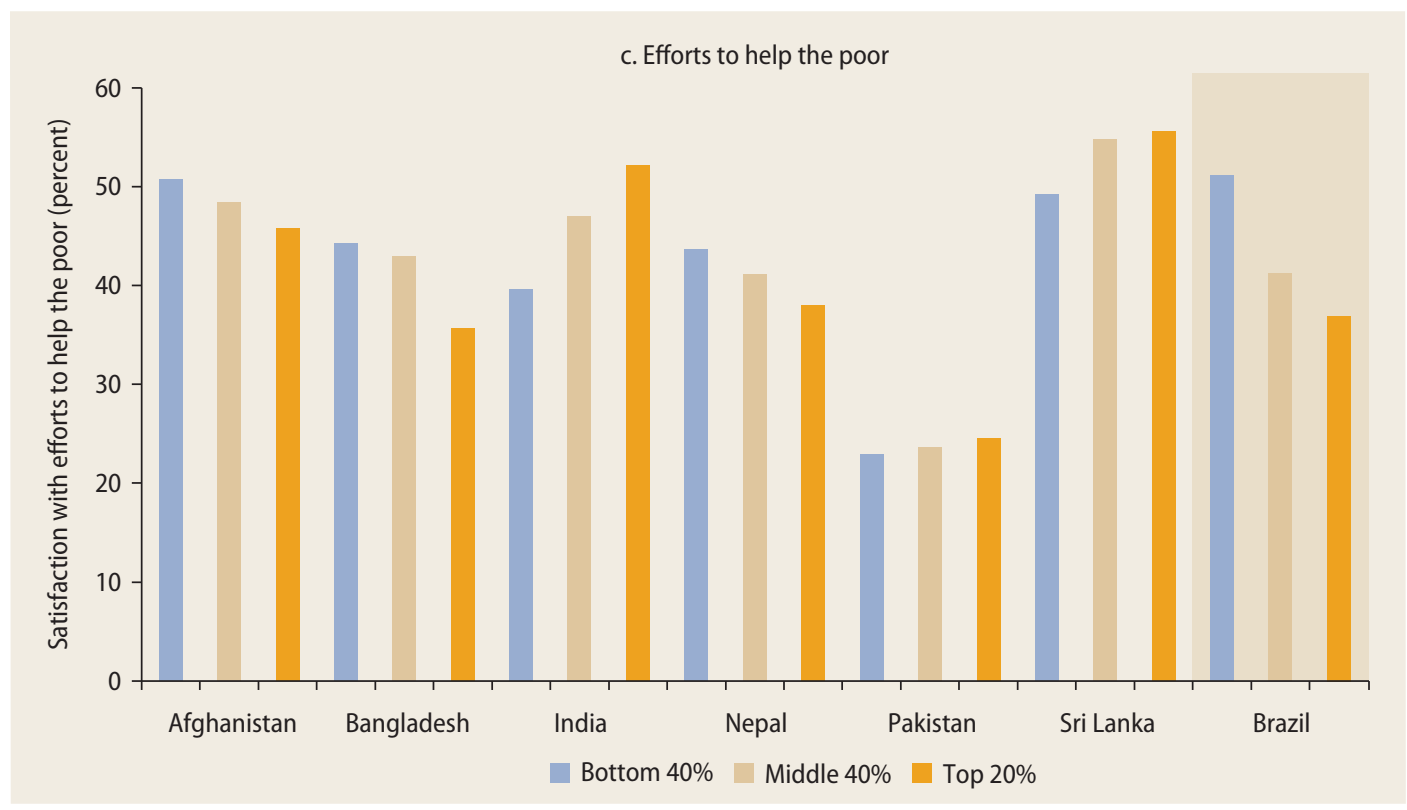

Source: Based on Gallup World Poll.

Note: Population groups are defined based on income or consumption per capita. Views on present (future) well-being are assessed on a scale from 1 (dissatisfied) to 10 (satisfied).

\section{FIGURE 13 Multiple factors affect household outcomes relative to others in society}

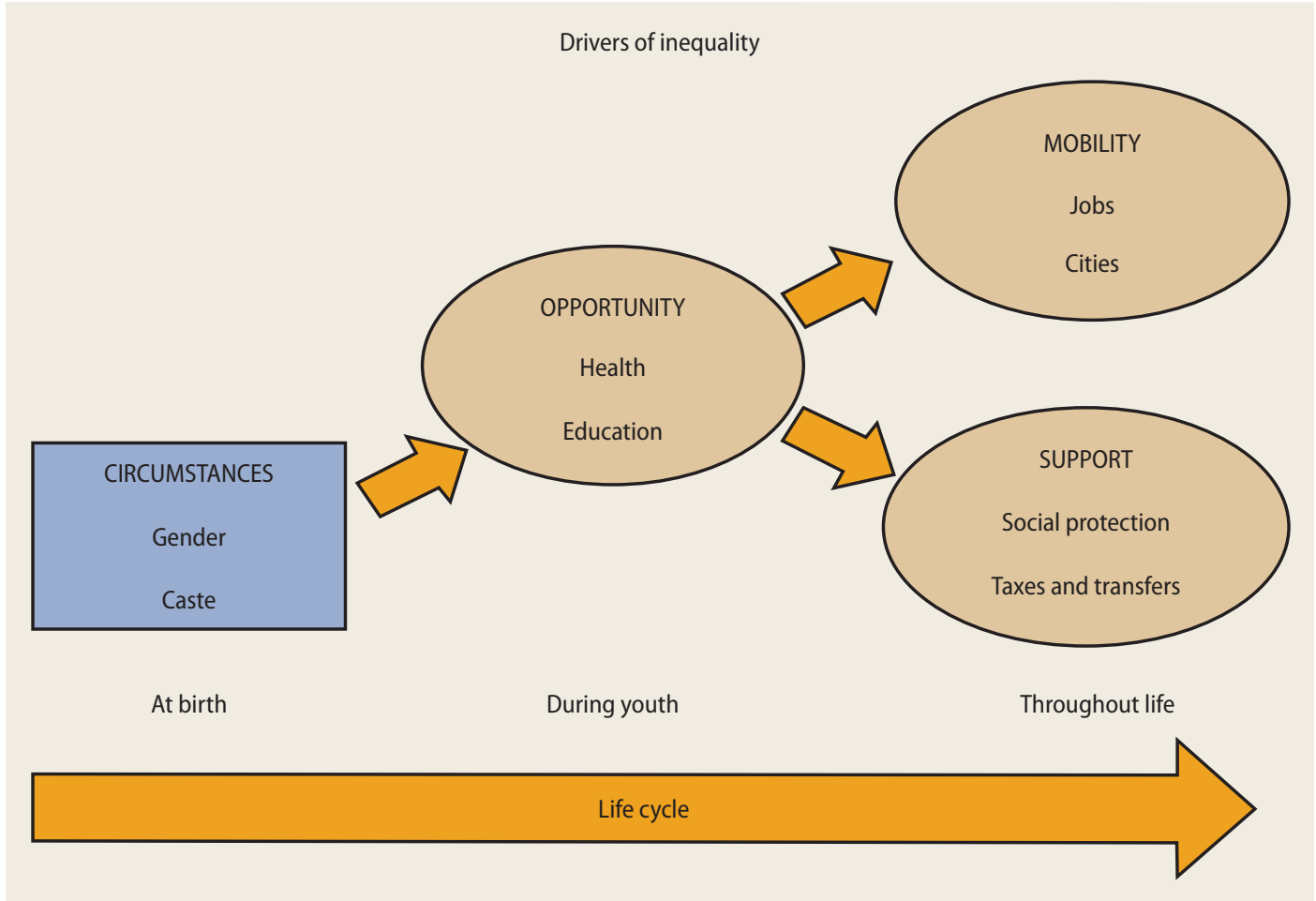


their job opportunities and the possibility of reaping benefits from migration affect earnings prospects. Throughout life, differences in innate abilities, inherited wealth, and shocks affect-positively or negativelymultiple aspects of well-being. In each of these phases, public policies-explicitly or implicitly-reduce or amplify the extent of inequality.

In sum, opportunity in childhood can be shaped by access to basic services, including health, education, and infrastructure; mobility during adult life can be enhanced by economic growth and rapid urbanization; and throughout life, support as government policies transferring resources to people or taxing them can help mitigate shocks and offset disadvantages.

\section{Limited opportunity}

Equality of opportunity is considered a key condition for a society to ensure distributional justice. Important outcomes-such as income or health status-are seen as determined by two main factors: efforts and circumstances. Equality of opportunity requires compensating people for disadvantages related to circumstances so the distributions of outcomes can be entirely attributed to efforts (Roemer 1998). Both conceptually and empirically, completely distinguishing efforts from circumstances is difficult, hence impeding disentanglement of opportunities from outcomes (Kanbur 2009). However, making access to basic services universal is at the core of equality of opportunity (Paes de Barros and others 2009; World Bank 2005b).

General agreement exists that the set of goods and services that every individual under 16 years of age should have access to includes nutrition, health care, basic education, and some forms of infrastructure. Within health and nutrition, the focus is often on institutional births and full immunization. In basic education, opportunity is associated with primary school attendance and completion and, in some cases, with secondary school attendance. The forms of infrastructure deemed essential for opportunity include clean water, improved sanitation, and electricity.

The coverage of basic services is a first and telling indicator of access. When the coverage of a specific service is universal, everybody has access to it; lower coverage rates mean that some are necessarily excluded. Exclusion is typically not random, however. People from disadvantaged backgrounds are less likely to get access to services. The extent to which access varies across clearly distinct groups-defined along gender, ethnicity, or caste lines-is significant in this respect. The greater the dispersion of access across groups, the greater is the degree of inequality for the same level of coverage. This simple intuition is captured by a synthetic indicator, called the Human Opportunity Index (HOI). The $\mathrm{HOI}$ is computed by multiplying the coverage rate by a measure of the dispersion of access across the relevant groups (Paes de Barros and others 2009). The HOI varies from zero, when nobody has access to services or the dispersion is extremely high, to 100 , when everybody has access, and it increases when coverage expands or becomes more equitable across groups.

Following the literature, this report uses characteristics that are more likely to be predetermined, hence unaffected by a child's own actions, to define groups. These characteristics are the place of residency, either urban or rural; a child's gender, religion, and caste; and the education level of the household head or the child's mother, depending on data availability. Religion is used only when data are available, and caste is used only in India's case.

In South Asian countries, despite the widespread commitment to rights, access to services related to health and nutrition tends to be limited (figure 14, panel a). The value of the HOI is worryingly low in the case of full immunization against vaccine-preventable diseases among children two years of age and younger. The HOI of most countries in the region does not cross the 50 percent mark. India and Pakistan perform poorly, with an HOI below 20 percent in the most recent year for which data are available. 
Access to primary education is far better. Countries in the region have generally done well in primary school attendance and even on completion (figure 14, panel b). In this, South Asia resembles other regions, reflecting the global drive toward universal enrollment in primary education. The picture is less encouraging for access to secondary school, especially in comparison with countries at a similar level of development. The HOI associated with secondary school completion is below 50 percent across the region, with the exception of Bhutan. Even in the bestperforming countries of the region-Bhutan, Maldives, and Sri Lanka-the HOI is smaller than that in traditionally inequitable countries, such as Brazil and South Africa.

International comparisons are less reliable with respect to infrastructure services. What it means to have access to improved water or to improved sanitation varies from one country to another. Moreover, access is often measured at the community level in South Asian countries but at the household level in others. If a power line arrives to a village, but only half the population in the village has electricity, coverage is twice as high when measured at the community level rather than the household level.

Even when considering the more generous access measure, at the community level, coverage of infrastructure services is low in most South Asian countries (figure 14, panel c). Access to sanitation is generally dismal. With the exception of Maldives and Sri Lanka, the HOI for improved sanitation services does not exceed 40 percent in South Asian countries. Access to electricity fares better in Maldives and Sri Lanka. In contrast, Afghanistan still lags far behind, with an HOI of about 10 percent. Access is also limited in Bangladesh and India, where the HOI hovers between 40 and 60 percent.

Opportunities in access to health and education services have been improving in the region over the past decade. Whereas most countries have registered $\mathrm{HOI}$ increases in access to health services, progress has been slower than for other basic services. When considering full immunization,
FIGURE 14 Opportunities in education are better than in health or sanitation, as measured by the $\mathrm{HOI}$

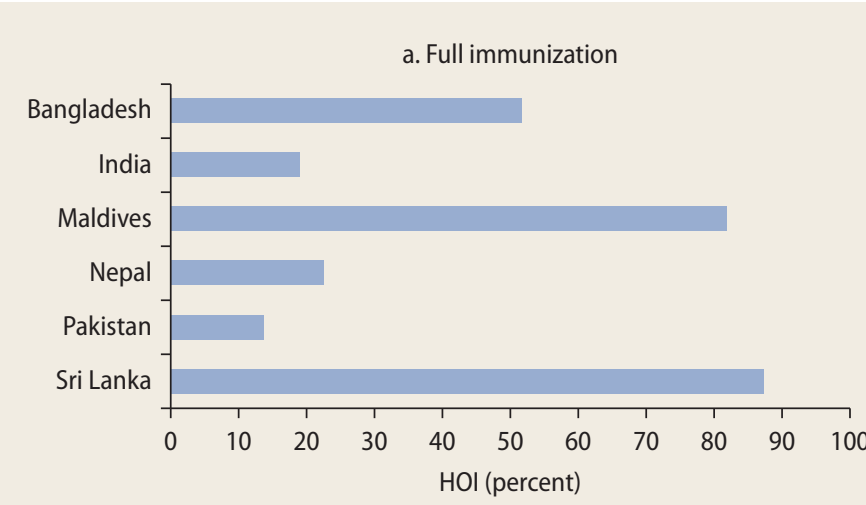

b. Primary school completion (14-18 years of age)

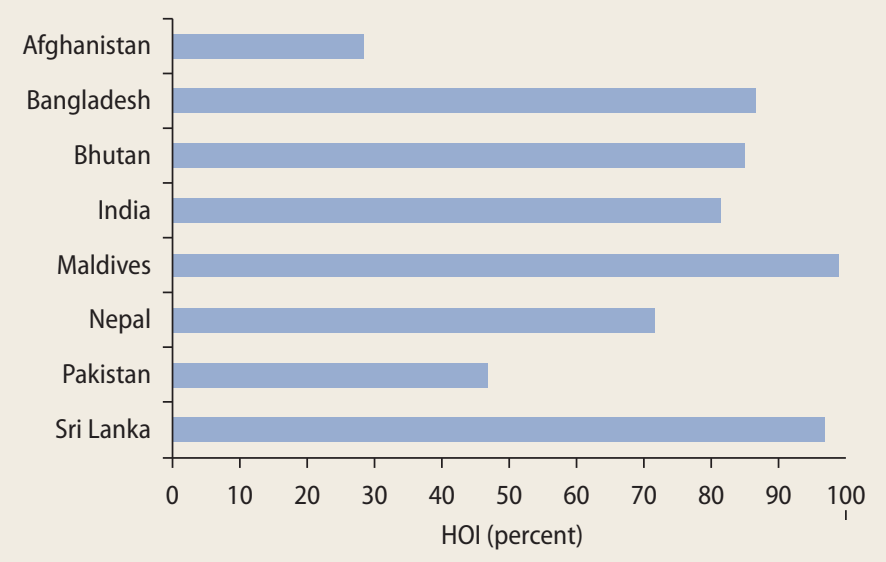

c. Improved sanitation

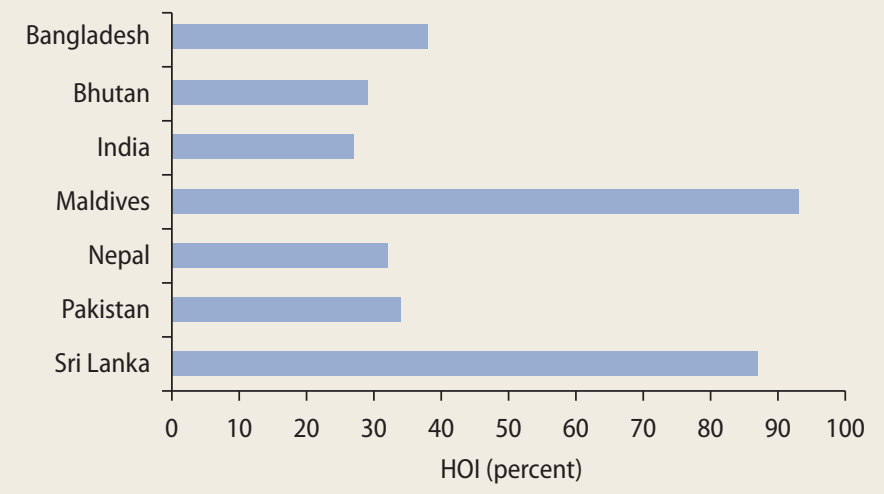

Sources: Based on DHS 2011 for Bangladesh, DHS 2005 for India, DHS 2009 for Maldives, DHS 2011 for Nepal, DHS 2007 for Pakistan, and DHS 2007 for Sri Lanka for health; NRVA 2007 for Afghanistan, HIES 2010 for Bangladesh, BLSS 2007 for Bhutan, NSS 2009-10 for India, HIES 2009-10 for Maldives, NLSS 2010 for Nepal, HIES 2010-11 for Pakistan, and HIES 2009-10 for Sri Lanka for education; and data from Andres and others 2013 for this report for infrastructure services.

Note: The HOl increases with equality in access across population groups. The HOl for full immunization is computed based on formal records instead of patient recall. 


\section{FIGURE 15 Better opportunity is driven by greater coverage}
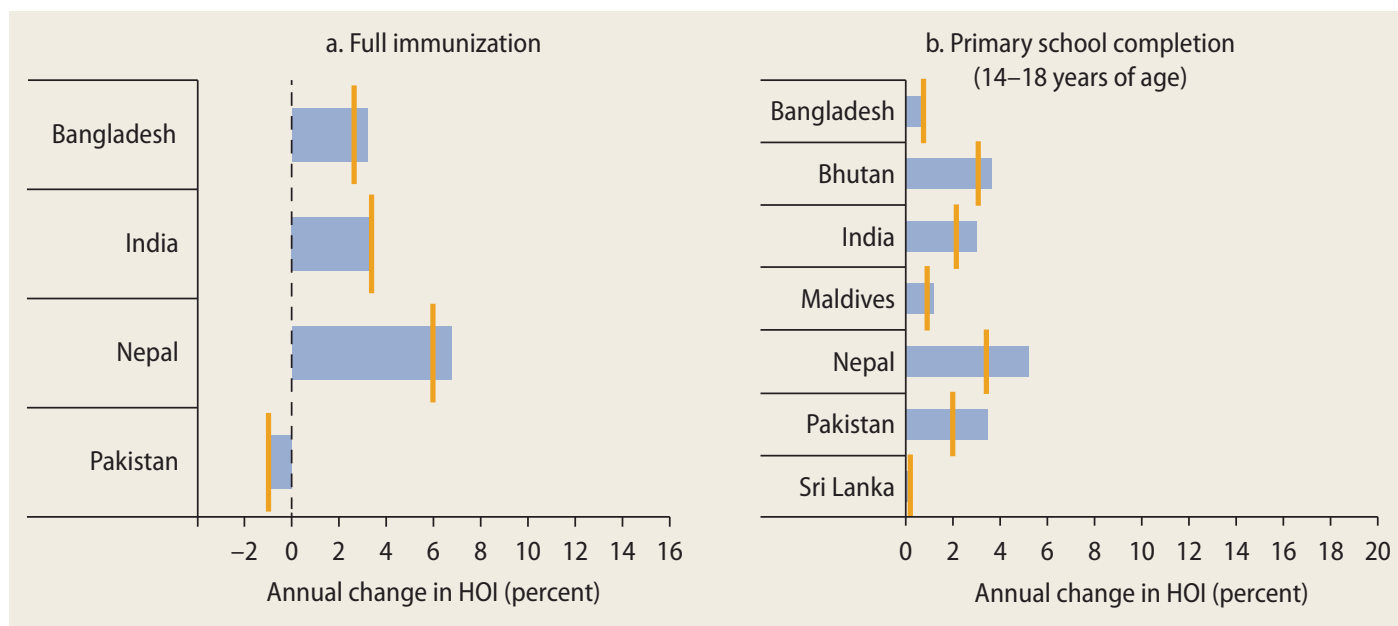

Sources: Based on DHS 1993 and 2011 for Bangladesh, DHS 1992 and 2005 for India, DHS 1996 and 2011 for Nepal, and DHS 1990 and 2007 for Pakistan for health; based on HIES 2005 and 2010 for Bangladesh, BLSS 2003 and 2007 for Bhutan, NSS 1993-94 and 2009-10 for India, HIES 2002-03 and 2009-10 for Maldives, NLSS 2003 and 2010 for Nepal, HIES 2001-02 and 2010-11 for Pakistan (Punjab), and HIES 2006-07 and 2009-10 for Sri Lanka for education. Note: Horizontal bars indicate the total change in the HOl; vertical lines indicate the change caused by increased coverage; the difference between the two reflects changes in equity.

opportunities increased over time in Bangladesh, Nepal, and India. By contrast, they declined slightly in Pakistan. As for institutional births, Nepal registered the fastest improvement. But overall progress has been slow, and inequality has declined only slightly in recent times. The annual change in HOI stands between 0.5 and 1 percentage point in most cases.

Countries in South Asia have also made significant strides in improving access to primary education. Maldives and Sri Lanka led the region in achieving almost universal primary education coverage. Progress in Bangladesh, India, Bhutan, Nepal, and Pakistan has also been significant, although at varying speeds. In Bhutan and Nepal, improvements in primary school attendance and completion were remarkable. In Bangladesh, the pace of change is slower, but the starting point was higher (with HOIs around 85 percent in 2005). In Afghanistan, school attendance grew between 2005 and 2007, but the HOI remains low.

The drivers of inequality in access in South Asia can be better understood by decomposing the change in the HOI between increases in coverage rates (scale effect) and reductions in the dispersion of coverage rates across groups (equity effect). The decomposition shows that greater coverage clearly drives the improvements of opportunities in health (figure 15). In the case of full immunization, almost all of the change in the HOI can be attributed to changes in coverage, with inequality across groups remaining stable. The decomposition of changes in the HOI yields a more diverse picture in the case of primary education. In Afghanistan, which showed rapid increases in its HOI for primary school attendance, the change has come mainly from greater coverage. In contrast, changes in equity in access play an important role in Nepal, a country that has recorded notable growth in primary school attendance and completion.

Although the measured access to health and education services in the region has generally improved, the magnitude of the improvement may overestimate the improvement in equity. This is because the quality of health and education services is likely to vary considerably across population groups, and the quality of services has important implications for later-life opportunities. An improvement in $\mathrm{HOI}$ is unlikely to capture 
the fact that qualitative differences in services may not have diminished substantively.

Several population groups receive systematically lower coverage of basic services because of their circumstances. Not surprisingly, location matters. Children residing in rural areas fare worse than those in urban areas with regard to basic health services, especially for institutional birth. The gap is often quite striking-in Nepal, for example, 32 percent of rural births are in a health facility, compared with 71 percent of urban births. Similar differences can be found in Bangladesh, India, and Pakistan.

The urban-rural gap is also evident in the provision of infrastructure services in the region, especially electricity. Rural areas fare much worse in terms of access to electricity, particularly in Afghanistan and Bangladesh.

Gender is another dimension along which important differences in coverage may exist. But this does not appear to be the case in South Asia, where boys' advantage is generally very small for basic health services and primary education. Gender gaps are much more pronounced at the secondary education level, however. In Sri Lanka and Bangladesh, girls attend secondary school at a marginally higher rate than boys, but in Bangladesh, the female advantage in participation does not continue through school completion. In general, secondary school completion rates are 5 to 10 percentage points higher for boys than for girls.

These analyses compare the coverage of basic services along a single dimension: location, gender, or mother's education. But disadvantaged children are often disadvantaged along several of those dimensions simultaneously. Overall, parent's education and location are among the most important circumstances behind inequality in access to health, education, and infrastructure services (figure 16). In Bangladesh, India, Nepal, and Sri Lanka, religion also explains some part of the inequality in access to primary education. In India, caste explains more than religion. In the case of secondary education, gender plays a significant role in explaining secondary school attendance and completion across countries in the region. Location turns out to be a critical circumstance for access to infrastructure services.

Several factors underlie South Asia's lackluster performance in ensuring equality in access to basic services. Importantly, public spending on education and health is relatively

\section{FIGURE 16 Parent's education and location are critically important circumstances}

a. Full immunization

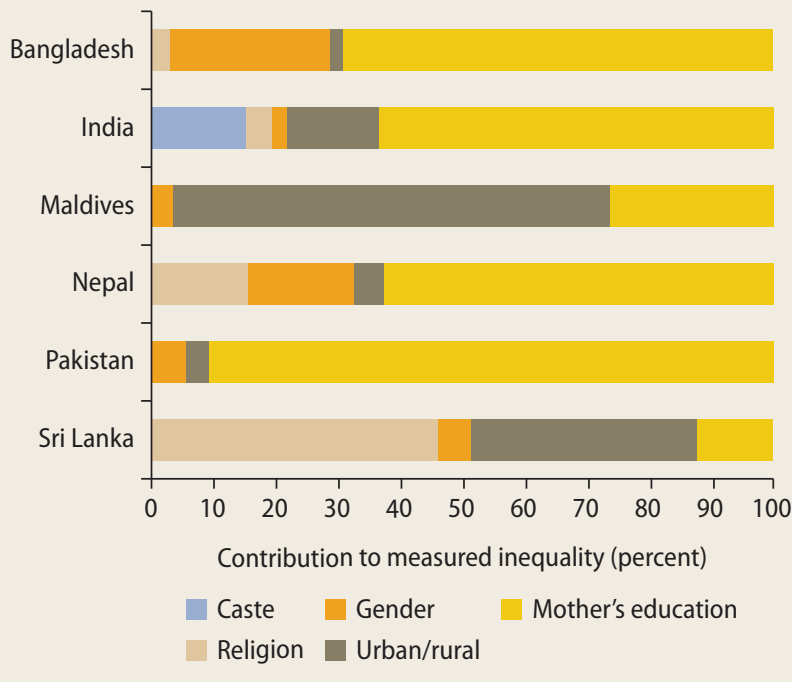

b. Primary school completion (14-18 years of age)

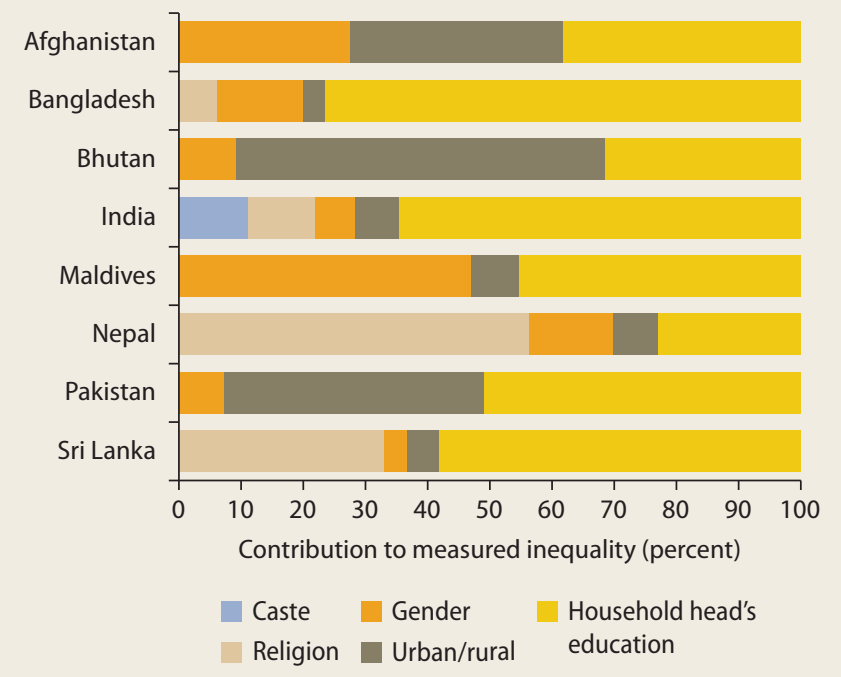


FIGURE 16 Parent's education and location are critically important circumstances (continued)

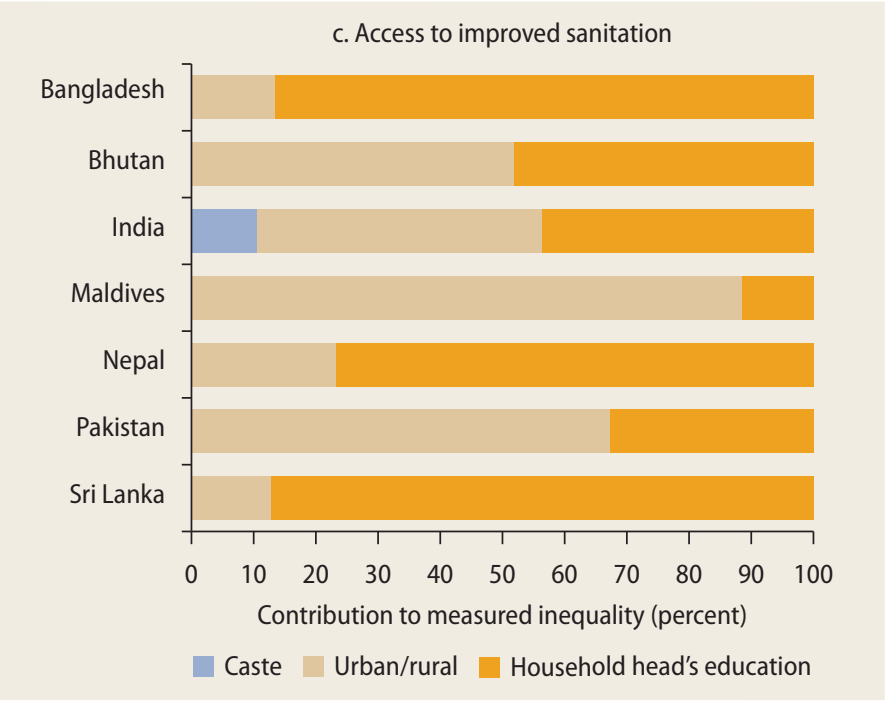

Sources: Based on DHS 2011 for Bangladesh, DHS 2005 for India, DHS 2009 for Maldives, DHS 2011 for Nepal, DHS 2007 for Pakistan, and DHS 2007 for Sri Lanka for immunization; NRVA 2007 for Afghanistan, HIES 2010 for Bangladesh, BLSS 2007 for Bhutan, NSS 2009-10 for India, HIES 2009-10 for Maldives, NLSS 2010 for Nepal, HIES 2010-11 for Pakistan, and HIES 2009-10 for Sri Lanka for education; and Andres and others 2013 for this report for infrastructure.

low in comparison with other countries at a similar level of development. A meaningful assessment involves comparing public spending on health or education as a fraction of GDP, rather than as a share of the budget, and controlling for the level of economic development. This assessment shows clearly that except for Bhutan and Maldives, countries in the region spend much fewer public resources on health services than could be expected, given their income per capita. South Asian countries also spend less on education than other countries at a similar level of development.

Equity requires committing additional resources to disadvantaged groups to offset their otherwise more limited access to basic services. However, the opposite is often observed in South Asia. In health, public spending is directed more toward the betteroff than to the poorest population groups (O'Donnell and others 2007). The extent of progressivity also varies across types of services. In Bangladesh, for example, spending on child care is clearly progressive, whereas curative care tends to be regressive (World Bank 2003).

In education, public spending tends to be progressive at lower grade levels but regressive at secondary and especially tertiary levels. For instance, the poorest 40 percent of the population in Bangladesh received 50 percent of public primary spending in 2010, up from 32 percent in 2005 . However, the richest 40 percent received about 80 percent of public spending directed to tertiary education (World Bank 2003, 2013a). A similar pattern is found in India and Pakistan.

\section{Substantial mobility}

Economic mobility is an avenue to longterm equality and a source of efficiency (Schumpeter 1955). At any point in time, differences exist in household well-being. But they can be partially offset if the choices households make on where to live and what kind of work to do are more rewarding, in relative terms, for the most disadvantaged. On the efficiency front, mobility leads to a better use of talent and strengthens incentives. If the distribution of creativity or resourcefulness across the population is less unequal than the distribution of income or consumption, societies with greater mobility may be able to mobilize the talent of all population groups. In a society where the poor and the rich are equally likely to succeed or fail, people belonging to all groups have a higher motivation to work hard. Mobility fosters aspiration, efforts, innovation, and self-fulfillment.

Although economists tend to think of mobility in terms of income and consumption, economic and social mobility are intertwined, especially through jobs. In most societies, jobs are fundamental sources of self-respect and social identity. The distribution of jobs within society and perceptions about who has economic mobility can shape individuals' perceptions of fairness and aspirations for the future (Akerlof and Kranton 2010; World Bank 2012b). In South Asia, marginalized population groups traditionally suffer from both material poverty and social indignity. This situation is most obvious in the case of 
the caste system, in which occupations are essentially set for individuals at birth.

In a perfectly mobile society, by contrast, occupational choices should be independent across generations. For instance, the children of manual and nonmanual workers would have similar prospects of securing nonmanual jobs. If so, growth should allow the people from marginalized groups to move into the mainstream of society.

This intuition of occupational independence can be followed to assess the extent of mobility across generations. Because of limitations of data availability, a measure of occupational independence across generations in South Asia can be computed only for India. There, a unique father-son matched data set exists, and it is based on a nationally representative sample. Data on self-reported occupation in the preceding year are available in the case of sons; in the case of fathers, data refer to occupation for most of life as reported by sons. For both generations, occupations are mapped into four categories in a broadly ascending order of economic returns and levels of social prestige: unskilled workers, farmers, skilled or semiskilled workers, and white-collar workers.

The analysis reveals considerable occupational mobility across generations (figure 17). The sons of unskilled fathers and those of farming fathers both saw significant prospects of moving to higher-ranked jobs in terms of economic returns and social prestige. Over 40 percent of the children of unskilled workers were holding other occupations. About 36 percent of the children of farmers worked as skilled or semiskilled workers or as white-collar workers.

Occupational mobility across generations has also increased over time (figure 18). The occupational transition matrix between fathers and sons of each birth cohort can be compared with the hypothetical transition matrix of a perfectly mobile society. The smaller the "distance" between the two matrices, the greater the mobility (Long and Ferrie 2013). Between the first (1945-54) and the last (1974-84) cohorts, this distance has declined significantly. On average, the
FIGURE 17 Considerable occupational mobility exists across generations in India

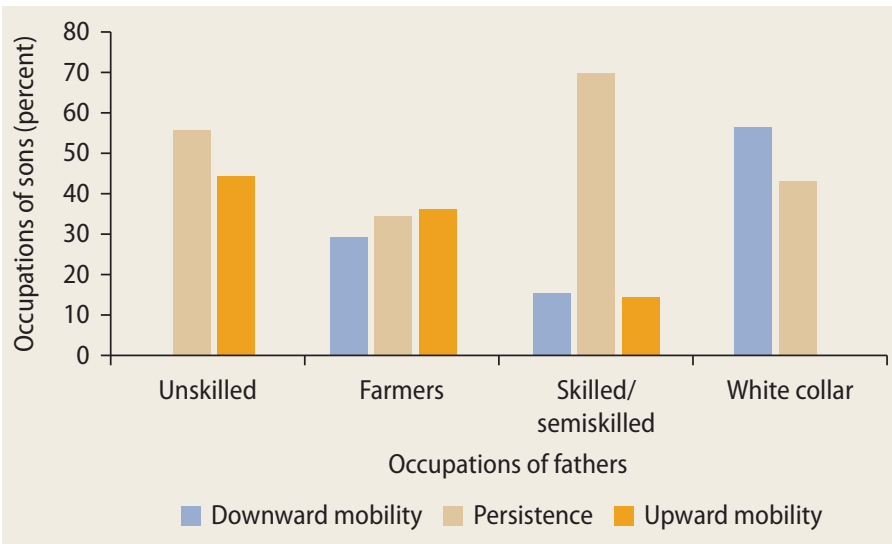

Source: Based on India Human Development Survey (IHDS) 2004-05.

FIGURE 18 Occupational mobility is higher for younger generations

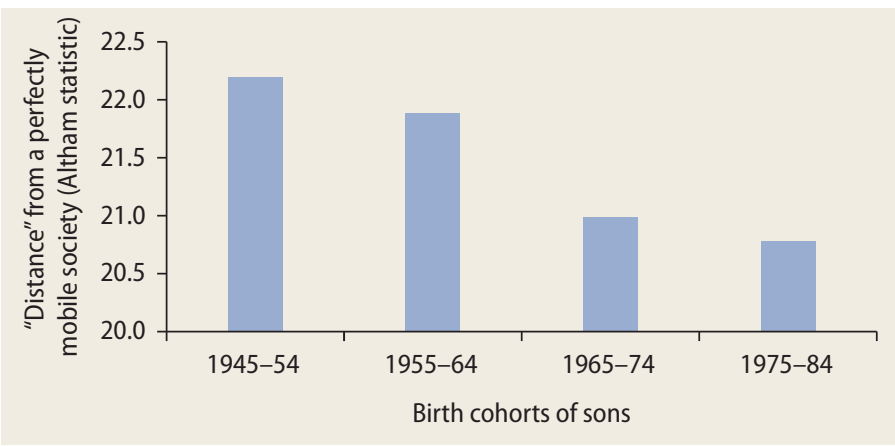

Source. Based on IHDS 2004-05.

Note: "Distance" is measured as the Altham statistic comparing the actual transition matrix to that of a hypothetical, perfectly mobile society.

children of people in basic occupations have seen rising prospects of taking higher-ranked occupations relative to the children of people in higher-ranked occupations. The conclusion appears to be robust to the classification of occupations and the methodology used for the comparison across cohorts (Singh and Motiram 2012).

The most notable improvements in mobility are found for Scheduled Castes, Scheduled Tribes, and Other Backward Castes. The transition matrices of socially marginalized groups are compared in this case with 
those of higher-caste Hindus for each cohort. The comparison shows that mobility among Muslims has been similar to that of highercaste Hindus, whereas mobility among Scheduled Castes and Scheduled Tribes and among Other Backward Castes has become higher than that of higher-caste Hindus over time. Again, the conclusion appears to be robust to the choice of methodology (Hnatkovska, Lahiri, and Paul 2013).

A truly mobile society is arguably one in which poorer households can manage to climb up the income or consumption ladder through their own efforts within a single generation. Mobility of this sort requires that the growth in the income or the consumption of the poor be faster than the growth of the average person. When splitting the total population by income status, a fraction should be able to move above the poverty line while some should be able to make solid progress into the middle class.

Mobility within a generation can be assessed by comparing the income or consumption of the same households between two periods (Fields 2010; Fields and Ok 1996). But doing so requires nationally representative information on the same households at two points in time-so-called panel datawhich is generally not available for South Asian countries. To overcome this difficulty, three synthetic panel data sets were built especially for this report, linking different rounds of nationally representative surveys. Two of the synthetic panels are for India; they cover the periods between 1993-94 and 2004-05, and between 2004-05 and 2009-10. The third panel is for Bangladesh between 2005 and 2010.

When splitting the population into three groups-poor, vulnerable, and middle class-upward mobility was considerable for both the poor and the vulnerable. In India, although some households fell into poverty between 2004-05 and 2009-10, more of them, about 15 percent of the total population or 40 percent of the poor, moved above the poverty line. Meanwhile, a sizable proportion of the poor and the vulnerable-over 9 percent of the total population or about 11 percent of the poor and vulnerable-moved into the middle class. Households from Scheduled Castes and Scheduled Tribes experienced upward mobility comparable to that of the rest of the population. In Bangladesh, between 2005 and 2010, about 19 percent of the total population, or half the poor, moved above the poverty line, and about 13 percent of the total population, or over 15 percent of the poor and vulnerable, moved into the middle class. Downward mobility was also considerable in both countries, however.

By these measures, upward mobility within a generation in Bangladesh and India was comparable to that of dynamic societies such as the United States and Vietnam (figure 19). Per capita consumption is higher and poverty incidence is lower in the United States and Vietnam than in South Asian countries, but over a comparable period, the four countries saw similar fractions of the poor moving above the poverty line and a considerable fraction of the poor and vulnerable moving into the middle class. Downward mobility was much bigger in the two South Asian countries, however, revealing the greater risks faced by the vulnerable and even the middle class.

At the level of villages, increasing mobility is largely associated with occupational change. The timing and the pace have varied across countries, but the shift has consistently involved an expansion of nonfarm employment. While the new jobs are mainly casual, they have supported considerable mobility. Wages of casual nonfarm workers were 30 percent to 50 percent higher than agricultural wages in rural India, Nepal, and Pakistan in the 2000s; they were 10 percent higher in rural Bangladesh during the first half of the 2000s (World Bank 2011). Although regular jobs tend to pay better, the earnings gap between regular and casual nonfarm jobs has narrowed over time in rural India, whereas the earnings gap between casual nonfarm jobs and agricultural jobs has increased (Himanshu and others 2013).

Internal migration has also helped South Asians find better jobs and investment 


\section{FIGURE 19 Upward mobility in South Asian countries is similar to that in the United States and Vietnam}

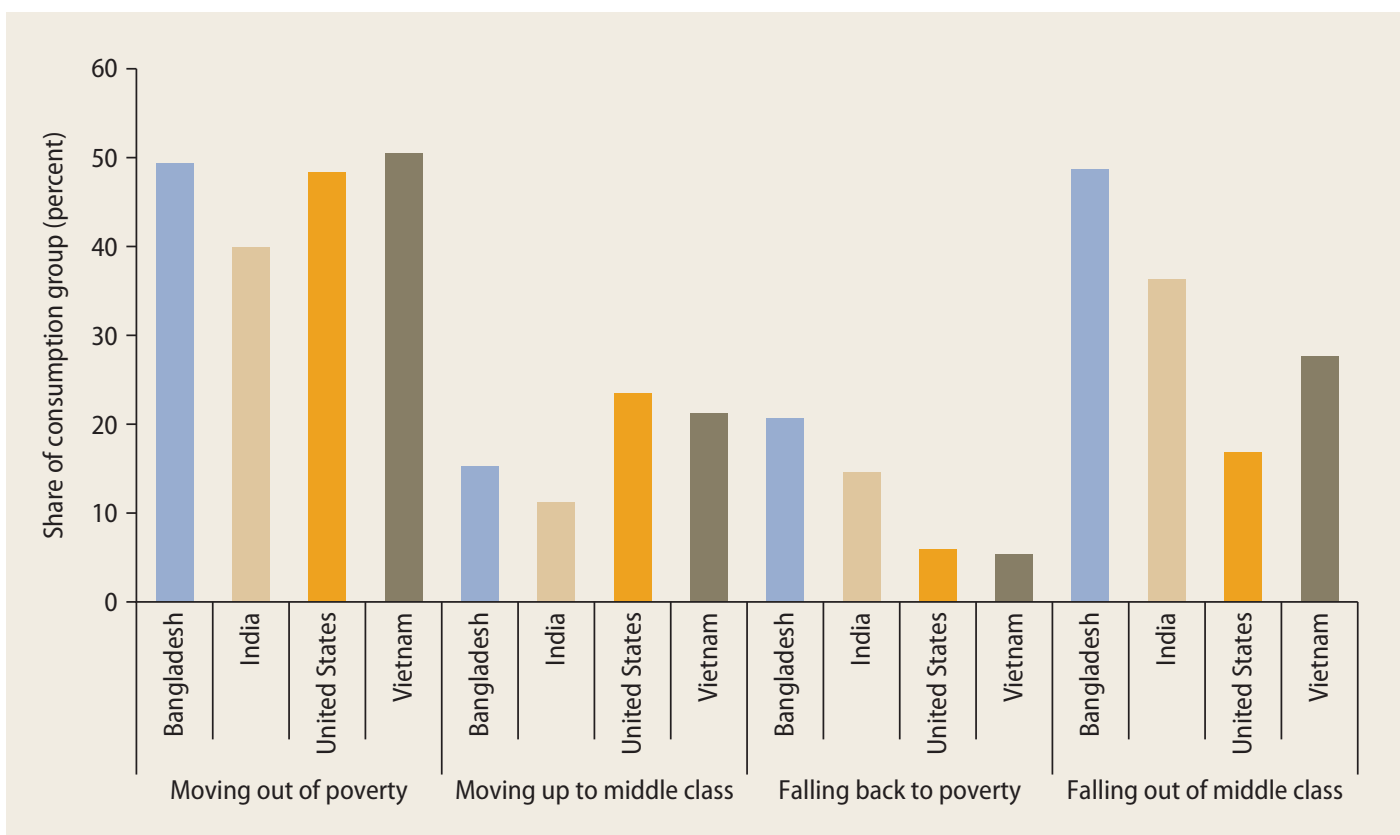

Sources: Based on Dang and Lanjouw 2014 for this report and Dang, Lanjouw, and Khandker 2014 for this report.

Note: The groups considered are the poor for moving out of poverty, the poor and the vulnerable for moving up to middle class, the nonpoor for falling back to poverty, and the middle class for falling out of middle class.

opportunities and achieve economic mobility. Among men, internal migration is primarily a mechanism to fulfill aspirations for employment and investment opportunities (table 1). For women, it is said to be associated to a greater extent with marriage and social reasons. However, special microsurveys focusing on female migrant workers in 20 Indian states found that a significant proportion of unemployed or housebound women enter into paid employment through migration (Mazumdar, Neetha, and Agnihotri 2011). In Bangladesh, the scale of female rural migration is such that it has changed social norms. About 90 percent of the female workers in urban garment sectors in the 1990s and early 2000s were estimated to be migrants from rural areas. Although a socially negative image of the garment workers as "fallen women" prevailed in the early 1990s, these migrants effectively defied and redefined their place in society over time (Afsar 2003; Deshingkar and Grimm 2005; Hossain, Sen, and Sawada 2014).
City dynamism is an important driver of the increasing mobility observed in South Asia. Mobility both across and within generations is greater in urban than in rural areas. In India, the sons of unskilled fathers in urban areas face a lower probability of staying in the same occupational category than their rural counterparts; they also face a much higher probability of taking on better jobs. Sons of farmers also face better prospects in urban areas than in rural areas (figure 20).

In both Bangladesh and India, within the same generation a larger fraction of the population manages to move above the poverty line in rural than in urban areas. Conversely, a larger fraction of the population makes it to the middle class in urban than in rural areas (table 2). Downward mobility in the form of falling below the poverty line is also considerably smaller in urban than in rural areas. Urban households whose members are employed as regular wage or salaried workers experience the highest upward mobility 
TAB LE 1 Changes in employment status reveal substantial mobility among migrant men in India

\begin{tabular}{|c|c|c|c|c|c|}
\hline \multirow[b]{2}{*}{ Before permanent migration } & \multicolumn{5}{|c|}{ After permanent migration (percent) } \\
\hline & Self-employed & $\begin{array}{l}\text { Regular } \\
\text { employee }\end{array}$ & Casual labor & $\begin{array}{l}\text { Unemployed or not } \\
\text { in labor force }\end{array}$ & Total \\
\hline Self-employed & 70.6 & '18.1' & 8.7 & 2.6 & 100 \\
\hline Regular employee & 9.9 & 83.8 & 2.6 & 3.7 & 100 \\
\hline Casual labor & 20.3 & ' $2-\overline{8} .5$, & 49.6 & 1.6 & 100 \\
\hline Unemployed or not in labor force & 17.3 & '3-34.2, & 14.4 & 34.1 & 100 \\
\hline Total & 24.1 & '39.7, & 19.2 & 17.0 & 100 \\
\hline
\end{tabular}

Source: Based on NSS 2007-08.

Note: The migrants considered are adult males 15 years of age and older. The circled cells show the shares of migrants who became regular wageworkers after migration.

\section{FIGURE 20 Upward mobility is much stronger in cities than in rural areas}

a. Urban India

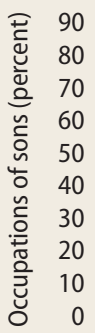

Unskilled

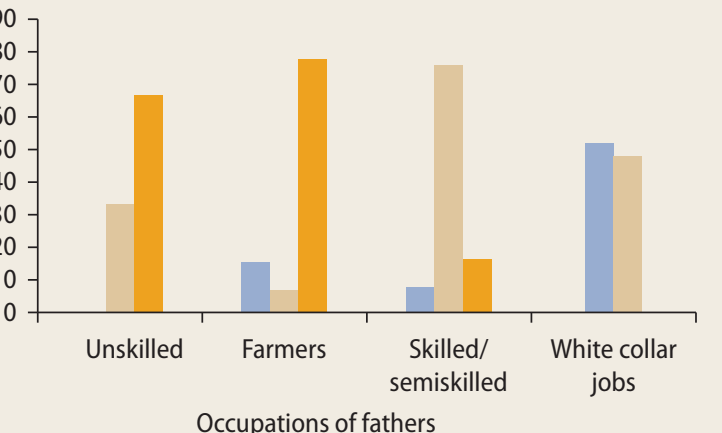

Occupations of fathers

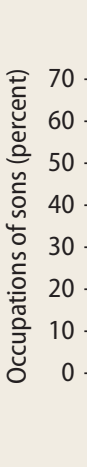

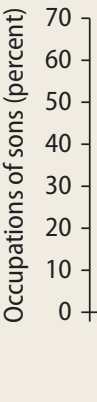

Downward mobility Persistence

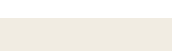

CuRE20 Upward mobility is much strongerincities than in ruralareas

Source: Based on IHDS 2004-05.

and the lowest downward mobility. But selfemployment and casual employment also support substantial improvements in living standards. In both Bangladesh and India, urban households whose members are selfemployed or who work as casual labor experience stronger upward mobility and smaller downward mobility than rural households.

This dynamism, including substantive transitions into the middle class, is taking place despite the prevalence of informality in South Asia's urban areas. The urban informal sector includes a considerable number of wage jobs, and they could be the main driver of upward mobility. For instance, about 18 percent of total urban employment in India is accounted for by men who are regular wageworkers in the informal sector and another 16 percent by men who are casual wageworkers in the informal sector. If both men and women are considered, about 57 percent of the informal workforce in urban areas earns wages.

In Bangladesh, the urban formal sector has been expanding because of the rapid growth of labor-intensive manufacturing, particularly in garments and textiles. Women gained more than men from the expansion of these 
TABLE 2 Rural jobs allow people to escape poverty; urban jobs are a ticket to the middle class

\begin{tabular}{|c|c|c|c|c|c|}
\hline & & \multicolumn{4}{|c|}{ Five years later (percent) } \\
\hline & & Poor & Vulnerable & Middle class & Total \\
\hline \multicolumn{6}{|c|}{ Bangladesh } \\
\hline \multicolumn{6}{|c|}{ Rural households } \\
\hline \multirow[t]{4}{*}{2005} & Poor & 23.0 & '17̄o, & , 28 & 43.6 \\
\hline & Vulnerable & 12.4 & 22.3 & 8 & 42.9 \\
\hline & Middle class & 1.5 & 6.2 & 5.9 & 13.5 \\
\hline & Total & 36.9 & 46.3 & 16.9 & 100.0 \\
\hline \multicolumn{6}{|c|}{ Urban households } \\
\hline \multirow[t]{4}{*}{2005} & Poor & 9.9 & '11.9, & $=29$ & 24.7 \\
\hline & Vulnerable & 7.9 & 22.5 & $1 \overline{4} \overline{1} . \overline{1}$ & 44.5 \\
\hline & Middle class & 1.4 & 10.2 & 19.1 & 30.8 \\
\hline & Total & 19.2 & 44.6 & 36.1 & 100.0 \\
\hline \multicolumn{6}{|l|}{ India } \\
\hline \multicolumn{6}{|c|}{ Rural households } \\
\hline \multirow[t]{4}{*}{ 2004-05 } & Poor & 26.3 & '15.5, & 10.8 & 42.7 \\
\hline & Vulnerable & 9.6 & 28.7 & 97,5 & 45.8 \\
\hline & Middle class & 0.3 & 4.7 & 6.5 & 11.5 \\
\hline & Total & 36.2 & 48.9 & 14.8 & 100.0 \\
\hline \multicolumn{6}{|c|}{ Urban households } \\
\hline \multirow[t]{4}{*}{ 2004-05 } & Poor & 11.2 & 19.4 & $10 \overline{10}$ & 21.3 \\
\hline & Vulnerable & 7.1 & 29.3 & , & 47.7 \\
\hline & Middle class & 0.4 & 8.8 & 21.8 & 31.0 \\
\hline & Total & 18.7 & 47.5 & 33.8 & 100.0 \\
\hline
\end{tabular}

Sources: Based on data from Dang and Lanjouw 2014 for this report and Dang, Lanjouw, and Khandker 2014 for this report.

Note: The household head's age is restricted to between 25 and 55 years on the first survey and adjusted accordingly for the second survey. The circled cells show the shares of the total population who experienced upward mobility. Percentages may not total to 100 because of rounding.

industries. About 60 percent of garment workers were female in 2009; the share might have climbed to about 80 percent by 2012 . Because the demand for female workers in the manufacturing sector has increased faster than that of male workers, women's wages have increased more rapidly than men's in recent years (Ahmed, Bakht, and Yunus 2011; Hossain, Sen, and Sawada 2014; LopezAcevedo and Robertson 2012; Zhang and others 2013).

Although urban areas present better prospects of economic mobility than rural areas, both the pace and the pattern of urbanization in South Asia are reasons for concern. In absolute terms, the urban population is massive and the rate of urbanization is impressive. Overall, 563 million people could be considered urban residents in South Asia in 2011, according to the countries' official definitions (UN 2012). However, countries in South Asia are still less urban than other countries at a similar level of development. From a mobility perspective, this amounts to a missed opportunity.

Urbanization also appears to be more organic in South Asia. Whereas people come to cities in the form of migration, cities also "come" to people through the densification of population and the transformation of economic activity in rural areas. These diverse urbanization processes have led to a range of cities with different characteristics, not just in terms of their size but also in terms of their governance structure. These differences in size and governance matter for mobility, because they shape the type of jobs available across different types of cities.

In India, districts can be classified depending on the size of their biggest city. This 
information, in turn, can be used to analyze the structure of urban employment at the district level. Districts with larger cities have a higher proportion of urban regular wageworkers than do districts with smaller cities (figure 21, panel a). Between districts with cities of more than 1 million people and the other districts, the difference is large and significant. Districts with larger cities also have a higher proportion of urban jobs in manufacturing and services relative to districts with smaller cities.

The governance of cities, in addition to their size, matters for urban economic mobility. In India, districts can be classified into six categories based on the administrative arrangements of their cities: state capitals, other cities with municipal corporations, municipalities, notified areas, nagar panchayat (including census towns), and industrial townships. The first five are in a broadly descending order in terms of administrative autonomy, capacity, and financial resources of city authorities. The last category, industrial townships, covers areas designated for industrial development that have some of the characteristics of special economic zones in other countries. Again, this information can be used to assess how urban employment varies across city characteristics at the district level.

The share of regular wage jobs in urban employment broadly declines with the autonomy, capacity, and financial resources of city authorities (figure 21, panel b). By contrast, the share of self-employment increases. The composition of urban employment in districts with industrial townships resembles that of districts with municipal corporations. Overall, districts with state capitals, municipal corporations, or industrial townships are associated with significantly greater shares of urban employment in regular wage jobs and in all wage jobs. These districts also have a higher share of urban employment in manufacturing and services. One could argue that urban governance improves as city size increases, so that the observed relationships would be misleading. However, the relationships hold even after controlling for the size category of the biggest city in the district.

\section{Inadequate support}

Households in every country suffer from shocks. Most are minor and can be cushioned relatively easily, but some can have longlasting impacts, adversely affecting nutrition, human capital, and asset accumulation. The vulnerability of households to shocks is determined partly by the types of risks they face. South Asian households are periodically exposed both to individual shocks and to economy-wide shocks, such as natural disasters, food price spikes, and armed conflict.

Natural disasters affected more than 750 million people in the region between 1990 and 2008, resulting in approximately 230,000 deaths and US\$45 billion in damages (World Bank 2009). Bangladesh stands out as one of the countries that have experienced the largest losses of human lives worldwide. Moreover, the frequency and magnitude of natural disasters are increasing, mainly because of climate change and accelerated snow melting in the Himalayas (Memon 2012). Food price inflation has been the main driver of headline inflation throughout most of the region, for example, the widespread food price inflation of 2007-08. South Asia is also prone to conflict and violence. The region accounted for at least 40 percent of the world's terrorist incidents in 2009 and 2010 (Global Terrorism Database 2009-14).

The vulnerability of households also depends on their own ability to manage those risks. Typically, the poor have a relatively weak capacity to self-insure or to pool risks beyond extended families. Informal mechanisms tend to be costly and inefficient, often breaking down when shocks affect entire communities.

In Pakistan, poorer and richer households rely on different coping strategies (figure 22). When faced with a shock, a large majority of households in the poorest quintile borrow money, reduced expenditures, switched to lower-quality food, or reduced the quantity of food they consume. Equally important, 11.5 percent of the poorest households reported selling agricultural assets to cope 


\section{FIGURE 21 The composition of urban employment varies with city size and governance in India}

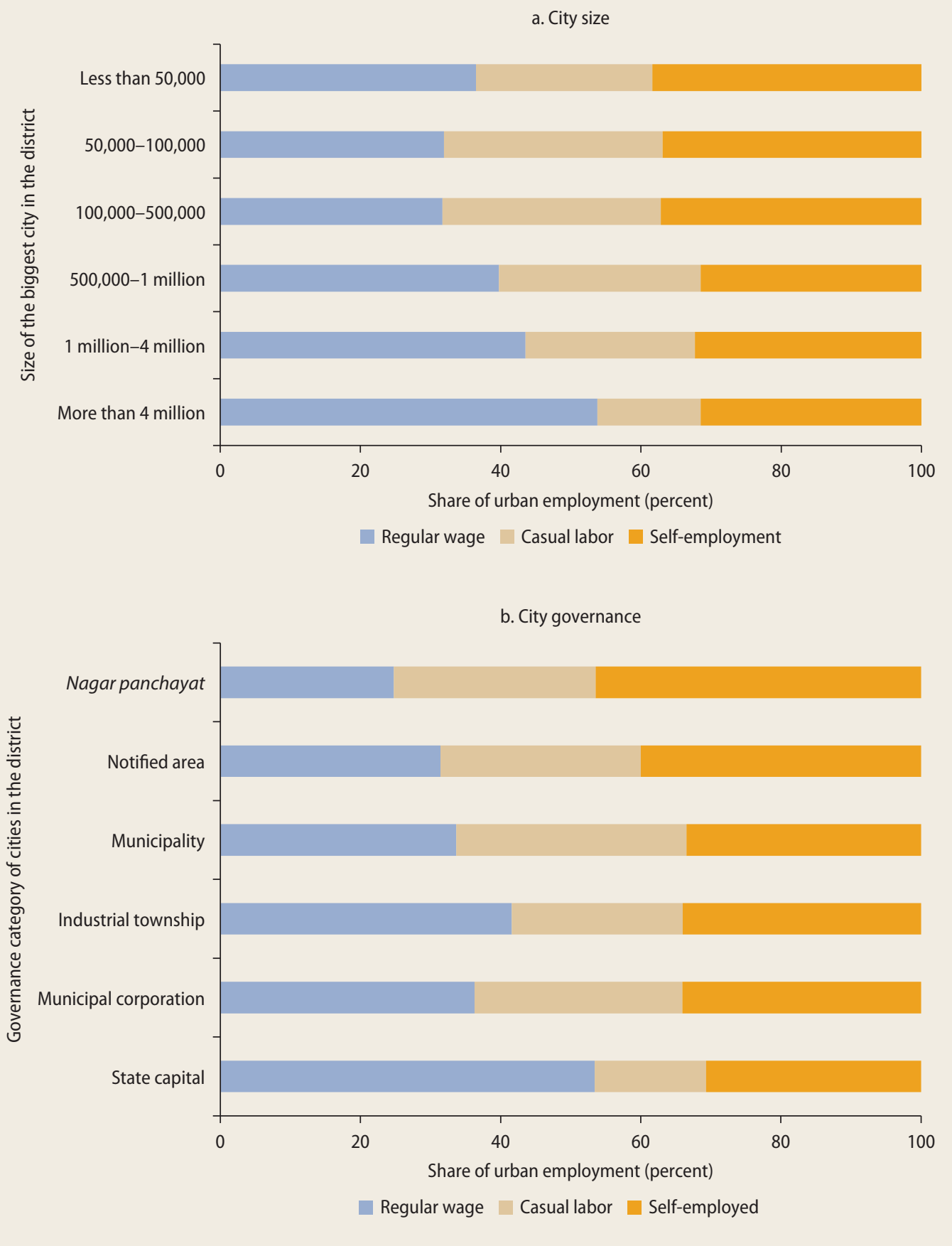

Sources: Based on NSS 2009-10 and RGCC 2012.

Note: Adult workers considered are 15 years of age and older. 


\section{FIGURE 22 In Pakistan, poorer and richer households cope with shocks in different ways}

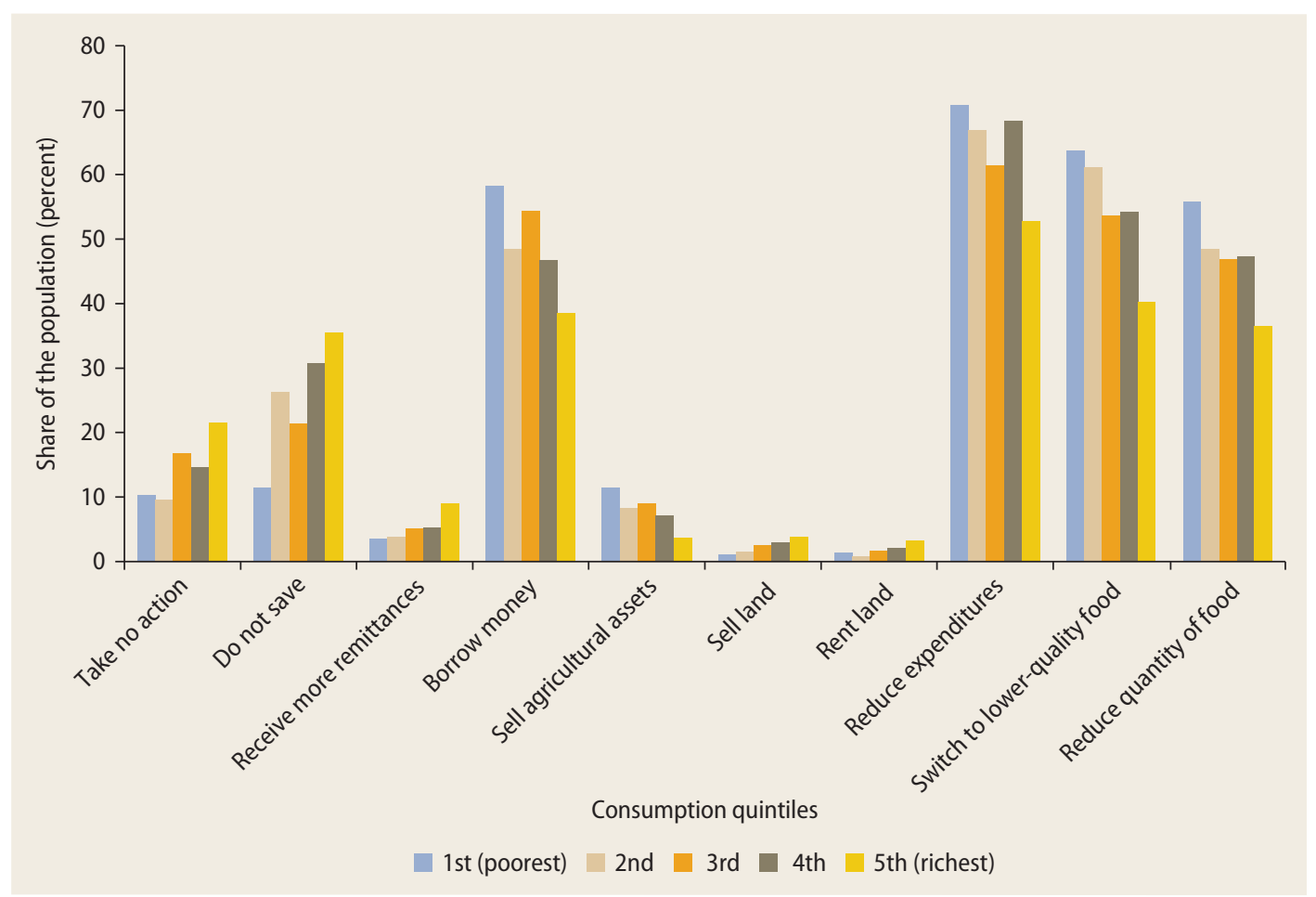

Sources: Based on Pakistan Social and Living Standards Measurement (PSLM) surveys for 2007-08 to 2009-10.

with the shock-a strategy that compromises their long-term ability to earn an income. In contrast, the wealthiest groups are much less likely to use these mechanisms.

Bad shocks can hit even before birth. Individuals differ in their inherited wealth, in their talent, in the value they attach to future well-being relative to present wellbeing, and in their willingness to work hard. Even children of the same parents can differ in these respects. In an ideal society with equality of opportunity and perfect mobility, these inherited differences would result in inequality of outcomes. Given that no society fully meets the ideal, the inequality of outcomes caused by inherited differences is often amplified by the legacy of inequities accumulating throughout life. Private transfers are unlikely to be sufficient to offset the consequences of these forms of randomness. To what extent inequality of outcomes resulting from these different forms of bad luck is tolerable-or even desirable-is a question to which different societies give different answers. But most have developed mechanisms for redress.

Government-sponsored mechanisms to cope with shocks are known as social protection; they typically comprise social assistance and social insurance programs. They are designed to prevent households that are affected by an adverse shock from experiencing too dramatic a fall in their living standards. Mechanisms to redress deeper differences in the fate of individuals and households fall under the broader heading of redistribution; the instruments used in this case are taxes, subsidies, and transfers. This type of support aims at bringing disadvantaged households to a higher level of welfare than they could attain on their own. The reach, generosity, and efficiency of social protection and redistribution mechanisms vary from one society to another and, as a 
result, the extent of inequality of outcomes varies as well.

South Asian countries have a mixed record on both fronts. Public spending on social protection programs has expanded over time. Measured as a fraction of GDP, it is in line with that of other countries at roughly the same development level. On average, developing countries spend 1.53 percent of their GDP on safety nets, and with the exception of Sri Lanka, most South Asian countries fall within the 0.25 percent to 2 percent range (Gentilini, Honorati, and Yemtsov 2014). The design of these programs also shows important strengths. The Female Secondary Schools Stipends Program of Bangladesh is known worldwide as the precursor of modern conditional cash transfers. The Benazir Income Support Programme of Pakistan is remarkably well targeted to poorer households and has helped them become more resilient to natural disasters. The Mahatma Gandhi National Rural Employment Guarantee Act of India-the largest public works program in the world-has dramatically reduced distress sales of land in years of drought.

Social protection spending is largely progressive across the entire region. When assessed on the basis of absolute spending per person, social protection programs are progressive in Bangladesh, Pakistan, and Sri Lanka. Bangladesh is the most effective in directing social protection resources to the poor. In 2010, the poorest 40 percent of households received a little over half the social assistance and over 75 percent of the social insurance. Because poorer households consume less, the same level of public spending makes a greater difference in their case. When assessed relative to the consumption level of the beneficiaries, social protection spending turns out to be largely progressive in all South Asian countries.

Overall, however, the coverage of social protection programs in South Asia is partial, their targeting is generally poor, and the amount of resources they make available to those who need them the most is often too modest (figure 23). In Nepal and Sri Lanka, a little more than half the poor receive support.
In most other countries, the coverage rate of social assistance spending is between 20 percent and 30 percent, though coverage has improved over time. Social assistance programs are not very well targeted. Across all countries in the region, 60 percent to 80 percent of the beneficiaries are not poor, and they receive between 50 percent and 80 percent of the funding. Although some of the nonpoor may stand just above the poverty line, a disproportionately large fraction of resources is captured by the better-off. The benefit adequacy of social assistance programs remains low in most countries considered.

The record is arguably more questionable in the case of redistribution. One of South Asia's salient characteristics is the low level of its tax revenue relative to GDP, which implies that the potential for the government to make a dent in inequality of outcomes is more limited than elsewhere. In developing countries, the overall tax collection as a percentage of GDP tends to be small (Chu, Davoodi, and Gupta 2000). It is even lower than the average in South Asian countries, where government revenue averages between 10 percent and 15 percent (map 1). The collection rates fall behind comparable developing countries, such as Brazil, China, and Mexico. Even after controlling for main structural factors, however, revenue mobilization in most South Asian countries is still below the average for countries at similar income levels (World Bank 2012a).

Tax revenue is low not because South Asian countries rely on unusual tax instruments but rather because the revenue "productivity" of those instruments is unusually low. A standard indicator of such productivity is the share of GDP in revenue collection for every percentage point of the basic tax rate. In countries such as Thailand or Vietnam, the productivity of value added tax (VAT) exceeds 50 percent and that of corporate income tax (CIT) reaches 30 percent. In contrast, the productivity of VAT in South Asian countries varies between 20 and 40 percent, and that of CIT hovers around a meager 10 percent (World Bank 2010, 2012a). Tax avoidance, tax evasion, and the 


\section{FIGURE 23 Social assistance is less adequate than social insurance but has greater coverage}

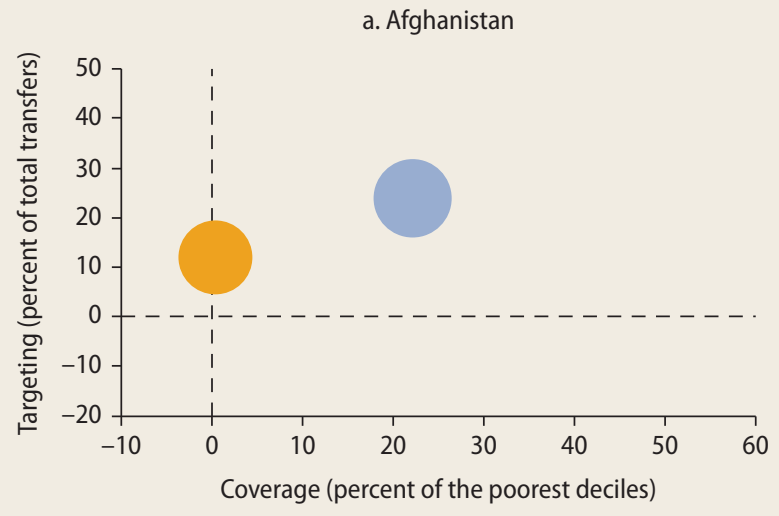

c. Maldives

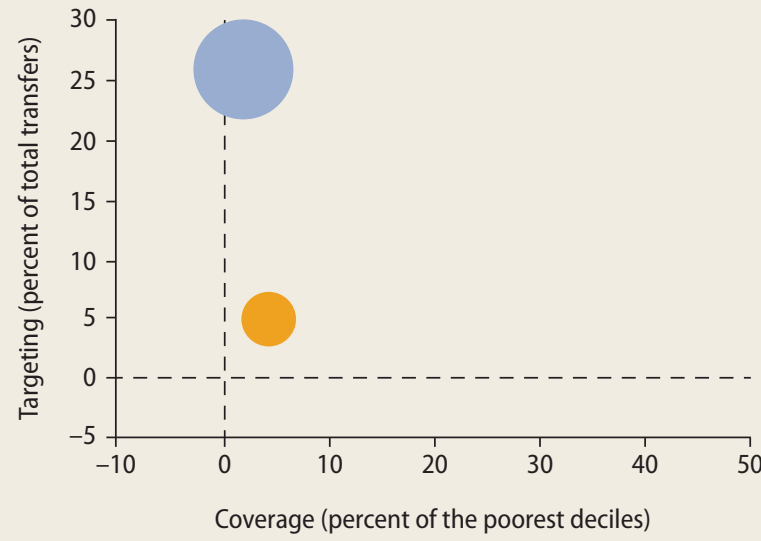

e. Pakistan

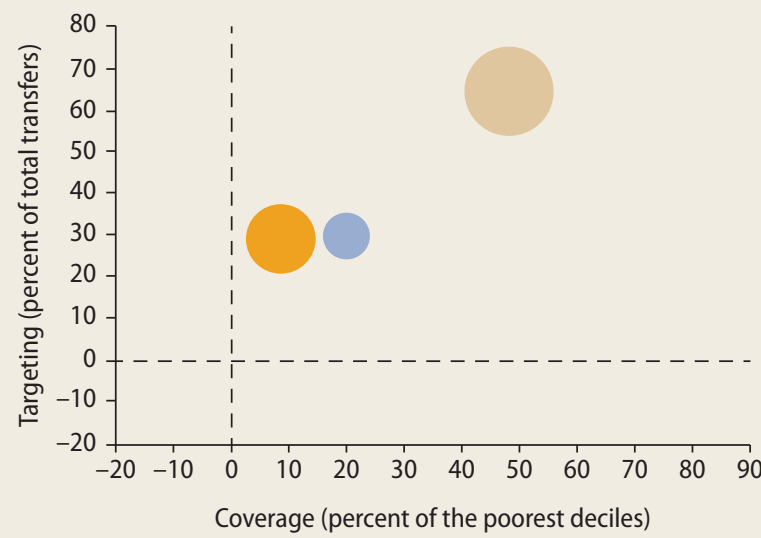

b. Bangladesh

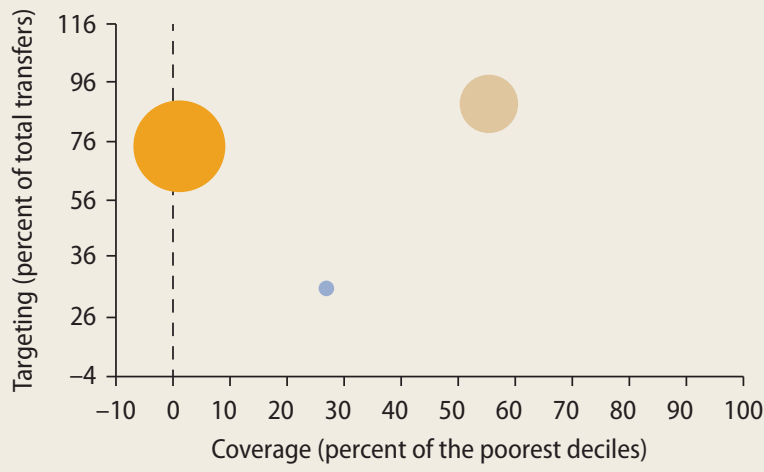

d. Nepal

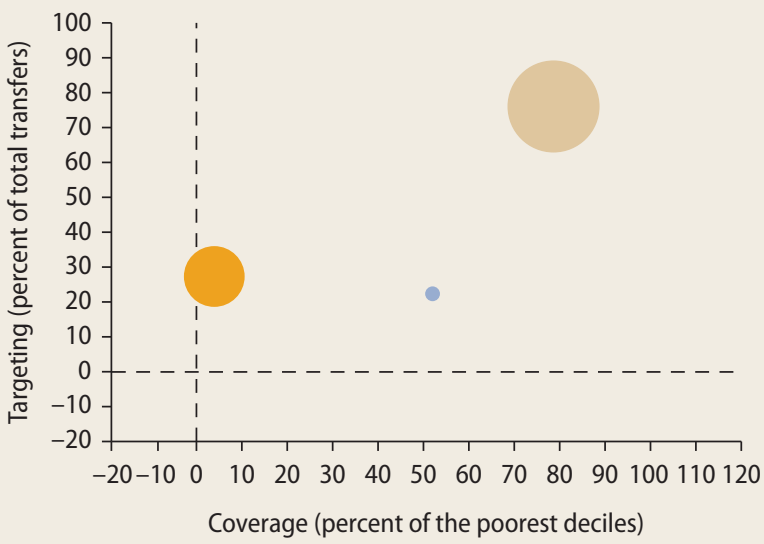

f. Sri Lanka

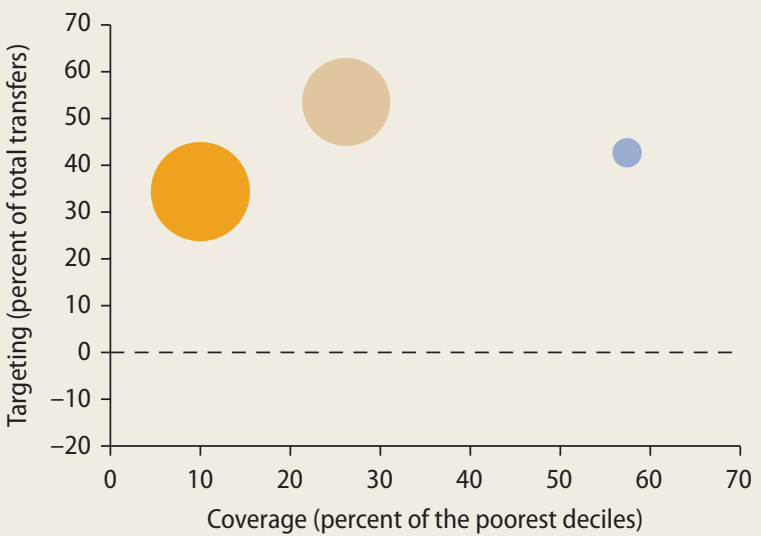

Social assistance programs Social insurance programs Remittances

Sources: NRVA 2007 for Afghanistan, HIES 2010 for Bangladesh, VPA 2004 for Maldives, NLSS 2010 for Nepal, PSLM 2010-11 for Pakistan, and HIES 2006 -07 for Sri Lanka. Note: Coverage is the percentage of the population in the bottom two deciles that receives the benefits. Targeting is the sum of transfers received by the bottom two deciles as a percentage of total transfers. Adequacy, measured by the size of the bubble, is the mean value of the transfer amount received by beneficiaries in the bottom two quintiles in percent of mean expenditure per capita in that group. Deciles are defined based on expenditure per capita net of social protection transfers. Remittances are used as a benchmark for government-funded social protection programs. 
MAP 1 Government revenue in South Asia is low compared with the rest of the world

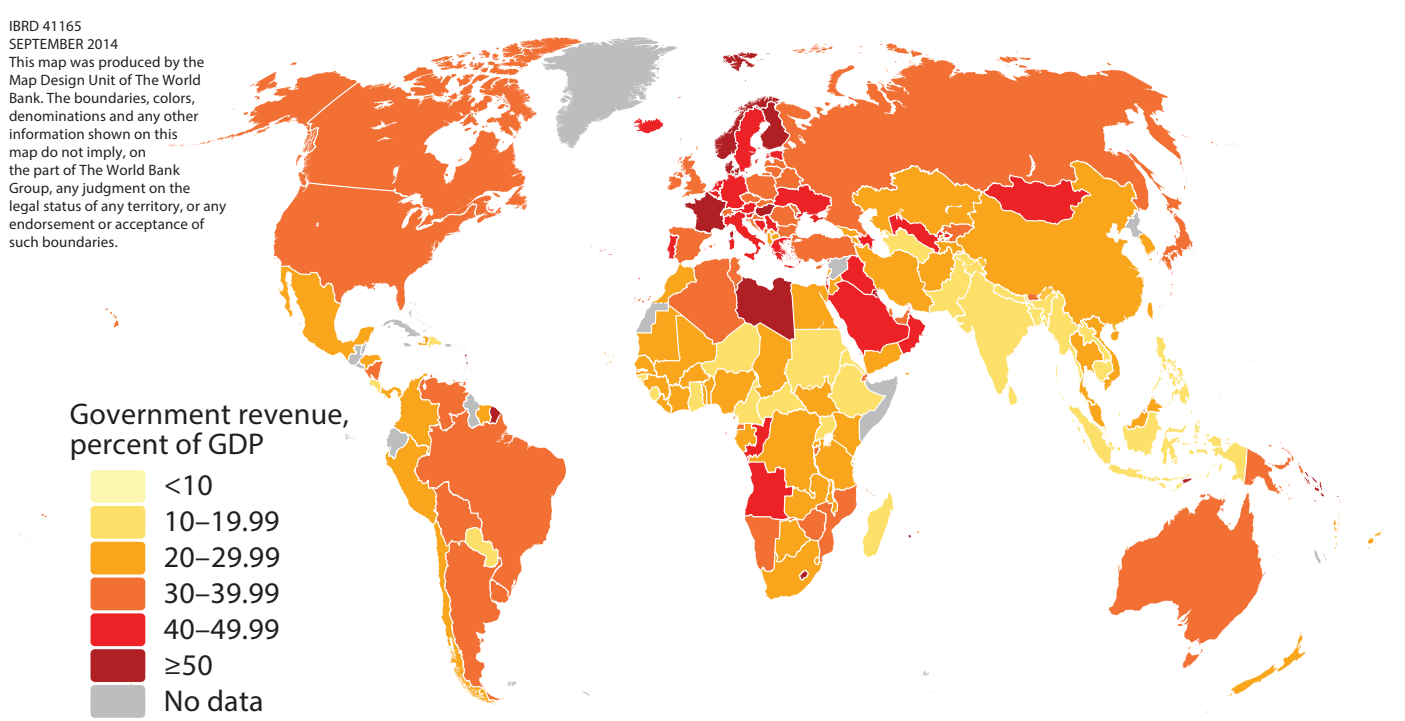

Source: Based on International Monetary Fund Data Mapper, http://www.imf.org/external/Datamapper/index.php.

underreporting of taxable amounts are widespread, as are exemptions and special regimes favoring the businesses with more clout. All of this results in a tax system of relatively low progressivity.

Taxes are only one transfer mechanism through which the distribution of income or consumption can be modified. From an individual's point of view, taxes and public spending can have similar consequences on income or consumption (although they typically affect incentives differently).

In South Asia, a substantial share of public spending goes into subsidies. Some of them are regressive and can crowd out the provision of essential public goods. An unusually large fraction of the typically low government revenue is often devoted to reducing the final price of food, fertilizer, gas, and electricity. Equity concerns are among the justifications for this type of spending. And in some cases, as for food, the justification has merit. But in countries where the poor generally lack access to the grid and often cook using biomass, subsidizing electricity is bound to be regressive.

The bias toward food and price subsidies is especially marked in India and Pakistan.
In India, the Public Distribution System (PDS) is responsible for the provision of subsidized food. It takes the largest share of resources among all social protection programs: 43 billion Indian rupees, compared to around 30 billion Indian rupees devoted to Mahatma Gandhi National Rural Employment Guarantee funding (Union Budget 2013-14, http://indiabudget.nic.in/budget2013-2014 /budget.asp). In Pakistan, subsidies absorbed more than 230 billion Pakistani rupees, or 1.3 percent of GDP, in fiscal year 2010-11; in comparison, the Benazir Income Support Programme consumed about 34 billion Pakistani rupees (Government of Pakistan 2010; World Bank 2013b).

The delivery mechanisms for these food subsidies lend themselves to inefficiencies and leakages. In India, PDS was found to have strong poverty reduction impacts, accounting for a significant fraction of the poverty decline between 2004-05 and 2009-10. Several states have made substantial improvements in infrastructure and delivery systems to plug leakage. However, the coverage rates were around 53 percent in rural areas and 33 percent in urban areas in 2011-12. Take-up rates were progressive across 
quintiles, but coverage rates of richest 20 percent in rural areas remained high. The illegal diversion and leakages were about 44 percent by the end of 2007-08 and around 35 percent in 2011-12 (Himanshu 2013; Jha and Ramaswami 2010; Khera 2011). In Pakistan, both federal and provincial governments intervene in markets for food products through mechanisms such as the "Utility Store" arrangement. The complexity of these mechanisms makes it difficult to quantify the full extent of the inefficiencies, but it is clear that part of the subsidy is appropriated by wheat flour millers and traders (World Bank 2013b).

In South Asia, fertilizer subsidies are crowding out investments in essential public goods. Agricultural growth critically depends on investments in research and development, extension services, and water and irrigation infrastructure. Since the assets created by such investments have the characteristics of public goods and thus tend to be underprovided by the market, public expenditures are pivotal in their provision. In Bangladesh, investment in these sectors has fallen from 5.2 percent of total public agricultural expenditures to 2.7 percent over less than a decade, mainly because of increased spending on the fertilizer subsidy (World Bank 2010). In Sri Lanka, total public expenditure in agriculture in 2011 increased by 64 percent over 2010 but mainly to finance growing spending on the fertilizer subsidy (MoFP 2012).

Energy subsidies are arguably even more regressive than food and fertilizer subsidies. In Bangladesh and Pakistan, energy subsidies amount to more than 4 percent of GDP, a level in line with global energy exporters such as the Arab Republic of Egypt, Qatar, and the República Bolivariana de Venezuela. In Sri Lanka and India, energy subsidies are about 2 percent, doubling the world average (IMF 2013).

Energy subsidies disproportionately benefit the better-off. In the case of the subsidies for liquefied petroleum gas (LPG) in India, the average household in the poorest quintile has less than a 20 percent probability of using LPG; in contrast, the average probability for an urban household in the richest quintile is almost 100 percent (Goutam, Lahoti, and Suchitra 2012). In the case of Pakistan, the poorest 40 percent of households used to receive less than 30 percent of total electricity subsidies, while the richest 20 percent received close to 40 percent of total subsidies. The distribution of benefits improved after the October 2013 tariff increase, but electricity subsidies remain regressive (figure 24). Electricity subsidies are regressive in Maldives as well.

A positive note comes from spatial transfers to lower-level administrative units, such as provinces and districts. In countries with high levels of informality and important spatial disparities, intergovernmental transfers are a more effective tool to reduce inequality than either taxes or transfers to individuals. When avoiding or evading rules is easy, taxes encourage individuals and firms to remain informal. Both taxes and transfers to individuals affect incentives to work and accumulate in ways that tend to be detrimental to efficiency. By contrast, intergovernmental transfers make resources available for the provision of public goods in places that would not be able to mobilize the resources to pay for them. The relevance of intergovernmental transfers is even greater in countries that are large and diverse, as is the case in Bangladesh, India, and Pakistan.

Intergovernmental transfers are defined by country-specific institutions. In India, the largest component of fiscal transfers comes from tax-sharing schemes, but discretionary transfers and the subsidies together are almost as large as the tax shares. The overall system of intergovernmental transfers in India is generally progressive and leads to a more equitable distribution of fiscal resources across constituencies (Ghani, Iyer, and Misra 2013). The same can be said of Pakistan and Sri Lanka, where poorer regions receive higher per capita fiscal transfers (Ghani 2010).

The relatively progressive nature of intergovernmental transfers does not imply, however, that public development spending per person is progressive (figure 25). Subnational 


\section{FIGURE 24 Electricity subsidies favor the better-off}
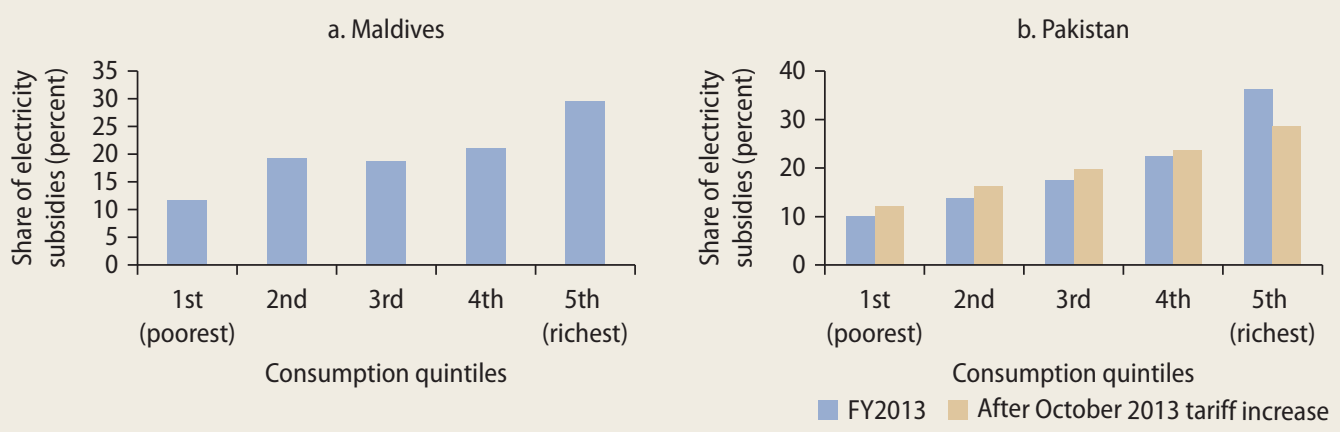

Sources: Redaelli 2013; Trimble, Yoshida, and Saqib 2011

Note: FY2013 = Fiscal Year 2013

\section{FIGURE 25 Development spending per person is lower in poorer states and districts}

a. Districts in Bangladesh

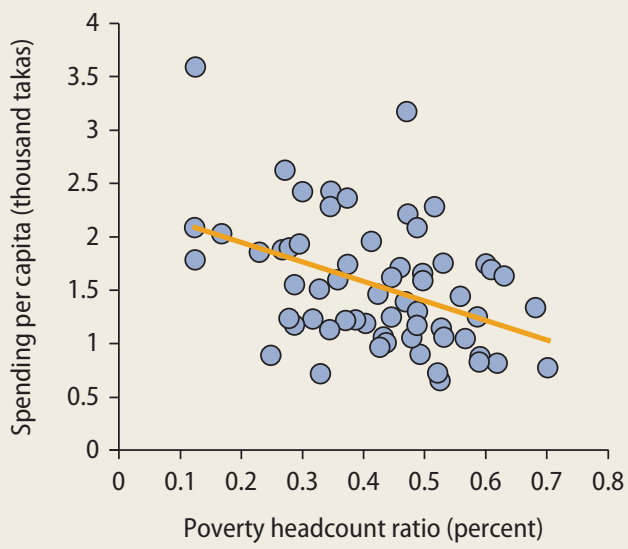

b. States in India

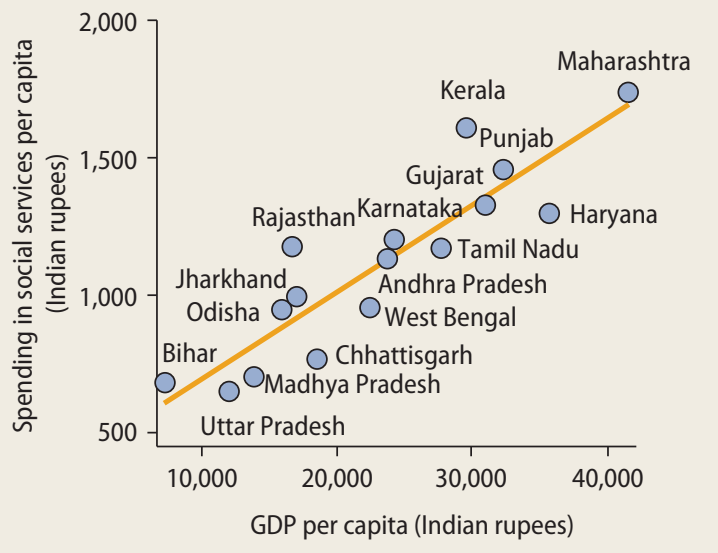

Sources: Iyer, Ghani, and Mishra 2010; World Bank 2010.

governments in poorer areas tend to have much less locally generated revenue than those in more affluent parts of the country. In addition, their capacity to spend their resources is more limited. For instance, a study covering 533 blocks in Bihar-India's poorest state-found that one-third of them did not have any block development officers. As a result, 20 percent of the funds allocated to the state had not been spent (World Bank 2005a). Weak capacity also undermines local monitoring of public spending, often leading to leakages or unspent funds (Murgai and Zaidi 2005).

\section{References}

Afsar, Rita. 2003. "Internal Migration and the Development Nexus: The Case of Bangladesh." Paper presented at the Regional Conference on Migration, Development and Pro-Poor Policy Choices in Asia, Dhaka, June 22-24.

Ahmed, Nazneen, Zaid Bakht, and Md. Yunus. 2011. "Size Structure of Manufacturing Industry and Implications for Growth and Poverty." 
Bangladesh Country Paper, Bangladesh Institute of Development Studies, Dhaka.

Akerlof, George A., and Rachel E. Kranton. 2010. Identity Economics: How Our Identities Shape Our Work, Wages, and Well-Being. Princeton, NJ: Princeton University Press.

Andres, Luis, Dan Biller, Mario Picon, and Agustin Echenique. 2013. "Increasing Opportunities in South Asia-Infrastructure." Background paper for this report, World Bank, Washington, DC.

Banerjee, Abhijit, and Thomas Piketty. 2005. “Top Indian Incomes, 1922-2000." World Bank Economic Review 19 (1): 1-20.

Bardhan, Pranab K. 2005. Scarcity, Conflicts, and Cooperation: Essays in the Political and Institutional Economics of Development. Cambridge, MA: MIT Press.

Barros, Ricardo, Mirela de Carvalho, Samuel Franco, and Rosane Mendonça. 2010. "Markets, the State, and the Dynamics of Inequality in Brazil." In Declining Inequality in Latin America: A Decade of Progress, edited by Luis F. López-Calva and Nora C. Lustig, 134-74. Baltimore: Brookings Institution Press.

Beaman, Lori, Esther Duflo, Rohini Pande, and Petia Topalova. 2012. "Female Leadership Raises Aspirations and Educational Attainment for Girls: A Policy Experiment in India." Science 335 (6068): 582-86.

Blattman, Christopher, and Edward Miguel. 2010. "Civil War." Journal of Economic Literature 48 (1): 3-57.

Chu, Ke-young, Hamid Reza Davoodi, and Sanjeev Gupta. 2000. "Income Distribution and Tax and Government Spending Policies in Developing Countries." IMF Working Paper WP/00/62, International Monetary Fund, Fiscal Affairs Department, Washington, DC.

Collier, Paul, and Anke Hoeffler. 2004. "Greed and Grievance in Civil War." Oxford Economic Papers 56 (4): 563-95.

Dang, Hai-Anh, and Peter Lanjouw. 2014. "Welfare Dynamics Measurement: Two Definitions of a Vulnerability Line and Their Applications." Background paper for this report and Policy Research Working Paper 6944, World Bank, Washington, DC.

Dang, Hai-Anh, Peter Lanjouw, and Shahidur Khandker. 2014. "Poverty Dynamics in Bangladesh: Recent Trends and Insights from Synthetic Panel Data.” Background paper for this report, World Bank, Washington, DC.

de Souza, Pedro H. G. 2012. "Poverty, Inequality and Social Policies in Brazil, 1995-2009."
Working Paper 87, International Policy Centre for Inclusive Growth, United Nations Development Programme, Brasilia, Brazil.

Deshingkar, Priya, and Sven Grimm. 2005. Internal Migration and Development: A Global Perspective. IOM Migration Research Series No. 19. Geneva: International Organization for Migration.

Dollar, David, Tatjana Kleineberg, and Aart Kraay. 2013. "Growth Still Is Good for the Poor.” Policy Research Working Paper 6568, World Bank, Washington, DC.

Duflo, Esther. 2012. "Women Empowerment and Economic Development." Journal of Economic Literature 50 (4): 1051-79.

Dundar, Halil, Tara Béteille, Michelle Riboud, and Anil Deolalika. 2014. Student Learning in South Asia: Challenges, Opportunities, and Policy Priorities. Washington, DC: World Bank.

Educational Initiatives. 2010. Student Learning Study. Status of Learning across 18 Sites of India in Urban and Rural Schools. Ahmedabad, India: Educational Initiatives. http://www .ei-india.com/wp-content/uploads/2012/01 /Main_Report_StudentLearningStudy_2010 _by_Educational_Initiatives1.pdf.

Ferreira Francisco, Phillippe Leite, and Julie Litchfield. 2008. "The Rise and Fall of Brazilian Inequality: 1981-2004." Macroeconomic Dynamics 12 (Suppl. S2): 199-230.

Fields, Gary S. 2010. "Does Income Mobility Equalize Longer-Term Incomes? New Measures of an Old Concept." Journal of Economic Inequality 8 (4): 409-27.

Fields, Gary S., and Efe A. Ok. 1996. "The Meaning and Measurement of Income Mobility." Journal of Economic Theory 71 (2): 349-77.

Forbes. 2014. “The World's Billionaires.” http:// www.forbes.com/billionaires/list. Accessed May 29, 2014.

Gandhi, Aditi, and Michael Walton. 2012. "Where Do India's Billionaires Get Their Wealth?" Economic \& Political Weekly, October 6, 10-14.

Gentilini, Ugo, Maddalena Honorati, and Ruslan Yemtsov. 2014. The State of Social Safety Nets 2014. Washington, DC: World Bank.

Ghani, Ejaz, ed. 2010. The Poor Half Billion in South Asia: What Is Holding Back Lagging Regions? New Delhi: Oxford University Press and World Bank.

Ghani, Ejaz, Lakshmi Iyer, and Saurabh Misra. 2013. "Promoting Shared Prosperity in South Asia." Economic Premise 110 (March): 1-8. 
Global Terrorism Database. 2009-14. National Consortium for the Study of Terrorism and Responses to Terrorism, START: A Center of Excellence of the U.S. Department of Homeland Security, University of Maryland, College Park, MD. http://www.start.umd.edu/gtd/.

Goutam, Prodyumna, Rahul Lahoti, and J. Y. Suchitra. 2012. "Subsidies for Whom? The Case of LPG in India." Economic and Political Weekly 47 (44).

Government of Pakistan. 2010. Poverty Reduction Strategy Paper. Islamabad: Finance Division, Government of Pakistan.

Himanshu, Abhijit Sen. 2013. "In-Kind Food Transfers-I: Impact on Poverty." Economic and Political Weekly.

Himanshu, Abhijit Sen, Peter Lanjouw, Rinku Murgai, and Nicholas Stern. 2013. "Non-farm Diversification, Poverty, Economic Mobility and Income Inequality: A Case Study in Village India." Policy Research Working Paper 6451, World Bank, Washington DC.

Hnatkovska, Viktoria, Amartya Lahiri, and Sourabh B. Paul. 2013. "Breaking the Caste Barrier: Intergenerational Mobility in India." Journal of Human Resources 48 (2): 435-73.

Hoff, Karla. 2012. "The Effect of Inequality on Aspirations." Background paper for this report, World Bank, Washington, DC.

Hoff, Karla, and Priyanka Pandey. 2006. "Discrimination, Social Identity, and Durable Inequalities." American Economic Review 96 (2): 206-11.

- 2012. "Making Up People-the Effect of Identity on Preferences and Performance in a Modernizing Society." Policy Research Working Paper 6223, World Bank, Washington, DC.

Horowitz, Donald L. 2000. Ethnic Groups in Conflict. 2nd ed. Berkeley and Los Angeles: University of California Press.

Hossain, Mahabub, Binayak Sen, and Yasuyuki Sawada. 2014. "Jobs, Growth and Development: Making of the 'Other' Bangladesh.” Background Paper for the World Development Report 2013, World Bank, Washington, DC.

IMF (International Monetary Fund). 2013. "Energy Subsidy Reform: Lessons and Implications.” IMF, Washington, DC, January 2.

Iyer, Lakshmi. 2009. “The Bloody Millennium: Internal Conflict in South Asia." Business, Government, and the International Economy Unit, Working Paper 09-086, Harvard Business School, Cambridge, MA.
Iyer, Lakshmi, Ejaz Ghani, and Saurabh Mishra. 2010. "Is Decentralization Helping the Lagging Regions?" In The Poor Half Billion in South Asia: What Is Holding Back Lagging Regions? ed. Ejaz Ghani, New Delhi: Oxford University Press and World Bank.

Jha, Shikha, and Bharat Ramaswami. 2010. "How Can Food Subsidies Work Better? Answers from India and the Philippines." ADB Economics Working Paper Series no. 221, Asian Development Bank, Manila, Philippines.

Kanbur, Ravi. 2009. "Intergenerationalities: Some Educational Questions on Quality, Quantity and Opportunity." Working Paper No. 48922, Department of Applied Economics and Management, Cornell University, NY.

Khera, Reetika. 2011. "Trends in Diversion of PDS Grain.” Working Paper No. 198, Centre for Development Economics, Delhi School of Economics, Delhi, India.

Lam, Wai Fung. 1998. Governing Irrigation Systems in Nepal: Institutions, Infrastructure, and Collective Action. Oakland, CA: ICS Press.

Lichbach, Mark Irving. 1989. “An Evaluation of 'Does Economic Inequality Breed Political Conflict?' Studies.” World Politics 41 (4): 431-70.

Long, Jason, and Joseph Ferrie. 2013. "Intergenerational Occupational Mobility in Great Britain and the United States since 1850." American Economic Review 103 (4): 1109-37.

Lopez-Acevedo, Gladys, and Raymond Robertson, eds. 2012. Sewing Success? Employment, Wages, and Poverty Following the End of the Multi-fibre Arrangement. Washington, DC: World Bank.

Malik, Sadia. 2009. "Horizontal Inequalities and Violent Conflict in Pakistan: Is There a Link?" Economic and Political Weekly.

_ 2011. "An Empirical Investigation of the Relationship between Food Insecurity, Landlessness, and Violent Conflict in Pakistan." PIDE Working Paper, Pakistan Institute of Development Economics, Islamabad.

Mansuri, Ghazala. 2013. "Inequality and Development." Background paper for this report, World Bank, Washington, DC.

Mazumdar, Indrani, N. Neetha, and Indu Agnihotri. 2011. "Gender and Migration in India." National Workshop on Internal Migration and Human Development in India: Workshop Compendium, Vol. II. New Delhi: UNESCO and UNICEF. 
Memon, Naseer. 2012. "Disasters in South Asia: A Regional Perspective." Karachi: Pakistan Institute of Labour Education and Research.

Milanovic, Branko. 2011. The Haves and the Have-Nots: A Brief Idiosyncratic History of Global Inequality. New York: Basic Books.

MoFP (Ministry of Finance and Planning, Sri Lanka). 2012. Annual Report 2011. Colombo: Treasury of Sri Lanka.

Murgai, Rinku, and Salman Zaidi. 2005. "Effectiveness of Food Assistance Programs in Bangladesh." Journal of Developing Societies 21 (1-2): 121-42.

Paes de Barros, Ricardo, Francisco H. G. Ferreira, Jose R. Molinas Vega, and Jaime Saavedra Chanduvi. 2009. Measuring Inequality of Opportunities in Latin America and the Caribbean. Washington, DC: World Bank; New York: Palgrave Macmillan.

Paz, Octavio. 1997. In Light of India. Harcourt Brace.

Redaelli, Silvia. 2013. "Sustainability, Efficiency and Equity of Electricity Subsidies in Maldives: Where Do We Stand and Options Moving Forward." Processed, World Bank, Washington, DC.

RGCC (Registrar General and Census Commissioner). 2012. Census of India, 2011. New Delhi: Registrar General and Census Commissioner, India, under Ministry of Home Affairs, Government of India.

Roemer, John E. 1998. Equality of Opportunity. Cambridge, MA: Harvard University Press.

Schumpeter, Joseph Alois. 1955. Imperialism [and] Social Classes: Two Essays. New York: Meridian.

Sen, Amartya. 1980. "Equality of What?" In The Tanner Lectures on Human Values, Vol. 1, edited by S. McMurrin, 353-69. Cambridge: Cambridge University Press.

- 1992. Inequality Reexamined. New York: Oxford University Press.

Singh, Ashish, and Sripad Motiram. 2012. "How Close Does the Apple Fall to the Tree?" Economic and Political Weekly 47 (40): 56-65.

Stiglitz, Joseph E. 2013. "Inequality Is Holding Back the Recovery." New York Times, January 19.
Trimble, Chris, Nobuo Yoshida, and Mohammad Saqib. 2011. "Rethinking Electricity Tariffs and Subsidies in Pakistan." Policy Note, World Bank Report 62971-PK, World Bank, Washington, DC.

UN (United Nations Department of Economic and Social Affairs/Population Division). 2012. World Urbanization Prospects: The 2011 Revision. New York: United Nations.

World Bank. 2003. Bangladesh: Public Expenditure Review. Report No. 24370-BD. Washington, DC: World Bank. - 2005a. Bihar: Towards a Development Strategy. Washington, DC: World Bank.

. 2005b. World Development Report 2006: Equity and Development. Washington, DC: World Bank; New York: Oxford University Press.

-2009. South Asia: Shared Views on Development and Climate Change. Washington, DC: World Bank.

- 2010. Bangladesh: Public Expenditure and Institutional Review: Towards a Better Quality of Public Expenditure. Report No. 47767-BD. Dhaka and Washington, DC: World Bank. 2011. More and Better Jobs in South Asia. Washington, DC: World Bank.

2012a. Creating Fiscal Space through Revenue Mobilization. South Asia Economic Focus. Washington, DC: World Bank.

. 2012b. World Development Report 2013: Jobs. Washington, DC: World Bank.

- 2013a. Bangladesh Education Sector Review: Seeding Fertile Ground-Education That Works for Bangladesh. Washington, DC: World Bank Group.

- 2013b. Pakistan-Towards an Integrated National Safety Net System: Assisting Poor and Vulnerable Households, an Analysis of Pakistan's Main Cash Transfer Program. Washington, DC: World Bank.

Zhang, Xiaobo, Shahidur Rashid, Kaikaus Ahmad, Valerie Mueller, Hak Lim Lee, Solomon Lemma, Saika Belal, and Akhter Ahmed. 2013. "Rising Wages in Bangladesh.” IFPRI Discussion Paper 1249, International Food Policy Research Institute, Washington, DC. 


\section{Why Inequality Matters}

E quality carries an intrinsic value for most of the world's great religions, including Buddhism, Christianity, Hinduism, Islam, and Judaism, as it does for most other faith traditions and ideologiesreligious or secular. Every normative theory of social arrangements that has stood the test of time also seems to demand equality of something.

What is meant by equality, however, varies from one faith to another and from one theory to another (Sen 1992). Reviewing what inequality means to different people and summarizing the long-standing intellectual pursuits around the concept would be an exceedingly ambitious undertaking. Instead, this report makes the deliberate choice of focusing on inequality of well-being among households. But justifying this choice requires revisiting a major debate in modern development economics, namely inequality of opportunities versus inequality of outcomes.

In A Theory of Justice, Rawls (1971) argued for both equality of opportunities and equality of outcomes. Roemer (1998a, 1998 b), in contrast, made a case for compensating people for disadvantages related to circumstances but tolerating the remaining inequality of outcomes. Roemer's conceptualization shifted the attention of development economics toward equality of opportunitiesoften defined in terms of access to basic services.

In South Asia, in particular, many children suffer from discrimination in access to basic services because of their socioeconomic circumstances, such as their caste or their gender. But between these circumstances and their actual well-being as adults lies a range of additional factors affecting how individuals function. The extent of mobility determines how opportunity is converted into well-being at later stages in life. A range of shocks can pull individuals who had similar opportunities as children in completely different directions over time. Measures of inequality in outcomes can capture the impact of these other factors, apart from opportunity, thus allowing a better understanding of the distribution of well-being across the population.

A focus on the inequality of outcomes requires a clear metric to assess well-being. Traditionally, that metric has involved a single monetary dimension represented by income or consumption per person, both in cash and in kind. However, the accuracy of this traditional metric is limited by data quality. In particular, concerns exist about how well surveys measure household income or consumption, especially among the better-off. Data 
constraints are even stronger when wealth, rather than income or consumption, is used as the monetary indicator to assess inequality.

Over the past decade, the interest in inequality analysis based on multidimensional indicators has been growing. Nonmonetary indicators shed light on aspects of well-being for which markets do not exist or are underdeveloped. That is the case with access to some basic services, such as health and education, on which data are often available. It is also the case with exposure to pollution, voice on public matters, or quality of social life, although these other aspects are harder to measure.

Using both monetary and nonmonetary indicators of well-being is particularly informative when the conclusions vary depending on the indicator used. Different conclusions can indeed shed additional light on what lies behind inequality.

Another metric that has spurred growing interest is subjective well-being. There is a long tradition reckoning that happiness is the ultimate goal of existence and claiming that people are to be trusted as the best judges of the overall quality of their lives. Subjective well-being matters also because many human thoughts and actions are based on perceptions and judgments, rather than data and reasoning. Understanding the subjective assessments of well-being by different population groups can complement inequality analyses based on objective measures.

In addition to the intrinsic value every great faith attaches to some form of equality, this report is concerned with the ways in which inequality affects social organization and economic performance. In other words, it takes a positive and not just a normative perspective. Seen this way, inequality is neither good nor bad. Some forms of inequality generate costs to society, whereas others entail benefits.

Inequality in outcomes has profound effects on how individuals and households behave. Some income inequality is necessary to encourage people to study, work, save, and invest. Returns to education are a clear example of a differentiation in labor earnings that spurs the accumulation of human capital and economic growth but at the same time results in inequality of outcomes. However, entrenched inequality of outcomes can undermine individuals' aspirations in youth and their subsequent educational and occupational choices. Incentives may also fail to change behavior when economic mobility is lacking. For example, entrenched poverty may lead to depression and behavior akin to "learned helplessness." Inequality of outcomes may affect the capacity of households to borrow to accumulate human and physical capital. If accumulation needs to build on individual or household savings, those at the bottom of the distribution may be unable to increase their capital significantly, and that in turn may perpetuate inequality.

Inequality also affects the ability of people to act collectively, the institutions that they set up, and the ways in which resources are allocated for the benefit of the group. A salient case is the provision of public goods. On the one hand, in a very unequal society, the betteroff typically have more power and are more effective at pulling in resources for the public goods they value. On the other hand, a high degree of inequality makes it more tempting for the better-off to opt out of public services altogether. In the end, which of the two effects prevails is likely to depend on whether opting out is an option.

Moreover, inequality of outcomes does not generate the right incentives when it rests on rents. In that case, individuals and households divert their efforts toward securing favoritism and protection instead of creating new wealth or innovating. Inequality based on rents leads to a suboptimal allocation of resources and consolidates institutional arrangements with negative long-term impacts on growth.

Last but not least, the existence of extreme inequality exacerbates social fragmentations and undermines social cohesion-the capacity of a society to manage collective decision making peacefully. Those suffering from extreme deprivation may turn to violence and conflicts as the last resort to address their concerns. This concern is not hypothetical in South Asia's often volatile societies. 
This positive perspective is necessary to understand why inequality should matter even to those who do not attach intrinsic value to equality. The positive perspective also provides a framework to focus the attention of policy makers on the truly bad forms of inequality and to pay attention to the costs and benefits of measures aimed at reducing inequality in outcomes.

\section{Inequality of what?}

Any defense or criticism of equality on normative grounds needs to begin by defining equality of what feature or equality in what space-for instance, income, wealth, opportunity, rights, or well-being. Among those thinkers perceived as favoring equality, John Rawls (1971) focused on primary goods, Ronald Dworkin (1981a, 1981b) on resources, Thomas Nagel (1986) on economic equality, and so on. The same is true of those perceived as being against equality. Robert Nozick (1974), for example, did not demand equality of well-being but rather equality of libertarian rights. Because the differences are substantive, demands by one theory for equality along a particular dimension amount to a justification of inequality along some other dimension (Sen 1992).

\section{Opportunities versus outcomes}

In modern economics, the thinking on social arrangements was initially shaped by welfarism, with utilitarianism being its most influential school of thought. According to utilitarianism, the social goal is to achieve "the greatest happiness for the greatest numbers" (Bentham [1781] 2000). In practice, utilitarianism amounts to taking the sum of the individual utilities as the metric of social welfare and assessing alternative social arrangements based on it. The lack of concern for the distribution of this sum among individuals or households makes the approach unsuitable for judging equality, despite its reputation as an egalitarian criterion. Similarly, the concept of Pareto optimality-whereby nobody should be made worse off-avoids distributional judgments altogether. In sum, the "social welfare function" does not involve interpersonal comparisons of well-being and, as such, does not provide a useful framework for distributional discussions (Milanovic 2009, 2011a, 2011b; Sen 1973, 1980).

Moving beyond the social welfare function, a number of scholars uphold the intrinsic value of economic justice and provide different conceptual frameworks for thinking about social arrangements. Most notable among them are John Rawls, Amartya Sen, Ronald Dworkin, and John Roemer. Their separate and important contributions offer some guidance on how to reconcile inequality and justice. Their differences also set the foundation of the debate on inequality of outcomes versus inequality of opportunities.

Rawls (1971) argues that distributional justice requires two principles to be met. The first is "an equal right to the most extensive basic liberty." The second is social arrangements "to everyone's advantage" and "attached to positions and offices open to all." "Open to all" can be interpreted as relating to opportunities, whereas “everyone's advantage" refers to outcomes. Clearly, in Rawls's eyes, both are important, and equality of opportunities alone is not sufficient.

These two principles are established under an important premise, "the veil of ignorance." Rawls assumes that individuals do not know their position in the overall distribution of assets, abilities, and preferences and therefore ignore how alternative social arrangements will affect them. As a result, individuals can assess principles of distributional justice only on the basis of general considerations, without reference to the implication these principles would have for them.

"Open to all" could be either a formal or a substantive equality of opportunity. A formal equality of opportunity, such as careers open to all, means that all people have the same legal right to access. A substantive equality of opportunity, in contrast, recognizes that given the distribution of natural endowments and social circumstances, not everybody has 
a fair chance in reality. Thus, a substantive equality of opportunity demands offsetting adverse circumstances over which individuals have no control or for which they cannot be held responsible. Rawls states that those who are at the same level of talent and ability and have the same willingness to use them should have the same prospects of success regardless of their initial circumstances.

Similarly, "everyone's advantage" can be assessed based on the principle of efficiency or on the difference principle. The principle of efficiency relates to Pareto optimality: an arrangement is said to be efficient if no rearrangement can make someone better off without at the same time making anyone else worse off. From this point of view, inequality of outcomes is justifiable as long as the arrangement is efficient. The difference principle is also called the maximin principle. It states that inequality is justifiable only if it is needed to raise the outcomes of the least advantaged in society.

Many of the thinkers who uphold the principle of justice have been greatly influenced by Rawls. Sen $(1973,1980,1992)$ argues for focusing on the differences in external factors and internal characteristics of human beings and for aiming for the equality of functioning across all. Dworkin (1981a, 1981b) demands a distribution of resources that compensate people for innate differences that they could not have controlled, including differences in talent. Roemer (1998a, 1998b) further develops this idea and suggests dividing factors that contribute to outcomes as either circumstances or efforts, with the former mainly linked to the socioeconomic status of parents. His idea of equal opportunity involves compensating people for disadvantages related to circumstances so that the distribution of outcomes can be entirely attributed to the distribution of efforts.

Views on the equality of outcomes differ. For Rawls, a substantive equality of opportunity, together with an equal liberty, is insufficient to ensure justice in a social arrangement. Judgment of the outcomes cannot be left to the principle of efficiency. The difference principle is required to protect the least advantaged.
Although not relying on exactly the same difference principle, Sen $(1973,1980)$ argues against the use of the principle of efficiency to assess the distribution of outcomes. He asks for the compensation of those who have less ability to convert income into welfare. He also demands that income distribution be assessed based on need rather than talent or effort.

Dworkin (1981a, 1981b) and Roemer (1998a, 1998b), in contrast, emphasize the sufficiency of equality of opportunity, arguing that individuals should take responsibility for their well-being once differences of circumstances are eliminated. They believe this approach can better answer conservative critics of egalitarianism, which they say fails to hold individuals responsible for their fate. Roemer's conceptualization, in particular, shifts the attention of many students of social arrangement and economic justice to the equality of opportunity.

Rawls's case for social arrangements that are both "open to all" and "to everyone's advantage" speaks to the importance of equality of outcomes. The difference between equality of opportunity and equality of outcomes may seem subtle, but it is nonetheless very important. Assessing inequality of opportunities is necessary but not sufficient. Both measures are informative on their own to understand the nature and extent of inequality in the South Asia region.

A substantive equality of opportunity remains an elusive goal in South Asia. In terms of access to basic services, many children are still suffering from discrimination because of their socioeconomic background. For example, in Afghanistan, Bhutan, India, Nepal, and Pakistan, girls have fewer chances than boys to study because of cultural and social reasons. Girls 12 to 18 years of age have both lower secondary school attendance rates and lower completion rates than boys of the same age group. In Afghanistan and Pakistan, the difference in attendance rates between boys and girls is as high as 25 percentage points and 14 percentage points, respectively. In India, the difference between girls' and boys' completion rates reaches 11 percentage points. Similarly, in parts of South Asia, some children receive 
services of poorer quality because of their caste, ethnicity, tribe, religion, or community. Although children who belong to certain groups are no longer systematically denied schooling today, they remain vulnerable to bias and prejudice by teachers (box 1.1).

Measuring and analyzing inequality of opportunities can shed light on the extent of discrimination in access to services. Various methods have been proposed for doing so (Roemer and Trannoy 2013). Among them is the Human Opportunity Index developed by Paes de Barros and others (2009), which is used extensively in this report. Assessing inequality of opportunities in the space of access to basic services is not sufficient, however. Social circumstances and initial endowments matter, of course. But between them and actual well-being lies a range of internal and external factors affecting how individuals function. Even children having the same access to basic services, building the same skills, and sharing the same aspirations may not be able to attain the same level of well-being.

The extent of economic mobility is one of the factors determining how opportunity is converted into well-being in adult life. Work opportunities, job transitions, and migration are among the mechanisms through which economic mobility materializes. Similarly, actual well-being may be affected by shocks. From severe health conditions to natural disasters to economic crises, a range

\section{BOX 1.1 Discrimination by teachers pushes children out of school}

Discriminatory treatment of lower-caste children in schools has persisted over decades, although in milder forms in recent years. Many children from lower castes remain scared to talk about the unequal treatment against them, including verbal abuse, physical punishment, or avoiding touching them, by some of the upper-caste teachers. Lower-caste children can be made to feel inferior in some schools. For example, they can be asked to sit separately and to perform unpleasant jobs such as cleaning toilets. They are seldom considered for leadership roles such as class monitor. These discriminatory practices and the entrenched social beliefs associated with them can change the attitude of many lowercaste children toward education and eventually push them out of schools.

The following story is a case in point (Thekaekara 2004). "Near Lucknow I met another group of bright, laughing kids. They'd all been admitted to school by a well-meaning social worker who had used a blend of threats and cajoling to convince the headmaster that the kids had to be admitted. He reminded the principal about the existence of the Prevention of
Atrocities Act by which practicing untouchability is punishable by law. The kids were excited, delighted as any kid would be, at the prospect of not cleaning latrines.

"A few months later, all of them had dropped out. The teacher beat them. Called them stupid. And rarely taught them anything. None of them could read or write after six months in school. They were now out every morning collecting plastic from garbage dumps. Earning Rs 20-30 a day, they went to movies sometimes. School was a distant dream, with not very pleasant memories."

Children can also be discriminated against or neglected in schools for their tribe or religion. In Uttar Pradesh state's Sonbhadra district, for example, students belonging to the Ghasiya tribal community reported that teachers often pay them little attention, and the children suffer from discrimination, such as being called as "dirty." Many of these children, facing such obstacles, attend school only sporadically. Some stop going to school altogether.

Sources: Adapted from Sedwal and Kamat 2011 and Human Rights Watch 2014. 
of unanticipated events can take two children with similar opportunities in different directions. Measures of inequality in outcomes can capture the impact of these internal and external factors and support a better understanding of the distribution of well-being across the population. Motivated by these observations, this report focuses on inequality of outcomes using a life cycle perspective.

\section{Monetary measures of inequality}

A focus on the inequality of outcomes requires a clear metric to assess well-being. Traditionally, that metric has involved a single dimension, represented by either individual income or individual consumption, both in cash and in kind. Analyses have thus relied on indicators of income inequality and poverty rates. Within this class of indicators, critical and sometimes difficult technical choices must be made, such as whether to use income or expenditure data and whether to use adult equivalent scales-taking into account that the needs of a child are less than those of an adult. Overall, the methodology has been refined with respect to various data and technical challenges and has stood the test of time. Most notably, monetary indicators have the attractive feature of using prices to aggregate the various components of consumption expenditure. Under relatively weak assumptions, relative prices are equal to the rate at which consumers themselves are willing to trade one such component for another. This regularity is not affected by the income levels or the potentially different utility functions of consumers (Atkinson and Bourguignon 2000).

In addition to income and consumption, wealth is an important but less frequently used monetary indicator. Wealth is generally measured as net worth, defined as total financial and nonfinancial assets net of total liabilities (OECD 2013). Whereas income and consumption capture a flow of resources over a period of time, wealth refers to a stock of resources at a point in time. Income can be saved to create wealth, and wealth can be converted into income and used to satisfy consumption needs. Wealth provides the means to smooth consumption in the short run and to raise it in the long run. Wealth gives a sense of security. It can also be used to finance entrepreneurial activities, either directly or as collateral (Davies and Shorrocks 2000; Keister 2000).

However, flow and stock monetary indicators are not interchangeable. At the household level, the correlation between wealth and income is relatively low. Many households are "asset rich and income poor," meaning that they could be expected to have a higher standard of living than their income suggests. More generally, considerable dispersion of wealth exists within income categories, with gaps in wealth being much larger than gaps in income.

Data availability has been the main hindrance to the analysis of wealth inequality, but the situation has rapidly improved for more advanced economies. For these countries, wealth indicators are estimated based on household surveys, surveys of financial institutions, specialized private databases covering certain assets, and national balance sheets (Cagetti and De Nardi 2008; Davies and others 2008; OECD 2013; Wolff 1996). Personal income tax filings have become an important source of information for this kind of analysis (Piketty 2011; Piketty, PostelVinay, and Rosenthal 2006). For developing countries, data remain a concern with some exceptions. Thus, China and India have conducted comprehensive household wealth surveys, whereas Indonesia has household surveys with a detailed wealth component ( $\mathrm{Li}$ and Zhao 2008; Subramanian and Jayaraj 2008). More and more household surveys also cover information on landholding and livestock. Personal tax income filings have also been used in India's case.

Once the monetary indicator is chosen, inequality is analyzed by using some summary measure of the dispersion in the chosen indicator within a population. Given the proliferation of such measures, some desirable properties may be spelled out to guide the choice between them (Atkinson and Bourguignon 2000). An example is the PigouDalton (or transfer) principle: for the chosen measure to be meaningful, a transfer from a 
poorer person to a richer person, all things equal, must result in an increase of inequality. Another example is the anonymity principle: if two people switch positions in the overall distribution, the measure of inequality should not change. Scale neutrality is yet another example: if all incomes are multiplied by a constant, the measure should not change.

These principles are selected based on value judgments, however. Most notably, the principle of scale neutrality reflects researchers' preference for "relative inequality" over "absolute inequality." Yet laboratory experiments suggest that the general public is more ambivalent between these two concepts (Amiel and Cowell 1999; Ravallion 2014).

The most frequently used measures of monetary inequality-including the Gini coefficient, the mean log deviation, and the Theil entropy index-all satisfy these axioms (box 1.2). However, these summary measures may not necessarily generate the same ranking in levels of income inequality across population groups or between two points in time for the same population group. The main reason for these potential discrepancies in ranking is that each of the measures embodies some assumption about the relative importance of inequality at different points in the income scale. Therefore, to reach robust conclusions, it is often necessary to rely on multiple measures.

Data availability and quality call for caution when one draws conclusions from monetary inequality. The representativeness of household surveys illustrates this point. In South Asia, as in other regions, consumption expenditures by different households are estimated based on household-level surveys. Concerns exist about how well surveys measure income or consumption (Datt and Ravallion 2009; Ravallion 2003). Survey-based consumption and income aggregates for nationally representative samples typically do not match the aggregates on private consumption obtained from national accounts (figure 1.1, panel a). The discrepancies between levels and growth rates of consumption as measured by India's National Sample Surveys (NSS) and national accounts have been of particular concern (figure 1.1, panel b). Since the 1970s, a growing disconnect exists between the measures. The consumption aggregate from the NSS was about half the household consumption component of the national account in 2004-05. The gap rose further in the late 2000s and stabilized subsequently.

National accounts, which estimate private consumption as a residual, do not necessarily provide a benchmark to which household expenditure surveys should aspire. Differences exist between what is being measured by the two data sources. Private consumption data from national accounts include sizable and rapidly growing components of household expenditures that are typically missing from surveys (Deaton 2005; Deaton and Kozel 2005). Aside from these differences, household surveys are vulnerable to low response rates among the rich and underreporting of expenditures among those who respond. A large and growing disconnect between two major data sources is cause for concern of underestimation of expenditures of the better-off. Such underestimation may lead to biased indicators of inequality (box 1.3), although it is not a major concern when the focus is on poverty.

Undersampling of the rich, low response rates, and underreporting are even more pronounced for wealth indicators. A practical approach is to compare survey-based estimates with the balance sheet total for the household sector and make adjustments. It is also informative to complement survey-based estimates with information from administrative records and personal income tax filings (Atkinson and Piketty 2010; Atkinson, Piketty, and Saez 2011; Banerjee and Piketty 2005; Piketty and Saez 2003). For the ultrarich, a useful check is the lists compiled by Fortune and Forbes magazines (Davies and Shorrocks 2000; Juster and Kuester 1991; OECD 2013; Wolff 1987).

\section{Multidimensional indicators of inequality}

Over the past decade there has been a growing interest in multidimensional indicators of well-being. In celebrating its 20th anniversary, 


\section{BOX 1.2 Standard statistical measures of monetary inequality}

The Gini coefficient is the most widely used measure of inequality. In the figure, the horizontal axis stands for the poorest $\mathrm{x}$ percent of households. For that reason, the axis is labeled "cumulative share of households from lowest to highest incomes." The vertical axis measures the income share of the poorest $\mathrm{x}$ percent of households. Because shares are added while moving up the ladder from the poorest 1 percent to the poorest 2 percent to the poorest $x$ percent, the vertical axis is labeled "cumulative share of income earned."

If the bottom $\mathrm{x}$ percent of households earned $\mathrm{x}$ percent of income and so on all the way to

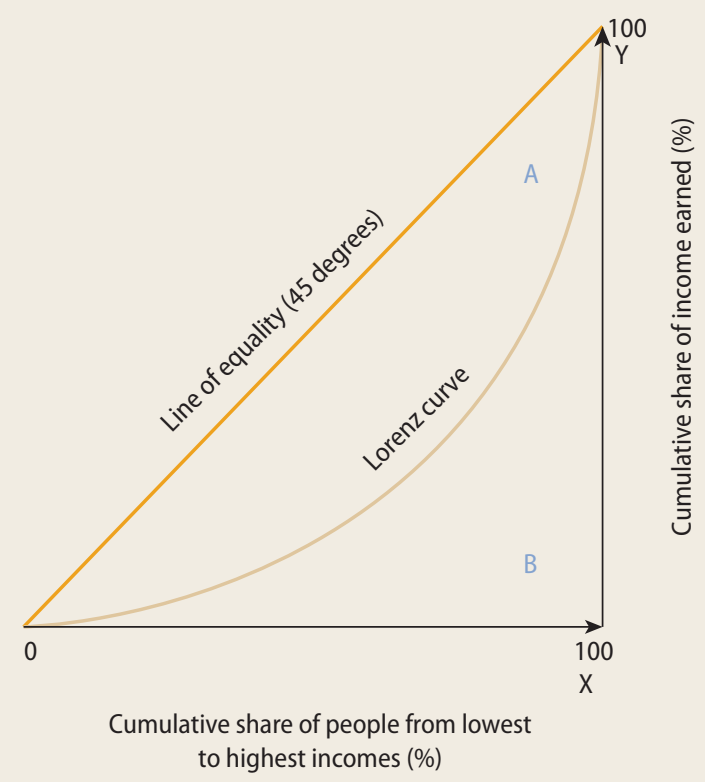

the top, the cumulative share would be the one marked "line of equality," signifying that income is equally distributed. If, going to the other extreme, all income were concentrated in the richest household, the graph of the distribution would be the line from $\mathrm{O}$ to $\mathrm{X}$ to $\mathrm{Y}$. The curve drawn in the figure, called the Lorenz curve, shows the actual income distribution and lies between the lines of complete equality and complete inequality. Thus, the more the Lorenz curve is bowed outward, the higher the inequality in the distribution of income. What the Gini coefficient measures is the area between the line of complete equality and the Lorenz curve (A), relative to the maximum such area could attain $(\mathrm{A}+\mathrm{B})$.

Another class of indicators widely used by economists is the Generalized Entropy (GE) Index. These indicators are derived from the notion of entropy in information theory. Entropy is an expected information content calculated as a weighted average of the information content of each observation. What varies across this class of indicators is the weight attached to each observation. For instance, the $\mathrm{GE}(0)$, or mean log deviation, attaches the same weight to all observations. The GE(1), or Theil index, attaches greater weight to observations that are further from the mean. One appealing feature of the GE Index is that changes in inequality can be broken down into changes in inequality between subgroups-say, between rural and urban areas—and within subgroups.

Source: Based on Atkinson and Bourguignon 2000. the authors of the Human Development Report of the United Nations state that "an individual's well-being cannot be evaluated by money alone. Income is of course crucial: without resources, any progress is difficult. Yet we must also gauge whether people can lead long and healthy lives, whether they have the opportunity to be educated and whether they are free to use their knowledge and talents to shape their own destinies" (UNDP 2010). The growing agreement on the multidimensional nature of well-being, however, is confronted by the ongoing disagreement about how best to measure it. 


\section{FIGURE 1.1 Estimates of expenditures differ between household surveys and national accounts}

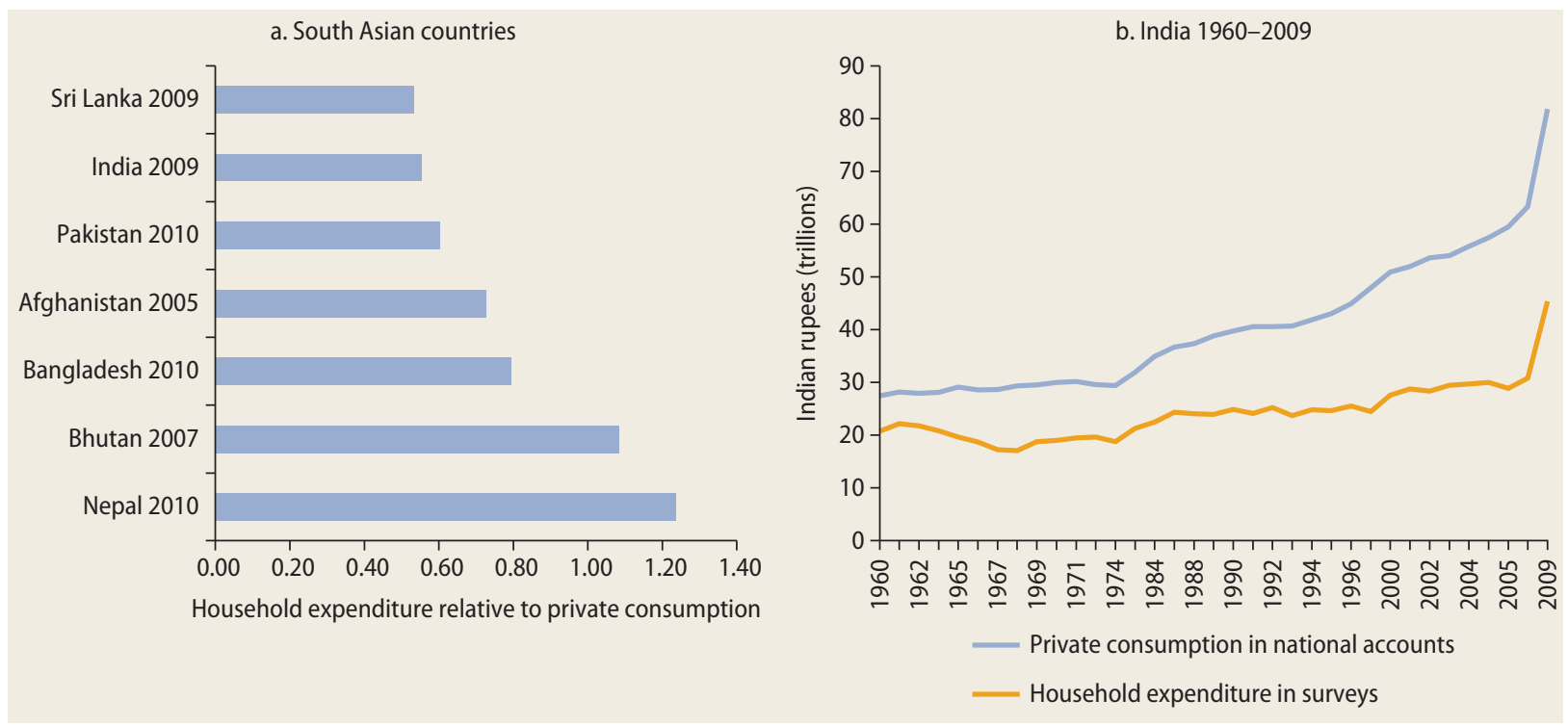

Sources: Based on data from the World Bank's World Development Indicators database, http://data.worldbank.org/data-catalog/world-development-indicators, and PovcalNet tool, http://iresearch.worldbank.org/PovcalNet/index.htm; Datt and Ravallion 2009; India's National Sample Surveys (NSS).

Choosing a monetary indicator as the measure of well-being implicitly assumes that individuals or households can freely reallocate their resources among, say, consumption, health, and education. If so, measuring the amount of resources available to individuals or households is enough to assess the maximum well-being they can attain. But in many cases a market for basic services and amenities may not exist or may be heavily distorted. For instance, individuals or households may want to get more health services, but that simply may not be an option if no health care facility is within a reasonable distance from where they live. This issue has been extensively discussed in the economic literature (Arrow 1971; Atkinson and Bourguignon 1982; Kolm 1977; Maasoumi 1986; Sen 1973, 1992). It calls for extending the analysis beyond income or consumption and for considering a broader array of determinants of well-being.

Nonmonetary indicators of different aspects of well-being are the starting point for a multidimensional analysis of inequality or poverty. The focus is on attributes that are meaningful not only because of their direct contribution to well-being but also because they help capture the heterogeneity of individuals, households, and countries. Access to some basic services such as health and education are obvious examples, and measures are often available for these aspects of well-being. For example, literacy and years of schooling are often used as proxies for the levels of knowledge and skills. The life expectancy rate at birth, child mortality rate, and nutritional status are often used as proxies for the quality of health. Other potentially relevant attributes are exposure to pollution, voice on public matters, and quality of social life, although these other aspects are harder to measure.

The main challenge is to move from indicators for individual dimensions of well-being to indicators of overall well-being. In the case of consumption bundles, information on prices can be used to tell how individuals or households see the trade-offs between different consumption bundles. But no similar, readily available weights are available to value nonmonetary dimensions of well-being. Thus, consensus remains elusive regarding the functional forms and criteria to evaluate well-being (Bourguignon 1999; Decancq 


\section{BOX 1.3 Some monetary indicators may underestimate the true extent of inequality}

The monetary indicators of inequality in this report are based on household survey data. Deriving the extent to which they are biased would require information on nonresponse rates and the underestimation of expenditures for those who respond. In the absence of such information, some assumptions must be made. A good place to start is to assume that the gap between measured expenditures and actual expenditures is greater for richer households. With this assumption, it is intuitive that average consumption is underestimated, and the poverty rate overestimated. Assessing the implications of this assumption for the measurement of inequality is less straightforward. One way to do so is to focus on the Lorenz curve, as in the figure.

If the gap between measured and actual expenditures increases with X, the true Lorenz curve is higher than the observed Lorenz curve for richer households and lower for poorer households. Given that both curves vary between zero and 100 , it follows that they must intersect each other for some value of X. With neither Lorenz curve lying completely above or below the other, no general statement about the Gini index can be made in the general case.

The bias from the underestimation of expenditures is clearer in the case of indicators of inequality that are more sensitive to the extremes of the distribution. For instance, the Theil index gives more weight to larger gaps between actual expenditure per capita and the level that would prevail if there were no inequality. The assumption that the underestimation of expenditures increases with $\mathrm{X}$ implies that the true gaps are somewhat larger than the observed ones for the

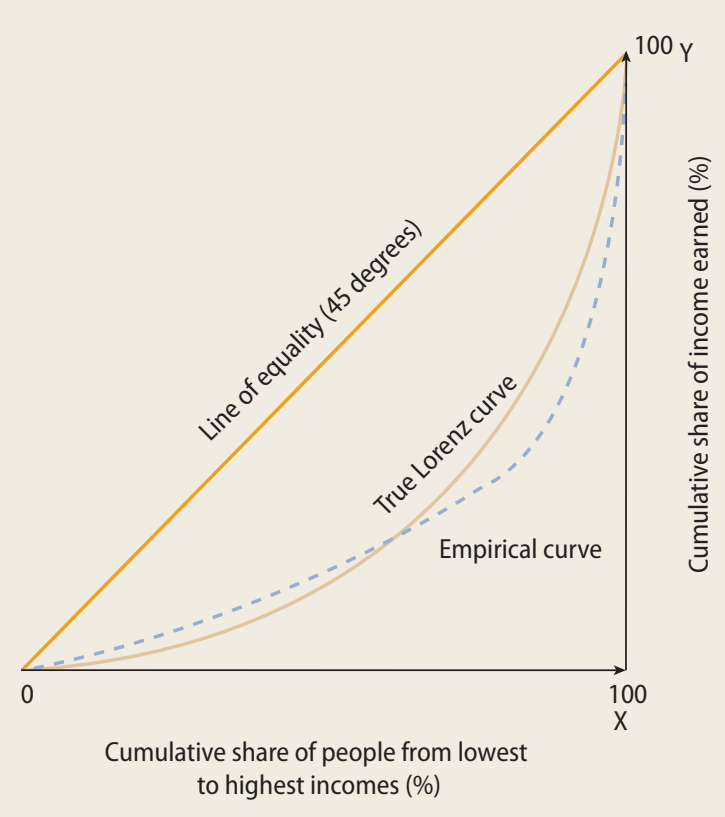

poor but much larger for the rich. Consequently, the Theil index is underestimated. Similarly, as long as the value of $\mathrm{X}$ for which the two curves intersect is between 10 percent and 90 percent, the ratio between the consumption of the top and the bottom deciles is underestimated.

An assessment of the biases in measurement is no substitute for better data, however. Information on the nonresponse rates among different types of households and on the underestimation of expenditures among those who do respond would allow researchers to construct more precise indicators of monetary inequality.

Source: Based on Korinek, Mistiaen, and Ravallion 2006. and Lugo 2013; Ferreira and Lugo 2013; Maasoumi 1999).

Since the pioneering work of Kolm (1977) and Atkinson and Bourguignon (1982), a number of approaches have been proposed to measure or analyze inequality in multiple dimensions. At the risk of oversimplification, these approaches can be classified into two groups (Lugo 2007; Maasoumi 1999; Tsui 1999). The most common one involves the use of two-step indexes. The first step is to aggregate attributes for each individual or household, and the second step is to apply a standard measure of inequality to 
the aggregate index. The second group of approaches seeks to identify a set of appropriate properties when multiple attributes exist and then looks for indexes that may satisfy these axioms.

Regardless of the approach chosen, the marginal contribution of each dimension of well-being to overall inequality needs to be identified. And handling the effects of correlations between attributes remains a challenge. Intuitively, the various components of human development are synergistically related to one another. When all dimensions are strongly correlated, then higher achievement along one dimension strongly reinforces higher achievement along other dimensions. In this case, focusing on just one dimension may be sufficient for measuring well-being. Conversely, when the correlation among dimensions is lower, multidimensional analyses become more informative (Seth 2010).

Using both monetary and nonmonetary indicators of well-being often leads to different conclusions regarding the extent of inequality or its trend over time. These different conclusions, in turn, may shed additional light on what lies behind inequality. For instance, a recent study compared consumption-based poverty estimates with a multidimensional poverty index across 25 Indian states and over time (Alkire and Seth 2013). The multidimensional poverty index included education, health, and access to basic services as the key nonmonetary dimensions of well-being (Alkire and Foster 2011). For each of these dimensions, a threshold level of achievement (or access) was set, thus allowing a determination of whether the person was deprived or not. An aggregate deprivation score was then computed for each person as the weighted sum of the deprivation scores along individual dimensions, and a threshold level for the aggregated score was defined to decide whether the person was poor or not.

A comparison of the poverty rate estimated this way and the standard estimates of the poverty rate is striking (figure 1.2). States that had a high multidimensional poverty index in 1999 saw slower progress by 2006 than those with an initial low level. But the conclusion was the opposite when considering standard poverty estimates. States that had higher standard poverty rates in 1993-94 showed a faster reduction in poverty by 2004-05 than those with low initial poverty rates. In other words, poverty rate declined faster in states where poverty rates were lower to start with when using a multidimensional poverty index. But poverty rate declined slower in states where poverty rates were lower when using consumption-based poverty estimates. Presumably, a similar contrast in conclusions could arise if the focus had been on inequality rather than poverty.

Given that each perspective is informative on its own, this report complements analyses of inequality based on monetary consumption with analyses based on nonmonetary indicators of well-being, including education and health. In the absence of a consensus on the functional form and criteria to construct multidimensional inequality indexes, the report simply explores the level of inequality along each dimension as well as the correlation between monetary and nonmonetary indicators. This combination provides the evidence needed for readers to make their own judgment about the "true" extent of inequality of well-being within countries in South Asia without imposing too much of the authors' own judgments on the relationship between these different dimensions.

\section{Subjective well-being}

Subjective well-being is another area in which interest has been growing rapidly. While pushing the boundaries of traditional approaches, multidimensional inequality analyses remain anchored in objective measures of well-being. The objective nature of these measures is reflected in the substance matter considered (for example, years of education) and in the assessment process (for instance, explicit criteria evaluated by external observers). Instead, subjective measures of well-being seek to directly capture cognitive life evaluation and mainly rely on selfreporting by individuals. 
A subjective approach to well-being reckons that happiness is the ultimate goal of existence while admitting that everybody has his or her own views on what a good life looks like. For this approach, observable indicators provide an incomplete measure of individual well-being. People are trusted to be the best judge of the overall quality of their lives. Individual scores of happiness or life satisfaction are evaluated based on self-reported assessments of short-term experiences and longer-term fulfillment (Frey and Stutzer 2002). In comparison with multidimensional indicators of well-being, subjective measures are more inclusive-not limited to the dimensions with available data. They also avoid the issue of developing a joint distribution of different aspects of well-being (Veenhoven 2004).

An example of subjective evaluation of well-being is the World Values Survey, which asks, "All things considered, how satisfied are you with your life as a whole these days?" Subjective well-being is assessed on a scale from 1 (dissatisfied) to 10 (satisfied) (Inglehart 2000). The Eurobarometer surveys, covering

\section{FIGURE 1.2 Monetary and nonmonetary indicators can lead to opposite conclusions}

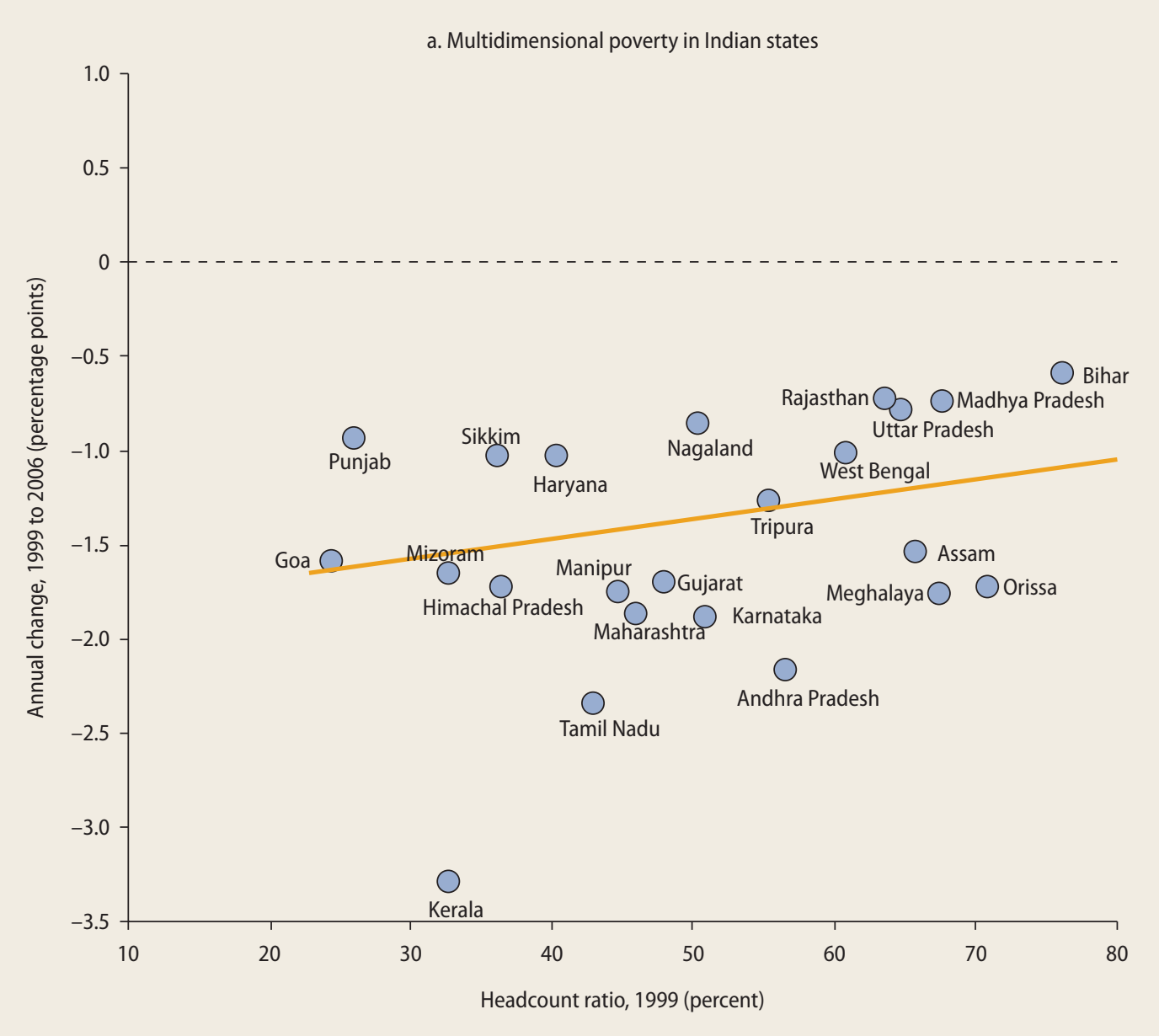


FIGURE 1.2 Monetary and nonmonetary indicators can lead to opposite conclusions (continued)

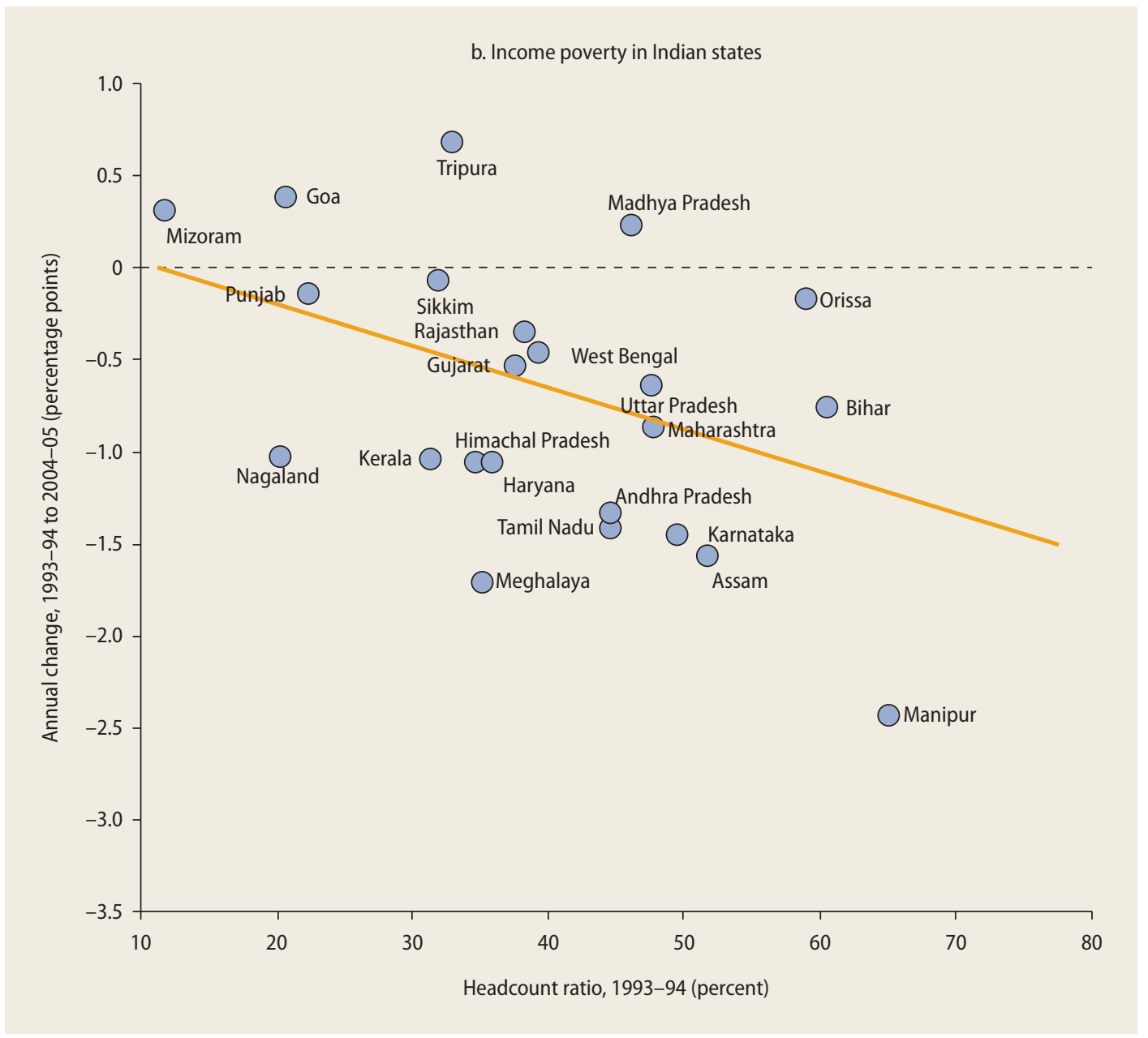

Source: Alkire and Seth 2013.

all members of the European Union, and the Gallup World Poll, surveying more than 160 countries, ask respondents a similar question.

The emotional aspects of individuals' well-being can be captured by questions on moment-to-moment affect (Kahneman and Krueger 2006; Stutzer and Frey 2012). Psychologists have been applying the experience sampling method for years. It collects information on individuals' actual experiences in real time in their natural environments (Stone and Shiffman 1994). A related new approach called the day reconstruction method (DRM) has been developed more recently (Kahneman and others 2004). In this approach, people are asked to reflect on how they felt during all the life episodes they went through the previous day. Compared to the life satisfaction evaluation, the DRM relies less on processes of retrospection. In combination with the time use information, the DRM aims to establish a cardinal indicator of well-being by considering the time spent in a predominantly negative affective state.

Because subjective survey data are based on individual's judgments, they are subject 
to both systematic and nonsystematic biases. The reported life satisfaction may depend in part on the order of questions, the wording of questions, the scales applied, the actual mood and memory of the respondent, and the immediate context. Not surprisingly, reported life satisfaction is found to fluctuate in natural settings over short time periods (Lucas, Diener, and Suh 1996).

However, the validity of data on reported life satisfaction has been supported by empirical evidence. Correlations have been documented between measures of life satisfaction and various objective physiological and medical criteria (Cohen and others 2003; KiecoltGlaser and others 2002). Findings from neuroscience research also lend some support for the view that life satisfaction measures are related to individuals' emotional states (Urry and others 2004). Some visible signs of cheerfulness, such as smiling, are positively associated with self-reported happiness, while different measures of happiness correlate well with one another (Diener and Suh 1999; Frey and Stutzer 2002). New approaches such as DRM stand to reduce measurement error.

These measures have begun to inform official statistics and have started to be discussed in policy debates. In his remarks to the General Conference of International Association for Research in Income and Wealth, Federal Reserve chairman Ben S. Bernanke emphasized subjective measures of well-being as a new direction of economic measurement (Bernanke 2012). The Kingdom of Bhutan is another unique case in point. Bhutan adopted Gross National Happiness as the national indicator of well-being in 1972 (box 1.4). The index is multidimensional and aims to include objective dimensions of well-being as well as subjective elements such as psychological wellness, balance with the environment, community vitality, and strength of family and social ties.

In addition to people's intrinsic interest in happiness, subjective well-being matters

\section{BOX 1.4 Bhutan uses a happiness index to measure well-being}

The Gross National Happiness (GNH) concept was designed to measure the quality of life and assess social progress in more holistic terms than the gross domestic product (GDP) allows. The term gross national happiness was coined in 1972 by Bhutan's fourth Dragon King, Jigme Singye Wangchuck, who opened the country to the age of modernization. He declared GNH to be more important than GDP, and from that time onward the country has oriented its development plans and policy choices toward raising GNH. The concept was taken seriously, as the Centre for Bhutan Studies, under the leadership of Karma Ura, developed a survey instrument to measure the population's general level of well-being.

The current GNH Index is an aggregation of performance across nine domains: psychological well-being, time use, community vitality, cultural diversity, ecological resilience, living standards, health, education, and good governance. Each of the domains covers a range of specific indicators-33 in all. For instance, psychological well-being includes life satisfaction, emotional balance, and spirituality. All three indicators are assessed based on self-reported cognitive assessments. Community vitality covers social support, which depicts the civic contributions made; community relationship, which refers to social bonding and a sense of community; family relationships; and perceived safety. Cultural diversity is measured in areas of language, artisan skills, cultural participation, and the way of harmony. Both community vitality and cultural diversity are constructed as a mixture of self-reported cognitive assessments and quantitative measures.

Source: Based on Ura, Alkire, and Zangmo 2012. 
because perceptions and intuitions influence individual decision making. The work by Daniel Kahneman and coauthors has profoundly challenged the validity of the rational-agent model, the foundation of modern economics (e.g., Kahneman 2003a, 2003b; Kahneman and Tversky 1984; Tversky and Kahneman 1974). Most critically, most of the time people are found to make judgments and choices based on intuition rather than through rational reasoning, and the rules governing intuition are generally similar to the rules of perception (Kahneman 2003b, 2011). In other words, perception and intuition shape behaviors. Perceptions may or may not match reality, and intuitive judgments may or may not be accurate, but correcting them is not easy. Therefore, taking into account subjective assessments of well-being by different population groups is important when assessing inequality.

\section{The costs (and benefits) of inequality}

From a positive point of view, any assessment of the extent of inequality in a country requires some notion of optimality. Taking for granted that inequality is neither good nor bad, the issue is to determine the level that is preferable from a societal point of view. That level is the turning point for which the costs of inequality start exceeding its benefits. Determining such a turning point in a precise way is clearly out of reach. But economic analysis helps identify the main costs and benefits and aids in getting a sense of their order of magnitude.

\section{Intrinsic value}

The first and most straightforward reason why inequality can be costly is because people may not like it. Cultures and religions around the world may differ in important respects, but they all seem to share a concern with fairness. The preference for equality, in one form or another, may be attributed to entrenched social norms and cultural beliefs.
A more recent strand of literature, based on laboratory experiments, provides support to the idea of a shared human preference for equality and fairness (World Bank 2005). In these experiments, individuals interact through behavioral games and play with real money under tightly controlled conditions. Results reject the standard economic hypothesis that individuals are exclusively concerned with their own material gain. Instead, some people behave in ways clearly inconsistent with the rational self-interest hypothesis. Additionally, people are heterogeneous. A sizable fraction of people in most experiments engage in altruistic behavior while others behave selfishly. Interestingly, fair-minded people can behave selfishly, and self-interested people can behave altruistically. Taken together, these experimental results lend support to the notion that equality and fairness matter intrinsically to people.

The flip side is that people also value inequality. Endorsing equality along some particular feature easily leads to a theory justifying inequality along a different feature (Sen 1992). More generally, ethical theories of social arrangements typically take a stance on the acceptable levels of inequality. For instance, by demanding equality of libertarian rights, Nozick (1974) defends potentially large levels of inequality in well-being. At the other end of the spectrum, Roemer (1998a, 1998b) narrows down the acceptable level of inequality of outcomes by requiring equality of opportunities, especially for children. Even Rawls (1971) agrees that some level of inequality in outcomes is acceptable if it is in the interest of the most disadvantaged (that is, if the difference principle is satisfied). Inequality, it seems, also has some value for human beings.

\section{Incentives}

At the risk of oversimplifying, some degree of monetary inequality is needed to create incentives for people to study and accumulate human capital, to work instead of taking leisure, to save for the future, and to invest in risky businesses. Without a certain 
difference in returns, people may not be motivated to undertake these activities. Because of its implications, inequality was taken to be unambiguously good for growth by some economists and philosophers, such as Max Weber and John Maynard Keynes (Milanovic 2011a). Economic transition in formerly socialist countries was all about reintroducing incentives that had been undermined by excessive egalitarianism.

Returns to education are a clear example of a differentiation in labor earnings that creates incentives to study but at the same time results in inequality in outcomes. In South Asia, as in other regions of the world, returns are larger the higher the educational attainment of the person (figure 1.3). Schooling is of course not the only determinant of labor earnings, and it accounts for only a fraction of earnings variation across individuals. But the relationship is robust, and it holds in South Asia even though the quality of education is not always high. Positive returns to education are consistent with the view that differences in earnings serve as rewards to efforts by children and their parents.

\section{Aspirations}

Entrenched inequality can significantly undermine individuals' aspirations in youth, affecting their subsequent educational and occupational choices. A series of experiments suggests that inequality of outcomes can have "framing effects" (Hoff 2012). An example of a frame, or stereotype, is the idea that marginalized groups are intellectually inferior. Confirmatory bias leads people to conform to the stereotypefor example, by discounting the abilities of those who belong to a marginalized group. Framing effects of this sort have been found to be salient in two experiments conducted in India.

In a laboratory experiment with high- and low-caste boys, cues to one's place in the traditional caste order are found to influence the ability of the low-caste boys to learn and the willingness of the high-caste boys to expend effort (Hoff and Pandey 2006, 2012). Students were assigned to sessions of six boys, taught how to solve mazes, and then asked to do it under monetary incentives. When names and castes were not disclosed to others in the session, there were no differences in the ability of high-and low-caste boys to learn this skill. But the simple contrivance of calling out the name and caste of the boys at the beginning of a session produced a marked caste gap in the ability to learn how to solve a maze. Compared with the anonymous sessions, these sessions reduced the failure rate from

\section{FIGURE 1.3 Returns to education create incentives to study}

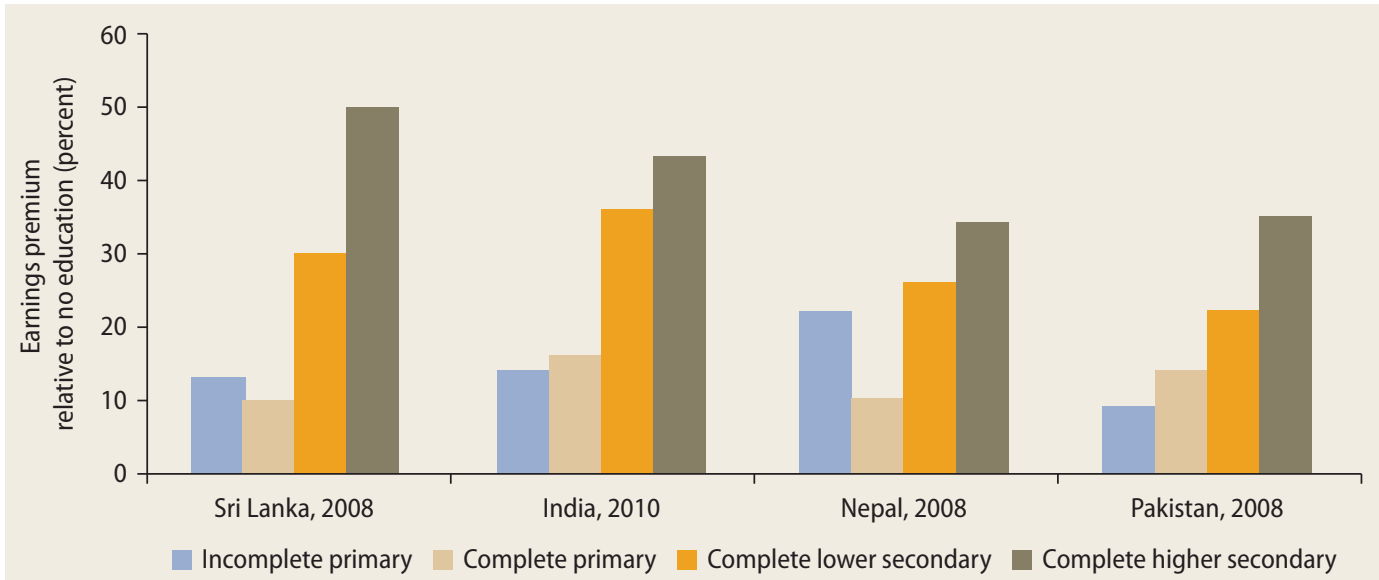

Source: World Bank 2011 
8 percent to 2 percent among the high-caste boys and increased the failure rate among the low-caste boys from 1 percent to 11 percent. The cue to caste was irrelevant to the problem. But making caste salient may have evoked in the children memories that changed how they think about themselves and about the world around them.

In another experiment, exposure to a more equal distribution of political power raised aspirations for girls. In 1993, India adopted gender quotas for village governments. The position of chief councilor (pradhan) was reserved for women in one-third of the village governments, which were randomly chosen. As a result, the number of women holding this post increased dramatically. This program was found to affect the aspirations of girls and of their parents (Beaman and others 2012). After about seven years of exposure to a female pradhan, the gender gap in aspirations was sharply reduced for teenagers and their parents. In particular, girls were less likely to want to be housewives, less likely to want their in-laws to determine their occupation, more likely to want to marry after 18 , and more likely to want a job that requires more education.

These preferences were mirrored in some tangible behavior. Whereas boys were more likely than girls to be enrolled in school in areas with no female pradhans and to be able to read and write, the gender gap in educational outcomes was completely erased in areas with seven years of exposure to a female pradhan. Because little else changed in terms of actual policy or career opportunities, seeing a woman achieving the position of local head likely provided a role model and changed how the girls think about themselves and about the world around them. It affected aspirations, which in turn affected educational choice (Banerjee and Duflo 2011; Duflo 2012).

\section{Behaviors}

Incentives may fail to change behavior when economic mobility is lacking.
Inequality of outcomes, especially in the absence of avenues to prosper, can greatly erode motivation for those at the bottom of the distribution (Hoff 2012). The poor and the disadvantaged who live in highly unequal societies may come to think of their places in the social order as fixed and unchangeable. They have no opportunity to play different roles or to be exposed to new role models, so they have little chance to change their worldviews and the way they perceive themselves. Entrenched poverty may lead to depression and behavior akin to "learned helplessness." The feeling that one has little power and few resources is likely to diminish goals and sap the capacity for hope.

A recent experiment in Bangladesh finds evidence linking poverty to hopelessness and inaction (Bryan, Chowdhury, and Mobarak 2012). The experiment was conducted in a region where preharvest famine is recurrent, and yet out-migration is not common. In the experiment, a US\$ 8 incentive was provided to individuals to migrate during the preharvest season. A very large effect on migration propensity was found. More than 40 percent of those receiving an incentive chose to migrate, whereas only 13 percent of control households did. The gains for those who migrated were large: about US $\$ 100$ in extra consumption over the season. Other evidence suggests that this large effect cannot be explained by imperfect information on employment opportunities at destination, nor can it be plausibly explained by risk aversion. The reason that these poor people do not save the US\$8 that they need to buy a ticket to migrate is likely that they have failed to think clearly about their opportunities. The stimulus of the gift of the US\$ 8 ticket leads them to make a major decision, with a very large return, that most individuals were not able to make otherwise (Banerjee and Duflo 2011; Duflo 2012).

Evidence also indicates that poverty is a causal factor in depression and that in poor regions depression is widespread (Case and Deaton 2009). In Bangladesh and in West Bengal, India, aid to the very poor 
significantly affects their incomes, consumption, and financial savings (Banerjee and Duflo 2011; Banerjee and others 2011; Duflo 2012). This experiment shows that a small and temporary financial assistance can motivate the very poor to action and lead them to make choices that substantially improve their well-being. Arguably, the outcome suggests that the very poor had become depressed and were failing to perceive the choices that they really faced.

\section{Access to finance}

Although inequality of outcomes may create incentives to accumulate human and physical capital, it may also affect the capacity of households to borrow for that purpose. If accumulation needs to build on individual or household savings, those at the bottom of the distribution may be unable to increase their capital significantly, and that in turn may perpetuate inequality.

Rural Pakistan provides ideal conditions to explore this hypothesis. There, land is almost wholly acquired through inheritance, with purchased land accounting for only

FIGURE 1.4 Greater inequality in landholdings is associated with lower asset accumulation among the poor

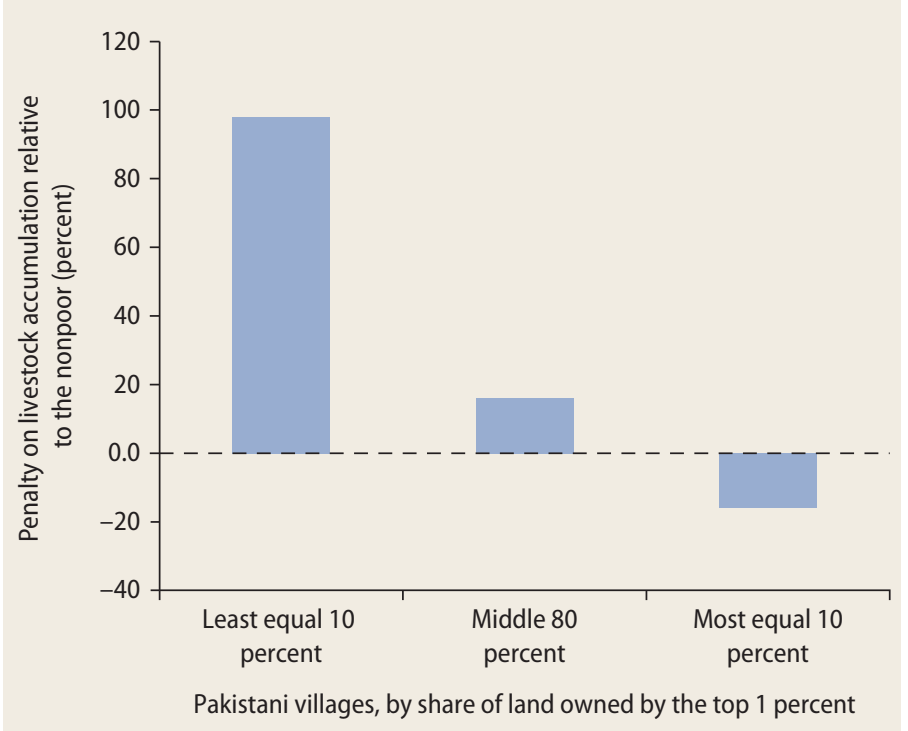

Source: Based on data from Mansuri 2013 for this report.
16 percent of all landholdings. Nor have any substantive shifts in ownership taken place because of land reforms or other policy or market changes. In the absence of an active market for land, farm plot sizes can be considered exogenous. Indeed, over the past 30 years, there has been little change in the distribution of land, so inequality in landownership is unlikely to reflect differences in ability or effort (Mansuri 2013). Concentration is the norm, with the median Gini coefficient for landholdings across villages being 0.74 . But the extent of concentration varies from one village to another, and this variation can be used to analyze whether inequality affects the accumulation of physical capital by households.

Accumulation of assets by households differs significantly between the most equal villages and the most unequal ones. The measure of accumulation is the annual change of livestock, which is perhaps the most divisible and liquid productive asset for rural households. Controlling for the initial poverty status and livestock holding of households, the poor are more likely to accumulate in villages with a lower level of land inequality (figure 1.4).

\section{Public goods}

The influence of inequality goes beyond individual or household behavior. Inequality also affects the ability of people to act collectively, the institutions they set up, and the ways in which resources are allocated for the benefit of the group. A salient case is the provision of public goods, where inequality can have effects of opposite signs. On the one hand, in a very unequal society, the rich typically have more power and clout, which makes them more effective at pulling in development resources for the public goods they value. From that perspective, inequality may be conducive to a greater provision of public goods, thus benefiting the poor as well. On the other hand, a high degree of inequality makes it more tempting for the rich and the upper-middle classes to opt out of public service because they can afford private alternatives. In this case, the quality of 
public services is bound to deteriorate, further harming the poor. In the end, which of the two effects prevails is likely to depend on whether opting out is an option.

Differences in land concentration among villages in Pakistan provide fertile ground to test the effect of inequality when opting out of some services is an option (Mansuri 2013). Land concentration at the village level has been stable for decades in Pakistan, partly because of distortions in land markets. This long-term stability implies that land concentration predates the current quality of public goods at the village level. If a causal relationship exists, it arguably goes from land concentration to the quality of public goods, and not the other way around.

For services such as electricity, drainage, access to public transport, and the nearest bank branch, greater land inequality is unambiguously associated with greater access to services (figure 1.5). The most unequal villages certainly do no worse than the most equal villages. For education services, however, things are somewhat different. Although the extent of land inequality has no correlation with the availability of public primary schools or with their physical condition, the teaching quality in those schools is far poorer in the most unequal villages. Notably, this negative impact of land concentration on teaching quality does not extend to private schools. These results imply that service quality and access tend to decline at very high levels of inequality for services for which the wealthy can move to private providers-such as schools.

Experiences of decentralization to local governments shed some light on the relationship between inequality and elite capture.

\section{FIGURE 1.5 Greater inequality reduces the quality of public services when the rich can opt out}

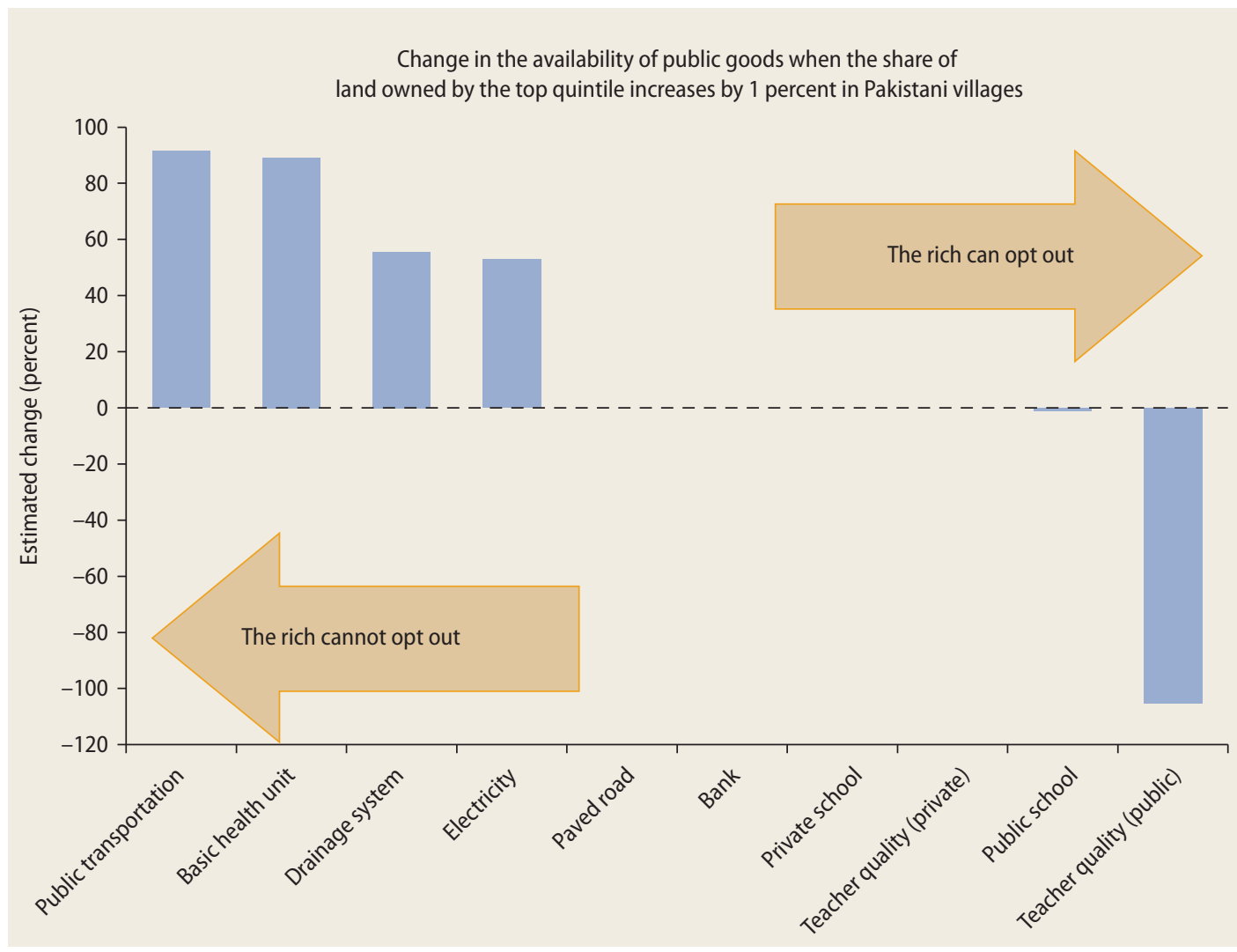


In principle, the decentralization of service delivery brings government decisions closer to the people, thereby improving responsiveness to local needs. When communities are highly uneven and accountability is low, however, decisions tend to be overly influenced by local elites at the expense of the rest of the population (Araujo and others 2008; Bardhan 2005; Bardhan and Mookherjee 2005; Drèze and Sen 1991; Madison [1787] 1961). Comparing local outcomes before and after decentralization episodes is a way to assess whether the extent of local inequality makes a difference.

In Bangladesh, the central government delegated the identification of beneficiary households under the Food-for-Education program to school-management committees at the community level. The targeting of the beneficiaries was worse in villages with larger land inequality (Galasso and Ravallion 2005). In West Bengal, India, the implementation of a set of development programs had been decentralized to the local governments for over a quarter of a century. In this case, the allocation of private goods such as farm inputs and credits was not particularly worse in villages with greater land inequality. However, the local government

\section{FIGURE 1.6 Inequality was highest under rent-seeking colonial rule}

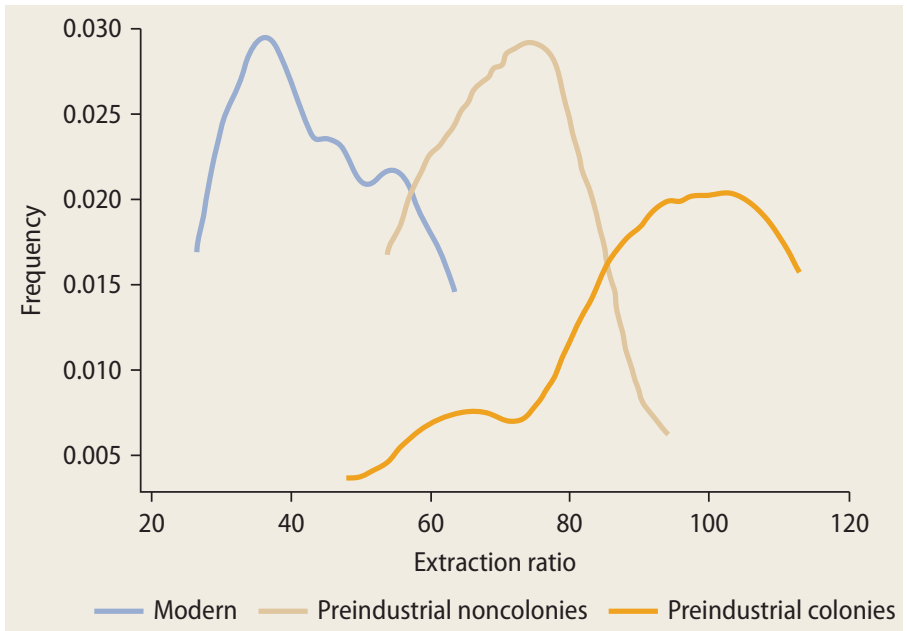

Source: Personal communication from Branko Milanovic based on Milanovic, Lindert, and Williamson (2011). was more likely to select local projects that generated less employment for the poor when landlessness and land inequality were greater (Bardhan and Mookherjee 2006).

\section{Rent seeking}

Inequality of outcomes does not generate the right incentives when it rests on rents (Stiglitz 2013). In that case, rather than being encouraged to study or to accumulate, individuals and households divert their efforts toward securing favoritism and protection. Rent seeking does not create new wealth or lead to innovations. Instead, it aims to manipulate the social and political environment in the pursuit of privilege-for example, by "lobbying" for a lower tax rate or "buying" a favorable regulatory environment. Rewarding such behaviors with high returns is costly to economic growth and social development. It leads to a suboptimal allocation of resources in the short term and consolidates institutional arrangements with negative long-term impacts on growth. Lucrative returns from rent seeking also foster corruption and nepotism.

Colonialism was an extreme case of rent seeking, associated with high inequality and a detrimental impact on local development. The extent of inequality in several preindustrial economies, including colonial settlements, has been compared with that of modern economies (Milanovic 2009, 2011a; Milanovic, Lindert, and Williamson 2011). To ensure comparability across very different data sets, a consistent measure of inequality is introduced. This is the inequality extraction ratio, defined as the quotient between the actual Gini coefficient and the maximum Gini coefficient. The maximum Gini coefficient is computed assuming that all people other than the elite have incomes at subsistence level whereas the elite earn what is left from aggregate income. Colonial settlements are associated with the highest inequality extraction ratios, typically around 100 percent (figure 1.6). The inequality extraction ratio was as high as 113 percent in Mogul India in 1750 and 97 percent in British India in 1947. 
These extreme levels of inequality were associated with crude rent-seeking behavior. Indigenous interests were suppressed, local resources and talents were exploited, and social and political institutions were manipulated to maximize the returns to colonial powers at the expense of the indigenous populations. The detrimental impact to local economic growth and social development was substantive and long-lasting. Evidence suggests that rent-seeking activities by colonial powers may have left local areas with a worse institutional legacy-higher concentration of landholdings, worse governance practices, and less access to justice-and lower longterm economic growth (Naritomi, Soares, and Assunção 2007). Native elites succeeding the colonizers often relied on similar institutions, however, and continued with similar policies of maximum extraction (Milanovic 2011a; Milanovic, Lindert, and Williamson 2011).

\section{Conflict}

Although a straightforward relationship between inequality and conflict would be hard to establish, some connections exist between the two. Inequality may damage trust-the foundation for social cohesionand thus weaken collective decision making. The problem is particularly salient in management of common resources. Across irrigation communities in south India and in Nepal, inequality is found to make resolving disputes in water allocation more difficult. Among 48 villages over six districts in India's Tamil Nadu state, the maintenance quality of distributaries and field channels was lower and water-allocation rules were more likely to be violated in villages with higher land inequality. When the water-allocation rules were perceived as being crafted by the village elite, dispute resolution was also more difficult (Bardhan 2005). In Nepal, income inequality undermines the management of irrigation systems, as found in a comparison of 150 agency- and farmer-managed systems (Lam 1998).

More broadly, inequality affects the economics of conflict (Lichbach 1989). In some cases, conflict reflects a systematic use of violence for economic gain, such as the control of resources, property, occupations, and business activities (Blattman and Miguel 2010; Collier and Hoeffler 1998, 2004). In others, economic factors lurk in the background of a conflict that erupts along social and political cleavages (Bardhan 2005; Horowitz 1998, 2000). Inequality, especially deprivation, may intensify the grievances felt by certain groups or can reduce the opportunity costs of initiating and joining a violent conflict.

Conflict may take many extreme forms. In South Asia, violence is more common in areas characterized by massive deprivation. Data from multiple sources, including the Global Terrorism Database, the Rand-MIPT Terrorism Incident Database, the Indian Ministry of Home Affairs, the Informal Sector Services Center (a nongovernmental organization in Nepal), and the South Asia Intelligence Review, confirm that internal violent conflicts-including communal violence, separatist movements, the Maoist insurgency, and terrorist attacks by religion extremistsare geographically correlated with the incidence of poverty across countries in South Asia (Iyer 2009).

In the case of India, the probability of a district being affected by Naxalites (Maoist rebels) can be linked to the characteristics of the district. Using data from the Indian Planning Commission and the South Asian Intelligence Review, the probability has been shown to rise with the district's poverty rate and to fall with its literacy rate (Borooah 2008). Indeed, with the exception of Jharkhand and Maharashtra, poverty incidence is higher in districts where Naxalites are better implanted (figure 1.7). The difference is particularly large in the case of rural areas. In Pakistan, the probability of violent attacks by insurgents, sectarians, and terrorists is also related to the socioeconomic characteristics of the district. Based on data collected by the Pakistan Institute of Policy Studies, the probability is found to increase with food insecurity and land inequality (Malik 2009, 2011).

Although these findings reflect only a correlation, other analyses suggest causality. 


\section{FIGURE 1.7 Poverty is higher in Indian districts suffering from Naxalite violence}

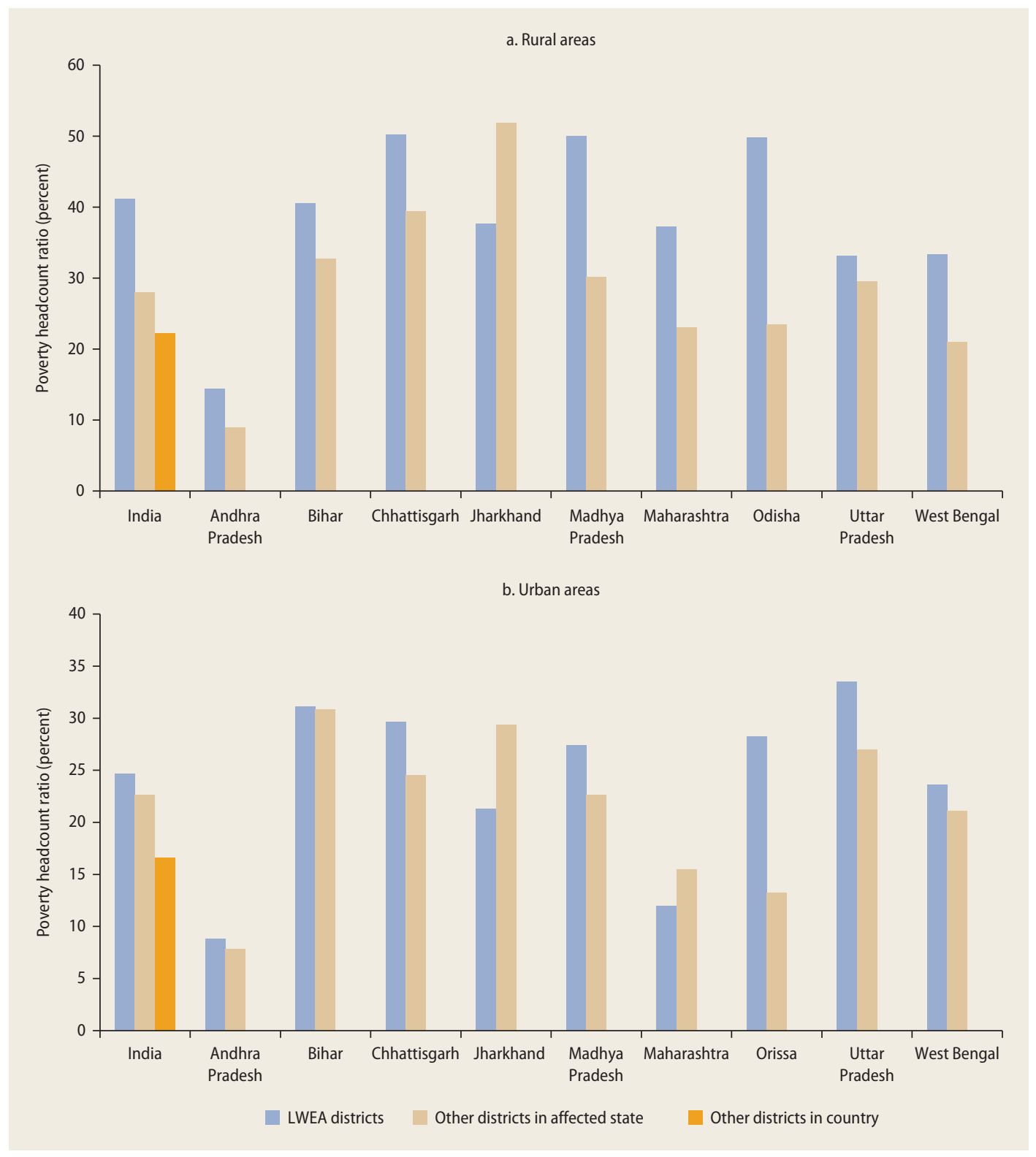

Source: Based on NSS 2011-12 data for India.

Note: LWEA = left-wing-extremism-affected districts. As defined by the Planning Commission in http://pcserver.nic.in/iapmis/state_district_list.aspx, India has 88 such districts. The headcount ratio is based on the national poverty line.

Based on a more comprehensive database, land inequality is found to strongly affect Naxalite violence (Gomes 2011). A significant relationship also exists between adverse shocks on agricultural production and renewable resources such as forests and the intensity of conflict in the Maoist belt of India
(Eynde 2013; Kapur, Gawande, and Satyanath 2012). In the case of Nepal, an analysis tracking civil war incidence and casualties across space and over time found that poorer districts were likely to be drawn into conflicts earlier and were associated with higher conflict-related deaths (Do and Iyer 2010). 
Using data on the recruitment by the Maoist insurgency in Nepal, another study finds that recruiting through abduction of young people was more intensive in districts where inequality between those with land and the landless had previously increased (Macours 2011).

The relationship between inequality and conflict is not mechanical, however. The impact of conflicts differs across income groups. The poor may have less sympathy to violent conflicts as they tend to be the ones affected the most. In Pakistan, a 6,000-person nationally representative survey was conducted to measure attitudes toward four militant organizations. Contrary to expectations, poor Pakistanis dislike militants more than middle-class citizens. The dislike is strongest among the urban poor, particularly those in violent districts, suggesting that exposure to terrorists attacks reduces support for militants (Blair and others 2012). Groups divided by social and political cleavages also tend to differ in their incomes, and as a result, changes in relative incomes across groups may exacerbate (or reduce) conflict. In India, where Muslims tend to be poorer than Hindus, one study found that an increase in Muslim expenditure per capita at the community level generates a large and significant increase in local religious conflict. In contrast, an increase in Hindu per capita expenditure does not lead to higher conflict (Mitra and Ray 2013). In this case, lower inequality at the local level is associated with greater violence, whereas greater inequality is not.

\section{References}

Alkire, Sabina, and James Foster. 2011. "Counting and Multidimensional Poverty Measurement." Journal of Public Economics 95 (7): 476-87.

Alkire, Sabina, and Suman Seth. 2013. "Multidimensional Poverty Reduction in India between 1999 and 2006: Where and How?" Oxford Poverty and Human Development Initiative, University of Oxford, U.K.

Amiel, Yoram, and Frank Cowell. 1999. Thinking about Inequality: Personal Judgment and Income Distributions. Cambridge: Cambridge University Press.
Araujo, M. Caridad, Francisco H. G. Ferreira, Peter Lanjouw, and Berk Özler. 2008. "Local Inequality and Project Choice: Theory and Evidence from Ecuador." Journal of Public Economics 92 (5): 1022-46.

Arrow, Kenneth J. 1971. "A Utilitarian Approach to the Concept of Equality in Public Expenditures." Quarterly Journal of Economics 85 (3): 409-15.

Atkinson, Anthony B., and François Bourguignon. 1982. "The Comparison of Multi-Dimensioned Distributions of Economic Status." Review of Economic Studies 49 (2): 183-201.

- eds. 2000. Handbook of Income Distribution. Vol. 1. Oxford: North-Holland, Elsevier.

Atkinson, Anthony B., and Thomas Piketty, eds. 2010. Top Incomes: A Global Perspective. Oxford and New York: Oxford University Press.

Atkinson, Anthony B., Thomas Piketty, and Emmanuel Saez. 2011. "Top Incomes in the Long Run of History." Journal of Economic Literature 49 (1): 3-71.

Banerjee, Abhijit, and Esther Duflo. 2011. Poor Economics: A Radical Rethinking of the Way to Fight Global Poverty. New York: PublicAffairs.

Banerjee, Abhijit, Esther Duflo, Raghabendra Chattopadhyay, and Jeremy Shapiro. 2011. "Targeting the Hard-Core Poor: An Impact Assessment.” J-PAL, Massachusetts Institute of Technology, Boston.

Banerjee, Abhijit, and Thomas Piketty. 2005. “Top Indian Incomes, 1922-2000." World Bank Economic Review 19 (1): 1-20.

Bardhan, Pranab K. 2005. Scarcity, Conflicts, and Cooperation: Essays in the Political and Institutional Economics of Development. Cambridge, MA: MIT Press.

Bardhan, Pranab, and Dilip Mookherjee. 2005. "Decentralizing Antipoverty Program Delivery in Developing Countries." Journal of Public Economics 89 (4): 675-704.

- 2006. "Pro-poor Targeting and Accountability of Local Governments in West Bengal." Journal of Development Economics 79 (2): 303-27.

Beaman, Lori, Esther Duflo, Rohini Pande, and Petia Topalova. 2012. "Female Leadership Raises Aspirations and Educational Attainment for Girls: A Policy Experiment in India." Science 335 (6068): 582-86. 


\section{Why inequality matters: Main messages and policy implications}

In recent years, debates on inequality in development economics have been dominated by the concept of equality of opportunity. Implicit in this concept is a focus on access to basic services such as health, education, and basic infrastructure in childhood, and especially on eliminating discrimination in access because of inherited circumstances, such as gender, ethnicity, or location. However, well-being in adult life clearly may be affected by other forces beyond the control of individuals. Not everybody faces the same employment and migration choices, so that children with equal access to immunization, schools, or sanitation may end up in very different places. Similarly, shocks such as disease or natural disasters may result in very different levels of well-being in adult life. Although equality of opportunity is essential, mobility and support matter as well. For this reason any comprehensive analysis needs to consider inequality of outcomes and not only inequality of opportunity.

Although most great faiths and political movements have normative views on inequality, a positive approach is warranted. Equality may have an intrinsic value that varies from one society to another, but it also has instrumental value. Because of its effects on social organization and economic performance, inequality actually has tangible costs and benefits. On the benefits side, some degree of inequality in outcomes is needed to encourage people to study, work, and save. On the costs side, entrenched inequality can undermine aspirations and lead to a psychological state of helplessness, so that incentives do not translate into behaviors. Excessive inequality can also get in the way of access to finance for the most deprived and result in missed investment opportunities. Deprivation can undermine social cohesion, nurturing violence and fostering conflict. Its effects on the provision of public goods are more mixed and crucially depend on whether the rich and the better-off can opt out and rely on private alternatives.

Because inequality has both costs and benefits, it cannot be labeled as unambiguously good or bad. For instance, a high level of inequality of outcomes resulting from rent seeking, privilege, and corruption is bound to be very bad for economic performance. But the same level of inequality in a society characterized by equality of opportunity in access to basic services and strong mobility through jobs and migration may provide all the right incentives and support rapid economic growth. From a policy perspective, then, the issue is not just the extent of inequality but also its sources. The goal is not necessarily to reduce (or increase) inequality but to focus efforts on reducing bad forms of inequality. And even in this respect, the cost-benefit logic inherent to the positive approach needs to be kept in mind. Reducing bad forms of inequality, such as rent seeking and discrimination, should be a government priority. But the overall cost of the instruments used to reduce inequality should not be higher than the expected benefits.
Bentham, Jeremy. (1781) 2000. An Introduction to the Principles of Morals and Legislation. Kitchener, ON: Batoche Books.

Bernanke, Ben S. 2012. "Economic Measurement." Remarks to the 32nd General Conference of the International Association for Research in Income and Wealth, Cambridge, MA (via prerecorded video), August 6.

Blair, Graeme, C. Christine Fair, Neil Malhotra, and Jacob N. Shapiro. 2012. "Poverty and
Support for Militant Politics: Evidence from Pakistan." American Journal of Political Science.

Blattman, Christopher, and Edward Miguel. 2010. "Civil War." Journal of Economic Literature 48 (1): 3-57.

Borooah, Vani K. 2008. "Deprivation, Violence, and Conflict: An Analysis of Naxalite Activity in the Districts of India." International Journal of Conflict and Violence 2 (2): 317-33. 
Bourguignon, François. 1999. “Comment on 'Multidimensioned Approaches to Welfare Analysis' by E. Maasoumi." In Handbook of Income Inequality Measurement, edited by Jacques Silber, 477-84. Norwell, MA: Kluwer Academic.

Bryan, Gharad, Shyamal Chowdhury, and Ahmed Mobarak. 2012. "Seasonal Migration and Risk Aversion.” Discussion paper 8739, Centre for Economic Policy Research, London.

Cagetti, Marco, and Mariacristina De Nardi. 2008. "Wealth Inequality: Data and Models." Macroeconomic Dynamics 12 (suppl. S2): 285-313.

Case, Anne, and Angus Deaton. 2009. "Health and Well-Being in Udaipur and South Africa." In Developments in the Economics of Aging, edited by David A. Wise, 317-49. Chicago: University of Chicago Press.

Cohen, Sheldon, William J. Doyle, Ronald B. Turner, Cuneyt M. Alper, and David P. Skoner. 2003. "Emotional Style and Susceptibility to the Common Cold." Psychosomatic Medicine 65 (4): 652-57.

Collier, Paul, and Anke Hoeffler. 1998. "On Economic Causes of Civil War." Oxford Economic Papers 50 (4): 563-73.

- 2004. "Greed and Grievance in Civil War." Oxford Economic Papers 56 (4): 563-95.

Datt, Gaurav, and Martin Ravallion. 2009. "Has India's Economic Growth Become More Pro-Poor in the Wake of Economic Reforms?" Policy Research Working Paper 5103, World Bank, Washington, DC.

Davies, James B., and Anthony F. Shorrocks. 2000. "The Distribution of Wealth." In Handbook of Income Distribution, Vol. 1, edited by Anthony B. Atkinson and François Bourguignon, 605-75. Oxford: NorthHolland, Elsevier.

Davies, James B., Anthony Shorrocks, Susanna Sandström, and Edward N. Wolff. 2008. "The World Distribution of Household Wealth." In Personal Wealth from a Global Perspective, edited by James B. Davies, 395-418. New York: Oxford University Press.

Deaton, Angus. 2005. "Measuring Poverty in a Growing World (or Measuring Growth in a Poor World)." Review of Economics and Statistics 87 (1): 1-19.

Deaton, Angus, and Valerie Kozel. 2005. "Data and Dogma: The Great Indian Poverty Debate." World Bank Research Observer 20 (2): 177-99.
Decancq, Koen, and María Ana Lugo. 2013. "Weights in Multidimensional Indices of Wellbeing: An Overview." Econometric Reviews 32 (1): 7-34.

Diener, Edward, and Eunkook M. Suh. 1999. "National Differences in Subjective WellBeing." In Well-Being: The Foundations of Hedonic Psychology, edited by Daniel Kahneman, Edward Diener, and Norbert Schwarz, 434-50. New York: Russell-Sage.

Do, Quy-Toan, and Lakshmi Iyer. 2010. "Geography, Poverty and Conflict in Nepal." Journal of Peace Research 47 (6): 735-48.

Drèze, Jean, and Amartya K. Sen. 1991. Hunger and Public Action. Oxford and New York: Oxford University Press.

Duflo, Esther. 2012. "Women Empowerment and Economic Development." Journal of Economic Literature 50 (4): 1051-79.

Dworkin, Ronald. 1981a. "What Is Equality? Part 1: Equality of Welfare." Philosophy and Public Affairs 10 (3): 185-246.

_ 1981b. "What Is Equality? Part 2: Equality of Resources." Philosophy and Public Affairs 10 (4): 283-345.

Eynde, Oliver Vanden. 2013. "Targets of Violence: Evidence from India's Naxalite Conflict." Working Paper. Paris School of Economics.

Ferreira, Francisco, and Maria Ana Lugo. 2013. "Multidimensional Poverty Analysis: Looking for a Middle Ground." World Bank Research Observer 28 (2): 220-35.

Frey, Bruno S., and Alois Stutzer. 2002. "What Can Economists Learn from Happiness Research?" Journal of Economic Literature 40 (2): 402-35.

Galasso, Emanuela, and Martin Ravallion. 2005. "Decentralized Targeting of an Antipoverty Program." Journal of Public Economics 89 (4): 705-27.

Gomes, Joseph Flavian. 2011. “The Political Economy of the Maoist Conflict in India: An Empirical Analysis.” Preliminary draft. http://www.uclouvain.be/cps/ucl/doc/core /documents/Gomes.pdf.

Hoff, Karla. 2012. “The Effect of Inequality on Aspirations.” Background paper for this report, World Bank, Washington, DC.

Hoff, Karla, and Priyanka Pandey. 2006. "Discrimination, Social Identity, and Durable Inequalities." American Economic Review 96 (2): 206-11.

- 2012. "Making Up People: The Effect of Identity on Preferences and Performance in a 
Modernizing Society.” Policy Research Working Paper 6223, World Bank, Washington, DC.

Horowitz, Donald L. 1998. "Structure and Strategy in Ethnic Conflict.” Paper prepared for the Annual World Bank Conference on Development Economics, Washington, DC, April 20-21.

-2000. Ethnic Groups in Conflict. 2nd ed. Berkeley and Los Angeles: University of California Press.

Human Rights Watch. 2014 "They Say We're Dirty": Denying an Education to India's Marginalized. New York: Human Rights Watch.

Inglehart, Ronald. 2000. World Values Surveys and European Values Surveys, 1981-1984, 1990-1993 and 1995-1997. Ann Arbor, MI: Inter-university Consortium for Political and Social Research.

Iyer, Lakshmi. 2009. "The Bloody Millennium: Internal Conflict in South Asia." Business, Government, and the International Economy Unit, Working Paper 09-086, Harvard Business School, Cambridge, MA.

Juster, F. Thomas, and Kathleen A. Kuester. 1991. "Differences in the Measurement of Wealth, Wealth Inequality and Wealth Composition Obtained from Alternative U.S. Wealth Surveys." Review of Income and Wealth 37 (1): 33-62.

Kahneman, Daniel. 2003a. "A Psychological Perspective on Economics." American Economic Review 93 (2): 162-68.

- 2003b. "Maps of Bounded Rationality: Psychology for Behavioral Economics." American Economic Review 93 (5): 1449-75.

—. 2011. Thinking, Fast and Slow. New York: Farrar, Straus and Giroux.

Kahneman, Daniel, and Alan B. Krueger. 2006. "Developments in the Measurement of Subjective Well-Being." Journal of Economic Perspectives 20 (1): 3-24.

Kahneman, Daniel, Alan B. Krueger, David A. Schkade, Norbert Schwarz, and Arthur A. Stone. 2004. "A Survey Method for Characterizing Daily Life Experience: The Day Reconstruction Method." Science 306 (5702): 1776-80.

Kahneman, Daniel, and Amos Tversky. 1984. "Choices, Values, and Frames." American Psychologist 39 (4): 341-50.

Kapur, Devesh, Kishore Gawande, and Shanker Satyanath. 2012. "Renewable Resource Shocks and Conflict in India's Maoist Belt." Center for
Global Development Working Paper No. 302, Washington, DC.

Keister, Lisa A. 2000. Wealth in America: Trends in Wealth Inequality. New York: Cambridge University Press.

Kiecolt-Glaser, Janice K., Lynanne McGuire, Theodore F. Robles, and Ronald Glaser. 2002. "Psychoneuroimmunology: Psychological Influences on Immune Function and Health." Journal of Consulting and Clinical Psychology 70 (3): 537-47.

Kolm, Serge-Christophe. 1977. "Multidimensional Egalitarianisms." Quarterly Journal of Economics 91 (1): 1-13.

Korinek, Anton, Johan A. Mistiaen, and Martin Ravallion. 2006. "Survey Nonresponse and the Distribution of Income." Journal of Economic Inequality 4 (1): 33-55.

Lam, Wai Fung. 1998. Governing Irrigation Systems in Nepal: Institutions, Infrastructure, and Collective Action. Oakland, CA: ICS Press.

Li, Shi, and Renwei Zhao. 2008. "Changes in the Distribution of Wealth in China, 1995-2002." In Personal Wealth from a Global Perspective, edited by James B. Davies, 93-111. New York: Oxford University Press.

Lichbach, Mark Irving. 1989. “An Evaluation of 'Does Economic Inequality Breed Political Conflict?' Studies." World Politics 41 (4): 431-70.

Lucas, Richard, Edward Diener, and Eunkook M. Suh. 1996. "Discriminant Validity of WellBeing Measures." Journal of Personality and Social Psychology 71 (3): 616-28.

Lugo, María Ana. 2007. "Comparing Multidimensional Indices of Inequality: Methods and Application." Research on Economic Inequality 14: 213-36.

Maasoumi, Esfandiar. 1986. "The Measurement and Decomposition of Multi-dimensional Inequality." Econometrica: Journal of the Econometric Society 54 (4): 991-97.

- 1999. "Multidimensioned Approaches to Welfare Analysis." In Handbook of Income Inequality Measurement, edited by Jacques Silber, 437-84. Norwell, MA: Kluwer Academic.

Macours, Karen. 2011. "Increasing Inequality and Civil Conflict in Nepal." Oxford Economic Papers 63 (2011). Cambridge, U.K.: Oxford University Press.

Madison, James. (1787) 1961. "Federalist 10." In Alexander Hamilton, James Madison, and John Jay, The Federalist, edited by B. F. 
Wright, 77-84. Cambridge, MA: Belknap Press of Harvard University.

Malik, Sadia. 2009. "Horizontal Inequalities and Violent Conflict in Pakistan: Is There a Link?" Economic and Political Weekly.

_. 2011. "An Empirical Investigation of the Relationship between Food Insecurity, Landlessness, and Violent Conflict in Pakistan." PIDE Working Paper, Pakistan Institute of Development Economics, Islamabad.

Mansuri, Ghazala. 2013. "Inequality and Development." Background paper for this report, World Bank, Washington, DC.

Milanovic, Branko. 2009. "Global Inequality and the Global Inequality Extraction Ratio: The Story of the Past Two Centuries.” Policy Research Working Paper 5044, World Bank, Washington, DC.

- 2011a. The Haves and the Have-Nots: A Brief Idiosyncratic History of Global Inequality. New York: Basic Books.

- 2011b. Worlds Apart: Measuring International and Global Inequality. Princeton, NJ: Princeton University Press.

Milanovic, Branko, Peter H. Lindert, and Jeffrey G. Williamson. 2011. "Pre-Industrial Inequality." Economic Journal 121 (551): 255-72.

Mitra, Anirban, and Debraj Ray. 2013. "Implications of an Economic Theory of Conflict: Hindu-Muslim Violence in India." NBER Working Paper No. 19090, National Bureau of Economic Research, Cambridge, MA. Nagel, Thomas. 1986. The View from Nowhere. New York: Oxford University Press.

Naritomi, Joana, Rodrigo R. Soares, and Juliano J. Assunção. 2007. Rent Seeking and the Unveiling of 'De Facto' Institutions: Development and Colonial Heritage within Brazil.” NBER Working Paper No. 13545, National Bureau of Economic Research, Cambridge, MA.

Nozick, Robert. 1974. Anarchy, State, and Utopia. New York: Basic Books.

OECD (Organisation for Economic Co-operation and Development). 2013. OECD Framework for Statistics on the Distribution of Housebold Income, Consumption and Wealth. Paris: OECD Publishing. http://dx.doi .org/10.1787/9789264194830-en.

Paes de Barros, Ricardo, Francisco H. G. Ferreira, José R. Monlinas Vega, and Jaime Saavedra Chanduvi. 2009. Measuring Inequality of Opportunities in Latin America and the Caribbean. Washington, DC: World Bank.
Piketty, Thomas. 2011. "On the Long-Run Evolution of Inheritance: France 1820-2050." Quarterly Journal of Economics 126 (3): 1071-131.

Piketty, Thomas, Gilles Postel-Vinay, and Jean-Laurent Rosenthal. 2006. "Wealth Concentration in a Developing Economy: Paris and France, 1807-1994." American Economic Review 96 (1): 236-56.

Piketty, Thomas, and Emmanuel Saez. 2003. "Income Inequality in the United States, 1913-1998." Quarterly Journal of Economics 118 (1): 1-41.

Ravallion, Martin. 2003. "Measuring Aggregate Welfare in Developing Countries: How Well Do National Accounts and Surveys Agree?" Review of Economics and Statistics 85 (3): 645-52.

-. 2014. "Income Inequality in the Developing World." Science 344 (6168): 851-55.

Rawls, John. 1971. A Theory of Justice. Cambridge, MA: Harvard University Press.

Roemer, John E. 1998a. Equality of Opportunity. Cambridge, MA: Harvard University Press. 1998b. Theories of Distributive Justice. Cambridge, MA: Harvard University Press.

Roemer, John E., and Alain Trannoy. 2013. "Equality of Opportunity." Cowles Foundation Discussion Paper No. 1921, Cowles Foundation for Research in Economics, Yale University, New Haven, CT.

Sedwal, Mona, and Sangeeta Kamat. 2011. "Education and Social Equity in Elementary Education." In Who Goes to School, edited by R. Govinda, 87-123. Cary, NC: Oxford University Press.

Sen, Amartya, ed. 1973. On Economic Inequality. New York: Oxford University Press.

- 1980. "Equality of What?" In The Tanner Lectures on Human Values, Vol. 1, edited by S. McMurrin, 353-69. Cambridge: Cambridge University Press.

. 1992. Inequality Reexamined. New York: Oxford University Press.

Seth, Suman. 2010. “A Class of Distribution and Association Sensitive Multidimensional Welfare Indices." Journal of Economic Inequality 11 (2): 1-30.

Stiglitz, Joseph E. 2013. "Inequality Is Holding Back the Recovery." New York Times, January 19.

Stone, Arthur, and Saul Shiffman. 1994. "Ecological Momentary Assessment (EMA) in 
Behavioral Medicine.” Annals of Behavioral Medicine 16 (3): 199-202.

Stutzer, Alois, and Bruno S. Frey. 2012. "Recent Developments in the Economics of Happiness: A Selective Overview.” Discussion Paper No. 7078, Forschungsinstitut zur Zukunft der Arbeit (Institute for the Study of Labor), Bonn, Germany.

Subramanian, S., and D. Jayaraj. 2008. "The Distribution of Household Wealth in India." In Personal Wealth from a Global Perspective, edited by James B. Davies, 112-33. New York: Oxford University Press.

Thekaekara, Mari Marcel. 2004. "No Hope, No Future." The Hindu, February 8. http://www.hindu.com/mag/2004/02/08 /stories/2004020800010400.htm.

Tsui, Kai-yuen. 1999. "Multidimensional Inequality and Multidimensional Generalized Entropy Measures: An Axiomatic Derivation.” Social Choice and Welfare 16 (1): 145-57.

Tversky, Amos, and Daniel Kahneman. 1974. "Judgment under Uncertainty: Heuristics and Biases." Science 185 (4157): 1124-31.

UNDP (United Nations Development Programme). 2010. Human Development Report 2010: The Real Wealth of Nations:
Pathways to Human Development. New York: Palgrave Macmillan.

Ura, Karma, Sabina Alkire, and Tshoki Zangmo. 2012. GNH and GNH Index. Thimpu, Bhutan: Centre for Bhutan Studies.

Urry, Heather, Jack Nitschke, Isa Dolski, Daren Jackson, Kim Dalton, Corrina Mueler, Melissa Rosenkranz, Carol Ryff, Burton Singer, and Richard Davidson. 2004. "Making a Life Worth Living." Psychological Science 15 (6): 367-72.

Veenhoven, Ruut. 2004. "Subjective Measures of Well-Being.” WIDER Discussion Paper No. 2004/07, United Nations University World Institute for Development Economics Research (UNU-WIDER).

Wolff, Edward N. 1987. "Estimates of Household Wealth Inequality in the U.S., 1962-1983." Review of Income and Wealth 33 (3): 231-56. - 1996. "International Comparisons of Wealth Inequality." Review of Income and Wealth 42 (4): 433-51.

World Bank. 2005. World Development Report 2006: Equity and Development. Washington, DC, and New York: World Bank and Oxford University Press.

. 2011. More and Better Jobs in South Asia. Washington, DC: World Bank. 


\section{The Extent of Inequality}

A ssessing the extent of inequality in a particular country or region can be sensitive to the indicators used. This is particularly so in South Asia, where monetary and nonmonetary indicators of wellbeing yield sometimes radically different pictures. Monetary indicators are based on cash and in-kind income or consumption; they may also refer to wealth. Nonmonetary indicators capture aspects of well-being, such as access to basic services, environmental quality, or voice in public matters.

Standard indicators based on consumption per capita suggest that South Asia has modest levels of inequality compared to other regions of the world. If Gini indexes are to be taken at face value, the extent of inequality in South Asia is much lower than in China, Mexico, or South Africa. Inequality in human development outcomes is higher than inequality in expenditures per capita, but it is not high enough to make South Asia an outlier among developing regions.

Yet the combination of monetary and nonmonetary indicators yields a somewhat different perspective. Figures on tax filings and asset holdings suggest that South Asians at the top are disproportionately rich on a global scale. At the same time, figures on malnutrition reveal that South Asians at the bottom are among the most destitute people worldwide. These additional pieces of information cast doubts on the picture that emerges from standard monetary indicators computed from household surveys.

The assessment of trends in inequality also depends on the indicator considered. Monetary inequality is increasing in most of South Asia. Growth has been effective at reducing poverty in the region, as it was earlier in East Asia. Yet growth has led to increasing inequality in both regions, despite being neutral overall with respect to distribution at the global level. Monetary indicators of inequality have increased in the poorest countries in the South Asia region in recent years and fallen only among the richest ones. A common hypothesis in economic development (the so-called Kuznets curve) is that inequality increases until countries attain a certain level of income and only declines as they become richer. This hypothesis is controversial, and no real consensus exists about its validity. But monetary indicators from South Asia are consistent with it. If so, a vast majority of South Asians could be confronted with an increase in monetary inequality in the years to come.

Trends in nonmonetary inequality are more mixed. On some dimensions, South Asia is becoming more equal, whereas 
on others, gaps keep widening. For example, the region has made substantial progress in educational attainment at the primary level; however, inequality is increasing in other dimensions, notably in health outcomes.

The diversity of the observed trends, depending on the indicator considered, makes it difficult to rely on a single metric to assess changes in inequality or progress toward shared prosperity. This difficulty comes on top of the measurement issues associated with some of the most common indicators. For instance, lower survey response rates among better-off households and greater underestimation of their expenditures by the available survey instruments may bias standard inequality measures such as the Gini index or the income share of the bottom 40 percent. But even in the absence of bias, the story on inequality in South Asia would be different if it were told based on monetary indicators, on education indicators, or on health indicators.

This diversity of assessments is actually welcome when interpreting what lies behind the level of inequality and its changes over time. Some of the indicators can be decomposed between population groups defined by characteristics such as gender, location, and caste, providing some clues. This exercise provides guidance on how to design policies in relation to basic services to ensure equality of opportunity. Other indicators can be traced over time for different population groups. For instance, changes in occupational status between fathers and sons or in expenditures per capita within the same generation reveal the extent of mobility for each of the groups. Findings help disentangle the contribution jobs and migration make to overall inequality. The same logic can be applied to shocks and public support: not all population groups are equally affected by disease, economic crises, or natural disasters, and the magnitude of the net transfers they receive from government, or make to it, varies as well. Results can be used to inform how social protection, taxation, and transfers should be organized. Patterns of subjective assessments of inequality across population groups offer complementary evidence for policy makers to act upon.

The diversity of the economic forces underlying the level of inequality and its changes over time is useful to articulate a conceptual framework to be used in the rest of this report. Some circumstances at birth, such as gender and caste, shape the options available to individuals. As children age, the opportunities to accumulate human capital become critically important; once they enter the labor force, job opportunities and the possibility of reaping benefits from migration affect earnings prospects. Throughout life, people experience shocks and are affectedpositively or negatively-by government policies transferring resources to them or taxing them, explicitly or implicitly. Through each of these phases, public policies may be able to affect the extent of inequality.

\section{Monetary indicators of inequality}

Different indicators are used in practice to measure inequality in the distribution of income or consumption. Each one captures different dimensions of inequality. Some, such as the Gini coefficient or the mean log deviation (MLD), focus on the entire distribution and can be seen as measuring the gap between actual consumption or income and the consumption or income that would prevail if there were no inequality. A Gini coefficient of zero expresses perfect equality, whereas a Gini coefficient of one corresponds to the extreme where all consumption or income is in the hands of one person or household. As for the MLD, an intuitive explanation is that, multiplied by 100 , it shows the percentage difference between the consumption of a randomly selected individual and the average per capita consumption in the country. The more unequal the distribution, the bigger the percentage difference. Other indicators emphasize the extremes of the distribution. The Theil index, for instance, increases more than linearly as the share of the rich increases. Finally, indicators such as the ratio between 
the 90th and the 10th percentile focus on particular points in the distribution.

None of the indicators is intrinsically better than others. A focus on different points or portions of the distribution or on the distribution in its entirety reflects a judgment on what aspect of inequality matters most. For instance, some may prefer to put the spotlight on the top 1 percent and others on the bottom 40 percent. This is not necessarily a matter of values or ideology. The same analyst may choose one particular inequality indicator to address an issue and another one to deal with a different issue.

Monetary indicators of inequality are generally computed based on individual records from representative household surveys (box 2.1). Overall, these indicators suggest that inequality in South Asia is moderate by international standards (figure 2.1).

\section{BOX 2.1 South Asian household surveys used in this report}

\begin{tabular}{|c|c|c|c|c|}
\hline Acronym & Name & Countries & Years & Description \\
\hline BLSS & $\begin{array}{l}\text { Bhutan Living } \\
\text { Standards Survey }\end{array}$ & Bhutan & 2003,2007 & $\begin{array}{l}\text { BLSS is a nationally representative survey. It gathers data on } \\
\text { consumption expenditure and other household information, } \\
\text { including demographic characteristics, education, health } \\
\text { and employment of household members, and household } \\
\text { remittances, housing, and access to public facilities and } \\
\text { services. The BLSS sample size is 4,007 in } 2003 \text { and 9,798 in } 2007 .\end{array}$ \\
\hline DHS & $\begin{array}{l}\text { Demographic and } \\
\text { Health Survey }\end{array}$ & $\begin{array}{l}\text { Bangladesh } \\
\text { India } \\
\text { Maldives } \\
\text { Nepal } \\
\text { Pakistan } \\
\text { Sri Lanka }\end{array}$ & $\begin{array}{l}1993,2011 \\
1992,2005 \\
2009 \\
1996,2011 \\
1990,2007 \\
2007\end{array}$ & $\begin{array}{l}\text { DHSs are nationally representative household surveys that } \\
\text { provide data for a wide range of monitoring and impact } \\
\text { evaluation indicators in the areas of population, health, and } \\
\text { nutrition. }\end{array}$ \\
\hline HIES & $\begin{array}{l}\text { Household Income } \\
\text { and Expenditure } \\
\text { Survey }\end{array}$ & Bangladesh & $2000,2005,2010$ & $\begin{array}{l}\text { HIES of Bangladesh is the core nationally representative survey } \\
\text { to provide important data such as income, expenditure, } \\
\text { consumption, and poverty situation. In particular, it contains } \\
\text { information on demographic characteristics, education, health } \\
\text { and employment of household members, and household } \\
\text { housing, economic activities, income, and consumption. The } \\
\text { first HIES round was conducted in } 1973-74 \text {, and } 15 \text { rounds have } \\
\text { been completed since then. The sample size of the } 2010 \text { survey } \\
\text { is } 12,240 \text { households; } 7,840 \text { were from rural areas and } 4,400 \\
\text { from urban areas. }\end{array}$ \\
\hline HIES & $\begin{array}{l}\text { Household Income } \\
\text { and Expenditure } \\
\text { Survey }\end{array}$ & Maldives & $\begin{array}{l}2002-03 \\
2009-10\end{array}$ & $\begin{array}{l}\text { HIES of Maldives collects detailed information on the } \\
\text { expenditure, income, demographic, and socioeconomic } \\
\text { characteristics from local households living in the } \\
\text { administrative islands of the country. The main objective is to } \\
\text { produce reliable statistics on different components of income } \\
\text { and expenditure of households in the capital, Malé, and the } \\
\text { Atolls to assess the economic well-being of the population. } \\
\text { Specifically, the results are used to bring about improvements } \\
\text { in the country's national accounts, consumer price index, and } \\
\text { vulnerability and poverty statistics. The survey covers } 834 \\
\text { households from Malé and } 40 \text { islands in the 2002-03 round, } \\
\text { and } 2,060 \text { households from Malé and } 39 \text { islands in the 2009-10 } \\
\text { round. }\end{array}$ \\
\hline
\end{tabular}




\section{BOX 2.1 South Asian household surveys used in this report (continued)}

\begin{tabular}{|c|c|c|c|c|}
\hline Acronym & Name & Countries & Years & Description \\
\hline HIES & $\begin{array}{l}\text { Household Income } \\
\text { and Expenditure } \\
\text { Survey }\end{array}$ & Sri Lanka & $\begin{array}{l}1995-96 \\
2002-03 \\
2006-07 \\
2009-10\end{array}$ & $\begin{array}{l}\text { HIES of Sri Lanka provides information on people's household } \\
\text { income and expenditure to measure their levels and changes } \\
\text { in living conditions. Data collected from this survey are used } \\
\text { to observe the consumption patterns to compute various } \\
\text { other socioeconomic indicators, such as poverty price indexes. } \\
\text { Generally, the survey is conducted over a } 12 \text {-month period to } \\
\text { capture seasonal variations. The general sample size is } 2,500 \\
\text { housing units. }\end{array}$ \\
\hline HIES & $\begin{array}{l}\text { Household Integrated } \\
\text { Economic Survey }\end{array}$ & Pakistan & $\begin{array}{l}2001-02 \\
2004-05 \\
2007-08 \\
2010-11\end{array}$ & $\begin{array}{l}\text { HIES of Pakistan was started in } 1963 \text { and has continued to } \\
\text { be carried out with breaks. It was merged with the Pakistan } \\
\text { Integrated Household Survey in 1998-99 and 2001-02. As } \\
\text { provincial level surveys, they are also part of the Pakistan } \\
\text { Social and Living Standards Measurement surveys. HIES } \\
\text { provides important information on household income, } \\
\text { savings, liabilities, consumption expenditure, and consumption } \\
\text { patterns at national and provincial levels with urban/rural } \\
\text { breakdown. It provides the requisite data on consumption for } \\
\text { estimation of poverty. }\end{array}$ \\
\hline IHDS & $\begin{array}{l}\text { India Human } \\
\text { Development Survey }\end{array}$ & India & 2004-05 & $\begin{array}{l}\text { The IHDS is a nationally representative, multi-topic survey } \\
\text { of } 41,554 \text { households in 1,503 villages and } 971 \text { urban } \\
\text { neighborhoods across India. The first round of interviews was } \\
\text { completed in 2004-05. }\end{array}$ \\
\hline NLSS & $\begin{array}{l}\text { Nepal Living } \\
\text { Standards Survey }\end{array}$ & Nepal & $\begin{array}{l}1995,2003 \\
2010\end{array}$ & $\begin{array}{l}\text { The main objectives of NLSS are to update data on living } \\
\text { standards and assess the impact of various government } \\
\text { policies and programs. Further, the survey tracks changes } \\
\text { experienced by previously enumerated households during the } \\
\text { past } 15 \text { and } 7 \text { years. It enumerated 7,020 households, of which } \\
5,988 \text { were from the cross-section sample and the remaining } \\
\text { 1,032 were from the panel sample. }\end{array}$ \\
\hline NRVA & $\begin{array}{l}\text { National Risk } \\
\text { and Vulnerability } \\
\text { Assessment }\end{array}$ & Afghanistan & 2005,2007 & $\begin{array}{l}\text { NRVA is a nationally representative multipurpose survey, } \\
\text { covering a variety of development sectors and cross-cutting } \\
\text { themes, such as poverty and the position of women. }\end{array}$ \\
\hline NSS & $\begin{array}{l}\text { National Sample } \\
\text { Survey }\end{array}$ & India & $\begin{array}{l}1993-94 \\
2002-03 \\
2004-05 \\
2007-08 \\
2009-10 \\
2011-12\end{array}$ & $\begin{array}{l}\text { NSS is a large, nationally representative household sample } \\
\text { survey program launched for collection of data on the } \\
\text { various aspects of the national economy required by different } \\
\text { agencies of the government, both central and state. }\end{array}$ \\
\hline PSLM & $\begin{array}{l}\text { Pakistan Social and } \\
\text { Living Standards } \\
\text { Measurement }\end{array}$ & Pakistan & $\begin{array}{l}\text { Annually, } \\
2004-05 \text { to } \\
2011-12\end{array}$ & $\begin{array}{l}\text { PSLM is designed to provide social and economic indicators in } \\
\text { the alternate years at provincial and district levels. It provides } \\
\text { a set of representative, population-based estimates of social } \\
\text { indicators and their progress under the Poverty Reduction } \\
\text { Strategy Paper/Millennium Development Goals. The PSLM } \\
\text { surveys are conducted at district and provincial levels, } \\
\text { respectively, in alternate years. The sample size of PSLM surveys } \\
\text { is approximately 80,000 households at district level and } \\
\text { approximately 18,000 at provincial level. }\end{array}$ \\
\hline
\end{tabular}




\section{BOX 2.1 South Asian household surveys used in this report (continued)}

\begin{tabular}{|c|c|c|c|c|}
\hline Acronym & Name & Countries & Years & Description \\
\hline VPA & $\begin{array}{l}\text { Vulnerability and } \\
\text { Poverty Assessment }\end{array}$ & Maldives & 2004 & $\begin{array}{l}\text { VPA covers households on all } 200 \text { inhabited islands. The scope } \\
\text { of the survey includes demographic characteristics, education, } \\
\text { health, and employment of household members, household } \\
\text { housing, economic activities, consumption, and access to } \\
\text { public facilities and services. It also reports information at the } \\
\text { community level. The } 2004 \text { survey is the second round and the } \\
\text { sample size is 2,728. }\end{array}$ \\
\hline
\end{tabular}

Sources: Based on World Bank's PovcalNet tool, http://iresearch.worldbank.org/PovcalNet/index.htm?4, and International Household Survey Network Survey Catalog, http://catalog.ihsn.org/index.php/.

\section{FIGURE 2.1 Based on standard monetary indicators, South Asia has moderate levels of inequality}

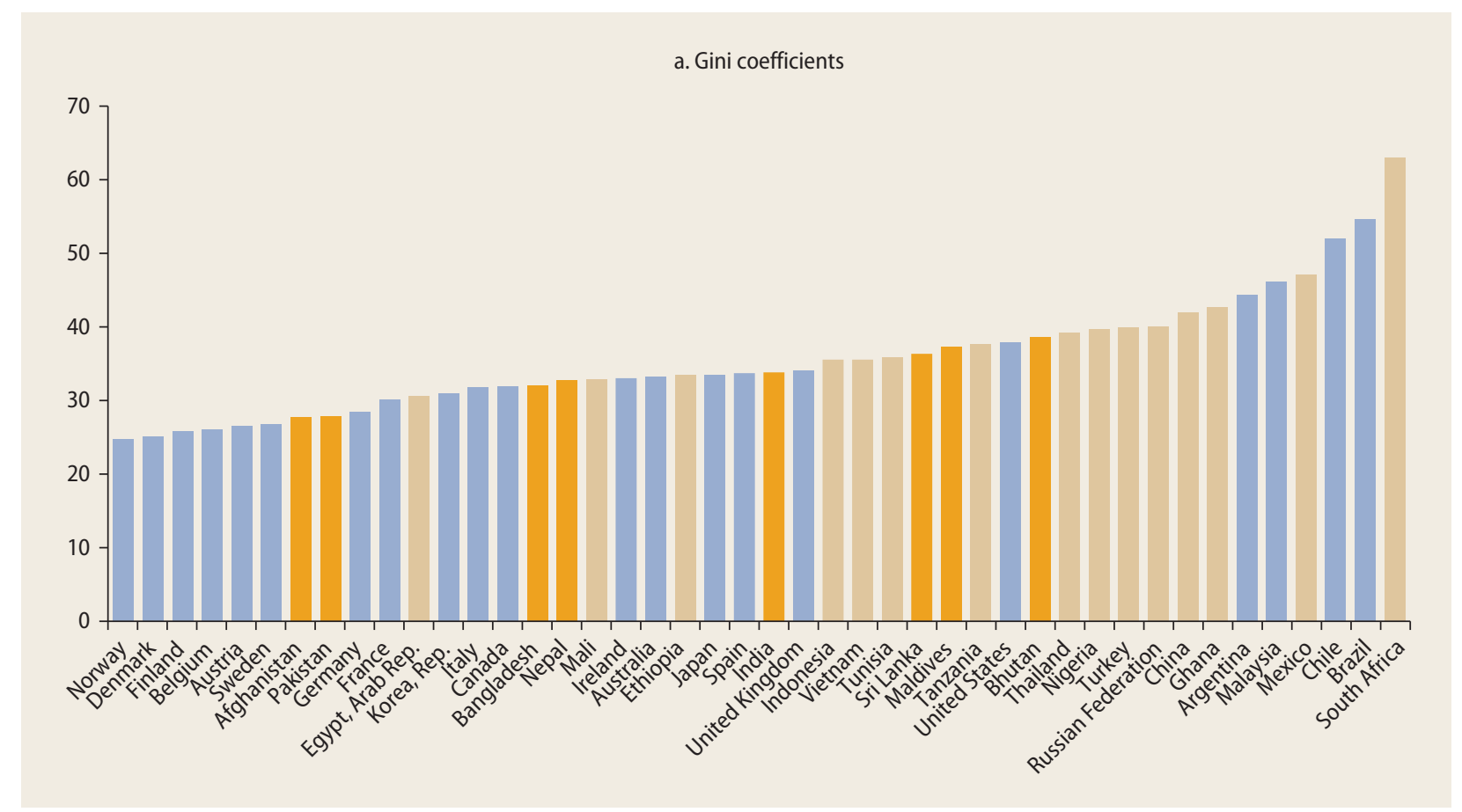




\section{FIGURE 2.1 Based on standard monetary indicators, South Asia has moderate levels of inequality (continued)}

\section{b. Share of the poorest 40 percent}

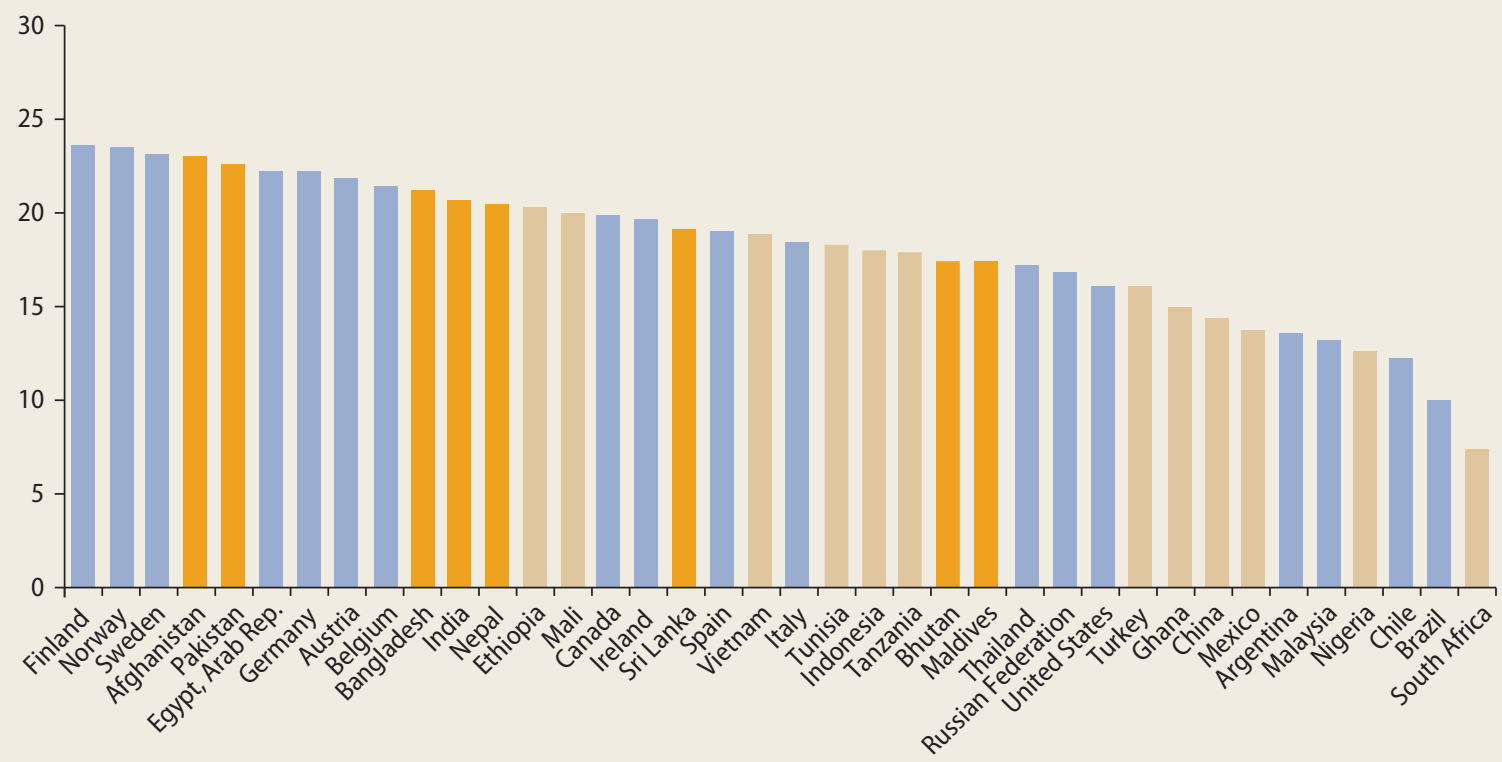

c. Ratio of richest to poorest decile

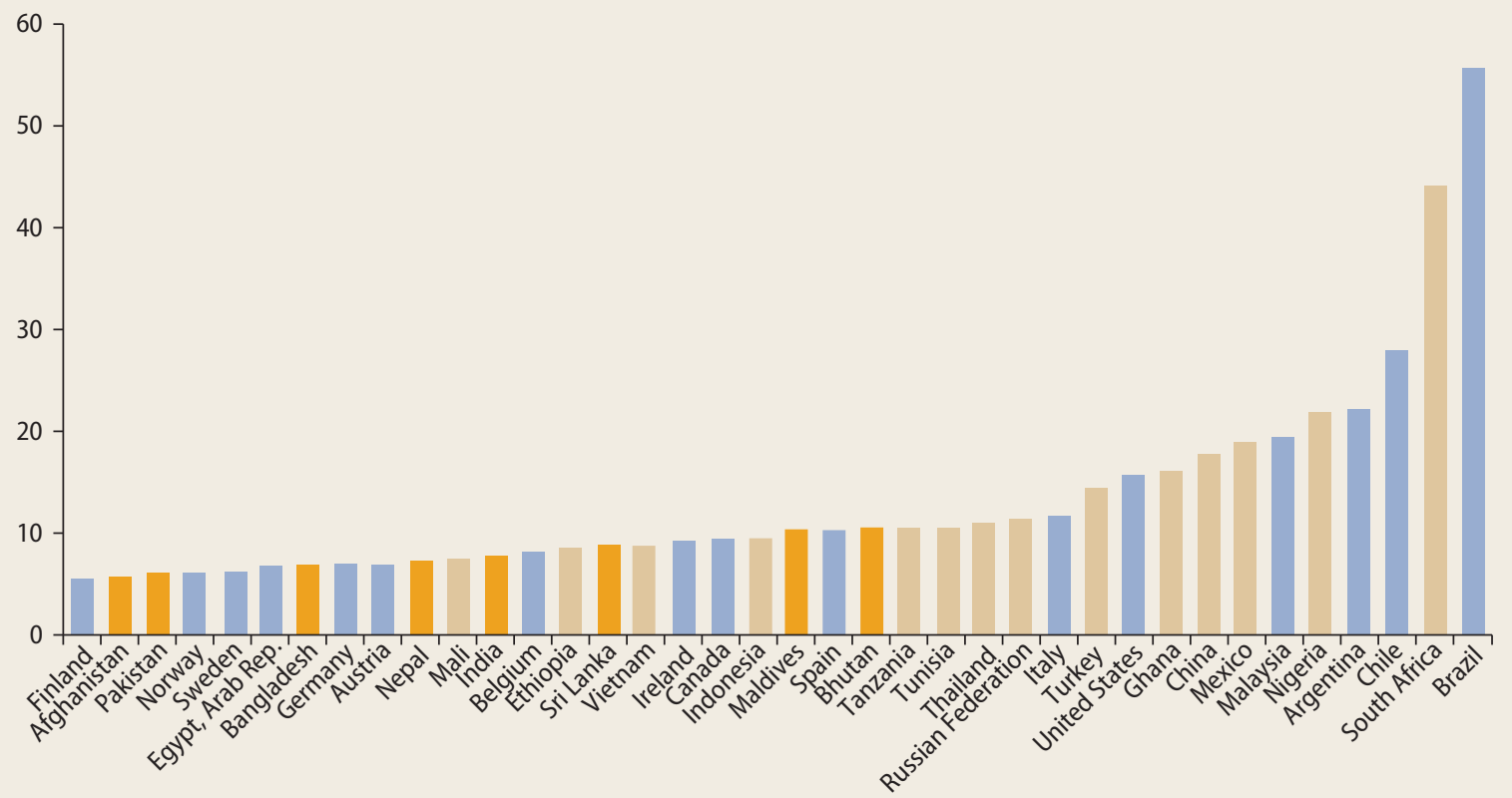

Sources: Based on World Bank's World Development Indicators (WDI) database, http://data.worldbank.org/data-catalog/world-development-indicators, and Organisation for Economic Co-operation and Development's Income Distribution and Poverty data series, http://stats.oecd.org/Index.aspx?DataSetCode=IDD.

Note: Orange and light brown bars indicate countries where inequality is estimated based on consumption per capita. Light blue bars indicate countries with estimates based on income per capita. 
Arguably, the comparison is tainted by the nature of the monetary indicators considered in different countries. In advanced economies, as well as in many Latin American countries, inequality is measured on the basis of income per capita. In South Asian countries, in contrast, most surveys convey information about household expenditure, allowing the estimation of consumption per capita but not of household income. Within a same country, income inequality is generally higher than consumption inequality. However, the conclusion that monetary inequality in South Asia is moderate holds even when comparing only countries for which data on expenditure per capita are available.

Gini coefficients of the most recent available years ranged between 0.28 and 0.40 in South Asian countries. Based on these estimates, inequality in South Asian countries was clearly lower than in China, Mexico, or South Africa. The share of the poorest 40 percent of households in total consumption also suggests that inequality in South Asian countries is not very high by international standards. Within-country inequality looks even less severe based on the gap between the observed extremes: the ratios between top and bottom deciles were smaller than 10 in South Asian countries, whereas the ratio was 19 in Mexico, 22 in Nigeria, and a staggering 44 in South Africa.

The conclusion based on international benchmarking needs to be assessed with several caveats in mind, however. The first is the already mentioned distinction between inequality in consumption per capita and inequality in income per capita. Not many household surveys in South Asia collect accurate data on both, which would allow a direct comparison of measures of inequality based on the two variables. An exception is the 2004-05 IHDS. Based on this survey, the Gini index for consumption was estimated at 0.34 , while the Gini index for income was estimated to be 20 points higher at 0.54 . This is less than the income inequality observed in South Africa, but it is still more than in Mexico.

A second caveat is that household surveys may not capture well the income or the consumption of the richest members of society. The survey questionnaires usually focus on the relatively basic basket of goods and services purchased by those who live around the poverty line. In so doing, they fail to capture the more diverse and sophisticated ways in which the better-off spend their money-and to remind respondents about them. Richer households also tend to shun surveys of this sort. The monetary compensation offered to respondents may provide a sufficient incentive to participate for the poor and near-poor but may be seen as a pittance by wealthier households. The latter may also be concerned about possible tax implications of their responses. One indication of underreporting is the size of the discrepancies between levels and growth rates of consumption as measured by sample surveys and by national accounts. Disconnect between the two major data sources is large in several South Asian countries, especially in India.

Individual tax returns can be used to examine the extent of undercounting of the rich in sample surveys. According to this data source, the income share of India's top 0.01 percent had more than doubled during the 1980s-from less than 0.4 percent to more than 0.8 percent (Banerjee and Piketty 2005). The trend was similar for the top 1 percent in the 1980s. But in the 1990s, a clear divergence arose between what was happening in the top 0.01 percent, and in the rest of the top 1 percent. From the mid1990s to the end of the decade, the share of the top 0.01 percent was in the 1.5 percent to 2 percent range, whereas the share of the top 0.1 percent was in the 3 percent to 4.5 percent range (figure 2.2). The rapid increase in the share of the former suggests that economic growth in recent years was more strongly biased in favor of the ultra-rich.

The rapid growth of income at the top of the distribution goes some way toward explaining the gap observed during the 1990s between average consumption estimates based on sample surveys and those based on national accounts. Assuming that the top 1 percent is not captured by 


\section{FIGURE 2.2 Top incomes have been rising in India since the 1980s}
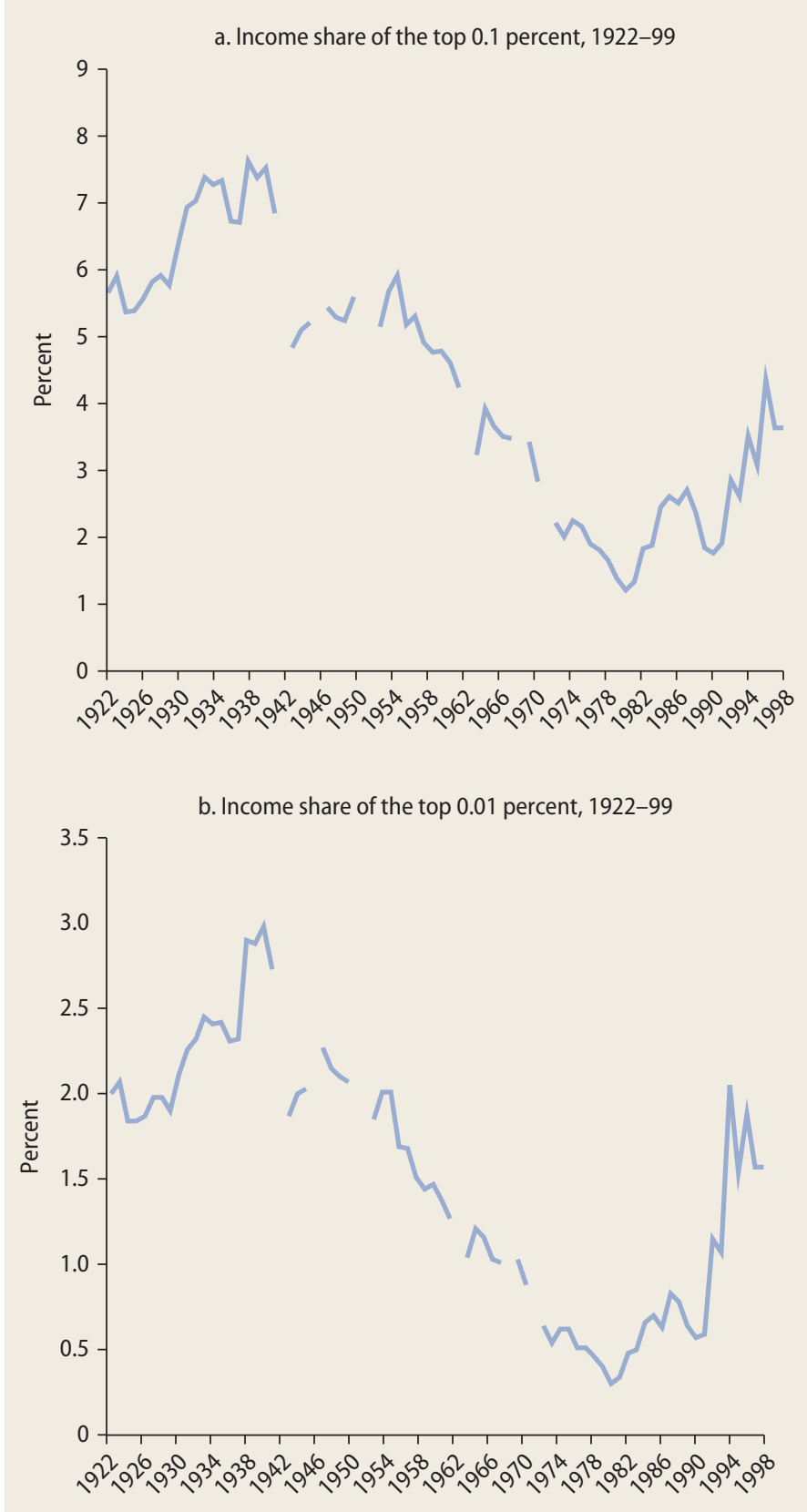

Source: Based on Banerjee and Piketty 2005.

household surveys is not enough to account for the full gap but explains 20 percent to 40 percent of it, depending on the assumptions. This fraction is large enough to give credence to the hypothesis that inequality measures based on consumption are biased downward, probably by a substantial margin.

The distribution of wealth provides a complementary perspective on monetary inequality. Every decade, a special round of the Indian NSS provides comprehensive information on asset holdings and debt for the population at large. The 59th round of the NSS, for example, presented detailed wealth information for both rural and urban households in 2002-03. Eight broad types of assets were covered, including land, building, agricultural machinery, nonfarm business equipment, transportation equipment, consumer durables, and financial assets. Debts included cash loans, in-kind loans, and other payables by households. Net worth is calculated as total financial and nonfinancial assets net of total debts.

This information indicates considerable inequality in asset holdings and in net worth in India. At the household level, the Gini coefficient is 0.668 for asset holdings and 0.680 for net worth; the MLD reaches 1.049 for asset holdings and 1.045 for net worth. As in other countries, the wealth distribution is more concentrated than the distribution of income per capita and especially more concentrated than that of expenditures per capita (figure 2.3).

Perhaps more striking than the extent of inequality is the vulnerability of the least wealthy. Net worth provides a measure of the ability of households to support their consumption in the event of an adverse shock. Households at the bottom are obviously more vulnerable than those at the top. But what is remarkable is how much more vulnerable they are (figure 2.4).

According to this data source, the average net worth of the top 10 percent of the population was more than 380 times that of the bottom 10 percent. For a typical household among the top 10 percent, this net worth could support consumption for more than 23 years. In contrast, for a typical household in the bottom 10 percent, this net worth was sufficient to support consumption for less than three months. 
Measuring the net worth of the betteroff is even more challenging than measuring their income or expenditure. Lack of response and misrepresentation are bound to be even more serious problems, resulting in a distorted picture of the wealth status of the very rich. To address this shortcoming of the data, direct information on billionaire wealth can be useful.

The concentration of billionaire wealth appears to be unusually large in India but much less so in Nepal. These are the only two countries in the region with publicly known billionaires. According to Forbes magazine (2014), total billionaire wealth represented about 10 percent of gross domestic product (GDP) in 2012. As such, India is an outlier in the ratio of billionaire wealth to GDP among economies at a similar development level (figure 2.5).

One concern is whether extraordinary wealth at the top of the distribution is the result of exceptional entrepreneurship or substantial rent seeking. There is no doubt that India has world-class entrepreneurs, commanding admiration for their innovation and management capacity, and many of them operate successfully in highly competitive global markets. At the same time, over a quarter of India's billionaire wealth is estimated to be inherited, 40 percent is based on inheritance, and 60 percent originates from "rent-thick sectors" such as real estate, infrastructure, construction, mining,

\section{FIGURE 2.3 The distribution of wealth is more concentrated than that of consumption in India}

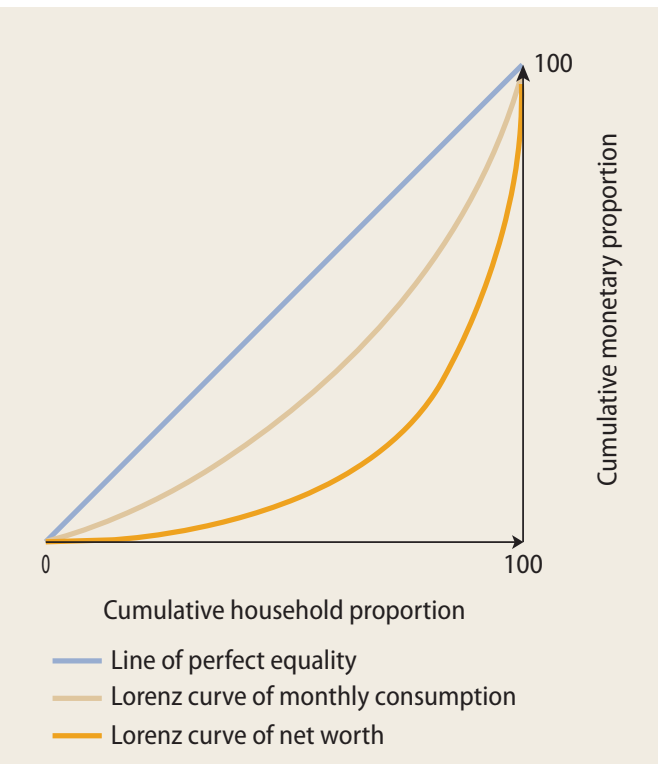

Source: Based on NSS 2002-03

\section{FIGURE 2.4 The least wealthy are alarmingly vulnerable}

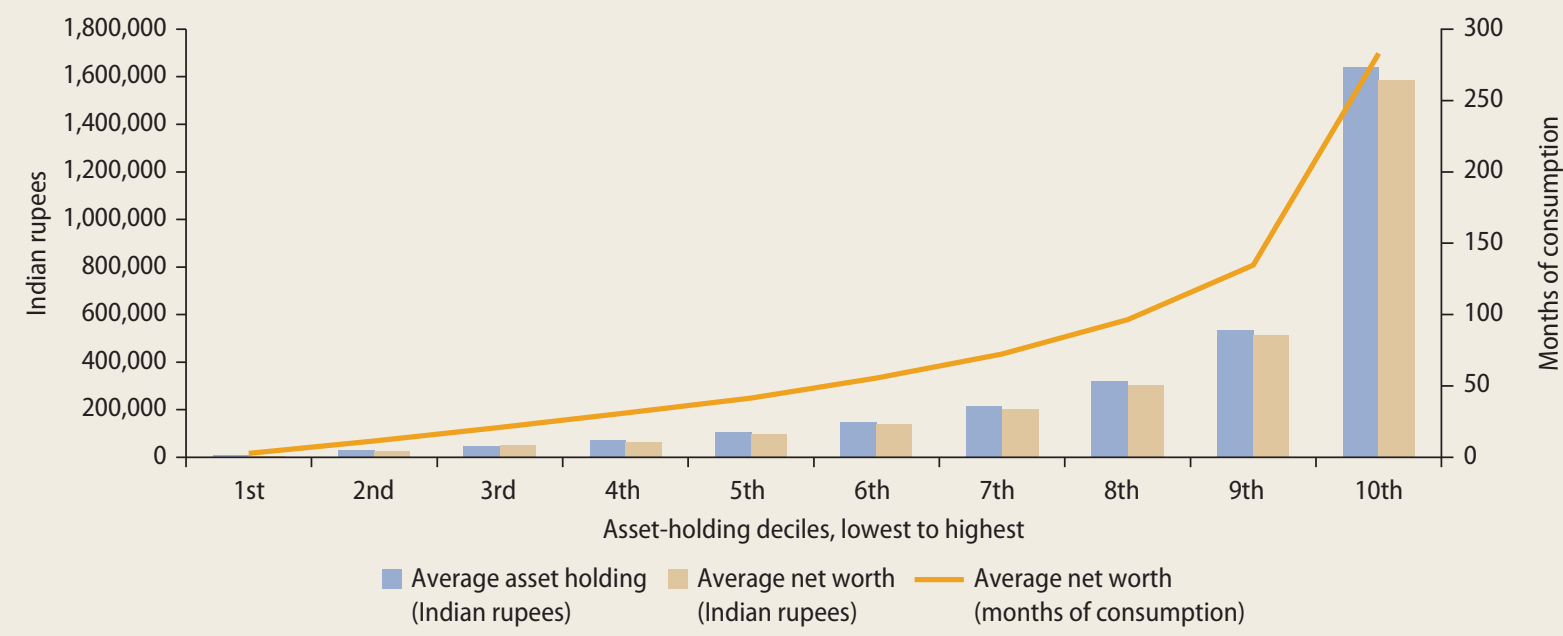


FIGURE 2.5 Billionaire wealth in India is exceptionally large

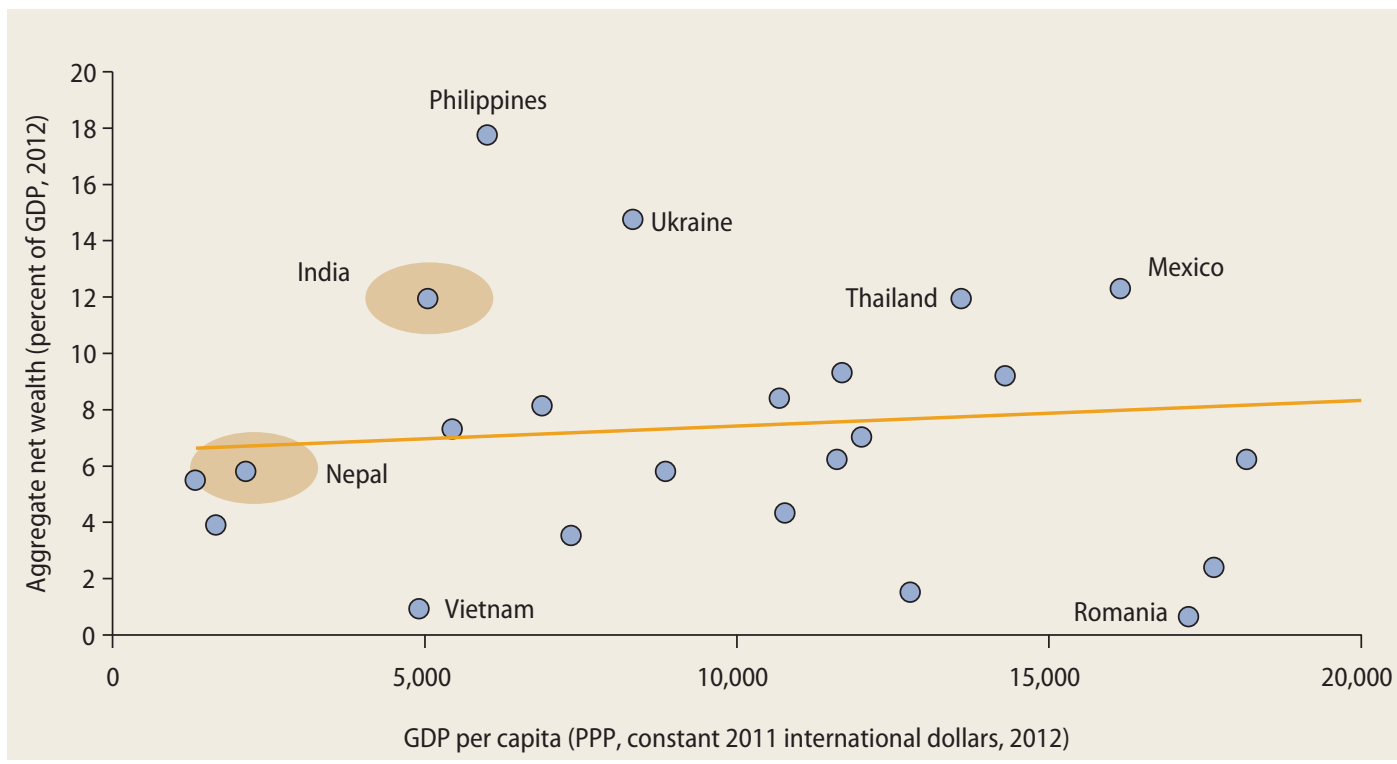

Sources: Based on Forbes magazine's billionaires database, http://www.forbes.com/billionaires/, and World Bank's WD/ database, http://data.worldbank.org /data-catalog/world-development-indicators.

Note: $\mathrm{PPP}=$ purchasing power parity.

telecommunications, cement, and media. This does not necessarily mean that wealth was acquired through the legal or illegal exercise of influence, but highlights that the potential for rent extraction exists (Gandhi and Walton 2012).

\section{Nonmonetary dimensions of inequality}

Both monetary and nonmonetary indicators capture important dimensions of inequality in outcomes. And they tend to be correlated, as shown by the fact that health status or educational attainment is typically higher among people who are better off in monetary terms. But the correlation is not perfect because monetary and nonmonetary indicators capture different concepts and can vary independently. Therefore, nonmonetary indicators provide additional information on distribution of well-being, beyond what is provided from monetary indicators of inequality.

Nonmonetary dimensions of inequality include the dispersion in human capabilities as reflected, for example, in health and education outcomes. Differences in these outcomes can affect individuals' abilities to do what they would value doing and to convert different means into well-being. Sen $(1980,1992)$ often takes the case of a person with physical disabilities to illustrate the point: such a person cannot function in the way an able-bodied person can. It follows that the extent of deprivation of a person with physical disabilities in comparison with others cannot be adequately judged by looking at incomes, because the person may be greatly disadvantaged in converting income into the desirable achievements. The same logic can be applied to a person who is malnourished, ill, or illiterate.

Nonmonetary indicators of well-being are very unevenly distributed among the South Asian population. A comparison of health outcomes across population quintiles, defined by a wealth index, is revealing in this respect. Gaps in neonatal mortality (death within the first 28 days of life) and in under-five child 
mortality (death within the first five years of life) between the top and the bottom quintiles are large, especially in India and Pakistan. For children who live, the main challenge is to be well nourished. Children (under two years old) belonging to the poorest quintile are more likely to be stunted in every country in the region, although the gap is relatively less glaring in Sri Lanka and the Maldives (figure 2.6).

By international standards, the health outcomes of the poor in South Asia are among the worst worldwide. The share of children (under five years old) who are stunted among the poorest quintile is above 50 percent in Bangladesh and Nepal and reaches 60 percent in India (figure 2.7). India and Pakistan also have some of the highest infant mortality rates and under-five child mortality rates in the poor across all comparators. Of 1,000 children born in India's poorest population quintile, 82 will die within 12 months and 117 within five years. The figures for Pakistan are 94 and 120, respectively.

Inequality in educational attainment is large as well, although showing wide differences across the region. From an international perspective, countries in South Asia seem to lie at both ends of the developing-country range. Among the countries for which comparable data are available, Maldives and Sri Lanka exhibit the lowest gaps in educational attainment between the population quintiles with the highest and the lowest expenditures per capita (figure 2.8). At the other end, gaps in Nepal, Afghanistan, and especially Bhutan are larger than elsewhere.

However, the international comparison is highly sensitive to the age group considered, because educational attainment is expanding rapidly throughout the region. The ratio of the years of education between the richest and the poorest quintiles in the distribution is generally high among people 20 to 29 years of age (figure 2.9), but gaps are being eliminated at the primary level, as reflected in the moderate dispersion in years of education among children 6 to 11 years of age. Again, there is considerable diversity, with Maldives, Sri Lanka, and Bangladesh being the countries with the lowest levels of inequality. But the dispersion is much narrower among younger population cohorts.

For the younger South Asian cohorts, inequality in relation to education is increasingly driven by quality, rather than by access. Evidence on learning outcomes is sparser than data on educational attainment, but it is quite consistent (World Bank 2013). An important source of information on the extent of cognitive skills acquired in school is a study that covered 2,399 government-run schools in India in 2009 (Educational Initiatives 2010). The coverage included samples from approximately 74 percent of the population from both urban and rural India. The actual number of test takers was 101,643 , representing a presence rate of 66 percent-more or less in line with the regular presence rate found in government schools-and about 5,600 teachers took the background questionnaires.

Average test performance was low: students scored barely 50 percent in grade 4 , between 46 and 48 percent in grade 6 , and between 46 and 47 percent in grade 8 . But considerable dispersion existed in test scores across students from different backgrounds. The inequality in learning outcomes can be seen by comparing test scores of children whose households have both a radio and a television to those who have neither (figure 2.10). The mean test scores for students in the first group are higher across the entire distribution than for those from the second group, especially in the lower grades.

Gaps in learning outcomes are large in other countries of the region as well. Bangladesh and Sri Lanka have achieved a high level of equality in years of schooling, but learning outcomes differ significantly across income groups. In Bangladesh, student achievement in English was 250 percent higher among the richest quintiles than among the poorest. In written math competency, the difference was more than 100 percent 


\section{FIGURE 2.6 Gaps in health outcomes are wide}

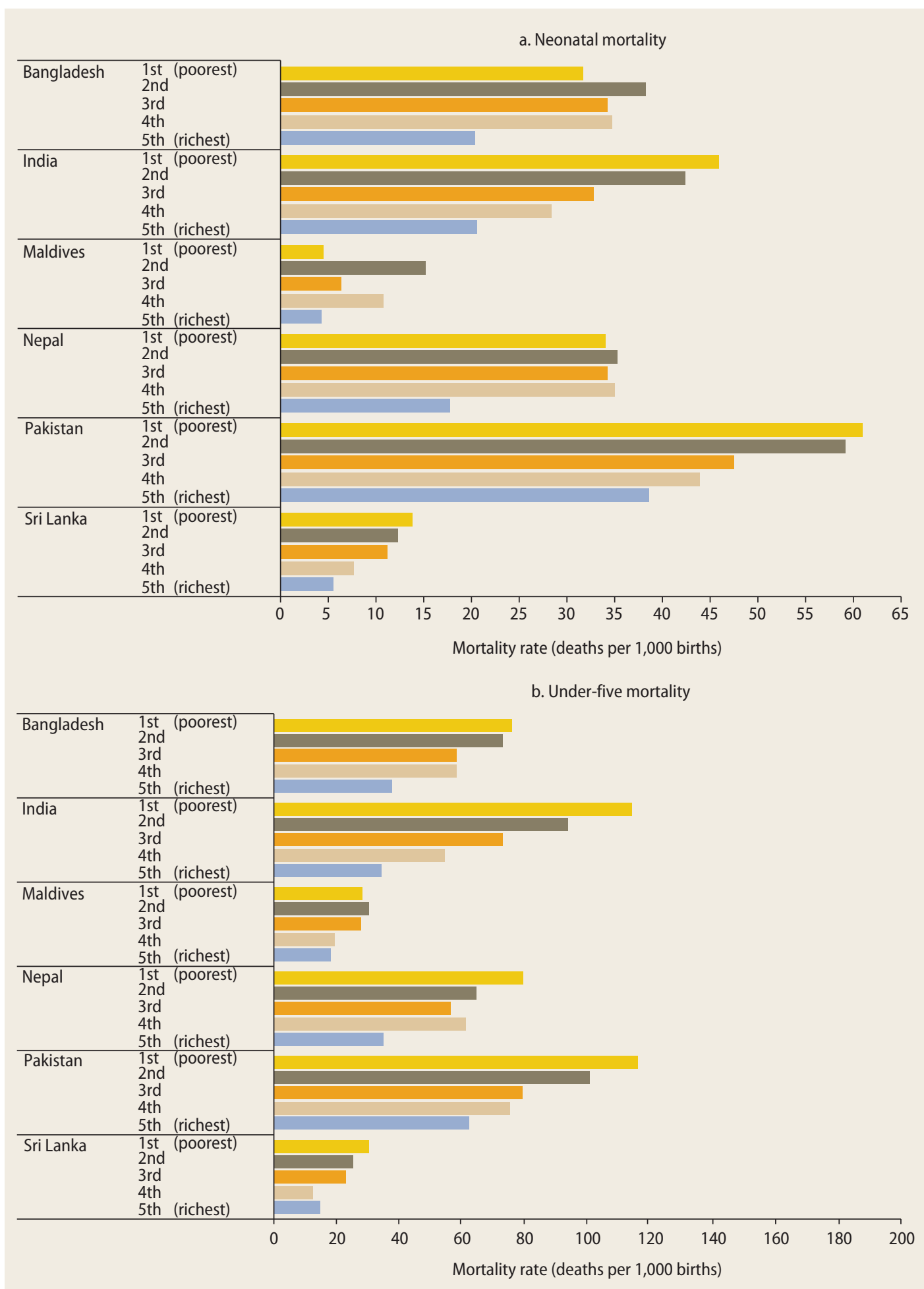


FIGURE 2.6 Gaps in health outcomes are wide (continued)

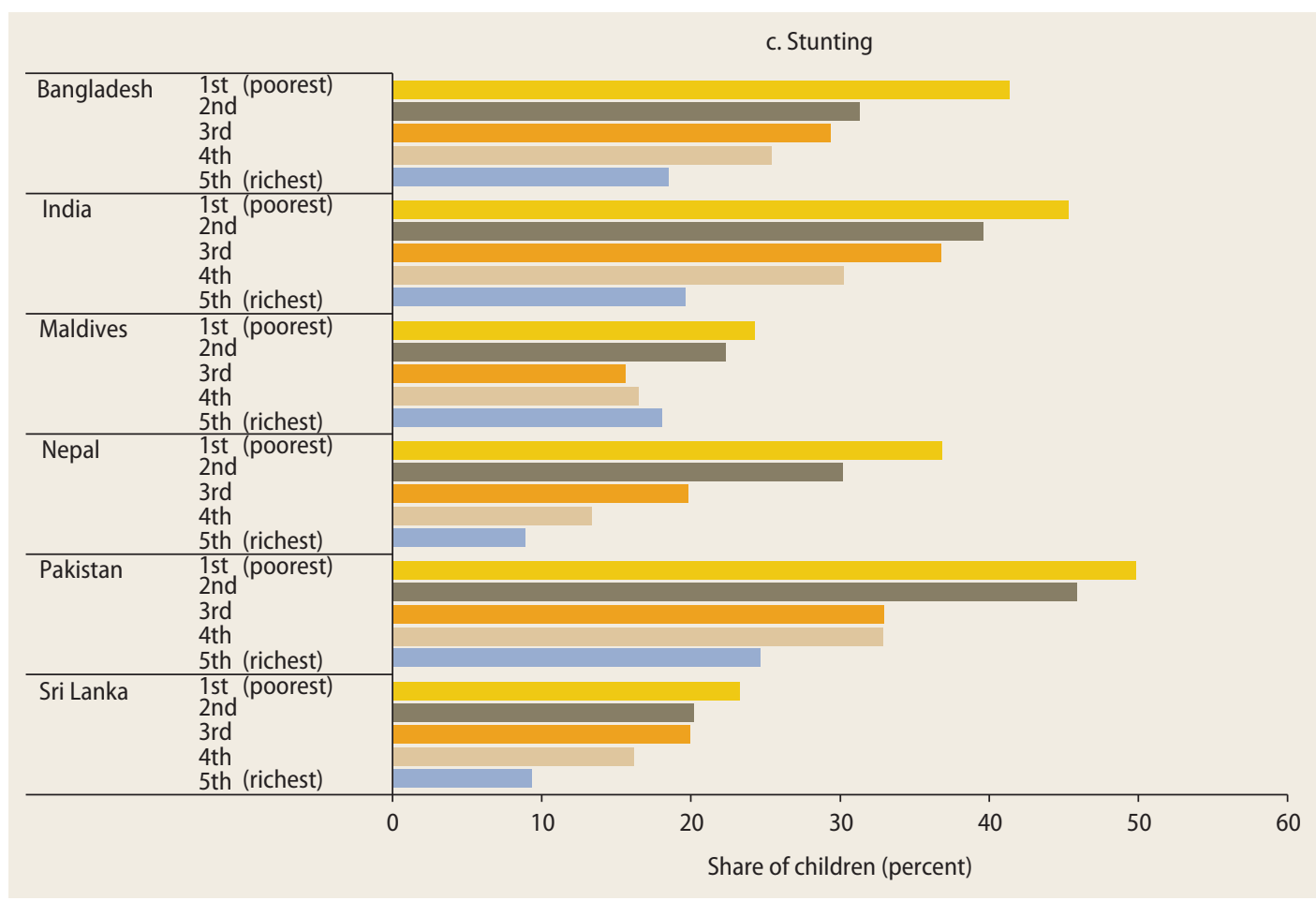

Sources: Based on DHS 2011 for Bangladesh, DHS 2005 for India, DHS 2009 for Maldives, DHS 2011 for Nepal, DHS 1990 for Pakistan, and DHS 2007 for Sri Lanka.

Note: Neonatal mortality rate is the number of deaths within the first 28 days of life per 1000 live births. Under-five mortality rate is the number of deaths to children younger than five years per 1,000 live births. Stunting is the percentage of children younger than two years whose height-for-age ratio is two standard deviations or more below the World Health Organization (WHO) Child Growth Standards.

(Asadullah and others 2009). In Sri Lanka, the test scores were a full standard deviation higher among students from the richest quintiles, relative to those from the poorest students (Aturupane, Glewwe, and Wisniewski 2013). Learning outcomes are also closely related to ethnicity. In Nepal, Madhesis and Dalits score much lower than other ethnic groups. In Sri Lanka, Burgher children score highest on standardized tests and Tamil children lowest (World Bank 2013).

\section{Monetary inequality is increasing}

Growth has been effective at reducing poverty in South Asia, as it was earlier in East Asia. In both regions, higher levels of income per capita have been associated with a lower share of the population living on less than $\$ 1.25$ a day in purchasing power parity (PPP). The pattern is clearly discernable when plotting comparable estimates of the poverty rate for countries in the two regions against the income per capita (also in PPP terms) those countries had in the years to which the poverty rates refer (figure 2.11). East Asian countries are on average richer than their South Asian counterparts, but both regions demonstrate enough diversity in incomes per capita to find countries at almost any point in the range from low- to middle-income levels of development.

The steepness of the relationship between the poverty rate and income per capita indicates how good growth has been for the poor. For instance, the lower the initial poverty rate, the more difficult is achieving 


\section{FIGURE 2.7 The health outcomes of the poor are among the worst worldwide}

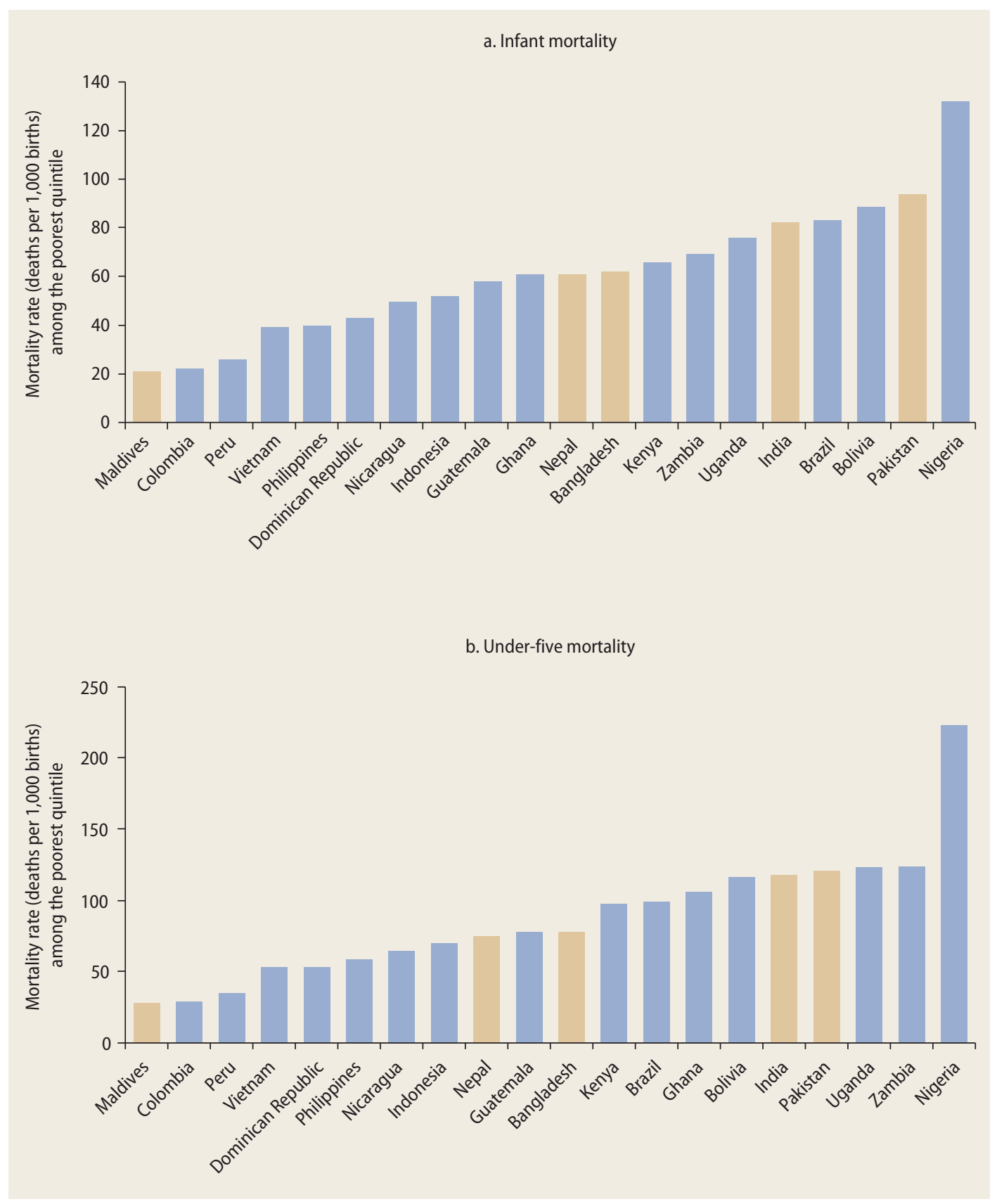

(continues next page) 


\section{FIGURE 2.7 The health outcomes of the poor are among the worst worldwide (continued)}

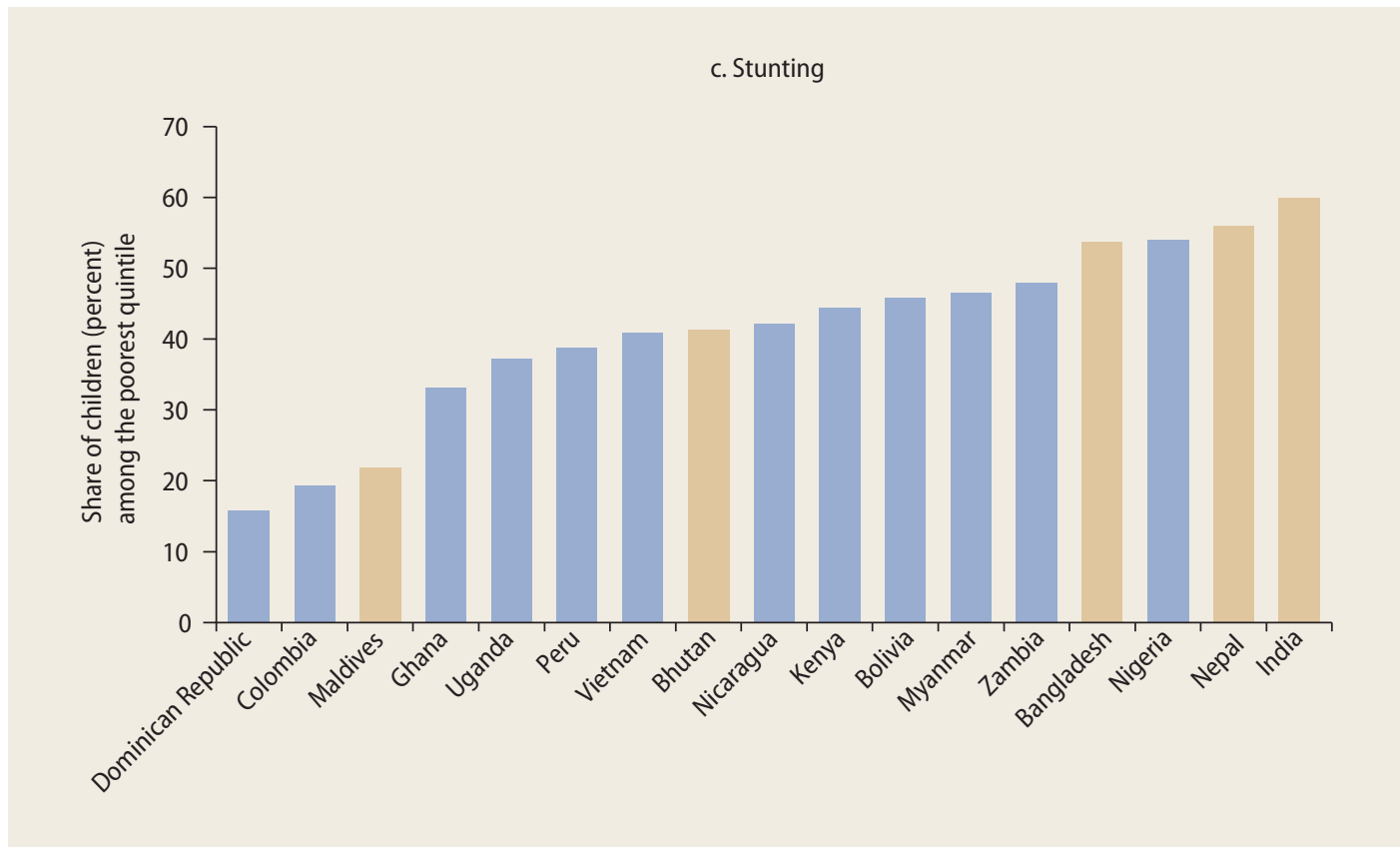

Source: Based on World Bank Health Nutrition and Population Statistics database, http://datatopics.worldbank.org/hnp/WealthQuintiles. Note: Infant mortality rate is the number of deaths to children younger than 12 months per 1,000 live births. Under-five mortality rate is the number of deaths to children younger than five years per 1,000 live births. Stunting is the percentage of children younger than five years whose $z$-scores are two standard deviations or more below WHO Child Growth Standards.

\section{FIGURE 2.8 Schooling among young adults is highly unequal in some countries in South Asia}

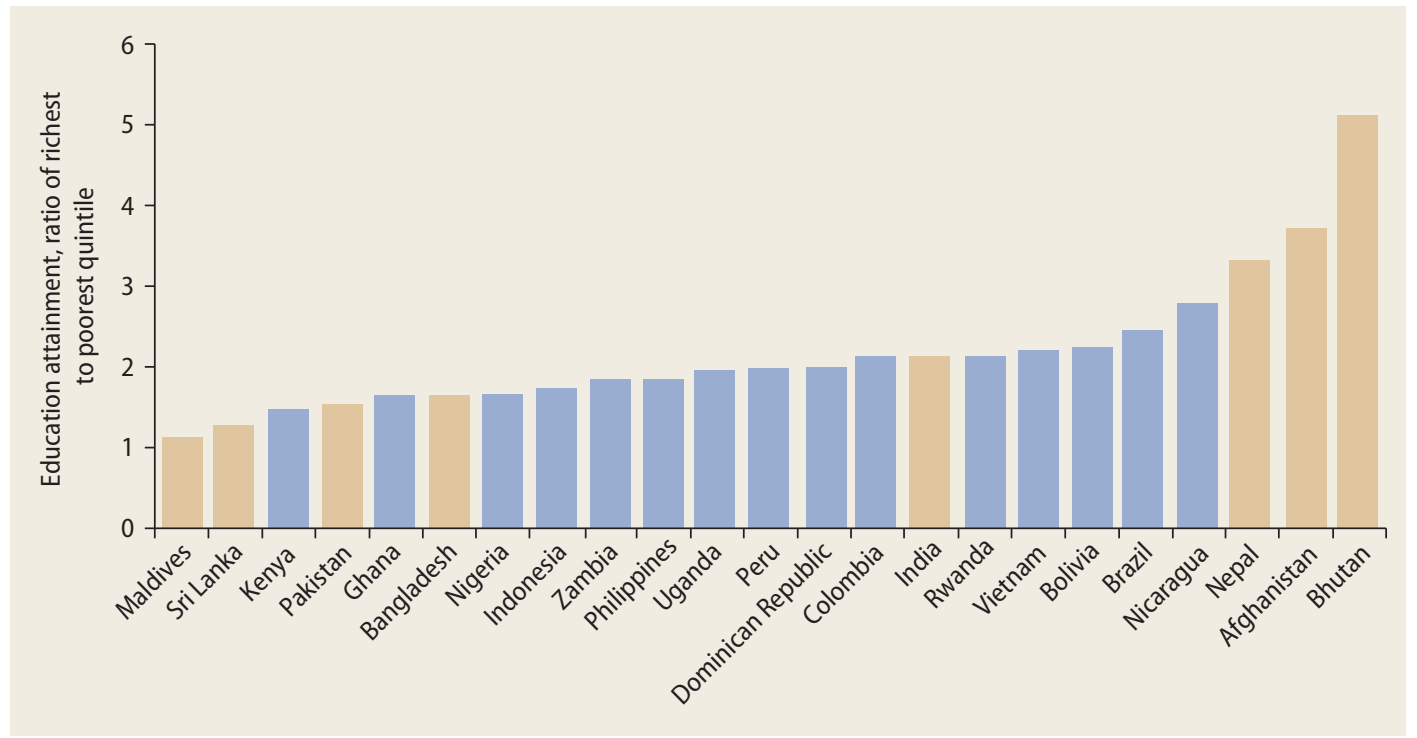

Sources: Based on NRVA 2007 for Afghanistan, HIES 2010 for Bangladesh, BLSS 2007 for Bhutan, NSS 2009-10 for India, HIES 2009-10 for Maldives, NLHS 2010 for Nepal, HIES 2010-11 for Pakistan, HIES 2009-10 for Sri Lanka, and World Bank Education Equality Country Profiles database, http://datatopics.worldbank .org/Education/wDHS/HProfiles.aspx.

Note: Educational attainment is measured in years of schooling. The population considered are 20 to 29 years of age. 


\section{FIGURE 2.9 Gaps in educational attainment are much narrower among children than among adults}

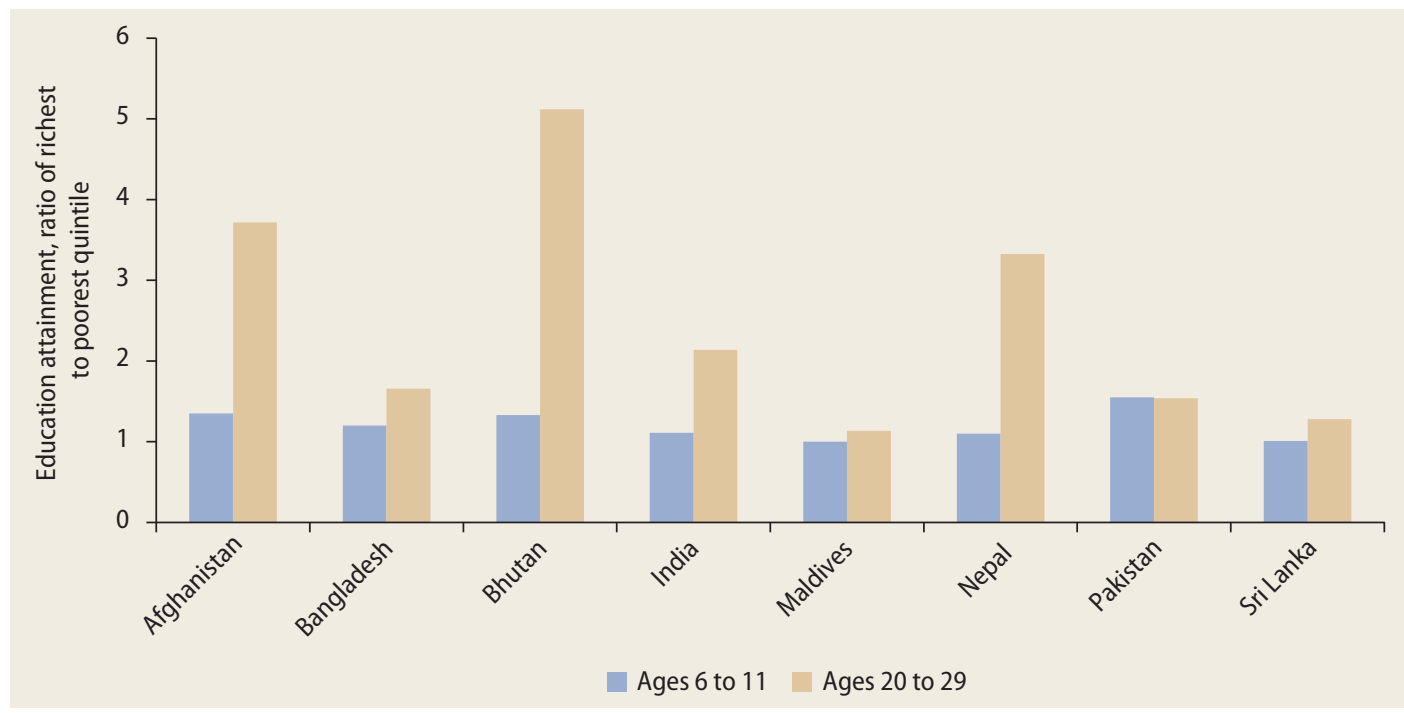

Sources: Based on NRVA 2007 for Afghanistan, HIES 2010 for Bangladesh, BLSS 2007 for Bhutan, NSS 2009-10 for India, HIES 2009-10 for Maldives, NLHS 2010 for Nepal, HIES 2010-11 for Pakistan, and HIES 2009-10 for Sri Lanka.

Note: Educational attainment is measured in years of schooling.

\section{FIGURE 2.10 Among children, similarities in schooling hide disparities in learning in India}

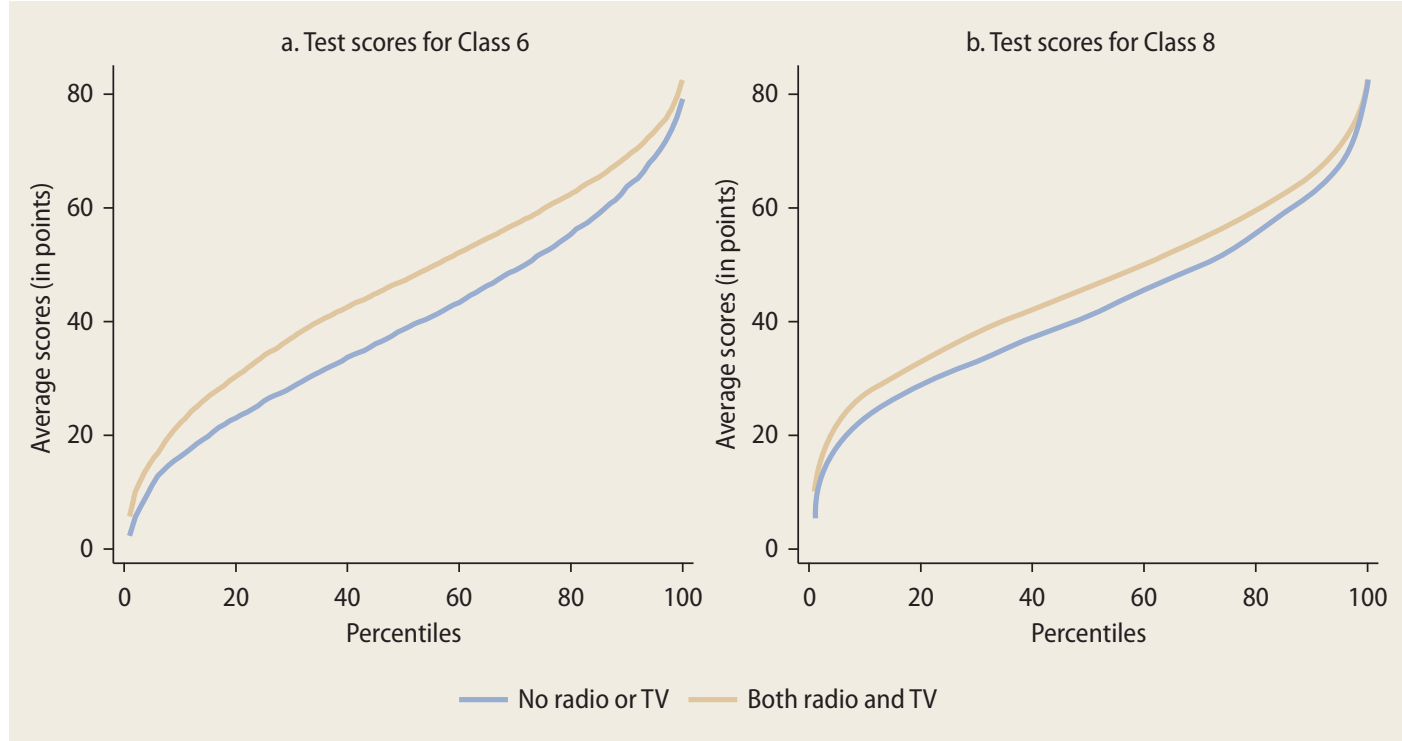

Source: Based on Educational Initiatives 2010. 


\section{FIGURE 2.11 Growth is reducing poverty in South Asia, as it did in East Asia}
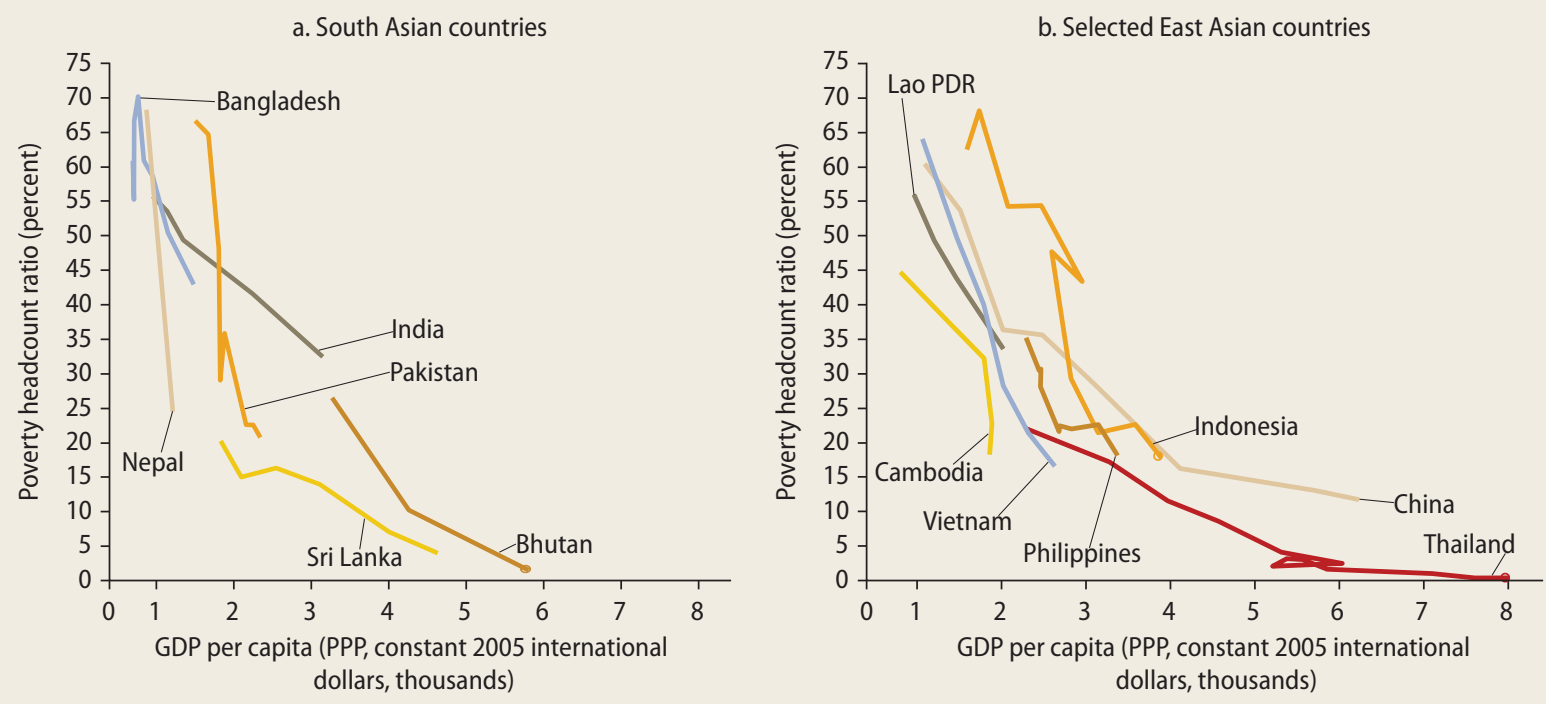

Sources: For South Asia, based on HIES 2000, 2005, and 2010 for Bangladesh; BLSS 2003 and 2007 for Bhutan; NSS 1993-94, 2004-05, and $2009-10$ for India; NLSS 1995 and 2010 for Nepal: HIES 2001-02, 2004-05, 2007-08, and 2010-11 for Pakistan (Punjab); and HIES 1995, 2002, 2006, and 2009 for Sri Lanka. For East Asia, based on the World Bank's WDI database, http://data.worldbank.org/data-catalog/world-development-indicators and PovcalNet tool, http://iresearch.worldbank.org/PovcalNet/index.htm: 1994-2009 for Cambodia, 1990-2009 for China, 1984-2010 for Indonesia, 1992-2008 for Lao PDR, 1985-2009 for Philippines, 1981-2010 for Thailand, and 1993-2008 for Vietnam.

Note: The headcount ratio is based on $\$ 1.25$ a day (PPP, constant 2005 international dollars). PPP $=$ purchasing power parity.

a steep reduction in poverty for the same growth in income per capita. Thus, the decline in poverty is gentler in Thailand, where the initial poverty rate (in 1980) was less than 25 percent, than it is in Vietnam, where the initial poverty rate was close to 65 percent (in 1992). Up to 2010, India had the gentlest rate of poverty decline among the South Asian countries, but preliminary analyses based on data for 2011-12 suggest that the speed of poverty reduction has accelerated substantially in recent years.

Growth has also led to increasing inequality in both regions. The relationship can be visualized by replacing the poverty rate considered in the previous analysis by the MLD of per capita consumption. In South Asia, the consumption of a randomly selected individual is between 10 percent and 30 percent lower than the average consumption per capita (figure 2.12). That is less than the average inequality observed in East Asian countries when they were at similar levels of income per capita. However, in both regions, countries with a higher income per capita are characterized by higher inequality.

Of course, no mechanical relationship exists between growth and inequality. A well-known hypothesis in development economics-known as the Kuznets curveis that inequality initially increases as countries grow into middle-income levels and then decreases as they become richer. But the empirical evidence on this relationship is mixed (Milanovic 2011). In addition, the extent of inequality depends on policy choices and not just on some economic fate. In East Asia, for instance, substantial heterogeneity exists, with increases in inequality in China and Indonesia that are higher than those observed in South Asia. The stable inequality displayed by Vietnam and the decline in inequality observed in Thailand are additional indications that inequality does not inevitably increase as GDP per capita grows.

Overall, inequality increases about as often as it falls during spells of growth 


\section{FIGURE 2.12 Richer countries tend to be more unequal in both South Asia and East Asia}
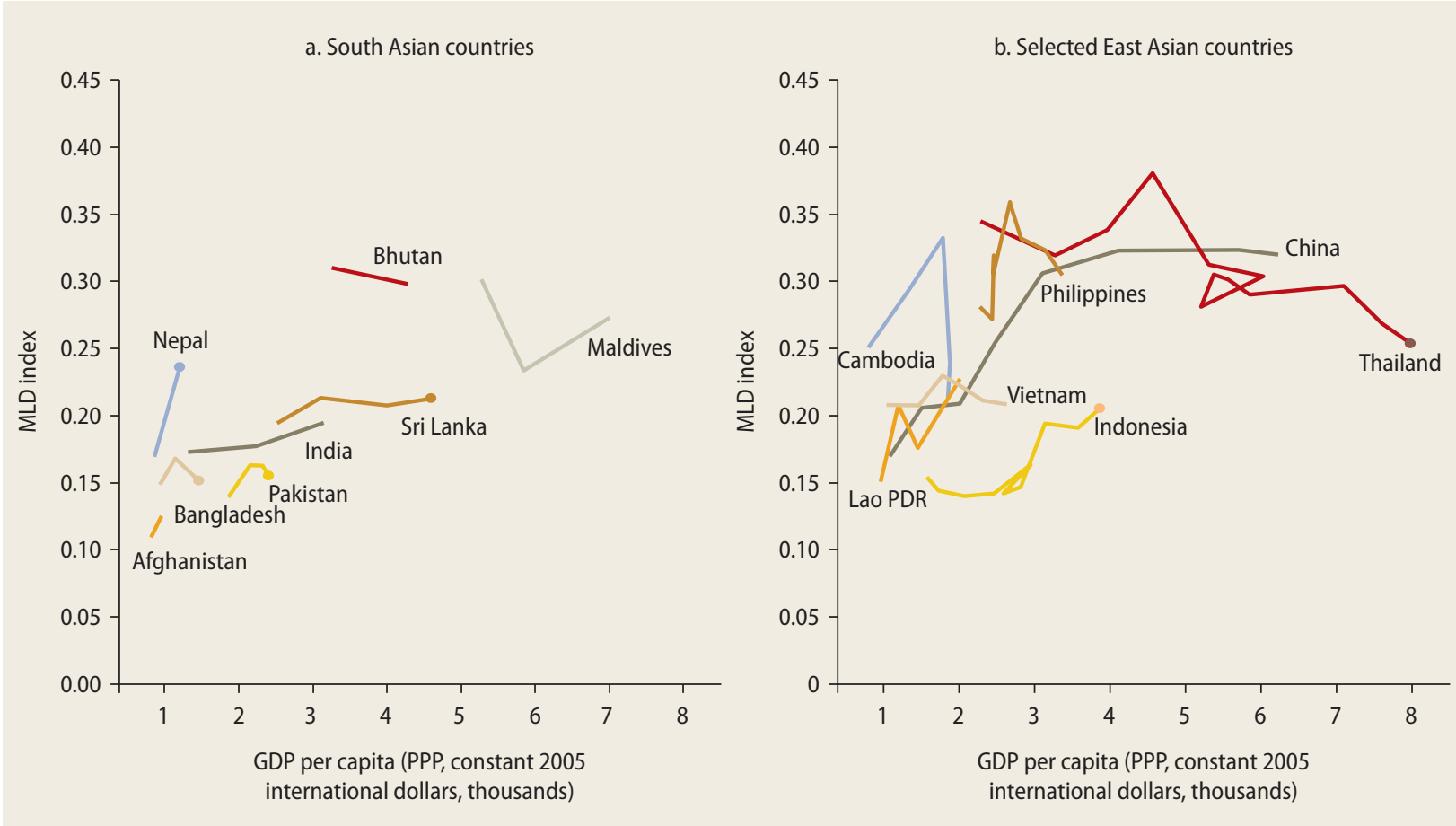

Sources: For South Asia, based on NRVA 2005 and 2007 for Afghanistan; HIES 2000, 2005, and 2010 for Bangladesh; BLSS 2003 and 2007 for Bhutan; NSS 1993-94, 2004-05, and 2009-10 for India; HIES 2002-03 and 2009-10, and Vulnerability and Poverty Assessment (VPA) 2004 for Maldives; NLSS 1995 and 2010 for Nepal; HIES 2001-02, 2004-05, 2007-08, and 2010-11 for Pakistan (Punjab); and HIES 1995-95, 2002-03, 2006-07, 2009-10 for Sri Lanka. For East Asia, based on the World Bank's WD/ database, http://data.worldbank.org /data-catalog/world-development-indicators and PovcalNet tool, http://iresearch.worldbank.org/PovcalNet/index.htm: 1994-2009 for Cambodia, 1990-2009 for China, 1984-2010 for Indonesia, 1992-2008 for Lao PDR, 1985-2009 for Philippines, 1981-2010 for Thailand, and 1993-2008 for Vietnam.

Note: MLD = mean log deviation; PPP = purchasing power parity.

(Ferreira and Ravallion 2008). New data actually reveal less income inequality in the developing world than 30 years ago because of falling inequality between countries. Average inequality within developing countries has been slowly rising, though staying fairly flat since 2000 . As a rule, higher rates of growth in average incomes have not put upward pressure on inequality within countries (Ravallion 2014).

For the world as a whole, when average consumption per capita increases by 1 percent, the consumption per capita of the poorest 20 percent of the population increases by 1.057 percent (figure 2.13). The corresponding figure for the poorest 40 percent of the population is 1.004 percent. None of these estimates is significantly different from 1.0 percent, meaning that growth is neutral overall with respect to distribution (Dollar, Kleineberg, and Kraay 2013).

That said, a rigorous statistical analysis of the available microeconomic data across countries suggests that growth has been more propitious to inequality in South Asia-and especially in East Asiathan elsewhere. Looking at the preceding analysis by geographical region, one can see that for the combined East and South Asia regions the estimated elasticity of the consumption per capita of the poorest with respect to average consumption per capita is substantially lower than 1.0 percent in both the 1990s and the 2000s (and significantly so in the 1990s) (figure 2.13). The fastest-growing countries, notably China, have increases in income inequality, making the income growth of the bottom 


\section{FIGURE 2.13 Prosperity has been shared less widely in South and East Asia}

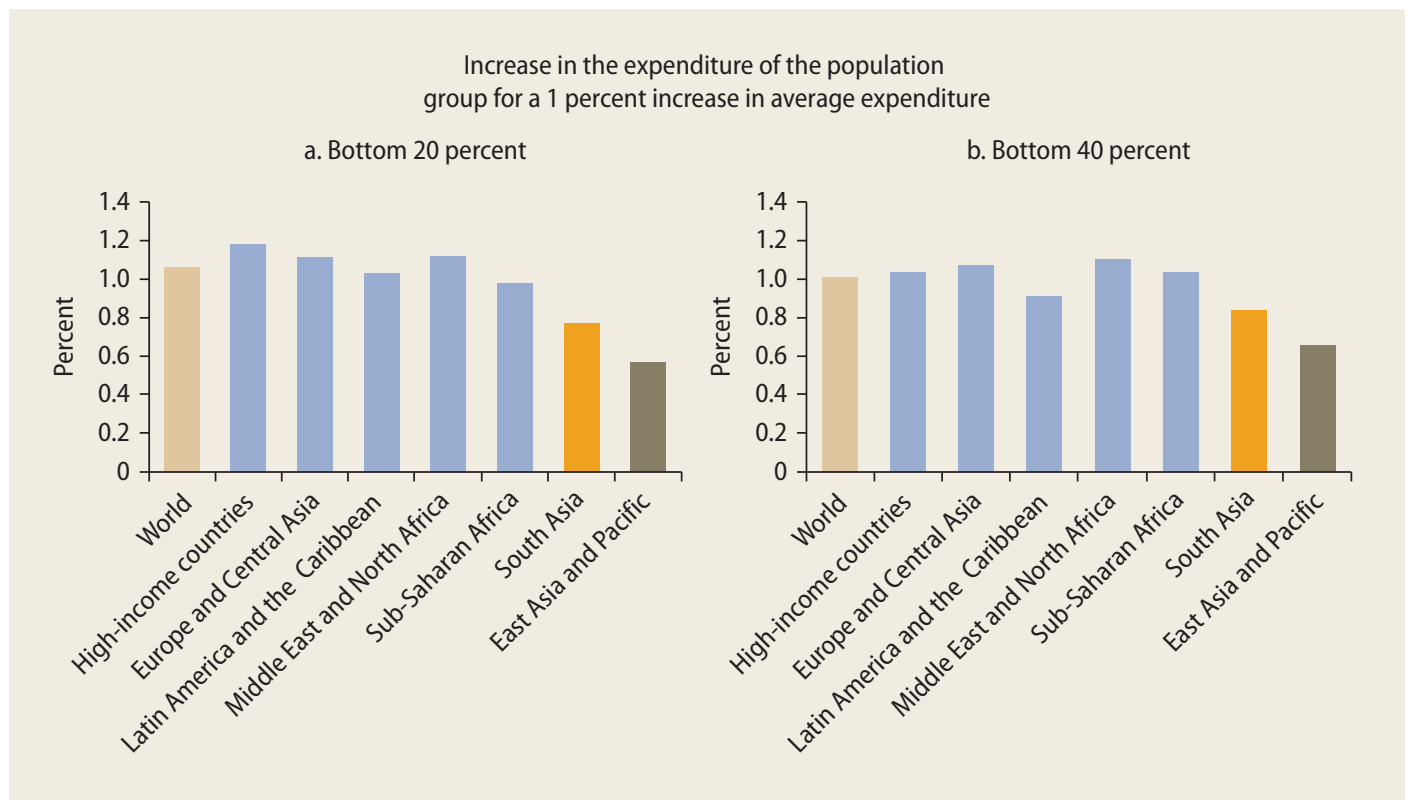

Source: Dollar, Kleineberg, and Kraay 2013

Note: Data are from 118 countries for which household surveys are available for at least two years since the 1970s.

40 percent lag behind average income growth. Latin America shows the opposite tendency in the 2000 s, with an estimate greater than 1.0 percent for the bottom 20 percent. This means that in fastergrowing Latin American countries, the income shares of the bottom quintiles also increased more.

Consistent with the Kuznets curve hypothesis, monetary indicators of inequality have increased in the poorest countries in the South Asia region in recent years, whereas they have decreased in the richest ones (figure 2.14). However, the only two countries for which a decrease is observable have a combined population of less than 1 million people, in a region accounting for a fourth of humankind. The vast majority of South Asians have experienced an increase in inequality, sometimes at a fast pace.

Although wealth data are available for only India, they suggest that inequality has persisted or slightly widened over the last few decades. The Gini coefficients for asset holdings and net wealth remained roughly
FIGURE 2.14 Monetary inequality is increasing across most of South Asia

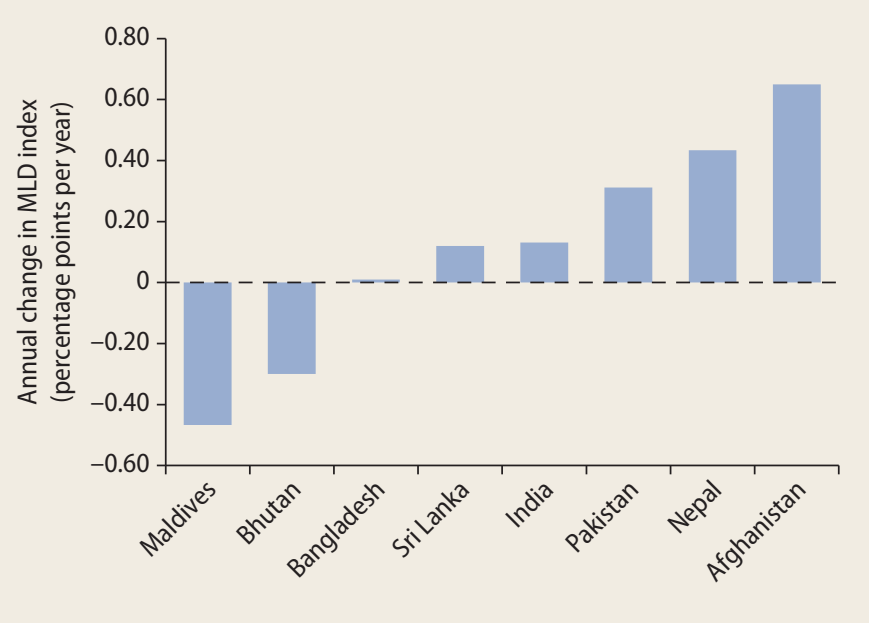

Sources: Based on NRVA 2005 and 2007 for Afghanistan, HIES 2000 and 2010 for Bangladesh, BLSS 2003 and 2007 for Bhutan, NSS 1993-94 and 2009-10 for India, NLSS 1995 and 2010 for Nepal, HIES 2002-03 and 2009-10 for Maldives, HIES 2001-02 and 2010-11 for Pakistan (Punjab), and HIES 1995-95 and 2009-10 for Sri Lanka.

Note: $\mathrm{MLD}=$ mean log deviation 
constant between 1991-92 and 2002-03. An analysis going back to 1961-62 confirms this rough stability (Subramanian and Jayaraj 2008). Meanwhile, the ratio of billionaire wealth to GDP has increased substantially in India, suggesting an increasing concentration of wealth at the top. The ratio rose from around 1 percent in the mid-1990s to 22 percent at the peak of the economic boom in 2008; the ratio was still about 10 percent of GDP in 2012 (Gandhi and Walton 2012).

\section{Mixed trends in nonmonetary inequality}

Although monetary indicators of well-being show that inequality has been on the rise in most of South Asia, the picture that emerges from nonmonetary indicators is less clearcut. Health outcomes show signs of widening inequality (figure 2.15). The ratios between the neonatal and under-five child mortality rates of the population quintiles with the highest and the lowest expenditures per capita have either stayed constant or increased in most countries. Bangladesh had a reduction in inequality in neonatal mortality. All other countries for which data are available at two points in time, on all indicators, show an increase in inequality in health outcomes. The increase is especially marked in the case of stunting.

This increase in inequality is not inconsistent with absolute progress for all population groups, reflecting cumulative improvements in coverage of a range of services in health as well as improvements in living standards, rising parental education, and decreasing barriers to access basic services. But progress generally has been faster among the better-off.

In contrast, inequality in education outcomes has unambiguously been on a downward trend (figure 2.16). Gaps in educational attainment among children 6 to 11 years of age either have been stable, mainly in countries that have achieved close to universal coverage of primary education, or have decreased. The decline in inequality is remarkable for the population at large. With the exception of Afghanistan, where the Taliban years led to fewer educational opportunities for children, especially girls, all other countries in the region have experienced a decrease in the ratio between the years of education of the top and bottom quintiles for people 15-65 years of age. In some cases, the decline has been substantial.

Learning assessments have been conducted among rural households in India and Pakistan since 2005. The findings from them suggest a general decline in average learning achievement. For instance, between 2008 and 2011 both the proportion of students in grade 3 who could read at grade 1 level and the proportion of students in grade 5 who could read at grade 2 level in rural India fell significantly. In arithmetic, student achievement appears to have plunged even further: the percent of third-graders able to perform subtraction fell from 40 percent to 30 percent and of fifth-graders able to perform division from 36 to 28 percent. In rural Pakistan, between 2008 and 2011 at every grade a small decline occurred in the percentage of students who can read a story or perform division (figure 2.17). Because rural households tend to be more disadvantaged, the decline in the learning outcomes of their children can be interpreted as a sign of growing inequality (Das and Zajonc 2008).

In Sri Lanka, however, inequality in learning outcomes has either remained stable or fallen over time. Although academic performance remains lower among children for whom Tamil is the language of instruction, the gap with the academic performance of children learning in Sinhala has narrowed in recent years, at least in the case of the first language and mathematics. It has remained roughly unchanged in the case of English (figure 2.18). Tamil households are generally poorer than Sinhala households, so this trend can be interpreted as evidence of declining inequality along an important nonmonetary dimension.

One explanation of the difference between India and Pakistan, on the one hand, and Sri Lanka, on the other, is the rapid expansion in school coverage that took place in the former two countries in recent years. 


\section{FIGURE 2.15 Inequality in health outcomes has remained stable or increased}

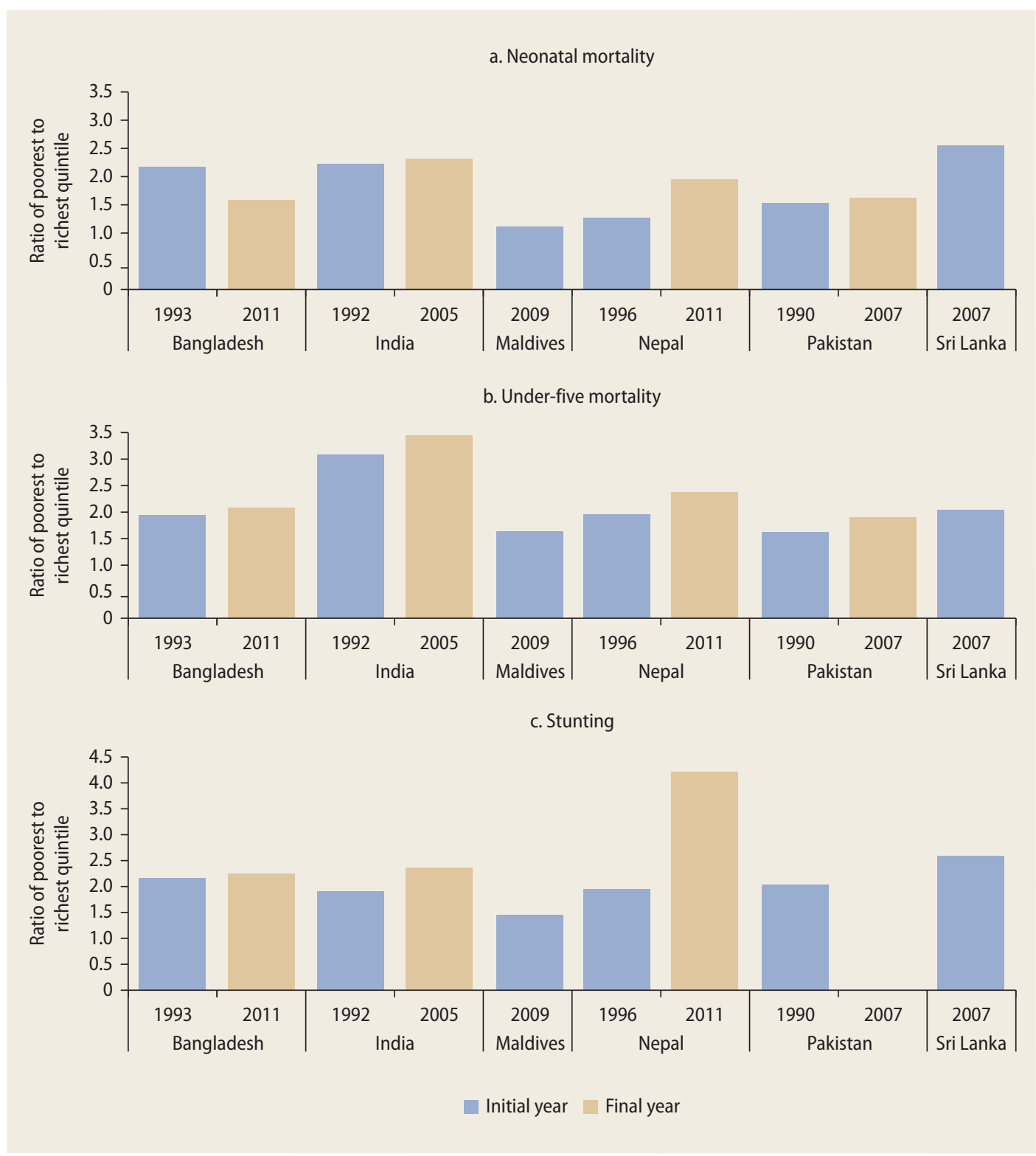

Sources: Based on DHSs.

Note: Neonatal mortality rate is defined as number of deaths to children younger than 28 weeks per 1,000 live births. Under-five mortality rate is defined as number of deaths to children younger than five years per 1,000 live births. Stunting is defined as percentage of children younger than two years whose z-scores are below minus two standard deviations from the median of the WHO Child Growth Standards.

Much of this expansion occurred through increased access to education for some of the most disadvantaged groups. For instance, in India school enrollment rates for children 6 to 10 years of age rose by 4.7 percentage points between 2005 and 2010 , but the corresponding figure in the case of children from scheduled castes and scheduled tribes was 6.6 percentage points. This composition effect is absent in Sri Lanka's case, where school enrollment rates have been consistently high for decades. 


\section{FIGURE 2.16 Inequality in educational attainment is generally decreasing}
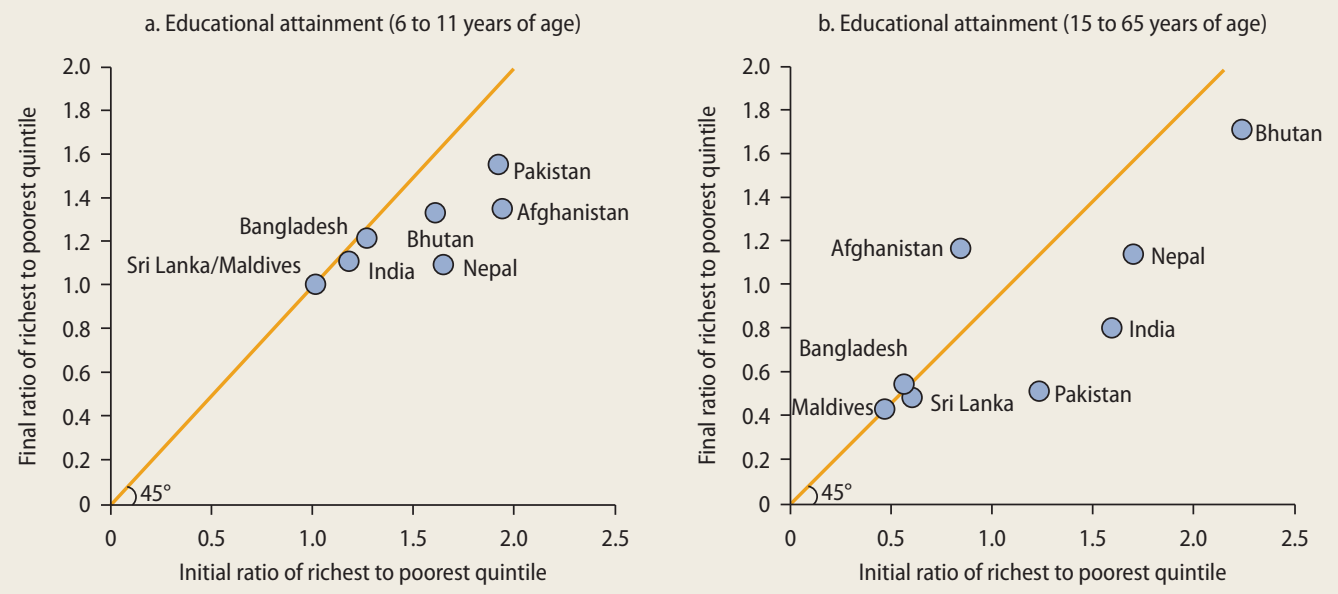

Sources: Based on NRVA 2005 and 2007 for Afghanistan, HIES 2000 and 2010 for Bangladesh, BLSS 2003 and 2007 for Bhutan, NSS 1993-94 and 2009-10 for India, NLSS 1995 and 2010 for Nepal, HIES 2002-03 and 2009-10 for Maldives, HIES 2001-02 and 2010-11 for Pakistan (Punjab), and HIES 1995-96 and 2009-10 for Sri Lanka.

Note: Educational attainment is measured in years of schooling.

\section{What lies behind inequality?}

A cursory analysis of the data available on monetary indicators of inequality in South Asian countries reveals some strongand somewhat predictable-patterns. Some monetary indicators of well-being, including the MLD and the Theil index, allow decomposing total inequality as the sum of inequality between population groups and inequality within population groups. The former is computed as the extent of inequality that would prevail if everyone in each of the groups had the average income or consumption per capita of the group as a whole. Population groups are typically defined along individual characteristics that are predetermined or difficult to modify, such as gender, ethnicity, or location. The estimated inequality between groups provides insights on the contribution the selected individual characteristics make to total inequality.

A standard partition of the population is on the basis of educational attainment. For instance, households can be classified depending on whether the household head has at least some secondary education or not. With this partition, inequality between groups accounted for 26 percent of total inequality in India in 2009-10, up from less than 13 percent in 1993-94 (these figures are computed based on the MLD). A similar upward trend is found in Bangladesh, Bhutan, Nepal, and Pakistan. Only in Sri Lanka did the contribution of education to total inequality somewhat decline between 1995-96 and 2009-10 (figure 2.19). Precise estimates depend on the assumptions made to compute the decomposition, but the conclusion that educational attainment accounts for a growing share of inequality in South Asia seems robust to the methodology used.

Another obvious correlate on inequality is location. Except in Sri Lanka, where differences between urban and rural areas are becoming less relevant over time, elsewhere in the region the urban-rural divide accounts for a substantially larger share of overall inequality now than it did barely 10 or 15 years ago. In India, when households are partitioned depending on whether they live in cities or not, differences between groups account for nearly 20 percent of total inequality in 2009-10, more than three times the ratio observed in 1993-94. The ratio reached 17 percent in Nepal in 2010, from less than 5 percent in 1995 (figure 2.20). 


\section{FIGURE 2.17 Learning outcomes have deteriorated in rural India and rural Pakistan}

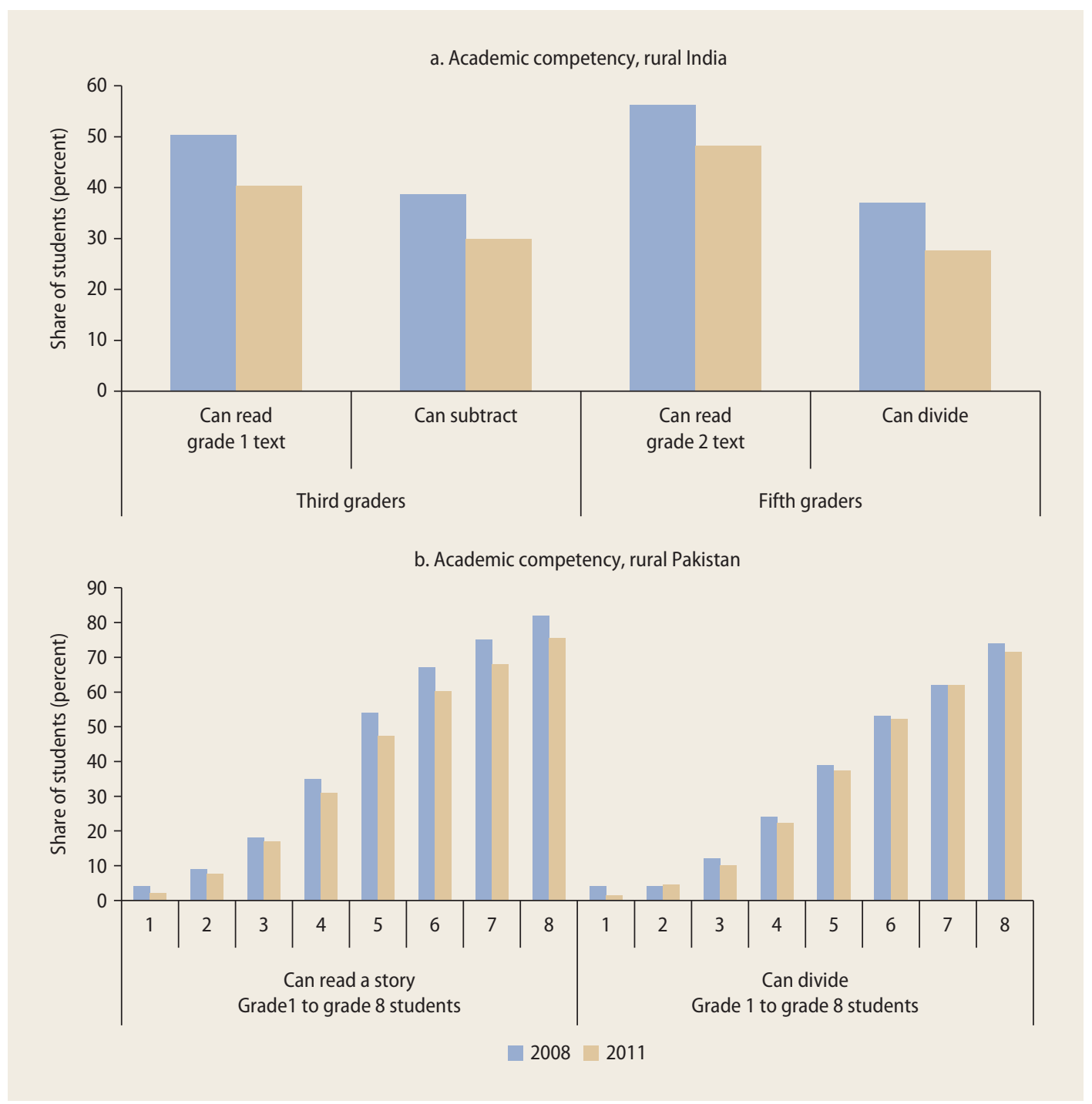

Sources: Annual Status of Education Report 2009, 2012; South Asian Forum for Education Development 2009, 2012.

Whereas education and place of residence are easily observable correlates of inequality, other less visible but not less powerful forms of social exclusion may also be at play. In India's case, a relevant partition of the population is between households whose head belongs to a Scheduled Caste or a Scheduled Tribe and other households. Contrary to expectations, caste explains a relatively small part of between-group inequality in consumption per capita-just around 7 percent in 2009-10. This finding is somewhat misleading, however. Caste accounts for a substantially larger share of overall inequality in some parts of India than in others. Indeed, caste turns out to be an important contributor to total inequality in most northern states (figure 2.21). On a more positive note, the contribution of caste to overall inequality declined in Andhra Pradesh and in Bihar, two major states that together account for 15 percent of India's population. 


\section{FIGURE 2.18 The gap in learning outcomes between ethnic groups is declining in Sri Lanka}

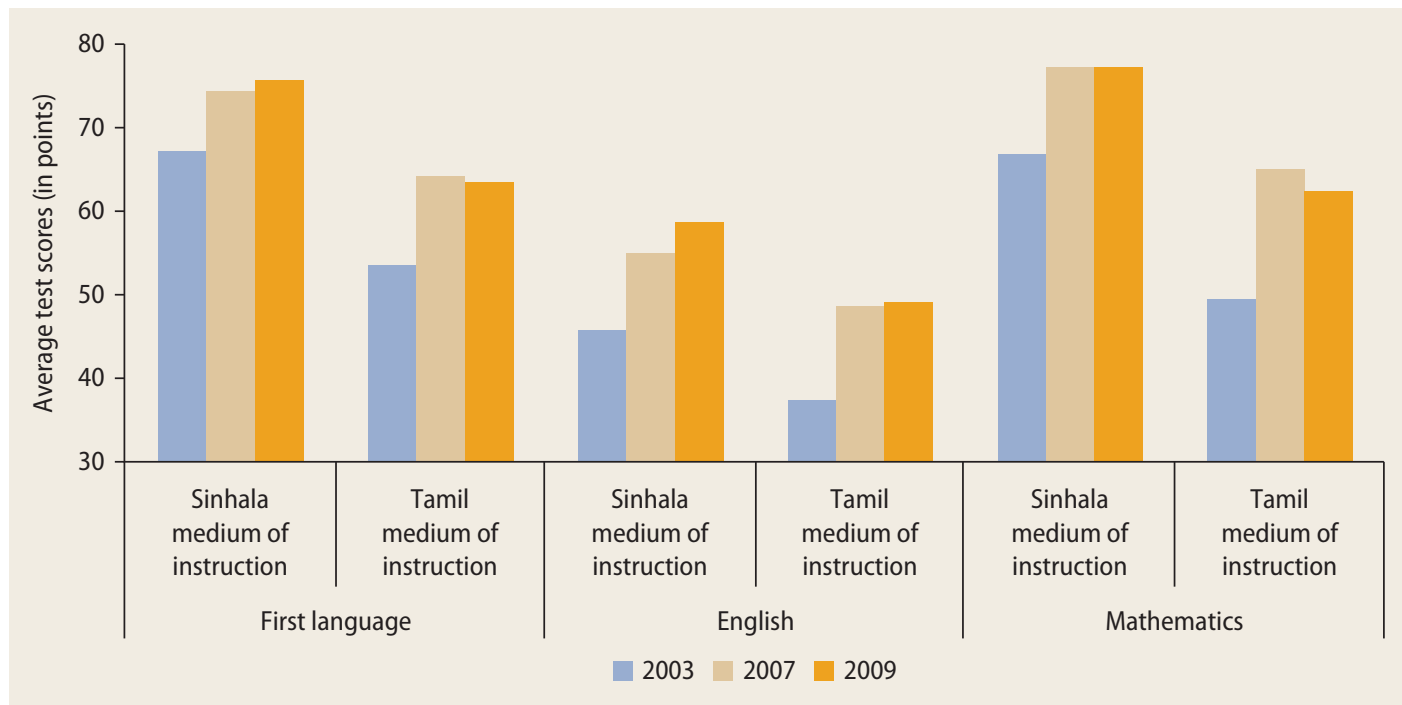

Source: National Research and Evaluation Centre (NEREC) 2009.

\section{FIGURE 2.19 Education explains a growing share of overall inequality}

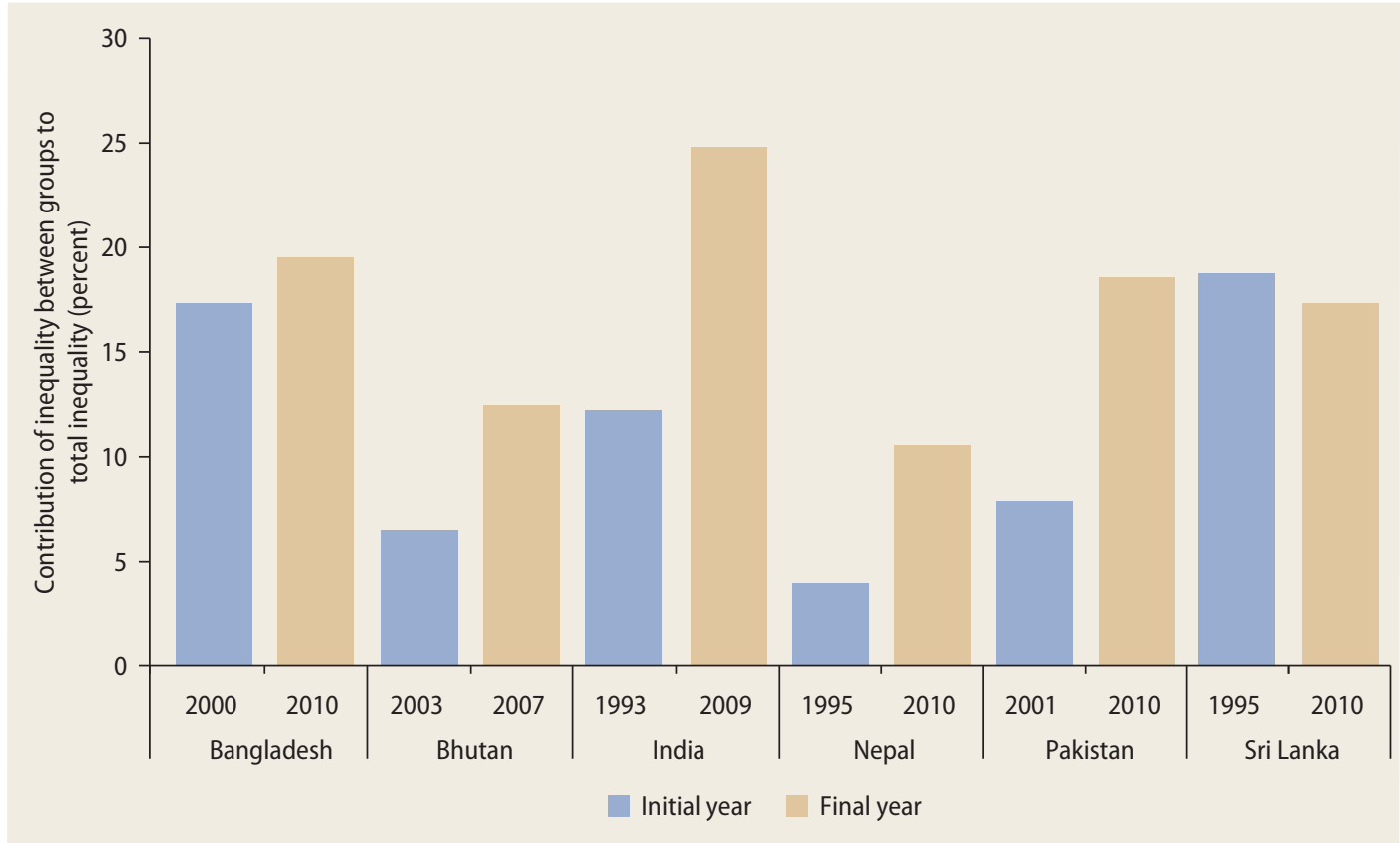

Sources: Based on HIES 2000 and 2010 for Bangladesh, BLSS 2003 and 2007 for Bhutan, NSS 1993-94 and 2009-10 for India, NLSS 1995 and 2010 for Nepal, HIES 2001-02 and 2010-11 for Pakistan (Punjab), and HIES 1995-96 and 2009-10 for Sri Lanka. 


\section{FIGURE 2.20 The rural-urban divide is becoming a more important source of inequality}

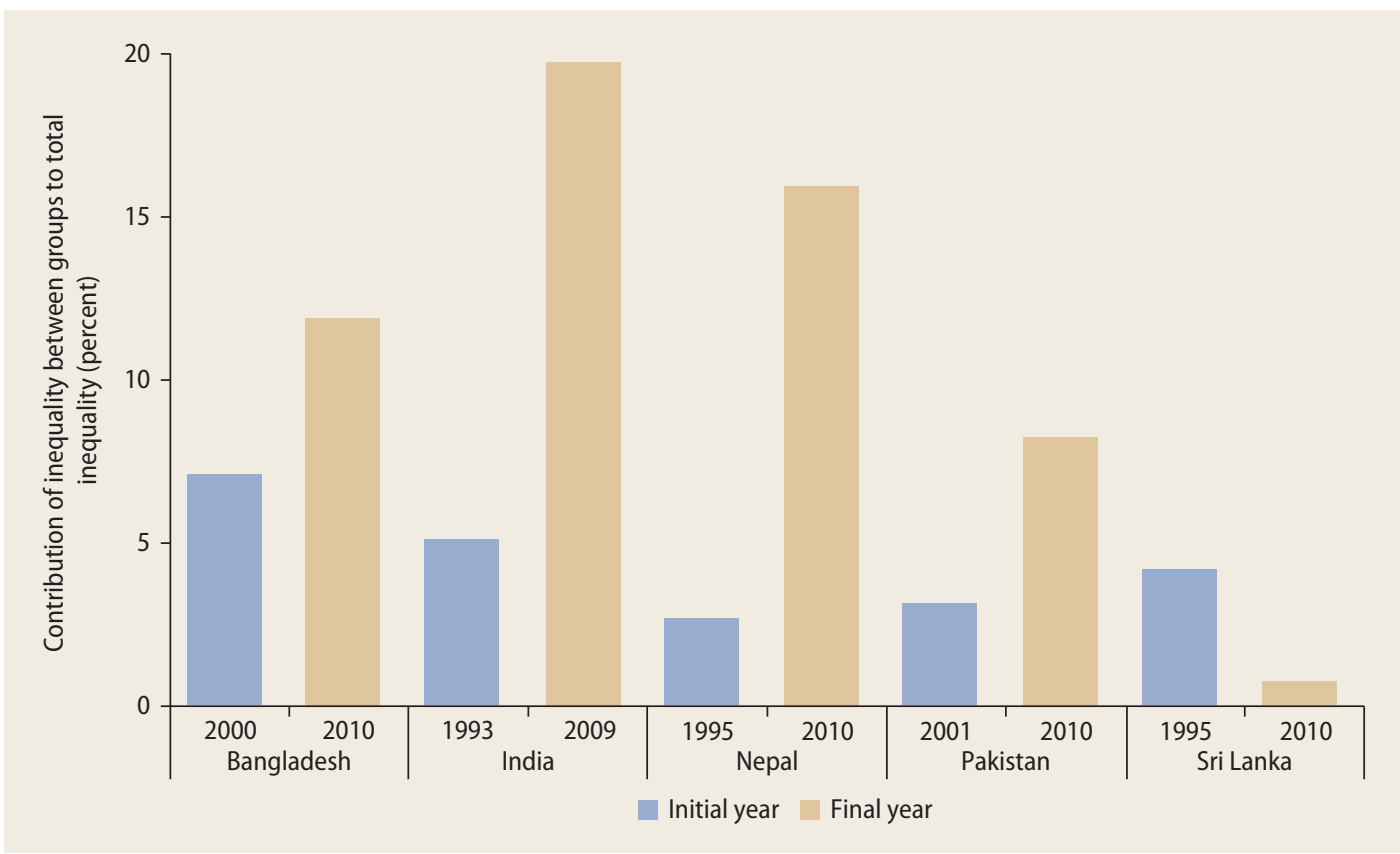

Sources: Based on HIES 2000 and 2010 for Bangladesh, NSS 1993-94 and 2009-10 for India, NLSS 1995 and 2010 for Nepal, HIES 2001-02 and 2010-11 for Pakistan (Punjab), and HIES 1995-96 and 2009-10 for Sri Lanka.

The preceding decompositions describe the contribution different individual characteristics make to total inequality. But they do not explain why those characteristics matter, and in particular they are totally silent on the interaction between those characteristics and a social and economic environment that is shaped by public policies. Based on the decompositions, households from lower castes are clearly at a disadvantage, but that could well be because they have fewer opportunities to access education and health services when young. Similarly, education emerges as a growing force behind inequality, but that could be the result of very different jobs being available to those with and without skills. Job opportunities may also differ substantially between rural and urban areas, and exposure to major shocks such as droughts and natural disasters might be different as well. Public policies can, in turn, result in better access to basic services, greater mobility through jobs, or improved social protection.

In South Asia, the contribution public policies make is often seen in a negative light. The
Gallup World Poll asks respondents about their satisfaction with basic services, their assessment of future well-being, and their views on government efforts to help the poor. The six South Asian countries covered by the Gallup World Poll are compared to Brazil, which is chosen as the benchmark because it has experienced a substantial reduction in inequality in recent years. Moreover, this reduction is generally attributed to policy changes leading to declining returns to education, pronounced rural-urban convergence, increases in social assistance transfers targeted to the poor, and a possible decline in racial inequality (Paes de Barros and others 2010; Ferreira, Leite, and Litchfield 2008; Lustig, Lopez-Calva, and Ortiz-Juarez 2012; and de Souza 2012).

In Brazil, according to the Gallup World Poll, satisfaction with access to public services is higher among poorer population groups, and a negative correlation exists between income per capita and expectations of a better life. Poorer population groups are also more satisfied with government 


\section{FIGURE 2.21 Caste is an important correlate of inequality in some Indian states}

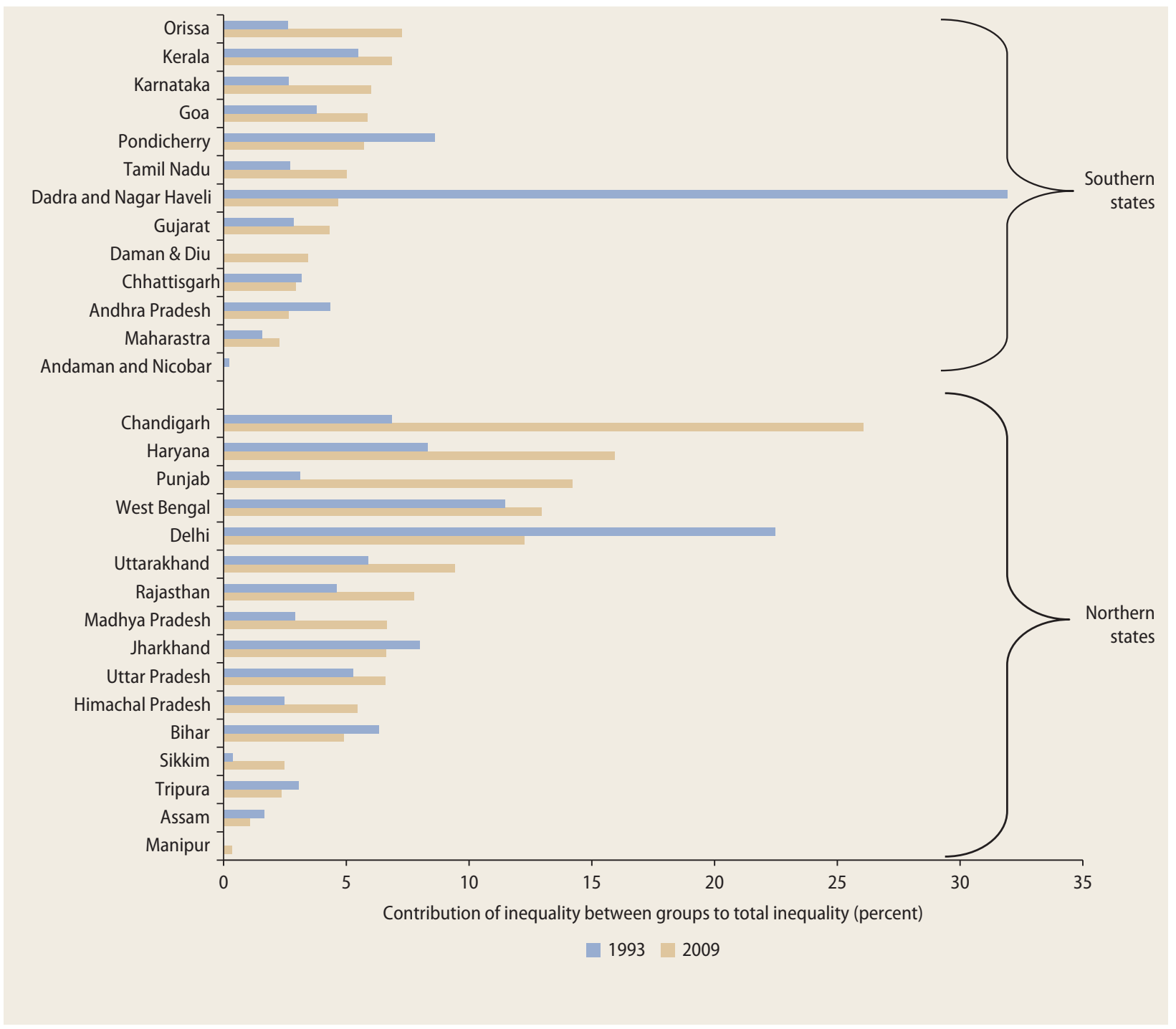

efforts to help them. Taken altogether, these responses reveal a positive view of equality of opportunity, upward mobility, and targeted support. All of this is at odds with responses to the same questions in South Asian countries (figure 2.22).

The role played by household characteristics such as education, location, and caste provides some clues about what lies behind inequality. Opinion polls, in turn, are informative on how public policies may offset or amplify the contribution from inherited circumstances.

A simple conceptualization of how these different variables come into play involves a person's life cycle (figure 2.23). Circumstances at birth, such as gender and caste, shape the options available to individuals, especially in relation to the accumulation of human capital. As people age and enter the labor force, their job opportunities and the possibility of reaping benefits from migration 


\section{FIGURE 2.22 South Asians do not see an environment conducive to lower inequality}

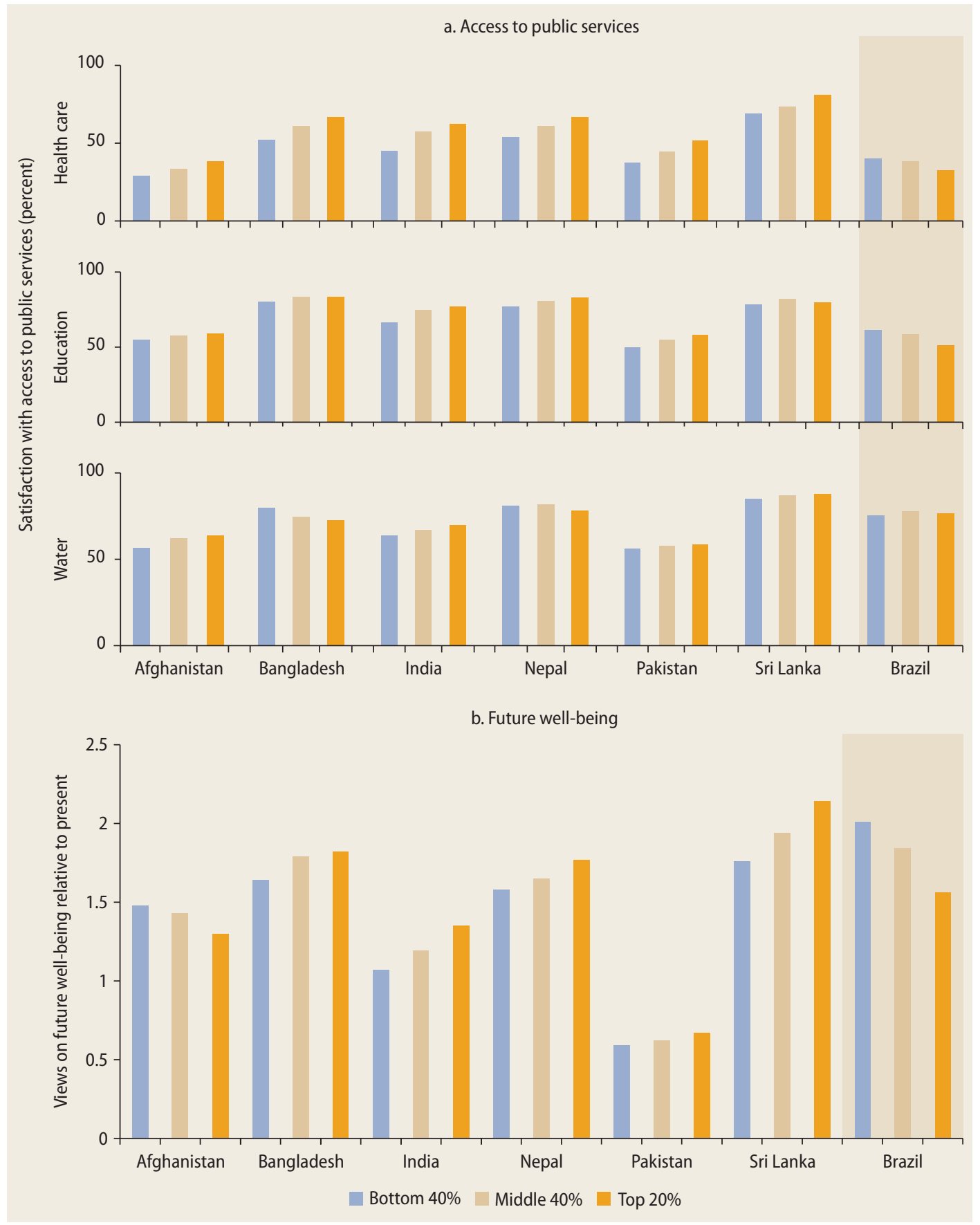

(continues next page) 


\section{FIGURE 2.22 South Asians do not see an environment conducive to lower inequality (continued)}

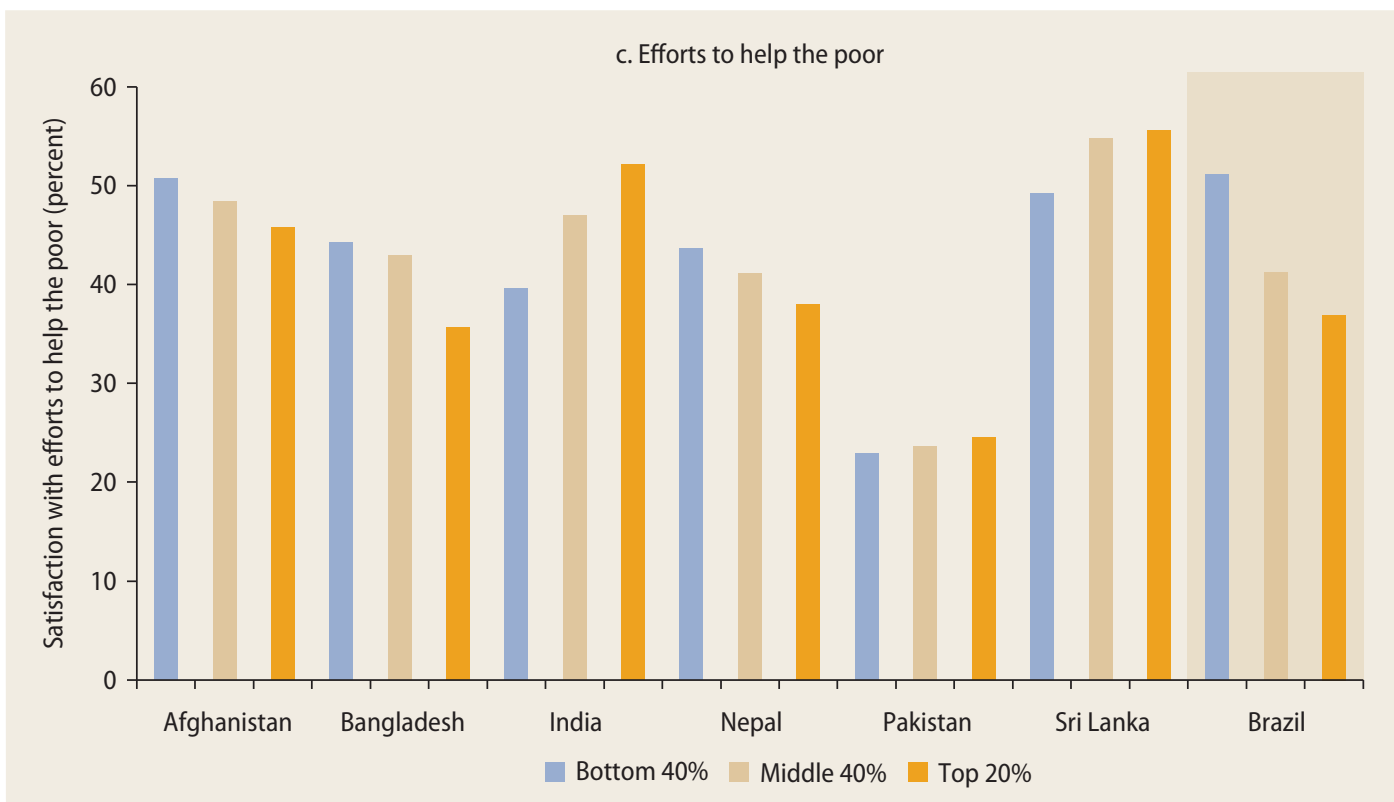

Source: Based on Gallup World Poll.

Note: Population groups are defined based on income or consumption per capita. Views on present (future) well-being are assessed on a scale from 1 (dissatisfied) to 10 (satisfied).

\section{FIGURE 2.23 Multiple factors affect household outcomes relative to others in society}

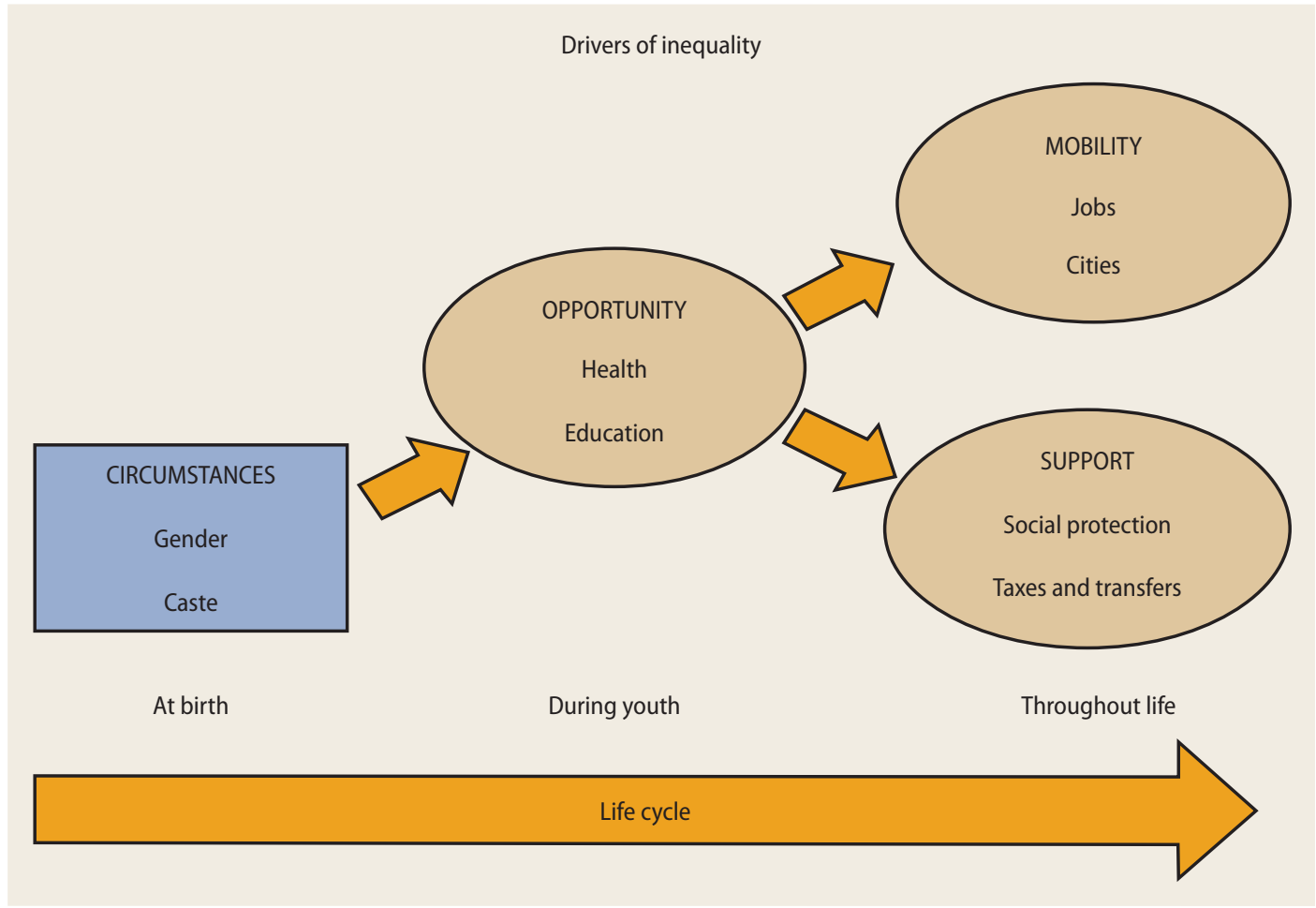


affect earnings prospects. Throughout life, people also experience shocks and are influenced by innate differences. Through each of these phases, public policies may affect the extent of inequality.

In sum, opportunity in childhood can be shaped by access to basic services, including health, education, and infrastructure; mobility throughout adult life can be enhanced by economic growth and rapid urbanization; and support as government transferring resources to people or taxing them can mitigate shocks and offset disadvantages.

\section{The extent of inequality: Main messages and policy implications}

Standard monetary indicators underestimate the true extent of inequality in South Asia. Taken at face value, the Gini index, the ratio between the expenditures of the top and bottom 10 percent of the population, and the share of the bottom 40 percent, all point out in the direction of moderate inequality. The numbers suggest that countries in South Asia are much less unequal than China, Mexico, or South Africa.

Nonmonetary indicators yield a more nuanced picture. Inequalities in human development outcomes such as infant mortality, under-five child mortality, or educational attainment are wide and make the extent of inequality in most countries of South Asia look similar to that of other developing countries. Several countries in the region are among the most unequal for which comparable data are available.

But the combination of monetary and nonmonetary indicators is most telling. Based on data on asset holdings, the wealth in the hands of India's billionaires is disproportionately high compared with that of other countries at similar income levels. Meanwhile, on human development indicators such as malnutrition, the poorest South Asians fare worse than most anyone else in the world. Seen this way, South Asia remains a land of extremes.

The diversity of assessments, depending on which indicator is used, is somewhat disturbing. It implies that a single metric to assess progress toward shared prosperity, such as the share of the bottom 40 percent, could be seriously misleading. But at another level this diversity should be welcome because it provides useful insights on the drivers of inequality in South Asia.
Trends in inequality are also different depending on the indicator considered. Monetary inequality is unambiguously increasing, except in the richest countries in the region. Overall, the bottom 20 and 40 percent of the population have seen their expenditures grow more slowly than the average in South Asia. Although considerable debate exists about the validity of the socalled Kuznets curve, trends in the region seem to conform to it, suggesting that pressures for monetary inequality will increase further in the coming years. Trends in nonmonetary inequality are less clear. South Asia is becoming even more unequal in relation to health outcomes. In contrast, the expansion of school coverage is reducing inequalities in educational attainment, although it may at the same time be widening disparities in learning outcomes.

Important insights are possible into the drivers of inequality in the region. Simple decompositions of total inequality between population groups suggest that characteristics such as educational attainment or location matter a lot. Both education gaps and the rural-urban divide account for a growing share of total inequality. The share is smaller in the case of caste, but it remains relevant in northern and eastern Indian states. However, the impact of these individual characteristics on inequality is mediated by economic structures and public policies. Opinion polls suggest that South Asians have negative views on access to basic services, prospects for improvement through life, and help for the poor. Beyond subjective assessments, any thorough assessment of the dynamics of inequality in the region, and the policies to address it, needs to focus on opportunity, mobility, and support. 


\section{References}

Asadullah, M., N. Chaudhury, D. Prajuli, L. R. Sarr, Y. Savchenko, and S. R. Al-Zayed. 2009. Secondary Education Quality and Access Enhancement Project (SEQAEP): Baseline Report. Washington, DC: World Bank.

Aturupane, Harsha, Paul Glewwe, and Suzanne Wisniewski. 2013. “The Impact of School Quality, Socio-Economic Factors and Child Health on Students' Academic Performance: Evidence from Sri Lankan Primary Schools." Education Economics 21 (1): 2-37.

Banerjee, Abhijit, and Thomas Piketty. 2005. “Top Indian Incomes, 1922-2000." World Bank Economic Review 19 (1): 1-20.

Das, Jishnu, and Tristan Zajonc. 2010. "India Shining and Bharat Drowning: Comparing two Indian States to the Worldwide Distribution in Mathematics Achievement." Journal of Development Economics.

de Souza, Pedro H. G. 2012. "Poverty, Inequality and Social Policies in Brazil, 1995-2009." Working Paper 87, International Policy Centre for Inclusive Growth, United Nations Development Programme, Brasilia, Brazil.

Dollar, David, Tatjana Kleineberg, and Aart Kraay. 2013. "Growth Still Is Good for the Poor.” Policy Research Working Paper 6568, World Bank, Washington, DC.

Educational Initiatives. 2010. Student Learning Study: Status of Learning across 18 Sites of India in Urban and Rural Schools. Ahmedabad, India: Educational Initiatives. http://www.ei-india.com/ wp - content/uploads/2012/01/Main_ Report_StudentLearningStudy_2010_by_ Educational_Initiatives1.pdf.

Ferreira, Francisco H. G., and Martin Ravallion. 2008. "Global Poverty and Inequality: A Review of the Evidence." Policy Research Working Paper 4623, World Bank, Washington, DC.

Ferreira, Francisco, Phillippe Leite, and Julie Litchfield. 2008. "The Rise and Fall of Brazilian Inequality: 1981-2004." Macroeconomic Dynamics 12 (Suppl. S2): 199-230.

Forbes. 2014. "The World's Billionaires." http://www.forbes.com/billionaires/list. Accessed May 29, 2014.

Gandhi, Aditi, and Michael Walton. 2012. "Where Do India's Billionaires Get Their Wealth?" Economic \& Political Weekly, October 6, 10-14.

Lustig, Nora, Luis F. Lopez-Calva, and Eduardo Ortiz-Juarez. 2012. "Declining Inequality in Latin America in the 2000s: The Cases of Argentina, Brazil, and Mexico.” Department of Economics Working Paper 1218, Tulane University, New Orleans, LA.

Milanovic, Branko. 2011. The Haves and the Have-Nots: A Brief Idiosyncratic History of Global Inequality. New York: Basic Books.

Ravallion, Martin. 2014. "Income Inequality in the Developing World." Science 344 (6168): 851-55.

Ricardo, Paes de Barros, Mirela de Carvalho, Samuel Franco, and Rosane Mendonça. 2010. "Markets, the State, and the Dynamics of Inequality in Brazil." In Declining Inequality in Latin America: A Decade of Progress, edited by Luis F. López-Calva and Nora C. Lustig, 134-74. Baltimore: Brookings Institution Press.

Sen, Amartya. 1980. "Equality of What?" In The Tanner Lectures on Human Values, Vol. 1, edited by S. McMurrin, 353-69. Cambridge: Cambridge University Press. 1992. Inequality Reexamined. New York: Oxford University Press.

Subramanian, S., and D. Jayaraj. 2008. "The Distribution of Household Wealth in India." In Personal Wealth from a Global Perspective, edited by James B. Davies, 112-33. New York: Oxford University Press.

World Bank. 2013. Student Learning in South Asia: Challenges, Opportunities, and Policy Priorities. Washington, DC: World Bank. 


\section{Limited Opportunity}

E quality of opportunity is considered a key condition for a society to ensure distributional justice. Those who have the same talent and ability and have the same willingness to use them should have the same prospects of success regardless of their initial circumstances (Rawls 1971). Important outcomes-such as income or health status-are seen as determined by two main factors: efforts and circumstances. The latter includes inherited characteristics such as gender or ethnicity as well as luck (Arneson 1989; Cohen 1989; Dworkin 1981a, 1981b; Roemer 1998). Equality of opportunity requires compensating people for disadvantages related to circumstances so the distributions of outcomes can be entirely attributed to efforts (Roemer 1998).

Both conceptually and empirically, completely distinguishing efforts from circumstances is difficult, hence impeding disentanglement of opportunities from outcomes (Kanbur 2009). However, broad consensus exists that making access to basic services universal is at the core of equality of opportunity (Paes de Barros and others 2009; World Bank 2005). Access to basic services improves the likelihood of a child maximizing her human potential and adding value to the world around her. The Universal
Declaration of Human Rights, the United Nations Convention on the Rights of the Child, and the Millennium Development Goals (MDGs) all reflect this consensus. The idea of opportunities as equal access to basic services by children is also consistent with the "rights approach" upheld by several countries in South Asia.

General agreement exists that the set of goods and services that every individual under 16 years of age should have access to includes nutrition, health care, basic education, and some forms of infrastructure. Within health and nutrition, the focus is often on institutional births and full immunization. In basic education, opportunity is associated with primary school attendance and completion and in some cases with secondary school attendance. The forms of infrastructure deemed essential for opportunity include clean water, improved sanitation, and electricity.

Reaching universal coverage of basic services is associated with equality of opportunity, but increases in coverage along the way may amplify inequalities (box 3.1). In developing countries, and especially in the poorest ones, coverage is far from universal, and households and individuals from more privileged backgrounds usually gain access first. Whereas MDG targets have given impetus 


\section{BOX 3.1 In demographic transitions, inequality of opportunity increases inequality of outcomes}

A simple diagrammatical representation can illustrate how inequality of opportunity shapes the dynamics of inequality of outcomes. Consider the well-being of individuals at two points in life: in childhood (initial well-being) and in adulthood (final well-being). In the figure, initial wellbeing is represented in the horizontal axis and

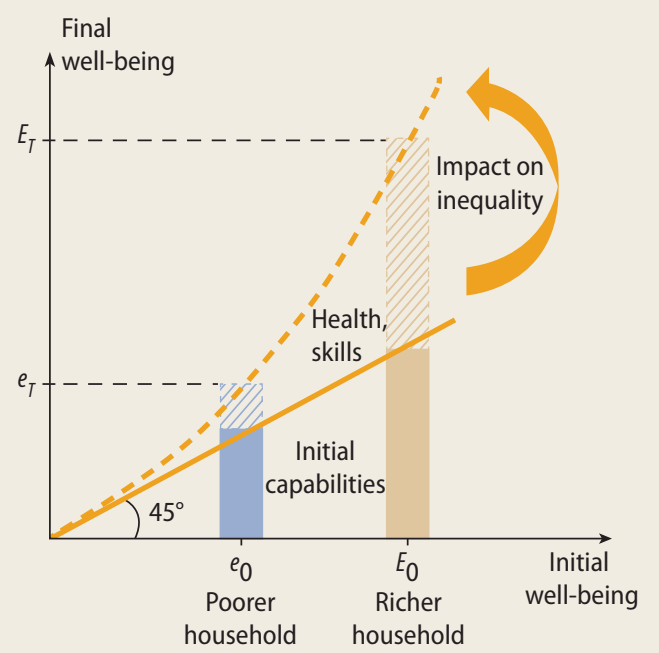

final well-being in the vertical axis. Inequality in outcomes is captured by the area between households along each of these two axes.

If inequality in outcomes were persistent, households would be aligned on a 45-degree line: differences in well-being would be as large in adulthood as they were in childhood. However, if richer households have better access to services than poorer households do, they are also in a better position to live in good health and accumulate skills. Throughout life, a higher human capital amplifies the differences stemming from initial outcomes, and households end up on a convex curve located above the 45-degree line.

The figure refers to the same households at two points in their lives, but inequality in outcomes is measured for the entire population. It is thus some weighted average of the inequality captured in the horizontal axis and in the vertical axis, with weights given by the size of the corresponding population groups. In countries undergoing a demographic transition, the weight of the adult group is increasing steadily. In their case, therefore, inequality of opportunity leads to a growing inequality in outcomes. to campaigns to increase coverage, equity in access has received less attention. When coverage is low, some households are excluded, particularly those lacking the abilities or resources to utilize these services fully.

In South Asia, access to health and education services has improved in recent times. However, the lack of access for children remains acute in relation to health and nutrition. Access is better in the case of primary education but remains low in secondary education. The picture becomes more diversified in the case of infrastructure services: access to improved sanitation is dismally low in most South Asian countries, with the exception of Maldives and Sri Lanka; access to electricity is also limited in most countries, while countries with a relatively high coverage face the challenge of improving the quality of access.

Several population groups receive systematically lower coverage of basic services because of their circumstances. Not surprisingly, rural areas fare worse than urban areas. Gaps in coverage are also pronounced when comparing children whose mothers or parents have different levels of educational attainment. Differences in coverage between girls and boys are small, however. Overall, measurable circumstances of childrenincluding their place of residence, their gender, their religion (or ethnicity), or their 
parents' education-explain a large fraction of the observed inequality in access to health, education, and infrastructure services.

Several factors explain South Asia's lackluster performance in ensuring equality in access to basic services. Importantly, public spending on education and health is relatively low in comparison with other countries at a similar level of development. Equity requires committing additional resources to disadvantaged groups to offset their otherwise more limited access to basic services. However, the opposite is often observed in South Asia. In health, public spending is directed more toward the better-off than to the poorest population groups. In education, public spending tends to be progressive at lower grade levels but regressive at secondary and especially tertiary levels.

\section{Inequality in access to basic services}

The coverage of basic services, measured as a percentage of the relevant population, is a first and telling indicator of access. When the coverage of a specific service is universal, everybody has access to it; lower coverage rates mean that some are necessarily excluded. Exclusion is typically not random, however. People from disadvantaged backgrounds are less likely to get access to services. The extent to which access varies across clearly distinct groups-such as women or ethnic minorities or lowercaste groups-is significant in this respect. The greater the dispersion of access across groups, the greater the degree of inequality for the same level of coverage.

This simple intuition is captured by a synthetic indicator, called the Human Opportunity Index (HOI). The HOI is computed by multiplying the coverage rate by a measure of the dispersion of access across the relevant groups. When people from all groups have equal access on average, the HOI is equal to the coverage rate. As the dispersion of access increases, the HOI declines. By construction, the HOI varies between zero, when coverage is nil or when the dispersion is extremely high, to 100 percent, when coverage is universal (box 3.2). This index can thus be used to assess inequality of opportunities in access to basic services in South Asia.

An important question concerns the factors that define children's background or circumstances in a particular country or set of countries. Following the literature, this report uses factors that are more likely to be predetermined, hence unaffected by a child's own actions. These factors are the place of residency, either urban or rural; a child's gender, religion, and caste; and the education level of the household head or the child's mother, depending on data availability. Religion is used only when data are available, and caste is used only in India's case.

The idea of opportunities as equal access to basic services by children is consistent with rights-based approaches to service delivery. Most countries in South Asia have explicitly recognized the right of children to education. Sri Lanka was a precursor, when it did so in 1945-three years before independence. Bangladesh passed the Compulsory Primary Education Act, which made primary education both free and compulsory, in 1993. Nepal enshrined in the Constitution of 1990, and further in the Seventh Amendment of the Education Act of 2001, the right of every child to free primary education. India's Right to Education Act, passed in 2009, recognized access to primary education as a constitutional right. The following year, Pakistan did likewise with the passage of the 18th amendment to the constitution, under article 25A.

More recently, four South Asian countries joined the Scaling Up Nutrition movement, which had been launched in 2010 and renewed in 2012 with updated goals. These four South Asian countries are Bangladesh, Nepal, Pakistan, and Sri Lanka. Complementing the MDGs, Scaling Up Nutrition aims at saving and improving lives through greater availability of nutritious food.

Despite this widespread commitment to rights, access to services related to health and nutrition tends to be limited in South Asia (figure 3.1). The value of the HOI is 


\section{BOX 3.2 The Human Opportunity Index}

The HOI measures the availability of services that are necessary to progress in life, adjusted by how unequally the services are distributed among different groups in the population. Two countries that have identical coverage of nutrition services for infants, for instance, may have a different HOI if the infants that lack this service systematically share a personal circumstance beyond their control, such as gender, caste, parental income, or place of birth. Put simply, the HOI is coverage corrected for equity.

The calculation of the HOI focuses on the dissimilarity index (D), originally a demographic measure of evenness widely used in the analysis of social mobility and typically applied to dichotomous outcomes. The D-index is defined as the weighted average of absolute differences of group-specific access rates ( $p i)$ from the overall average access rate $(\bar{p})$ :

$$
D=\frac{1}{2 \bar{p}} \sum_{i=1}^{n} \beta_{i}\left|p_{i}-\bar{p}\right|
$$

By construction the D-index varies between zero and one. A value of zero indicates that access rates for all groups considered are the same, while positive values indicate that certain groups of individuals have a lower probability of access to the service considered. In practical terms, the D-index reflects the percentage of the coverage rate of a particular opportunity that has to be discounted to obtain the HOI, that is,

$$
H O I=\bar{p}(1-D) \text {. }
$$

The HOI can be increased by providing more services to all ("scale effect") or by distributing services more fairly ("equalization effect").

Consider two countries, A and B, and consider a basic opportunity such as access to primary education. Suppose that in both countries,
50 percent of all children go to school. From the perspective of overall coverage, both countries look alike. Now suppose that in country A, no girl attends school, but in country B, 50 percent of both girls and boys attend school. The HOI discounts the coverage rate of 50 percent in country A because access is more unequal. For country $\mathrm{B}$, there is no discounting because there is no gender inequality, making the HOI 50 percent, or equal to the coverage. Because country $\mathrm{B}$ has a higher $\mathrm{HOI}$, it is more equal than country A, even though the enrollment rate is the same in both countries.

The HOI has practical appeal because it allows summarizing the evolution of the inequality of opportunity over time without having to track the different circumstances one by one. In addition, it has technical properties that make it an attractive measure of inequality. First, it is sensitive to scale-if access improves for all groups by, say, a factor of $\mathrm{K}$ (additively or multiplicatively), then the HOI changes by the same factor, K. Second, the HOI rewards Pareto improvement: if the coverage rate improves for one circumstance group, without decreasing coverage rates for the remaining groups, the HOI rises. Third, the HOI always improves if access changes in a way that favors groups with coverage rates below the average.

However, the HOI provides a lower bound on the inequality prevalent in a given place. Its calculation can include only those circumstances that are measurable and for which data exist. If more circumstances were added to the set considered in the analysis, the HOI would increase. Having a lower bound measure complicates comparison between countries or geographical regions, especially if the purpose is to investigate which country or region is more inequitable overall and not which one has a lower minimum level of inequality. 


\section{FIGURE 3.1 The Human Opportunity Index for basic health services is low in most of South Asia}

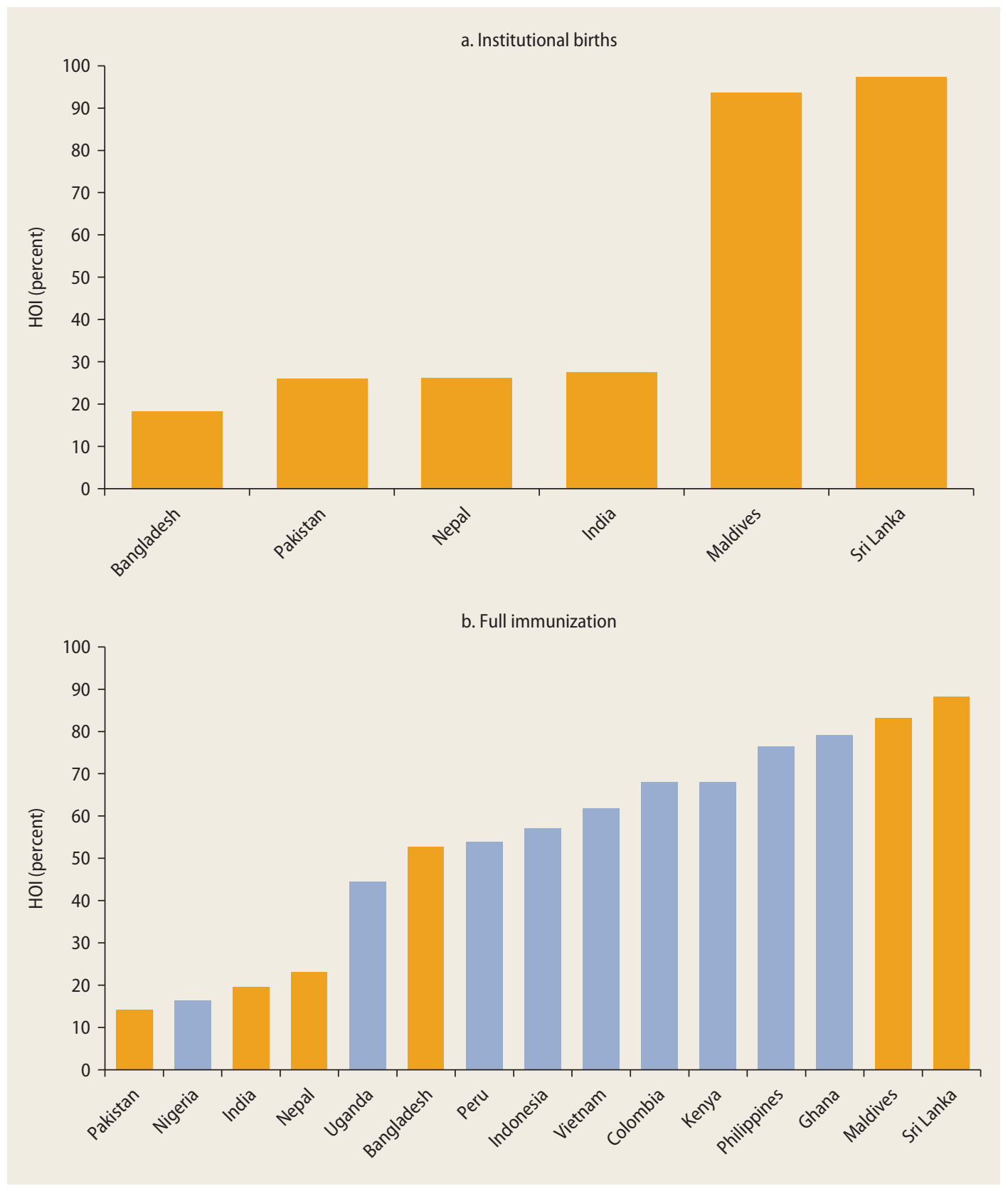

Sources: Based on Demographic and Health Survey (DHS) 2011 for Bangladesh, DHS 2005 for India, DHS 2009 for Maldives, DHS 2011 for Nepal, DHS 2007 for Pakistan, DHS 2007 for Sri Lanka, and data from World Bank Visualize Inequality dashboard (http://www1.worldbank.org/poverty/visualizeinequality/) for other countries.

Note: The HOI for full immunization is computed based on formal records instead of patient recall. HOl estimates differ from $\mathrm{HOI}$ reported by the World Bank Visualize Inequality dashboard because a different set of circumstances is used. In this report, circumstances include only predetermined factors, namely the gender of the child, parental education, geographic location (urban or rural), caste, and religion. 
worryingly low in the case of full immunization against vaccine-preventable diseases among children two years of age and younger. The HOI of most countries in the region does not cross the 50 percent mark. In Bangladesh, it stands at approximately 50 percent; in Nepal, it is 30 percent. India and Pakistan perform poorly with an HOI below 20 percent on the most recent year for which data are available. The extent of inequality in access in these two countries has consistently remained the highest in the region and has only decreased slightly over time.

Access to primary education is far better. Countries in the region have generally done well in primary school attendance and even on completion (figure 3.2). Bhutan and India report HOIs for primary school completion between 80 percent and 90 percent, while Bangladesh, Maldives, and Sri Lanka are above 90 percent. Nepal and Pakistan have also done well for primary school attendance though less so for completion. In this, South Asia resembles other regions, reflecting the global drive toward universal enrollment in primary education.

The picture is less encouraging for access to secondary school, especially in comparison with countries at a similar level of development. The HOI associated with secondary school completion is below 50 percent across the region, with the exception of Bhutan. In Afghanistan, it is less than 5 percent. Even in the best-performing countries of the region-Bhutan, Maldives, and Sri Lankathe HOI is smaller than that in traditionally inequitable countries, such as Brazil and South Africa.

International comparisons are less reliable with respect to infrastructure services. What it means to have access to improved water or to improved sanitation varies from one country to another. Moreover, access is measured at the community level in South Asian countries but at the household level in others. If a power line arrives to a village, but only half the population in the village has electricity, coverage is twice as high when measured at the community level rather than the household level. Hence, the analysis of inequality of opportunity in access to infrastructure services can be conducted with some level of confidence at the country level but not across countries.

Still worth noting is that by construction the HOI cannot exceed the coverage rate. And even when considering the more generous access measure, at the community level, coverage is low in most South Asian countries (figure 3.3).

The smaller countries in the region perform well in the case of access to electricity. Maldives has virtually universal access, and in Sri Lanka the HOI exceeds 80 percent. In contrast, Afghanistan still lags far behind, with an HOI of about 10 percent. Access to electricity is also limited in Bangladesh and India, where the HOI hovers between 40 percent and 60 percent. Access to sanitation is generally dismal. With the exception of Maldives and Sri Lanka, the HOI for improved sanitation services does not exceed 40 percent of the population in South Asian countries.

\section{Coverage is improving, equity less so}

Opportunities in access to health and education services have been improving in most countries over the past decade. Whereas most countries have registered $\mathrm{HOI}$ increases in access to health services, progress has been slower than for other basic services (figure 3.4). When considering full immunization, opportunities increased most rapidly in Bangladesh, as measured by the annual change in the HOI. By contrast, they declined slightly in Pakistan. As for institutional births, Nepal registered the fastest improvement. But overall progress has been slow, and inequality has declined only slightly in recent times. The annual change in HOI stands between 0.5 and 1 percentage point in most cases.

Countries in South Asia have made significant strides in improving access to primary education. Maldives and Sri Lanka led the region in achieving almost universal primary 


\section{FIGURE 3.2 The Human Opportunity Index for education is low in Afghanistan and Pakistan}

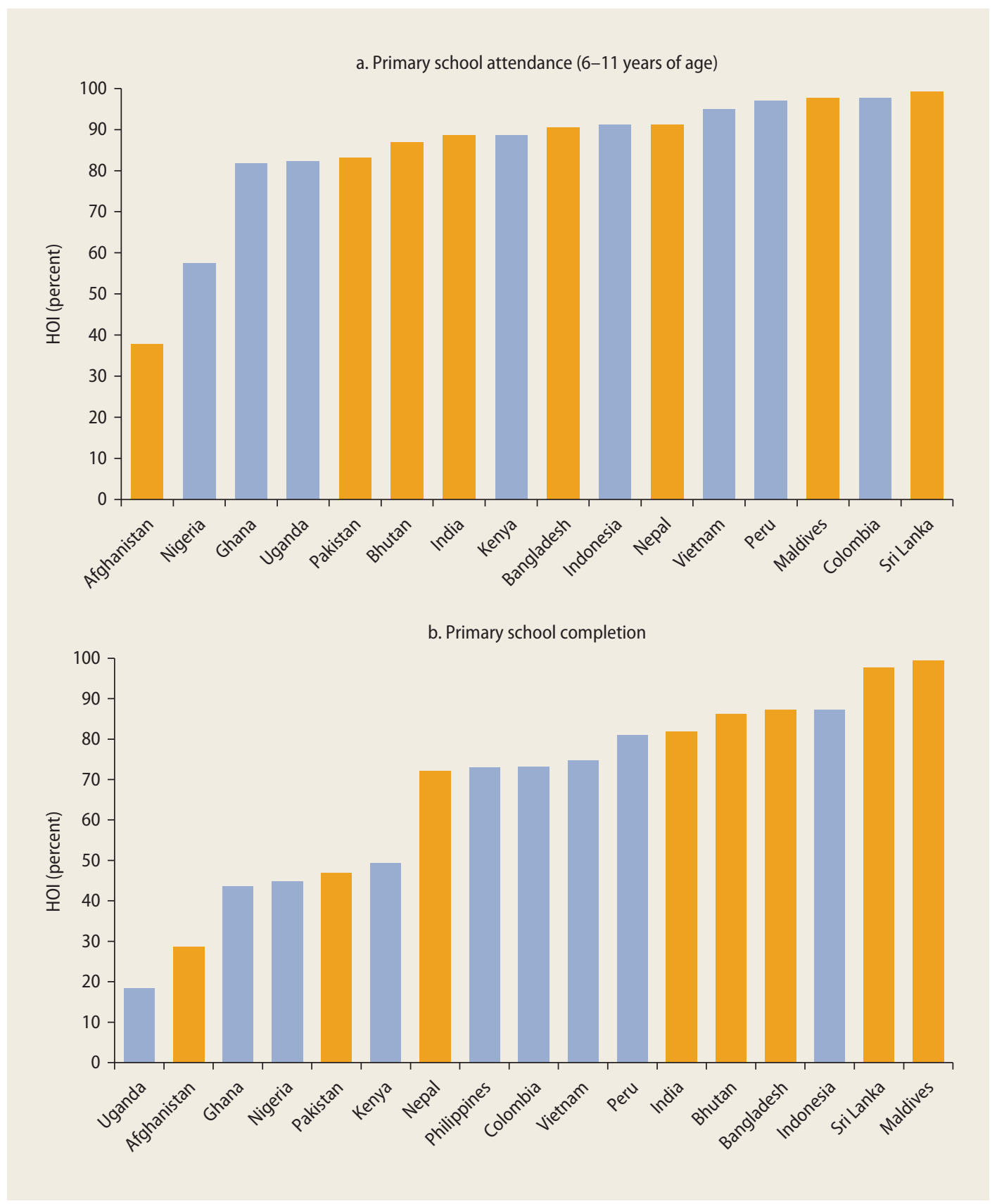

Sources: Based on National Risk and Vulnerability Assessment 2007 for Afghanistan, Household Income and Expenditure Survey (HIES) 2010 for Bangladesh, Bhutan Living Standards Survey 2007 for Bhutan, National Sample Survey 2009 for India, HIES 2009 for Maldives, Nepal Living Standards Survey 2010 for Nepal, HIES 2010 for Pakistan, HIES 2009 for Sri Lanka, and data from World Bank Visualize Inequality dashboard (http://www1.worldbank.org/poverty /visualizeinequality/) for other countries.

Note: The $\mathrm{HOl}$ is computed based on gross completion rates and not on students completing primary school at the appropriate age. $\mathrm{HOl}$ estimates differ from $\mathrm{HOI}$ reported by the World Bank Visualize Inequality dashboard because a different set of circumstances is used. In this report, circumstances include only predetermined factors, namely the gender of the child, parental education, geographic location (urban or rural), caste, and religion. 
FIGURE 3.3 The Human Opportunity Index for sanitation is especially low

a. Electricity

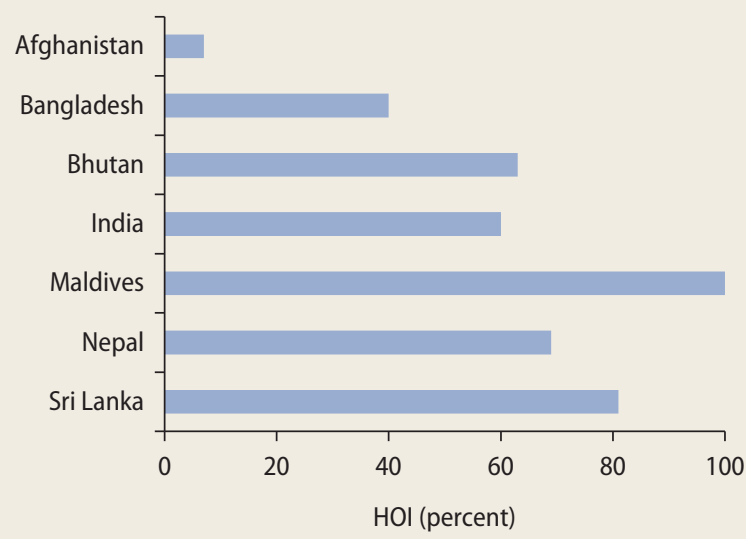

b. Improved sanitation

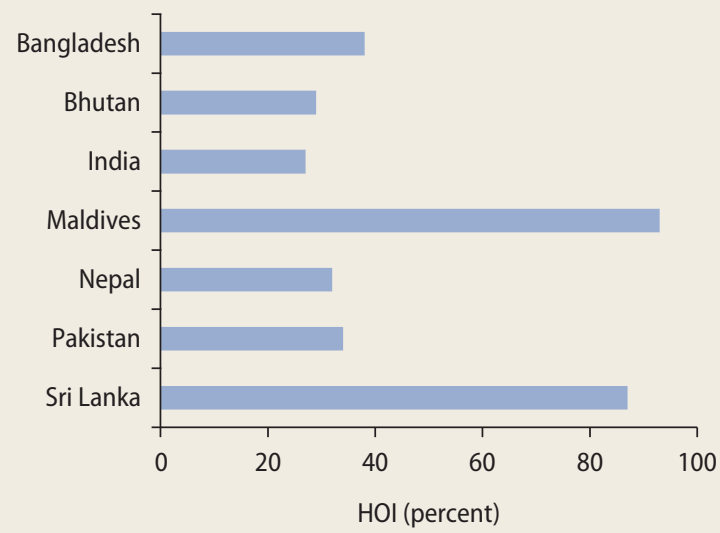

Source: Based on Andres and others 2013 for this report.

Note: Definition of what it means to have access to improved sanitation varies across countries

education coverage. The HOIs associated with both attending and completing primary school were greater than 95 percent in these two countries already in the mid-2000s, and they are by now only 2 percentage points short of the 100 percent mark, which explains their slower rate of change. Progress in Bangladesh, India, Bhutan, Nepal, and Pakistan has also been significant, although at varying speeds. In Bhutan and Nepal, improvements in primary school attendance and completion were remarkable. In Pakistan, school attendance saw more rapid progress than school completion. In Bangladesh, the pace of change is slower, but the starting point was higher (with HOIs around 85 percent in 2005). In Afghanistan, school attendance grew between 2005 and 2007, but the HOI remains low.

The drivers of inequality in access in South Asia can be better understood by decomposing the change in the HOI between increases in coverage rates (scale effect) and reductions in the dispersion of coverage rates across groups (equity effect). The decomposition shows that greater coverage clearly drives the improvements of opportunities in health (figure 3.5). In the case of full immunization, almost all of the change in the
HOI can be attributed to changes in coverage, with inequality across groups remaining stable. The bolstering of vaccination programs through initiatives such as National Immunization Days has contributed to this increase in coverage. For institutional births, the main driver of the increase in the HOI has also been greater coverage, although there has also been an increase in equity across all the countries covered in the analysis.

The decomposition of changes in the HOI yields a more diverse picture in the case of primary education (figure 3.6). For instance, in Afghanistan, which showed rapid increases in its HOI for primary school attendance, the change has come mainly from greater coverage. In contrast, changes in equity in access play an important role in Bhutan, India, Nepal, Maldives, and Pakistan. As a country that has recorded notable growth in primary school attendance and completion, Nepal is a case in point. The overall increase in HOI in Nepal is much more pronounced than the scale effect would imply, because of an important reduction in inequality in access. This equity effect is large enough to account for approximately one-third of the annual increase in the HOI for both attendance and completion. 


\section{FIGURE 3.4 Opportunities have improved faster in primary education than in health services}

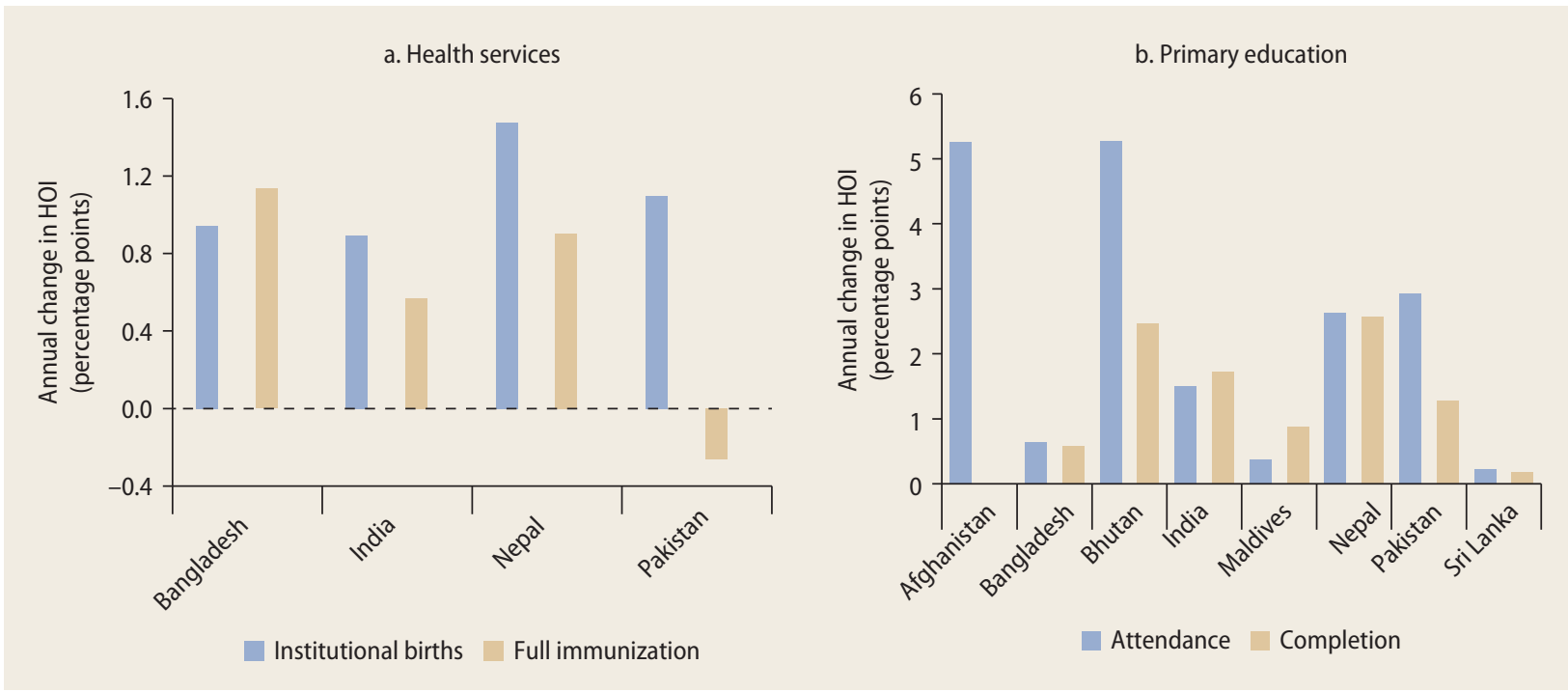

Sources: For health, based on Demographic and Health Survey (DHS) 1993 and 2011 for Bangladesh, DHS 1992 and 2005 for India, DHS 1996 and 2011 for Nepal, and DHS 1990 and 2007 for Pakistan; for education, based on National Risk and Vulnerability Assessment 2005 and 2007 for Afghanistan, Household Income and Expenditure Survey (HIES) 2005 and 2010 for Bangladesh, Bhutan Living Standards Survey 2003 and 2007 for Bhutan, National Sample Survey 1993 and 2009 for India, HIES 2003 and 2009 for Maldives, Nepal Living Standards Survey 2003 and 2010 for Nepal, HIES 2001 and 2010 for Pakistan (Punjab), and HIES 2006 and 2009 for Sri Lanka.

\section{FIGURE 3.5 Better opportunities in health are driven by greater coverage of basic services}

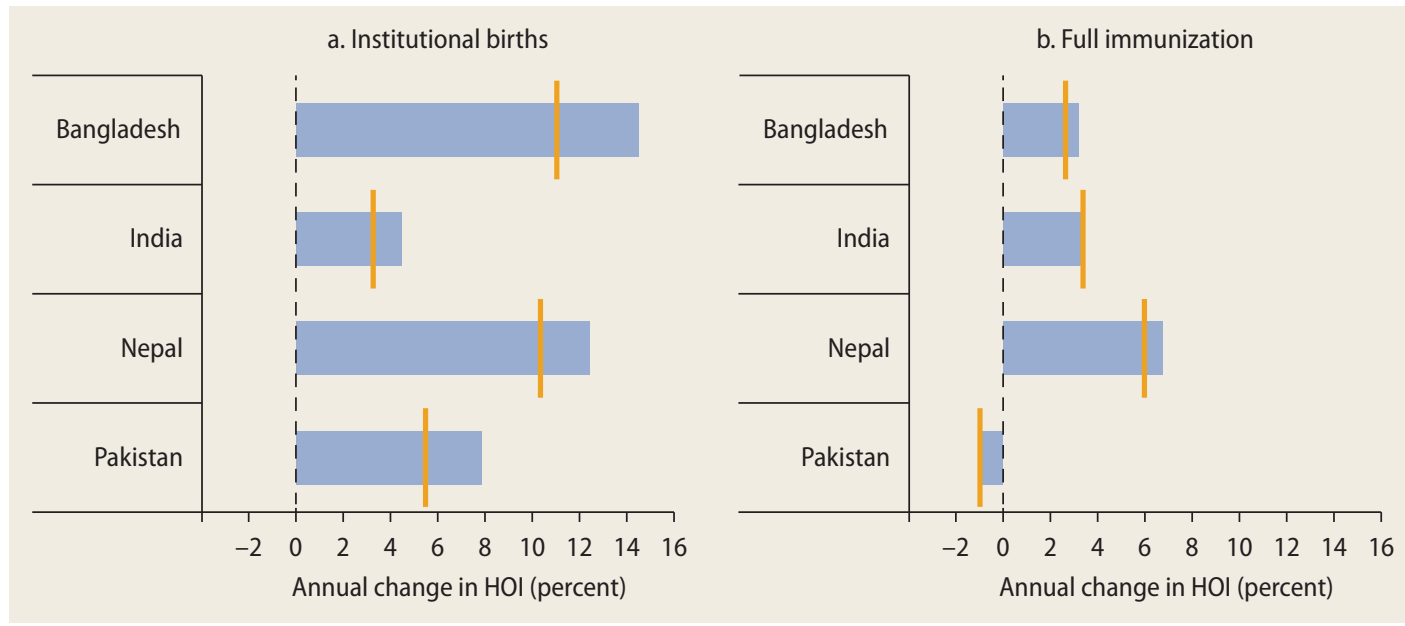

Sources: Based on Demographic and Health Survey (DHS) 1993 and 2011 for Bangladesh, DHS 1992 and 2005 for India, DHS 1996 and 2011 for Nepal, and DHS 1990 and 2007 for Pakistan.

Note: Horizontal bars indicate the total change in the $\mathrm{HOl}$; vertical lines indicate the change caused by increased coverage; the difference between the two reflects changes in equity.

Although the measured access to health and education services in the region has generally improved, the magnitude of the change may overestimate the improvement in equity. This is because the quality of health and education services is likely to vary considerably across population groups, and the quality of services has important implications for later-life opportunities. For instance, whereas the improvement in the HOI for primary 


\section{FIGURE 3.6 Better opportunities in education reflect greater coverage and higher equity in some countries}

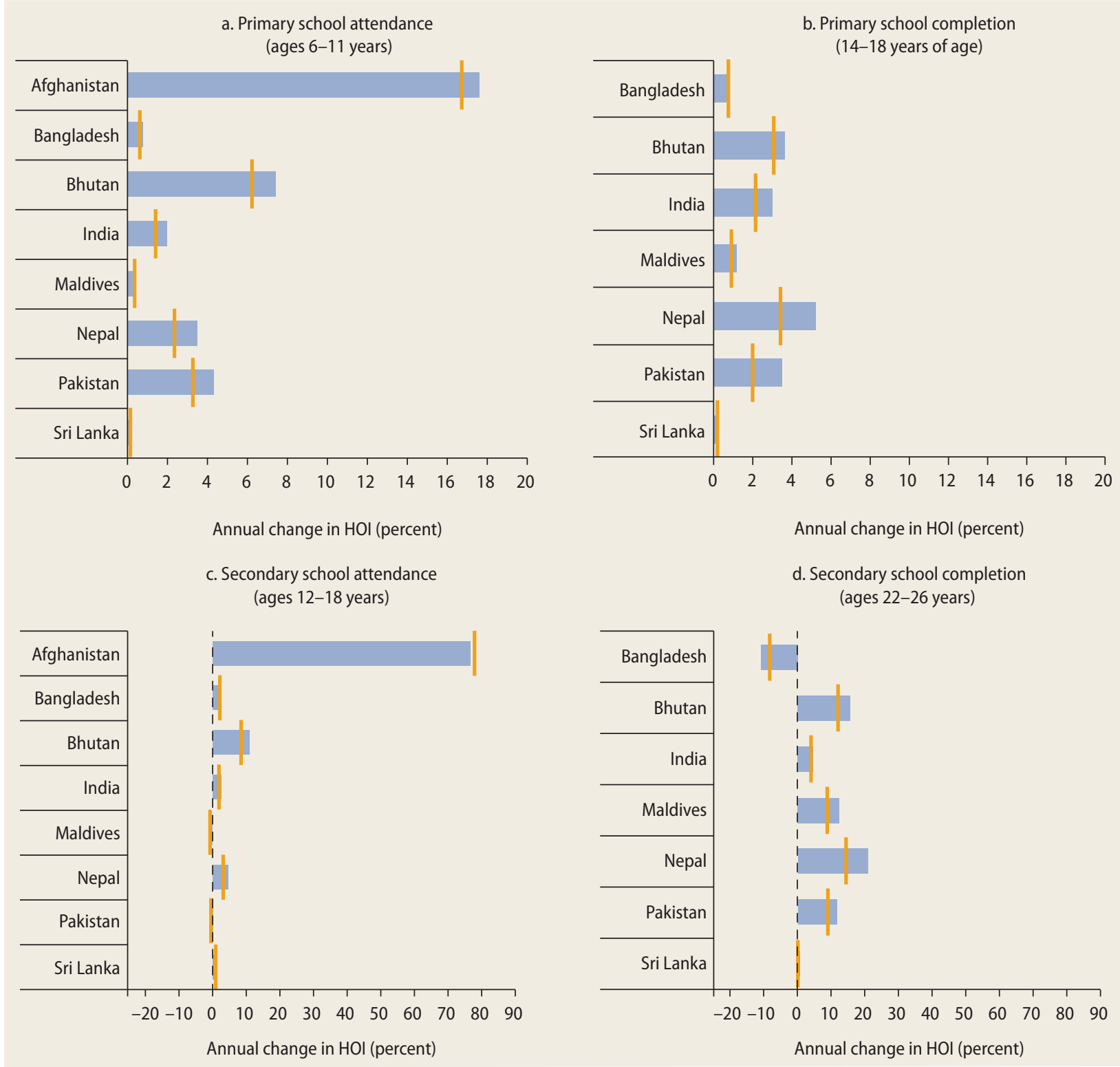

Sources: Based on National Risk and Vulnerability Assessment 2005 and 2007 for Afghanistan, Household Income and Expenditure Survey (HIES) 2005 and 2010 for Bangladesh, Bhutan Living Standards Survey 2003 and 2007 for Bhutan, National Sample Survey 1993 and 2009 for India, HIES 2003 and 2009 for Maldives, Nepal Living Standards Survey 2003 and 2010 for Nepal, HIES 2001 and 2010 for Pakistan (Punjab), and HIES 2006 and 2009 for Sri Lanka.

Note: Horizontal bars indicate the total change in the HOl; vertical lines indicate the change caused by increased coverage; the difference between the two reflects changes in equity

school attendance in India may reflect a narrowing of enrollment gaps between different castes, in reality the type of schools high-caste and low-caste students are likely to attend could be quite different in terms of resources and learning. An improvement in
HOI is unlikely to capture the fact that qualitative differences in services may not have diminished substantively.

Another important caveat refers to differences within countries. These differences can be wide in the case of basic health services. 
For example, the HOI associated with institutional births in Kerala stands at almost 100 percent, much higher than for India as a whole. In Nepal, coverage in the mountainous region stands at 19 percent, compared with 41 percent in the Tarai. Significant differences also exist in coverage across religious groups in all countries. In India, for instance, coverage has always been higher among Christians and Buddhists than among other religious groups. The same holds true for Hindus in Bangladesh.

Despite the substantial increase in coverage, differences between states or provinces can also be sizable in the case of primary education opportunities. Bangladesh and Nepal show much less within-country variation than India and Pakistan. In these last two countries, federalism implies that states or provinces take a leading role in designing service-delivery policies in their jurisdiction.

\section{Who is covered?}

Several population groups receive systematically lower coverage of access to basic services because of their circumstances, including location, gender, education level of the mother, ethnicity, or caste.

Children residing in rural areas fare worse than those in urban areas with regard to basic health services, especially when it comes to institutional birth (figure 3.7). The gap is often quite striking-in Nepal, for example, 32 percent of rural births are in a health facility, compared with 71 percent of urban births. Similar differences can be found in Bangladesh, India, and Pakistan.

In the case of primary education, the gap between urban and rural areas is generally low, with the exception of Afghanistan and Pakistan (figure 3.8). This holds true not just for primary school attendance but also for primary school completion. The picture is different in the case of secondary schools. Overall coverage rates are much lower, and the gap between rural and urban areas is large, especially for school completion.

The urban-rural gap is also evident in the provision of infrastructure services in the region, especially electricity (figure 3.9). Rural areas fare much worse in terms of access to electricity, especially in Afghanistan and Bangladesh.

\section{FIGURE 3.7 The coverage of institutional births is lower in rural areas}

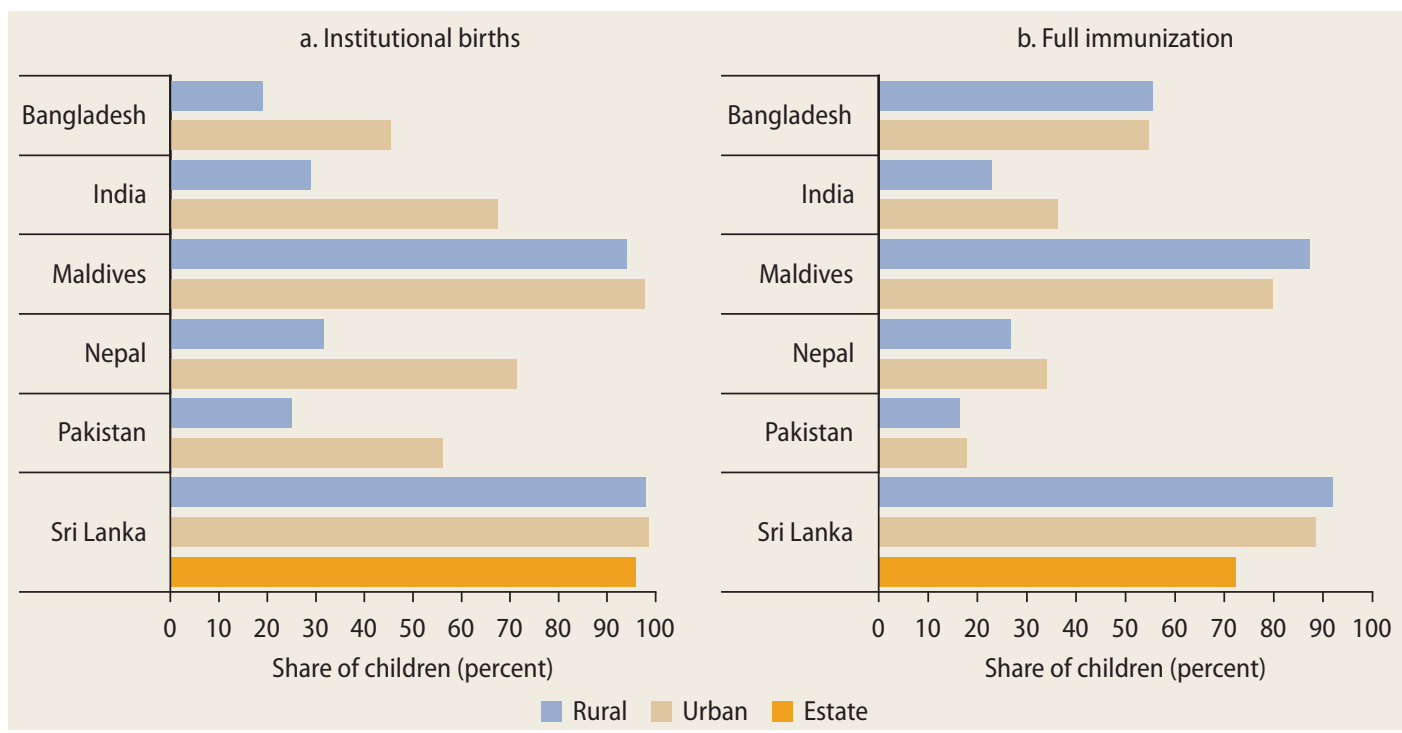

Sources: Based on Demographic and Health Survey (DHS) 2011 for Bangladesh, DHS 2005 for India, DHS 2009 for Maldives, DHS 2011 for Nepal, DHS 2007 for Pakistan, and DHS 2007 for Sri Lanka. 


\section{FIGURE 3.8 The urban-rural gap in coverage remains large for secondary education}

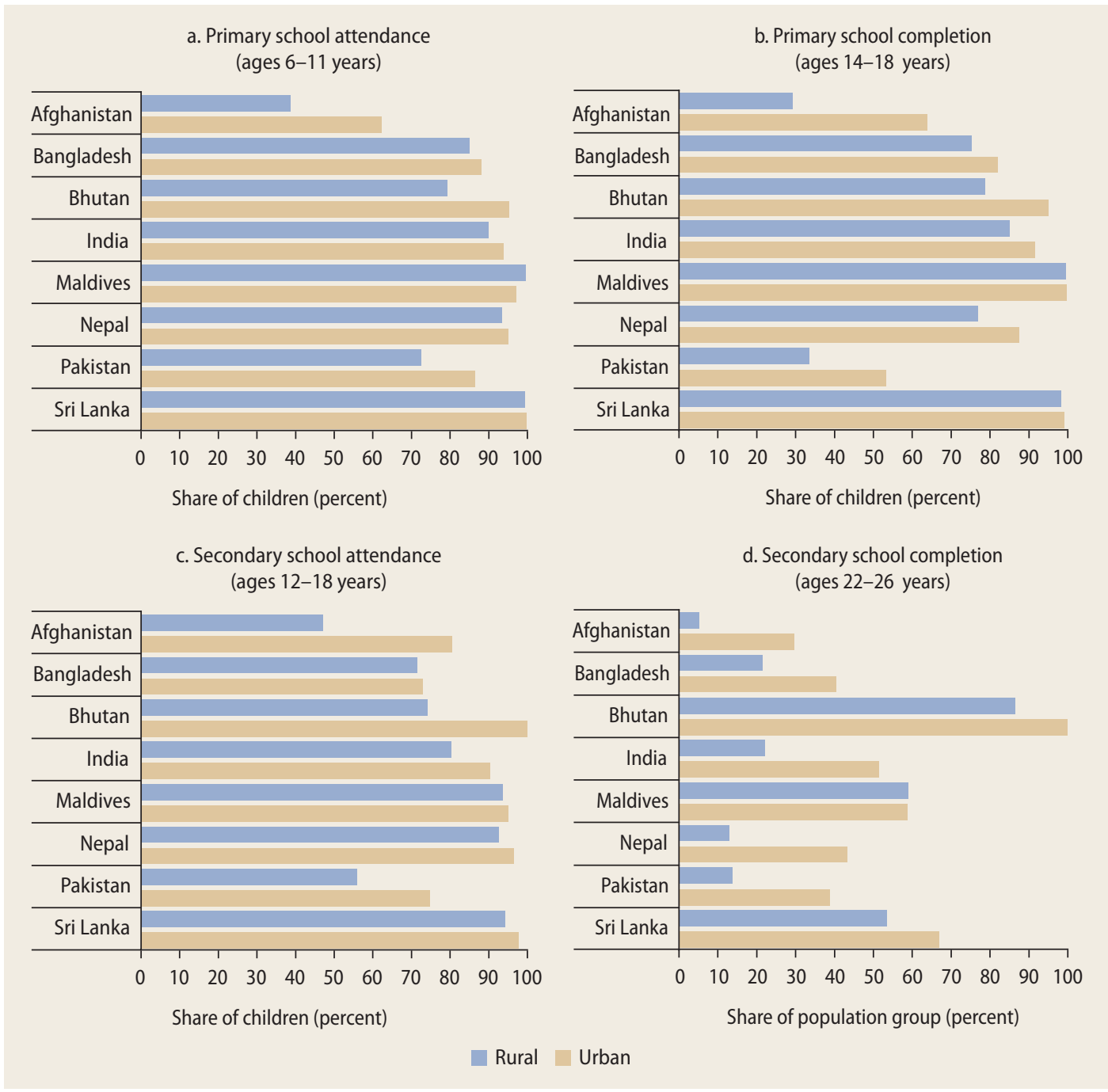

Sources: Based on National Risk and Vulnerability Assessment 2007 for Afghanistan, Household Income and Expenditure Survey (HIES) 2010 for Bangladesh, Bhutan Living Standards Survey 2007 for Bhutan, National Sample Survey 2009 for India, HIES 2009 for Maldives, Nepal Living Standards Survey 2010 for Nepal, HIES 2010 for Pakistan, and HIES 2009 for Sri Lanka.

Within cities, the disparity in access to services between slum and nonslum urban areas adds more nuance to the general picture of an urban-rural divide. For instance, in Bangladesh, children of slum dwellers tend to have lower rates of school participation than children living in nonslum urban areas (figure 3.10). The relatively higher opportunity costs of schooling faced by poor slum dwellers is only part of the story. Evidence suggests a shortage of schools exists for slum areas and this shortage is most acute at the secondary level (World Bank 2013).

The disparity in access to basic services between slum and nonslum urban areas is also evident in the case of health care. In the urban slums in Dhaka, slum dwellers use pharmacies as their primary source of health 


\section{FIGURE 3.9 Access to electricity is lower in rural} areas

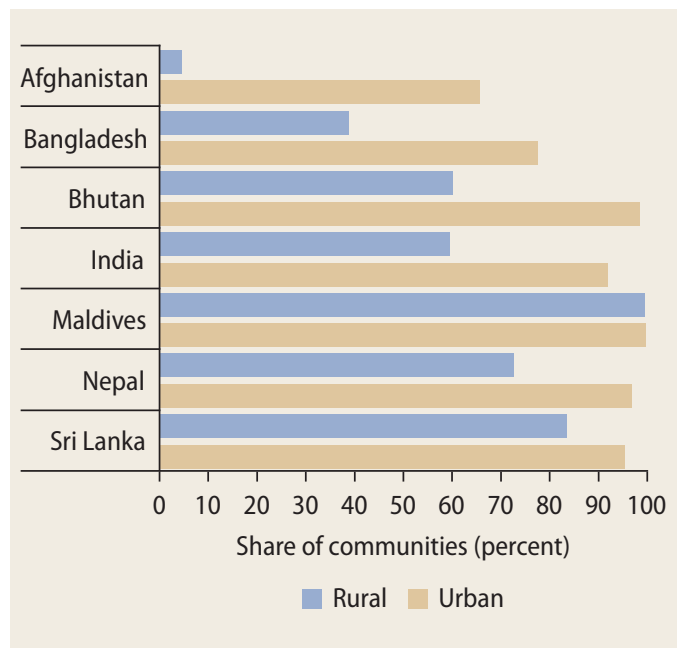

Source: Based on Andres and others 2013 for this report.

care, just as residents of rural areas do, despite the fact that cheaper government health care services are generally available. But the services provided by pharmacies are often of poor quality. For instance, only 8 percent of the drug dispensers working in pharmacies in Dhaka correctly treated dysentery patients. Similar situations have been observed in many of the urban slums of South Asia (Khan, Grübner, and Krämer 2012).

Gender is another dimension along which important differences in health coverage may exist. But this does not appear to be the case in South Asia, where boys' advantage is generally very small for basic health services (figure 3.11).

Gender differences in coverage are also low in the case of primary education (figure 3.12). Attendance rates are similar for boys and girls, except in Afghanistan and Pakistan, where girls are at a disadvantage. Completion rates are slightly lower for girls than for boys, but the gap is not too different from that observed for attendance. In Bangladesh and Bhutan, completion rates are actually higher for girls.

Gender gaps are much more pronounced at the secondary level, however. In Sri Lanka and Bangladesh, girls attend secondary school
FIGURE 3.10 In Bangladesh, children of slum dwellers have less access to education

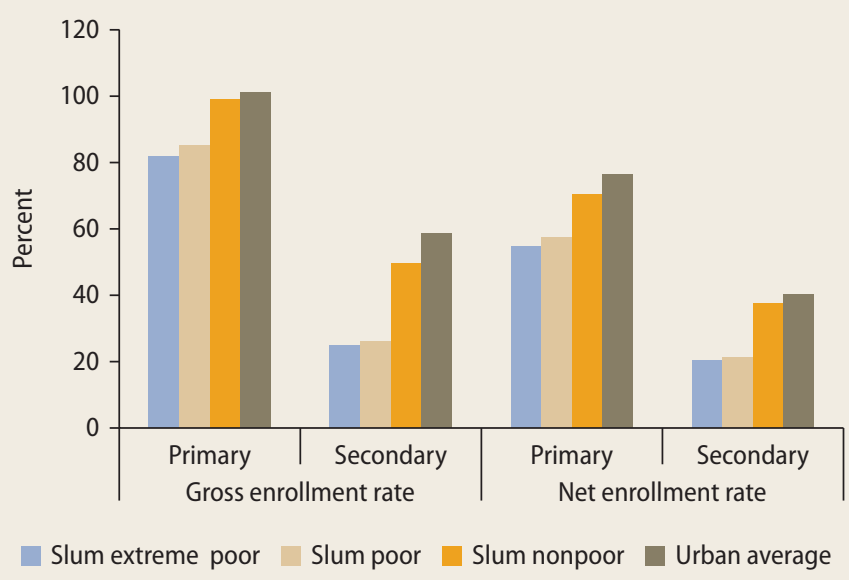

Source: World Bank 2013.

at a marginally higher rate than boys, but in Bangladesh the female advantage in participation does not continue through school completion. In general, secondary school completion rates are 5 to 10 percentage points higher for boys than for girls.

Although access to infrastructure facilities such as sanitation and electricity concerns locations more than individuals, the implications can be different for men and women. For instance, lack of toilets at school is well known to create a more severe obstacle for attendance among girls than among boys. Similarly, lack of electricity at home reduces the efficiency of domestic chores such as cooking, thereby penalizing labor force participation by women more than participation by men. Evidence also indicates that electrification reduces fertility rates in rural areas. One probable impact of electrification on fertility is through television. A small but important body of evidence on the impacts of television on gender roles and women's empowerment supports this conclusion. For example, access to cable television is found to result in lower acceptance of spousal abuse, lower son preference, more female autonomy, and a greater likelihood of sending young girls to school in rural India (Jensen and Oster 2009). 
FIGURE 3.11 The coverage of health services is almost the same for boys and girls in South Asia

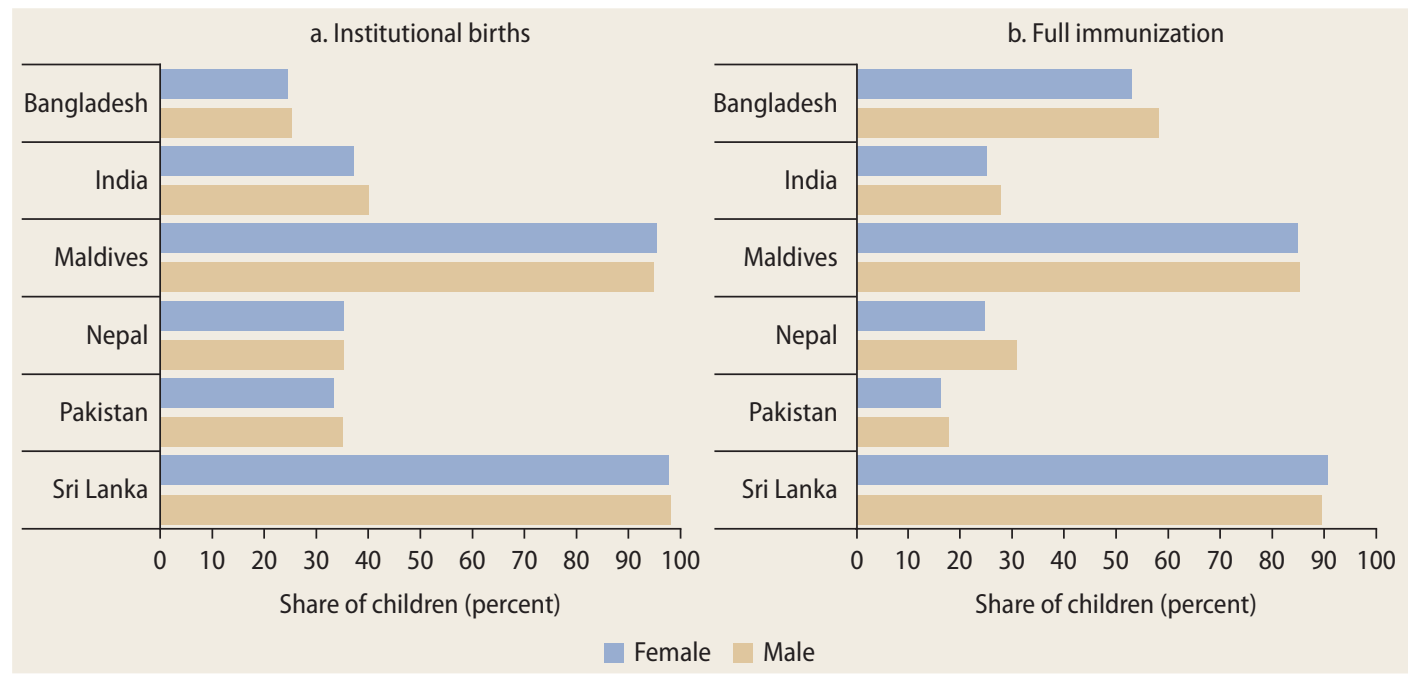

Sources: Based on Demographic and Health Survey (DHS) 2011 for Bangladesh, DHS 2005 for India, DHS 2009 for Maldives, DHS 2011 for Nepal, DHS 2007 for Pakistan, and DHS 2007 for Sri Lanka.

Gaps in coverage are also associated with the educational attainment of parents. In Bangladesh, India, Nepal, and Pakistan the coverage of institutional births is dramatically higher among mothers with higher education than among those with no education. In Bangladesh, India, only 13 percent of children with mothers who have no education are fully immunized, compared with 52 percent of children with mothers who have higher education (figure 3.13).

Parents' level of education generally does not make a big difference in a child's access to or completion of primary education. But parents' level of education plays an important role in whether the child attends and completes secondary school (figure 3.14). Children whose parents' have only 1 to 6 years of education have much lower secondary participation and completion rates than those whose mothers have 13 years of education or more. Even in Sri Lanka, where coverage is high, the gap between the two groups reaches 23 percentage points for school participation and a staggering 67 percent for school completion. The pattern is similar throughout the region.

The disadvantages faced by children with low parental education are illustrated by the case of first-generation learners. Illiterate parents or guardians often fail to fully understand the schooling process. As a result, first-generation learners receive limited guidance and support for schooling at home; they are more prone to nonenrollment, low attendance, and dropout and face more difficulty in making the transition from primary to secondary education (Govinda and Bandyopadhyay 2011).

These analyses compare the coverage of basic services along a single dimension, be it location, gender, or mother's education. But disadvantaged children are often disadvantaged along several of those dimensions simultaneously. An individual typically does not belong to just one disadvantaged circumstance group but to many such groups. These multiple disadvantages reinforce one other, resulting in much lower coverage.

\section{The role of inherited circumstances}

The insight that children's characteristics, such as their place of residence, their gender, or their mother's education, affect their access to basic services can be used to assess 


\section{FIGURE 3.12 Gender gaps in coverage are small for primary education but large for secondary education}

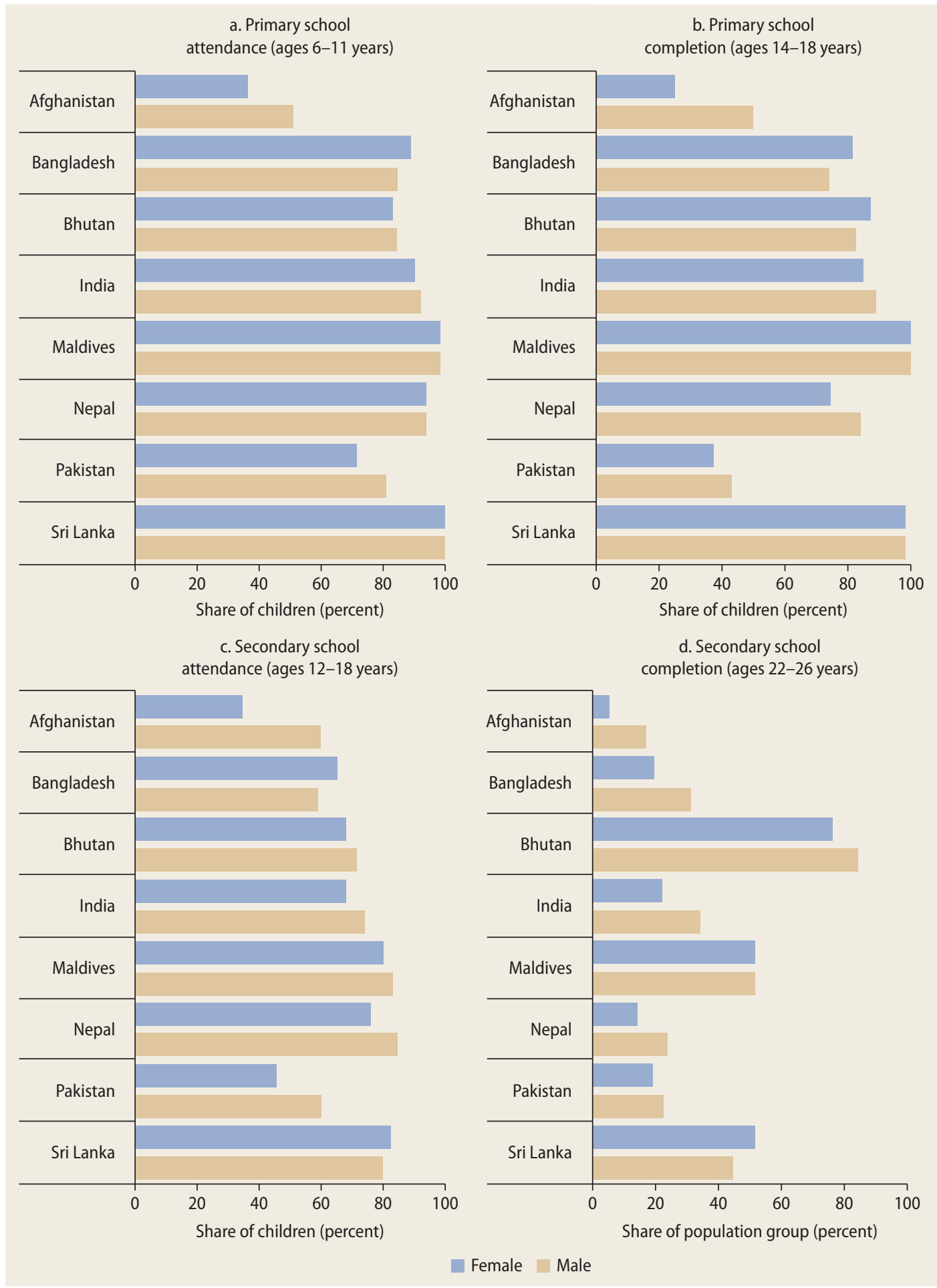

Sources: Based on National Risk and Vulnerability Assessment 2007 for Afghanistan, Household Income and Expenditure Survey (HIES) 2010 for Bangladesh, Bhutan Living Standards Survey 2007 for Bhutan, National Sample Survey 2009 for India, HIES 2009 for Maldives, Nepal Living Standards Survey 2010 for Nepal, HIES 2010 for Pakistan, and HIES 2009 for Sri Lanka. 
FIGURE 3.13 The coverage of health services differs widely by mother's education

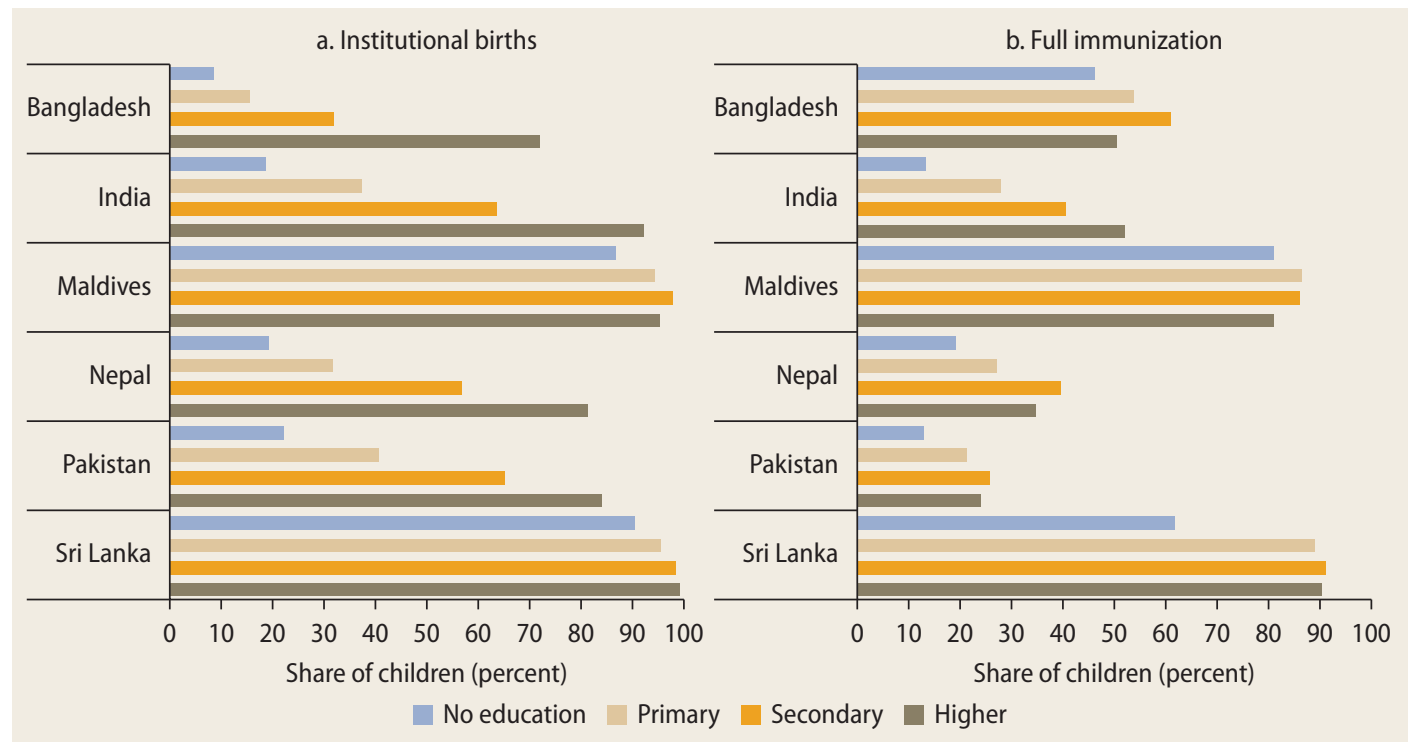

Sources: Based on Demographic and Health Survey (DHS) 2011 for Bangladesh, DHS 2005 for India, DHS 2009 for Maldives, DHS 2011 for Nepal, DHS 2007 for Pakistan, and DHS 2007 for Sri Lanka.

the overall contribution of inherited circumstances to inequality of opportunity. Several approaches have been proposed to do this (e.g., Ferreira and Gignoux 2011). Among them, the HOI framework is particularly appealing because it also allows decomposing inequality of opportunity between specific inherited circumstances and assessing how the contribution of each varies over time.

However, the HOI provides a lower bound on the inequalities prevalent in a given place. Its calculation can include only those circumstances that are measurable and for which data exist. If more circumstances were added to the set considered in the analysis, the HOI would increase (Paes de Barros and others 2009; Molinas and others 2010). The contribution of each circumstance thus corresponds to the measurable lower bound of inequalities, not to the actual inequalities in access.

In practice, the contribution of inherited circumstances to inequality of opportunity can be assessed by applying Shapley decompositions on the dissimilarity index. Shapley decompositions, originally proposed by Shorrocks (1999), show by how much inequality changes as a consequence of adding one more circumstance. Because circumstances are correlated with each other, the change in inequality when a circumstance is added depends on the initial set of circumstances to which it is added. To calculate the impact of each circumstance, the average of all possible changes to different combinations of other circumstances is computed.

Besides the three circumstances considered above-location, gender, and parents' education-the decomposition exercise for South Asian countries takes into account religion and, in India's case, caste. With the exception of Sri Lanka, location and mother's education explain a large fraction of the observed inequality in access to health services (figure 3.15). Taken together, they contribute at least 70 percent of the inequality in full immunization, rising to 94 percent in Pakistan and 96 percent in Maldives. The explanatory power ranges between 43 percent (Sri Lanka) and 98 percent (Pakistan) in the case of institutional births. Only in Sri Lanka is religion the most important correlate of inequality in access to health services.

Location and the education level of household head also explain a large part of 
FIGURE 3.14 Parents' education is highly correlated with children's secondary school attainment

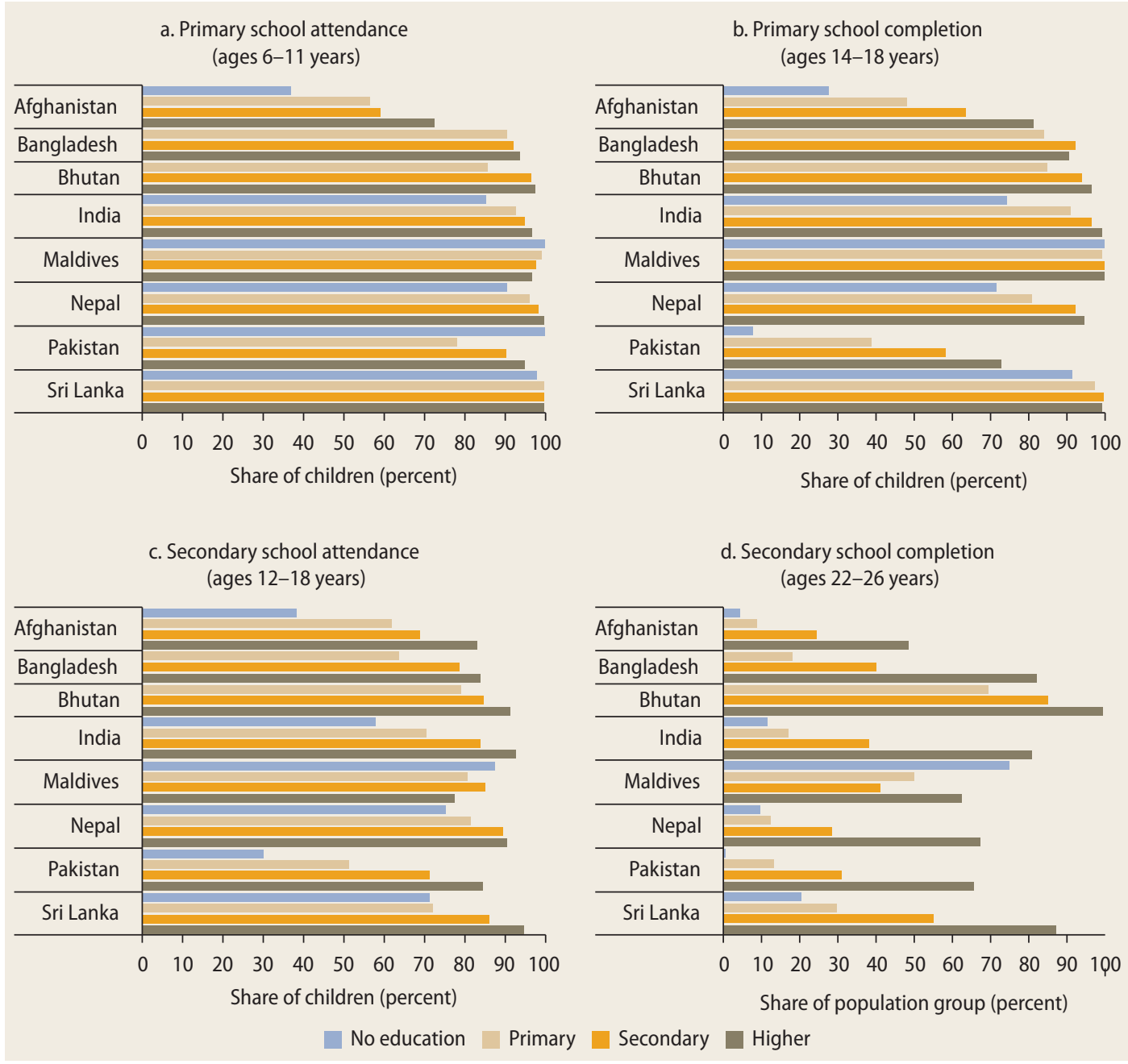

Sources: Based on National Risk and Vulnerability Assessment 2007 for Afghanistan, Household Income and Expenditure Survey (HIES) 2010 for Bangladesh, Bhutan Living Standards Survey 2007 for Bhutan, National Sample Survey 2009 for India, HIES 2009 for Maldives, Nepal Living Standards Survey 2010 for Nepal, HIES 2010 for Pakistan, and HIES 2009 for Sri Lanka.

the inequality in access to primary schooling and in its completion (figure 3.16). In several countries in the region, importantly Bangladesh, India, Nepal, and Sri Lanka, religion also explains some part of the inequality in access to primary education. In India, caste explains more than religion.

The relevant circumstances are more diverse in the case of secondary education. Although the education of the household head and location of residence continue to be important, gender plays a significant role in explaining secondary school attendance and completion across countries in the region.

For infrastructure, both the location of the household and the education level of household head are critically important circumstances. Their relative contribution varies by the types of services and across countries (figure 3.17). The location of the household is the most important circumstance in access to electricity in Afghanistan, Bangladesh, 
FIGURE 3.15 Location and mother's education are critically important circumstances in access to health services

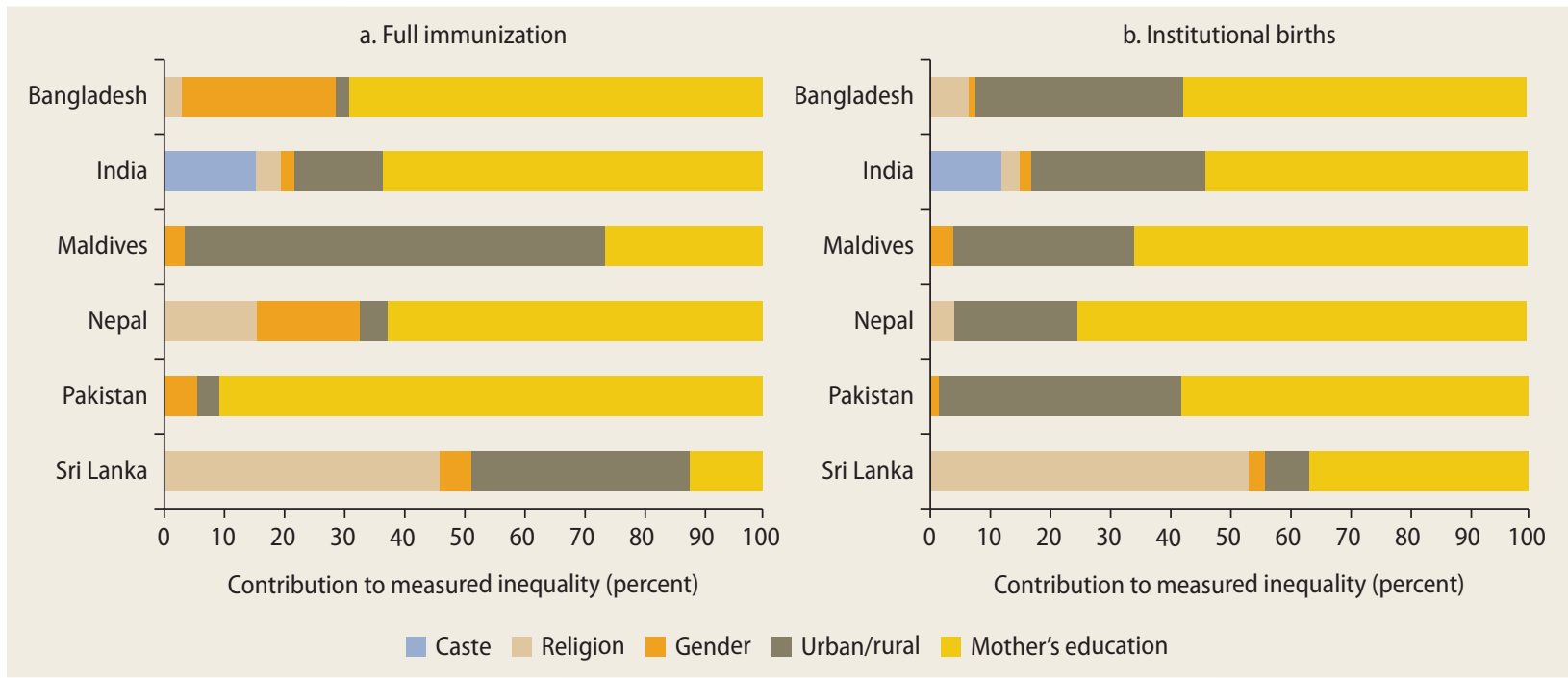

Sources: Based on Demographic and Health Survey (DHS) 2011 for Bangladesh, DHS 2005 for India, DHS 2009 for Maldives, DHS 2011 for Nepal, DHS 2007 for Pakistan, and DHS 2007 for Sri Lanka.

Bhutan, and India. It is also the dominant circumstance for access to sanitation in Maldives and Pakistan. In Nepal and Sri Lanka, the education level of the household head is more important in explaining the inequality of opportunity in access to infrastructure services. In India, caste also plays an important role.

\section{Limited resources and low progressivity}

Several factors explain South Asia's lackluster performance in ensuring equality in access to basic services. Importantly, public spending on education and health is relatively low. No doubt, higher public spending by itself may not be conducive to better outcomes, because the efficiency of spending matters as well. However, bigger public outlays are a prerequisite for improving coverage. Moreover, equity requires committing additional resources to children of disadvantaged groups to offset their more unfavorable circumstances. Unfortunately, the opposite is often observed in the region, with the betteroff benefiting from higher levels of public spending than those with greater needs.
Low levels of public spending are not immediately apparent when considering the share of government expenditures devoted to health care and education. For most countries in the region, that share is indeed close to the average for advanced countries. But advanced countries have much larger government expenditures relative to their gross domestic product (GDP) than their South Asian counterparts, so this comparison is only partially relevant.

A more meaningful comparison involves comparing public spending on health care as a fraction of GDP, rather than as a share of the budget, and controlling for the level of economic development. This comparison shows clearly that except for Bhutan and Maldives, all countries in the region spend much less public resources on health services than could be expected, given their income per capita (figure 3.18).

Public spending on health is also low in comparison with out-of-pocket spending by households. Whereas public expenditures on health care are below the global average, out-of-pocket expenditures are well above, with the exception of Bhutan. Outof-pocket expenditures accounted for about 


\section{FIGURE 3.16 Gender and religion matter for access to education}

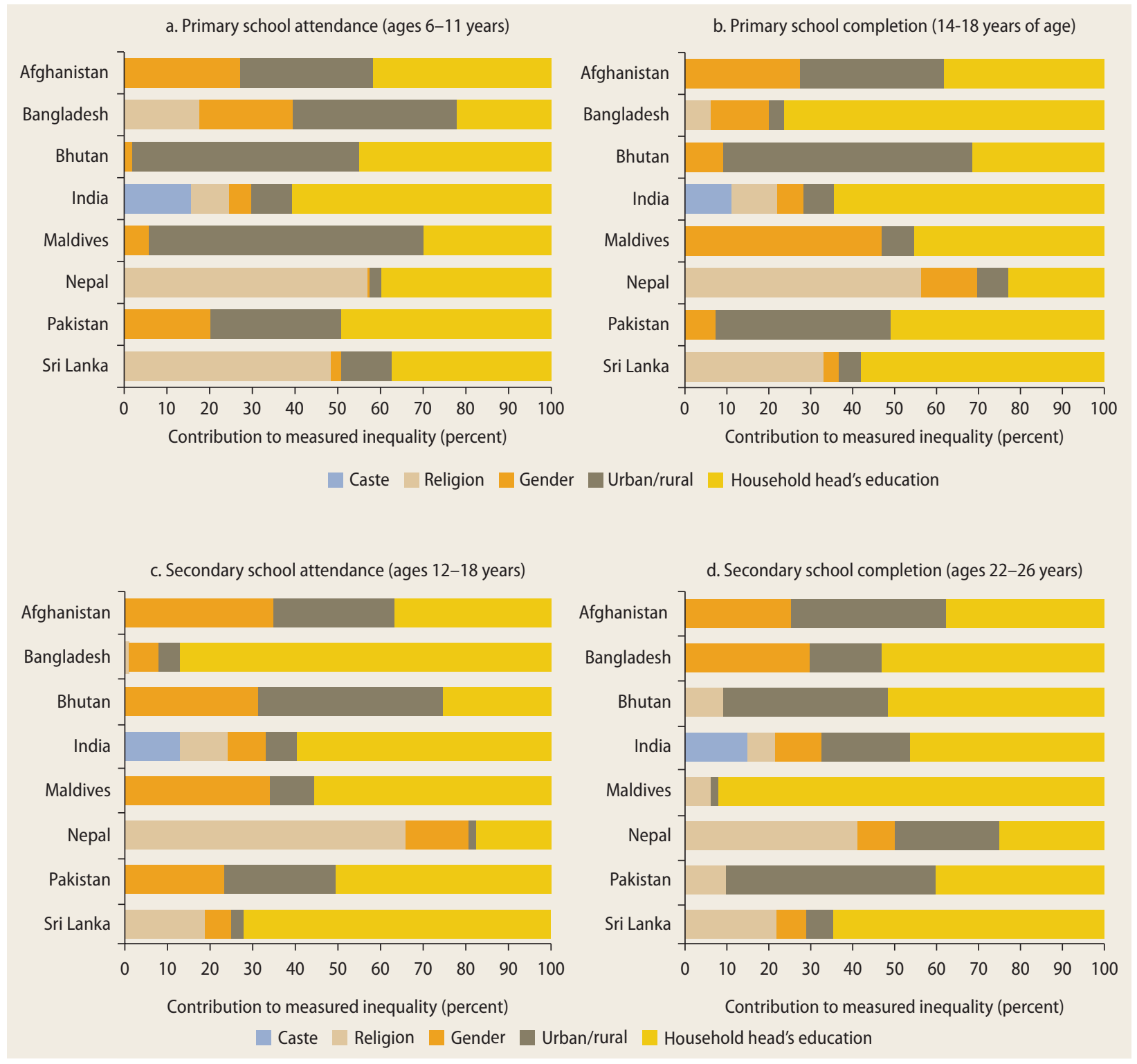

Sources: Based on National Risk and Vulnerability Assessment 2007 for Afghanistan, Household Income and Expenditure Survey (HIES) 2010 for Bangladesh, Bhutan Living Standards Survey 2007 for Bhutan, National Sample Survey 2009 for India, HIES 2009 for Maldives, Nepal Living Standards Survey 2010 for Nepal, HIES 2010 for Pakistan, and HIES 2009 for Sri Lanka.

58 percent of total health expenditures in the South Asia region in 2012. By contrast, the average out-of-pocket spending in the world is about 18 percent. The combination of low public outlays and high out-ofpocket expenditures is typically associated with a higher vulnerability of the population to fall into poverty or remain poor because of catastrophic expenditures. Regional trends over the past 10 years do not indicate major changes regarding this vulnerability. 


\section{FIGURE 3.17 Location is a critical circumstance for access to infrastructure services}

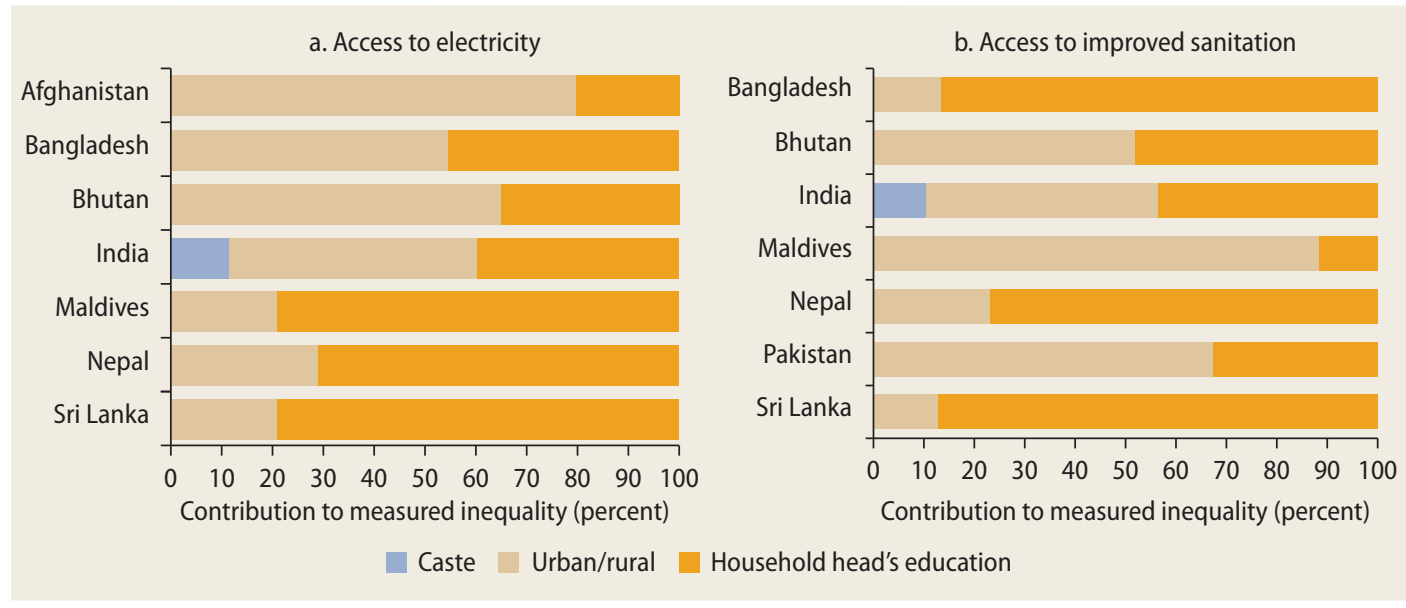

Source: Based on Andres and others 2013 for this report.

\section{FIGURE 3.18 Limited public resources are spent on health services in South Asia}

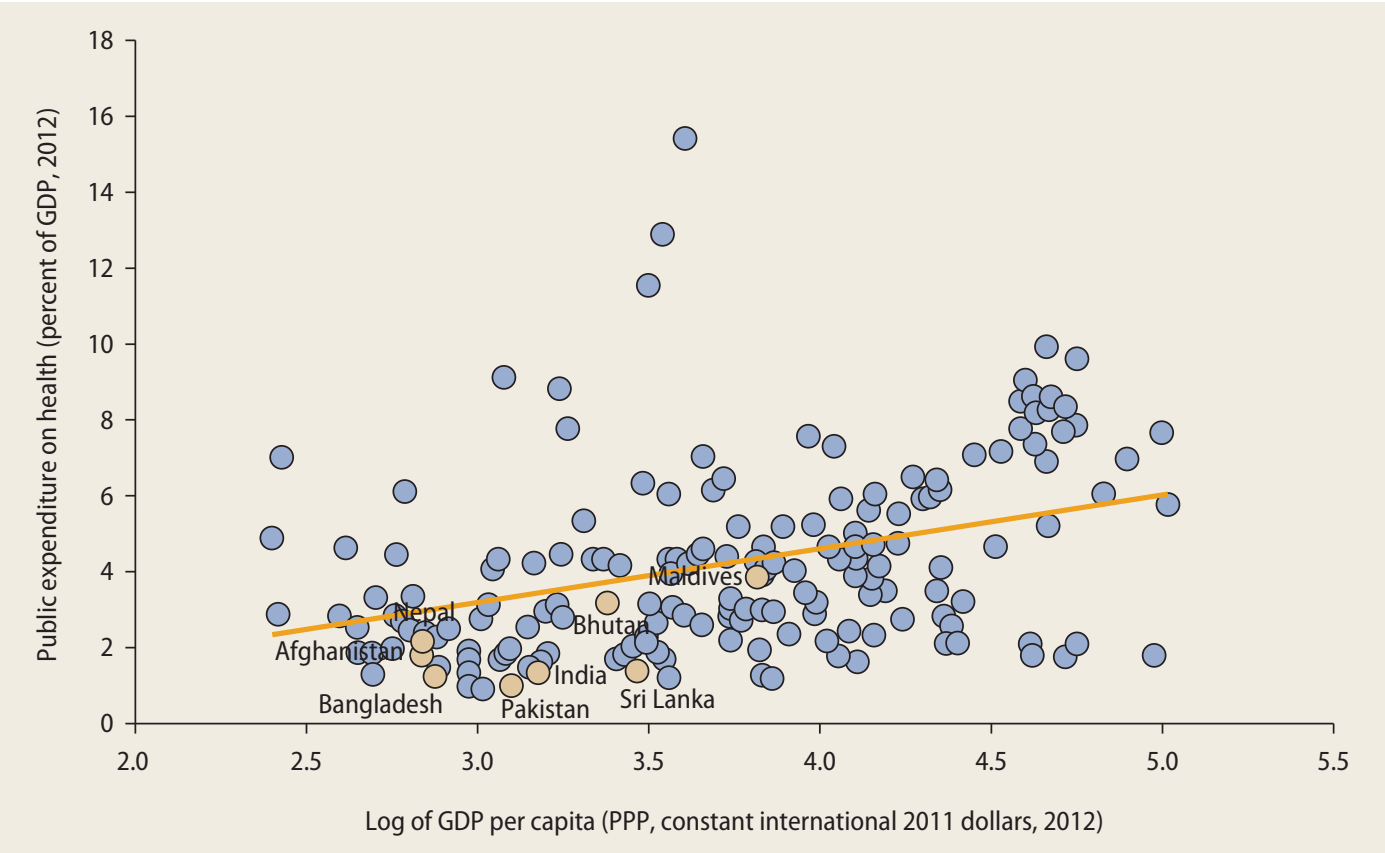

Source: Based on data from the World Bank's World Development Indicators database, http://data.worldbank.org/data-catalog/world-development -indicators.

Not only are public resources allocated to health care low in most South Asian countries, but in most of the region they are also allocated with low progressivity. Overall, public spending on health care is distributed in a relatively even manner in Sri Lanka. But it is directed more toward the better-off than to the poor in Bangladesh, India, and Nepal. Furthermore, public spending still works to reduce the gap between the rich and the poor 
in Bangladesh but does not appear to do so in India and Nepal (O'Donnell and others 2007). This is in clear contrast to public health spending patterns in East Asian economies, which are much more pro-poor.

The progressivity of public spending varies across health services. Public spending on hospital care, which tends to support more sophisticated services, is biased toward the better-off. By contrast, spending on nonhospital care is pro-poor. Because a large share of public spending on health care is generally allocated to hospital care, the overall spending pattern is regressive.

Nepal is a case in point. Spending on hospitals and mobile clinics is found to benefit the richer population more while gross subsidies for local health facilitates are significantly progressive. Even after taking fee payments into account, public spending on hospitals-net spending - is still biased against the bottom population quintile, because of the prohibitive access costs (Silva-Leander 2012). The extent of progressivity also varies across types of services. In Bangladesh, for example, spending on child care is clearly progressive, whereas curative care tends to be regressive (figure 3.19).

South Asian countries also spend less on education than other countries at a similar level of development (figure 3.20). In particular, Bangladesh, India, Pakistan, and Sri Lanka all sit far below the international trend line between public spending on education and income level. India's public spending per student on primary education puts it among the lowest quintile of all countries with available information. Its public spending per student on secondary education is higher but still falls below the average of comparators. Trends have not been encouraging either. Overall, rapid economic growth in South Asia did not lead to significant increases in per student expenditure, which generally remained constant (World Bank 2014).

The extent of progressivity in public spending varies across education levels. It tends to be progressive in the case of primary education but regressive at secondary and especially at tertiary levels. For instance, the poorest 40 percent of the population in Bangladesh
FIGURE 3.19 Spending is progressive only for some health services in Bangladesh

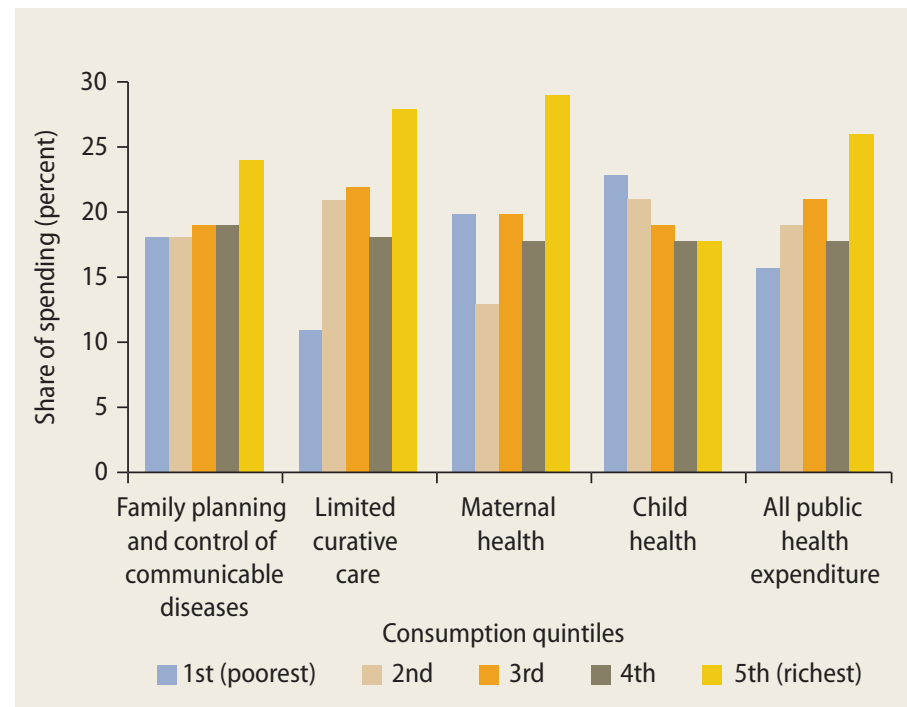

Source: World Bank 2003.

received 50 percent of public primary spending in 2010, up from 32 percent in 2005. However, the richest 40 percent received about 80 percent of public spending directed to tertiary education (figure 3.21). A similar pattern is found in India and Pakistan.

The different extent of progressivity across education levels results partly from the very different shares of the relevant population covered by each level. Access to primary education has been broadened greatly in the region, but access to secondary and tertiary education remains low. However, public spending per student is generally higher for the latter. In India, for instance, public spending per student is above the world average for tertiary education but below it for primary and secondary education. Because access to higher education is highly correlated with household income, geographical location, and social background, the result is a more regressive pattern of spending when moving from lower to higher levels of education (World Bank 2014).

Public spending on education is also found not to reach its intended beneficiaries. Because the more disadvantaged suffer disproportionately from resource waste of this 


\section{FIGURE 3.20 Limited public resources are spent on education services}

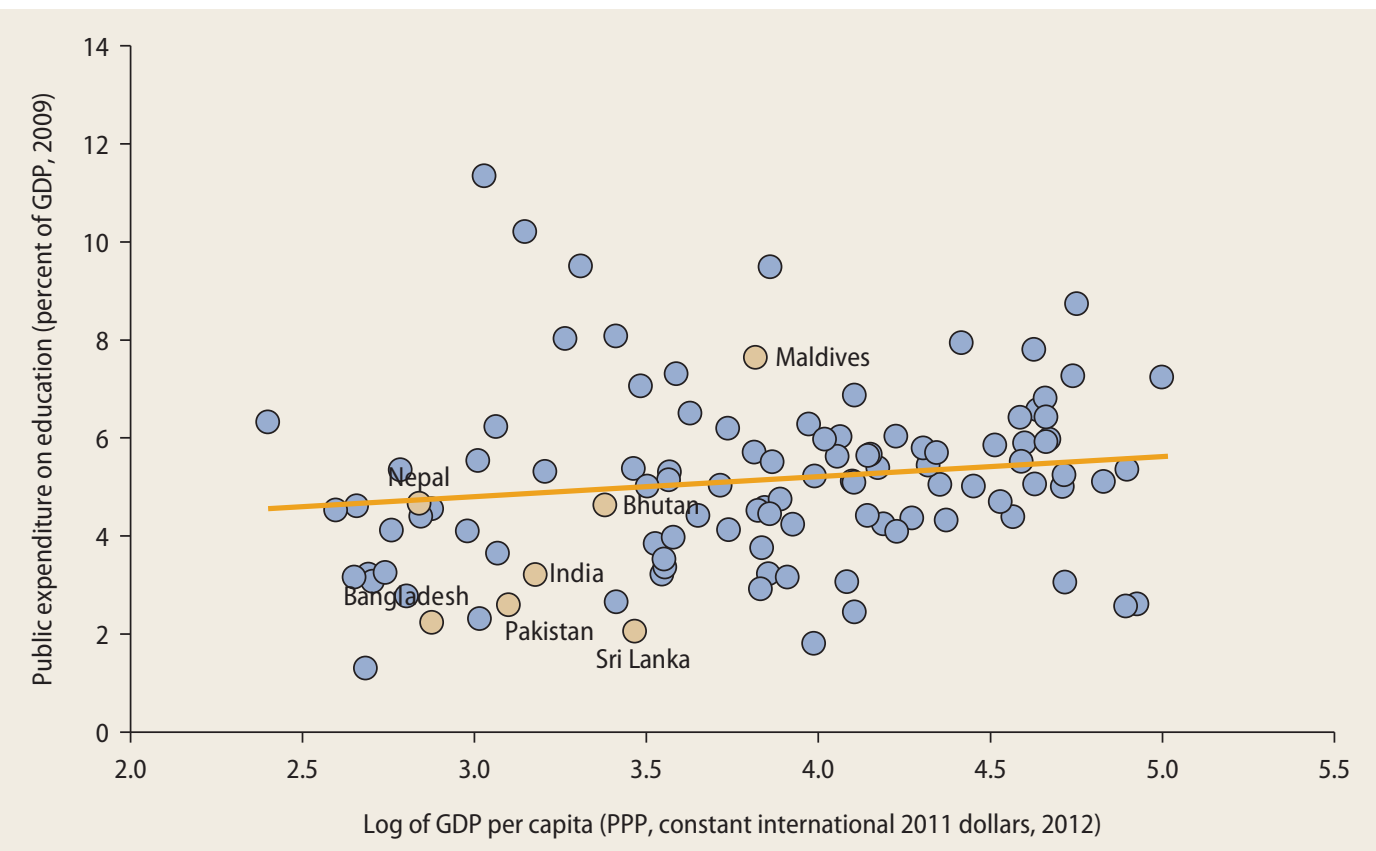

Source: Based on data from the World Bank's World Development Indicators database, http://data.worldbank.org/data-catalog/world-development -indicators.

\section{FIGURE 3.21 In Bangladesh, education spending is progressive only at the primary level}

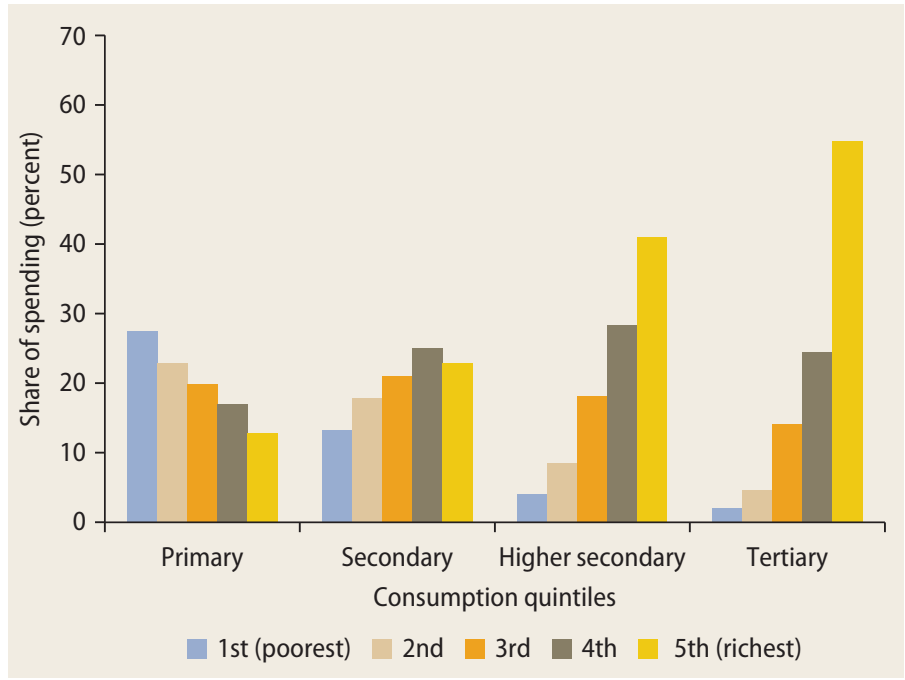

Source:World Bank 2013. sort, public spending can be less progressive than figures suggest. An example is the use of funds under Sarva Shiksha Abhiyan-India's flagship program for universalizing elementary education. Schools frequently do not get their money in whole or on time (Dongre, Chowdhury, and Aiyar 2012). Among nine districts of seven Indian states, no district gets all the funds allocated to it. Considerable variation occurs between districts and across schools, however. Some districts get a much higher percentage of the funds allocated to them; in some districts, only 11 percent to 12 percent of schools report receiving the grants annually. Many districts receive funds late in the school year, which prevents them from procuring important teaching and learning materials or from undertaking school maintenance until they are five or six months into the school year. 


\section{Limited opportunity: Main messages and policy implications}

Equality of opportunity is associated with notions of fairness. It is widely believed that people who have the same talent and the same willingness to work hard should have the same prospects of succeeding, regardless of their circumstances at birth. Access to basic services such as health, education, and infrastructure, especially at the beginning of life, is seen as essential to ensure they do. Equality of opportunity also matters for positive reasons. Typically, children from better-off households have greater access to basic services in their childhood, which allows them to live a healthier life and to accumulate more human capital than children from more disadvantaged backgrounds. As a result, the gap in well-being is bigger in adulthood than in childhood. In societies undergoing demographic transitions, the share of adults increases steadily, implying that a stable inequality of opportunity translates into a growing inequality of outcomes.

In South Asia, access to basic health services, including immunization and institutional birth, tends to be limited. Access to primary education tends to be better, because most countries in the region have reached universal school coverage or are on the way to attaining it. In between these two extremes, the picture on access to secondary education and to basic infrastructure services such as electricity and sanitation is more mixed. The coverage of all these services is generally expanding, but progress is less in equity, because disadvantaged population groups remain consistently excluded. Even the progress in coverage is somewhat misleading, because the expansion in access to basic services often occurs at levels of quality below those available for better-off groups.
Circumstances at birth-including location along the rural-urban divide, gender, religion or caste, and parents' education-remain crucial determinants of access. The coverage of basic services is consistently lower in rural areas than in urban areas. Gender is not an important correlate of access in the case of health services and primary education, but girls have lower access to secondary education than boys. Mother's education makes a substantial difference in access to health services and in school attainment. Overall, location and mother's education account for most of the inequality in access to health, whereas gender and religion also matter for the inequality in access to education. Location is a critical factor in relation to access to basic infrastructure services.

Low coverage of basic services and limited equity in accessing them can be traced to insufficient and often regressive public spending. Compared with spending in other countries at a similar level of development, public spending on health and education represents a lower share of GDP in South Asian countries. Depending on the service considered, public spending can be progressive-more tilted toward the poor-or regressive. For instance, spending on child health and on primary education tends to be progressive, whereas outlays related to hospital care or tertiary education are regressive. Although the number of beneficiaries of the regressive programs is smaller, spending on them is larger. This makes the overall public spending on the provision of basic services regressive, thus undermining equality of opportunity.

\section{References}

Andres, Luis, Dan Biller, Mario Picon, and Agustin Echenique. 2013. "Increasing Opportunities in South Asia-Infrastructure.” Background paper for this report, World Bank, Washington, DC.
Arneson, Richard J. 1989. "Equality and Equal Opportunity for Welfare." Philosophical Studies 56 (1): 77-93.

Cohen, Gerald A. 1989. "On the Currency of Egalitarian Justice.” Ethics 99 (4): 906-44.

Dongre, Ambrish, Anirvan Chowdhury, and Yamini Aiyar. 2012. "Unpacking School 
Finances." Background paper for this report, World Bank, Washington, DC.

Dworkin, Ronald. 1981a. "What Is Equality? Part 1: Equality of Welfare." Philosophy and Public Affairs 10 (3): 185-246.

- 1981b. "What Is Equality? Part 2: Equality of Resources." Philosophy and Public Affairs 10 (4): 283-345.

Ferreira, Francisco H. G., and Jérémie Gignoux. 2011. "The Measurement of Inequality of Opportunity: Theory and an Application to Latin America." Review of Income and Wealth 57 (4): 622-57.

Govinda, R., and Madhumita Bandyopadhyay. 2011. "Access to Elementary Education in India: Analytical Overview." In Who Goes to School? Exploring Exclusion in Indian Education, edited by R. Govinda. New Delhi: Oxford University Press.

Jensen, Robert, and Emily Oster. 2009. "The Power of TV: Cable Television and Women's Status in India." Quarterly Journal of Economics 124 (3): 1057-94.

Kanbur, Ravi. 2009. “Intergenerationalities: Some Educational Questions on Quality, Quantity and Opportunity." Working Paper No. 48922, Department of Applied Economics and Management, Cornell University, NY.

Khan, M. M. H., Oliver Grübner, and Alexander Krämer. 2012. "Frequently Used Healthcare Services in Urban Slums of Dhaka and Adjacent Rural Areas and Their Determinants." Journal of Public Health 34 (2): 261-71.

Molinas, José R., Ricardo Paes de Barros, Jaime Saavedra, and Marcelo Giugale. 2010. Do Our Children Have a Chance?: The 2010 Human Opportunity Report for Latin America and the Caribbean. Conference Edition. Washington, DC: World Bank.

O'Donnell, Owen, Eddy van Doorslaer, Ravi P. Rannan-Eliya, Aparnaa Somanathan,
Shiva Raj Adhikari, Deni Harbianto, Charu C. Garg, Piiya Hanvoravongchai, Mohammed N. Huq, Anup Karan, Gabriel M. Leung, Chiu Wan Ng, Badri Raj Pande, Keith Tin, Kanjana Tisayaticom, Laksono Trisnantoro, Yuhui Zhang, and Yuxin Zhao. 2007. "The Incidence of Public Spending on Healthcare: Comparative Evidence from Asia." World Bank Economic Review 21 (1): 93-123.

Paes de Barros, Ricardo, Francisco H. G. Ferreira, Jose R. Molinas Vega, and Jaime Saavedra Chanduvi. 2009. Measuring Inequality of Opportunities in Latin America and the Caribbean. Washington, DC: World Bank; New York: Palgrave Macmillan.

Rawls, John. 1971. A Theory of Justice. Cambridge, MA: Harvard University Press.

Roemer, John E. 1998. Equality of Opportunity. Cambridge, MA: Harvard University Press.

Shorrocks, Anthony F. 1999. "Decomposition Procedures for Distributional Analysis: A Unified Framework Based on the Shapley Value." Department of Economics, University of Essex, Colchester, U.K.

Silva-Leander, Sebastian. 2012. "Benefit Incidence Analysis in Health." Nepal Health Sector Support Programme (NHSSP), Government of Nepal.

World Bank. 2003. Bangladesh: Public Expenditure Review. Report No. 24370-BD. Washington, DC: World Bank.

- 2005. World Development Report 2006: Equity and Development. Washington, DC: World Bank.

- 2013. Bangladesh Education Sector Review: Seeding Fertile Ground-Education That Works for Bangladesh. Washington, DC: World Bank Group.

2014. Student Learning in South Asia: Challenges, Opportunities, and Policy Priorities. Washington, DC: World Bank. 


\section{Substantial Mobility}

E conomic mobility has often been seen as an avenue to long-term equality (box 4.1). The celebrated Austrian economist Joseph Schumpeter (1955) is said to have likened income distribution to a hotel. The rooms at the top are luxurious, those on the middle levels are ordinary, and those in the basement are downright shabby. At any given time, the occupants of the hotel experience very unequal accommodations. At a later time, if one reexamines who is living where, one finds that some have moved to higher floors, some have moved to lower floors, and some have stayed where they were. The difference in the quality of hotel rooms provides a static measure of inequality. The movement of hotel guests among rooms of different quality is mobility. The more movement of guests that occurs among floors, the greater is the likelihood of longterm equality in accommodations.

Economic mobility is also a foundation for efficiency. Mobility leads to a better use of talent. If the distribution of creativity or resourcefulness across the population is less unequal than the distribution of income or consumption, societies with greater mobility may be able to mobilize the talent of all population groups and not only those of the better-off. Mobility also strengthens incentives. In a society where the poor and the rich (or at least their children) are equally likely to succeed or fail, people belonging to all groups have a higher motivation to work hard. Mobility has been seen to foster aspiration, efforts, innovation, and self-fulfillment. Last but not least, mobility reduces waste. Highly mobile societies are less prone to social conflict and less tempted by redistributive policies, both of which have negative implications for economic growth.

Although economists tend to think of mobility in terms of income and consumption, economic and social mobility are intertwined, especially through jobs. In most societies, jobs are fundamental sources of self-respect and social identity. The distribution of jobs within society and perceptions about who has economic mobility can shape individuals' perceptions of fairness and aspirations for the future. In South Asia, marginalized population groups traditionally suffer from both material poverty and social indignity. This situation is most obvious in the case of a caste system, where occupations are essentially set for individuals at birth. In a perfectly mobile society, by contrast, occupational choices should be independent across generations. For instance, the children of manual and nonmanual workers would have 


\section{BOX 4.1 For a given inequality of opportunity, mobility reduces the inequality of outcomes}

Even if equality of opportunity were assured, at any point in time differences in well-being would exist across households. Even when they have the same access to health, education, and basic infrastructure, people may differ in their talent or in their natural inclination to work hard. As a result, some inequality of outcomes can be expected even in youth, when people are just leaving school and making their first choices on where to live, whether to work, and what kind of work to do.

This initial inequality of outcomes would of course be even greater if no real equality of opportunity exists, as is generally the case in South Asia. However, it does not follow that countries lacking equality of opportunity are condemned to experience a large and potentially growing inequality of outcomes. Whether this happens depends in large part on how the workings of the economy reward the choices people make about where to live and what kind of work to do. In rapidly urbanizing societies, switching out of agriculture, moving to cities, and working for a wage may offer avenues for mobility to some of the poorest population groups. Thus, despite being at a disadvantage in terms of health or skills, poorer households could end up experiencing bigger gains in well-being than the better-off, and inequality of outcomes in adulthood could be smaller than in childhood. The figure illustrates that possibility.
This simple analysis has important implications. Because much of the debate on inequality has focused on opportunities, policy emphases have been on access to basic services, including health, education, and infrastructure as seen from the household perspective. But the role of mobility as a driver of reduced inequality of outcomes calls for a focus on jobs and the rural-urban transformation. Even if this case also has implications for infrastructure, the kind of investments needed could be quite different.

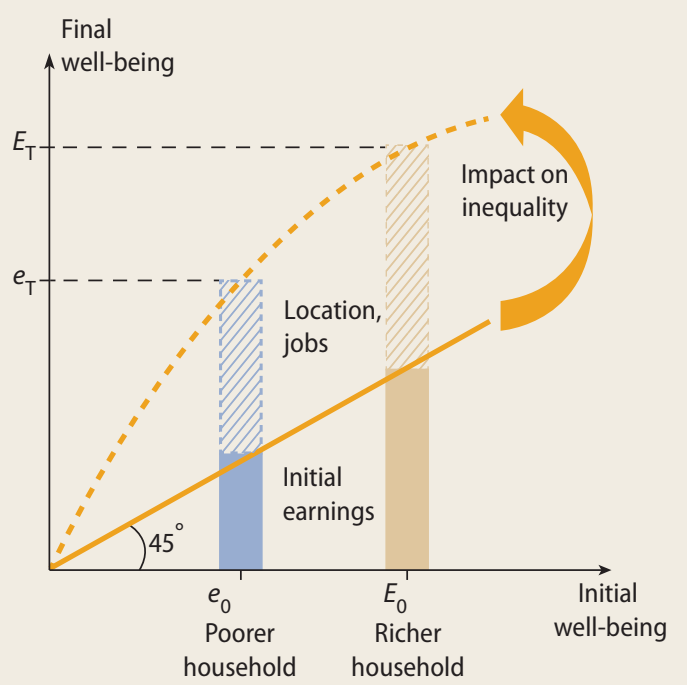

similar prospects of securing nonmanual jobs. If so, growth should allow the people from marginalized groups to move into the mainstream of society.

These intuitions can be followed to assess the extent of mobility across and within generations in South Asian countries. Contrary to expectations, economic mobility has become substantial in the region in recent decades, especially for socially marginalized groups. In India, the sons of unskilled or farming fathers see significant prospects of working in occupations with higher income and greater social prestige. Moreover, the association between the occupations of sons and fathers has declined steadily over time. That is, occupational mobility has become higher for younger generations. The improvement is more pronounced for the more socially marginalized populations, namely, the Scheduled Castes, the Scheduled Tribes, and Other Backward Castes.

In the case of Bangladesh and India, when splitting the population into three groupspoor, vulnerable, and middle class-a sizable proportion of the poor moves up to the 
vulnerable group within the same generation, while a large proportion of the vulnerable moves into the middle class. In India, the upward mobility of households belonging to Scheduled Castes and Scheduled Tribes is similar to that of the rest of the population. In a way, the dynamism of market forces appears to have trumped the rigidity of social institutions.

At the level of villages, increasing mobility is largely associated with occupational change. Rural areas in South Asian countries have seen nonfarm activities expanding and generating many of the new jobs. Although nonfarm employment is mainly casual, it has supported mobility. The earnings gap between regular and casual nonfarm jobs has narrowed over time, whereas the earnings gap between casual nonfarm jobs and agricultural jobs has increased. Growing integration with urban economies, expanding markets, and migration opportunities are also shaking up traditional social structures and offering a chance for the most disadvantaged in these villages to prosper.

Urbanization and the associated geographical differences in economic dynamism are important forces underpinning mobility. Those geographical differences lie behind internal migration. In South Asia, permanent internal migration accounts for a significant fraction of the population across countries. Many move to fulfill their aspiration for jobs and investment opportunities. Indeed, permanent migration is an important strategy for upward mobility for both men and women. Seasonal migration has been consistently identified as more likely to originate in groups that are poorer and more socially marginalized and in places that are more prone to natural disasters and conflict. For people from these groups and regions, temporary migration is a viable accumulation strategy, an effective seasonal distress reduction mechanism, and even an escape route from social discrimination.

Cities themselves support greater mobility than rural areas, both within and across generations. A larger fraction of poor and vulnerable households achieves middle-class status in urban areas in Bangladesh and India despite the existence of a large urban informal sector. Urban wage employment, regardless of whether it is formal or informal, offers better prospects of economic mobility for a massive number of households in South Asia. Urbanization is taking place through diversified processes, however. People move to cities through migration, but cities also "move" to people through the transformative effect of economic activity in formerly rural areas. These diverse processes have created cities with different characteristics. The availability and nature of jobs-hence mobility prospectsvary across cities of different types.

\section{Mobility across generations}

Whereas economists tend to assess mobility on the basis of monetary indicators such as income or consumption, mobility has social dimensions as well. Sociologists generally see mobility through the lens of classes and, often, occupational groups. Some of them believe that occupation is the most critical factor in an individual's social standing, life chances, and level of material comfort and that occupation defines the extent to which an individual is advantaged or disadvantaged (Giddens 2009).

Increasingly, economists have started to adopt occupational change as a metric for measuring mobility, partly because of data availability (Long and Ferrie 2007, 2013). More important, economists have started to recognize the broader implications of occupations and jobs. Jobs contribute to individuals' view on who they are and their relationships with others. In most societies, jobs are fundamental sources of self-respect and social identity. Some jobs are empowering and others are less so. In the extreme case, the lack of jobs can contribute to violence. The distribution of jobs within society and perceptions about who has access to job opportunities influence individuals' perceptions of fairness and aspirations for the future (Akerlof and Kranton 2010; World Bank 2012b).

In South Asia, economic and social mobility are historically intertwined. 
The caste system, an inflexible and lineagebased social ordering of Hinduism, is a clear manifestation of the links between the two dimensions. The ancient Hindu society stratified the population into mutually exclusive, hereditary, and occupational-specific compartments. The occupations reserved for the top castes were generally nonmanual and not linked to the production of objects or the provision of services. In contrast, the occupations mandated for out-castes (Scheduled Castes) were menial in nature: for example, skinning dead cows and sweeping roads. Occupations were essentially set for individuals at birth, leaving little space for aspiration, efforts, innovation, and fulfillment (Deshpande 2000). Other socially marginalized populations, including Scheduled Tribes, and other religious and ethnic minorities traditionally suffer from social indignity and material poverty.

In contrast, a perfectly mobile society is one where occupation in one generation is not particularly informative to predict occupation in the next one. That would imply that the sons of fathers in occupations with higher economic returns and social prestige have no advantage in securing such an occupation relative to sons of fathers in occupations with lower economic returns and social prestige. This extreme situation, described as "occupational independence," captures the notion of perfect mobility across generations. Under complete occupational independence, the children of farmers and those of engineers would have similar prospects of securing an engineering job, while the children of Scheduled Castes and those of other population groups would face similar probabilities of doing nonmanual jobs.

Because of limitations of data availability, a measure of occupational independence across generations in South Asia can be computed only for India (box 4.2). There, matched father-son information is reported by the IHDS and it is based on a nationally representative sample. The sons in this data set include birth cohorts from as early as 1945 and as late as 1984. Data on selfreported occupation in the preceding year are available in the case of sons; in the case of fathers, data refer to occupation for most of life as reported by sons. For both generations, occupations are mapped into four categories in a broadly ascending order of economic returns and levels of social prestige: unskilled workers, farmers, skilled or semiskilled workers, and white-collar workers.

The analysis reveals considerable occupational mobility across generations (figure 4.1). The sons of unskilled fathers and those of farming fathers both saw significant prospects of moving to higher-ranked jobs in terms of economic returns and social prestige. Over 40 percent of the children of unskilled workers were holding other occupations. About 36 percent of the children of farmers worked as skilled or semiskilled workers or as white-collar workers. The children of white-collar fathers experienced the highest downward mobility rate among all four groups-over 55 percent.

Occupational mobility across generations is not only substantial, but it has also increased over time (figure 4.2). Based on the notion of occupational independence, the analysis compares the occupational transition matrices of sons from each of the four birth cohorts (1945-54, 1955-64, 1965-74, and 1975-84) with the hypothetical transition matrix of a perfectly mobile society. The comparison shows that the differences between two successive 10-year cohorts are not always significant. However, the mobility experienced by sons relative to the perfectly mobile society has increased significantly between the first and the last cohorts. On average, the children of people in basic occupations have seen rising prospects of taking higher-ranked occupations relative to the children of people in higher-ranked occupations. The conclusion appears to be robust to the classification of occupations and the methodology used for the comparison across cohorts (Singh and Motiram 2012).

The increases in occupational mobility across generations over time may be more pronounced than what is being observed. Two important caveats relate to the data. Fathers and sons potentially are of different 


\section{BOX 4.2 Measuring mobility}

Economists have developed multiple measures to assess the extent of mobility. These measures reflect different notions of what economic mobility actually is (Björklund and Jäntti 2000; Fields 2008; Fields and Ok 1996, 2000; Salverda, Nolan, and Smeeding 2011). Broadly speaking, three types of measures exist: movement, origin independence, and long-term equalization of outcomes such as earnings and incomes (see Ferreira and others 2011 for surveys; Fields 2008). Movement measures focus on changes in the distribution of outcomes over time. Origin-independence measures focus on the correlation between positions in the distribution of outcomes at two points in time. Longterm equalization measures focus on inequality in permanent outcomes. These measures can be analyzed for the same individuals over time (intragenerational mobility) or for related individuals across generations (intergenerational mobility). Because the analysis requires information on the same individuals or households at different points in time, data availability heavily influences the selection of indicators of mobility.

Comparing occupations over time is in a way more complex than comparing income or consumption. Empirically, classes and occupational groups are taken as either intrinsically discrete and unordered or as associated with different levels of prestige. In the first case, greater fluidity among the groups-in any direction-is seen in a positive light. In the second case, only greater movement from low- to high-prestige attainment-greater upward mobility-is seen as socially desirable (Erikson and Goldthorpe 1992; Ganzeboom and Treiman 1996; and Björklund and Jäntti 2000 for a survey).

Assessing occupational mobility requires computing how people's occupations change over time, under the form of a transition matrix. The question is whether having a father in a higher-ranked occupation improves the odds of a son being in a higher-ranked occupation and by how much. When there are only two occupations, that question can be answered by looking at the cross-product ratio, defined as the ratio of (a) the odds that sons of fathers in the basic occupation will be in the basic rather than the higher occupations to (b) the odds that sons of fathers in the higher occupation will be in the basic rather than the higher occupation. If the knowledge of a father's occupation yields no information about the odds of a son being in the basic or higher occupation the crossproduct ratio is equal to one.

When there are more than two occupations, the number of cross-products increases. Altham statistics can be used to combine all of them to compare the actual transition matrix to the hypothetical matrix of a perfectly mobile society, in which all cross-product ratios are equal to one (Ferrie 2005; Long and Ferrie 2007). ages and thus may be at different points of their life cycle. Individuals of the four cohorts are of different ages and are likely to be at different points of their life cycle as well. When individuals are younger, they are more likely to start with the profession of their parents or to land jobs with lower economic and social prestige. The data do not allow more refinement to control for age differences. Without accounting for age differences, the analysis may underestimate the increases in occupational mobility over time.

The most notable improvements in mobility are found for Scheduled Castes, Scheduled Tribes, and Other Backward Castes. The analysis is conducted separately for sons from two broader birth 
FIGURE 4.1 Considerable occupational mobility exists across generations in India

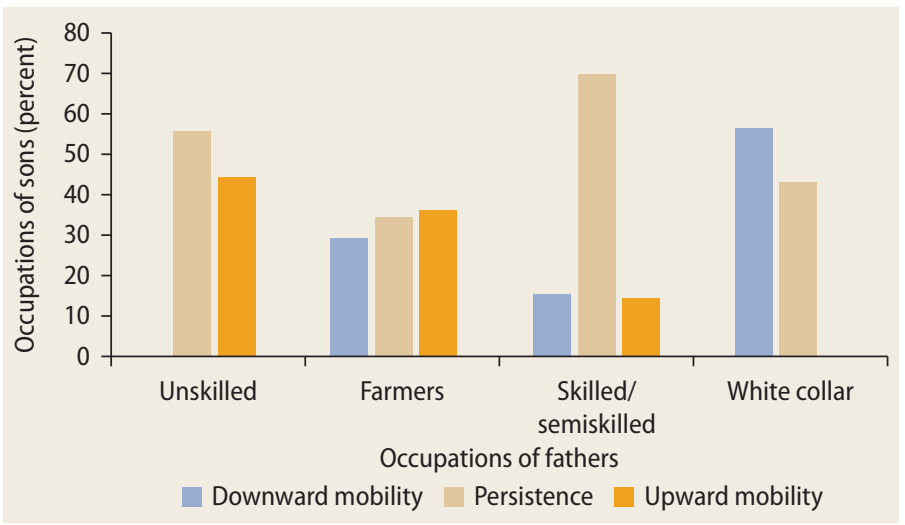

Source: Based on India Human Development Survey (IHDS) 2004-05.

\section{FIGURE 4.2 Occupational mobility is higher for younger generations}

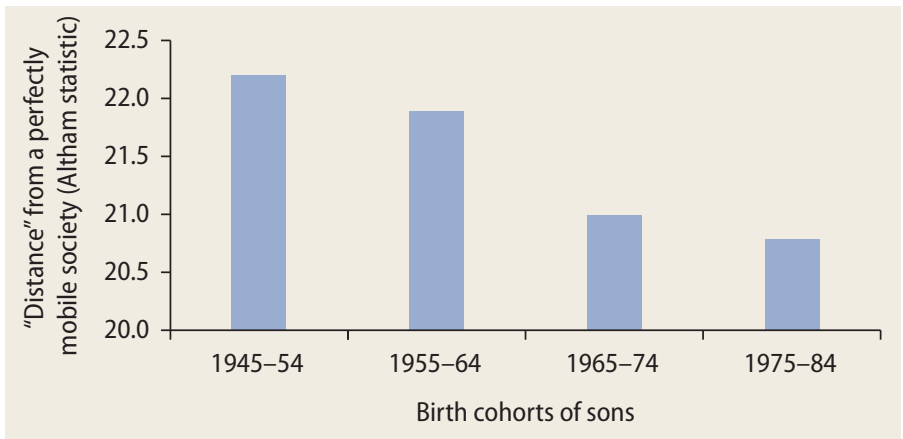

Source: Based on IHDS 2004-05.

Note: "Distance" is measured as the Altham statistic comparing the actual transition matrix to that of a hypothetical, perfectly mobile society.

cohorts, 1945-64 and 1965-84, to have sufficiently large samples. The transition matrices of socially marginalized groups are compared in this case with those of highercaste Hindus. The comparison shows that mobility among Muslims is similar to that of higher-caste Hindus, whereas mobility among Scheduled Castes and Scheduled Tribes and among Other Backward Castes has become higher (table 4.1). Again, the conclusion appears to be robust to the choice of methodology (Hnatkovska, Lahiri, and Paul 2013).

\section{Mobility within the same generation}

A truly mobile society is arguably one in which poorer households can manage to climb up the income or consumption ladder through their own efforts within a single generation. Mobility of this sort requires that the growth in the income or the consumption of the poor be faster than the growth of the average person. When splitting the population into three groups-poor, vulnerable, and middle class - a fraction of the poor should be able to move above the poverty line while some of the vulnerable should be able to make solid progress into the middle class. A truly mobile society is one in which this prospect also exists for socially marginalized groups.

Mobility within the same generation can be assessed through the average growth rate of household income or consumption between two periods (Ferreira and others 2012; Fields 2010; Fields and Ok 1996). But doing so requires nationally representative information on the same households at two points in time-so-called panel data-which is generally not available for South Asian countries. One exception is the Pakistan Social and Living Standards

TABLE 4.1 Occupational mobility has increased more for the most disadvantaged population groups in India

\begin{tabular}{lcc}
\hline Disadvantaged group & Occupational mobility, cohort born in & Occupational mobility, cohort born in \\
\hline Muslims & No45-64 & 1965-84 \\
$\begin{array}{l}\text { Scheduled Castes and Scheduled } \\
\text { Tribes }\end{array}$ & Less than among higher castes & No difference from higher castes \\
Other Backward Castes & No difference from higher castes & Slightly more than among higher castes \\
\hline
\end{tabular}


Measurement survey, but the period it covers-between 2007 and 2009-is too short to meaningfully track economic and social mobility. To overcome this difficulty, three synthetic panel data sets were especially built for this report, linking different rounds of nationally representative surveys (box 4.3). Two of the synthetic panels are for India; they cover the periods between 1993-94 and 2004-05 and between 200405 and 2009-10 and are based on the
National Sample Survey (NSS) 1993-94, NSS 2004-05, and NSS 2009-10. The third panel is for Bangladesh between 2005 and 2010 and is based on the Household Income and Expenditure Survey (HIES) for 2005 and 2010.

For India, results show that consumption growth was faster among the poor than among the better-off (figure 4.3). The trend is not apparent when comparing the consumption per capita of any one decile of

\section{BOX 4.3 How synthetic panels are constructed}

Panel data conventionally underpin the analysis of economic mobility over time. However, such data are not readily available for most developing countries. In South Asia none of the publicly available household expenditure surveys is a real panel over a sufficient period of timemore than two years-to allow a meaningful assessment of economic mobility. The methodology to construct synthetic panels was introduced to address this limitation in data. The robustness of results derived from these panels, relative to real panel data, is still being assessed. But consensus exists that synthetic panels provide a promising way forward in the absence of real panel data.

To illustrate the way the synthetic panel methodology works, consider the Indian NSS of 2004-05 and that of 2009-10. The approach consists of using data on households appearing in the 2004-05 survey as the base year and predicting their consumption in 2009-10 through an imputation methodology. Probabilities are predicted for households falling into different combinations of living standards in the two periods (e.g., being poor in both periods, or being poor in the first period but nonpoor in the second period, and so on). Underlying the predicted status in each period is household consumption per capita. For each survey, household consumption per capita is predicted based on observable household characteristics and is broken down into two components. The first component is associated with observable characteristics of the households-such as size, age composition, education, or assets-and the corresponding estimated coefficients. The second component is associated with nonobservable household characteristics-such as entrepreneurship or work ethic-and is captured through the error term.

The first component of predicted consumption is constructed by applying the coefficients estimated for the 2009-10 survey to the corresponding observable characteristics in the 2004-05 survey. The second component is estimated based on the estimated correlation coefficient of the error terms between both surveys. If a point estimate on this correlation coefficient is used, a point estimate of this component can be constructed; otherwise, if a range of estimates is used, an upper and a lower bound estimate result. The predicted consumption in 2009-10 of each household appearing in the 2004-05 survey is estimated as the sum of the predicted values of the two components. 
FIGURE 4.3 Consumption grows faster among the poor than among the better-off

a. India, $1993-94$ to $2004-05$

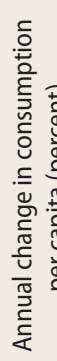

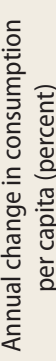

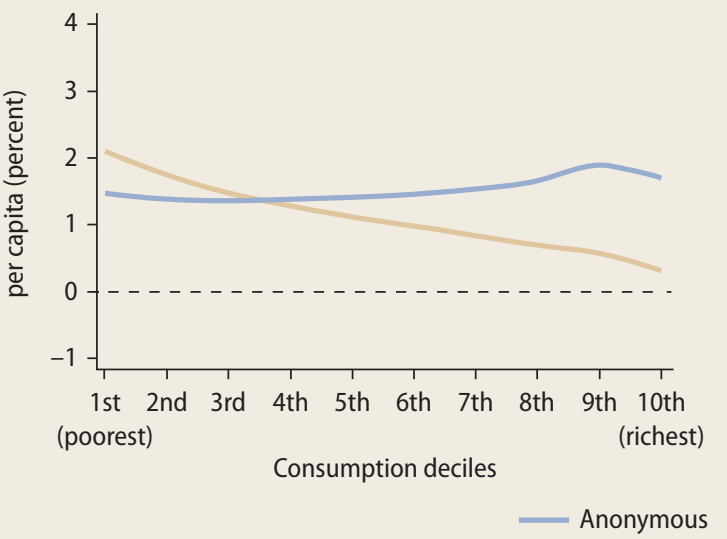

b. India, 2004-05 to 2009-10

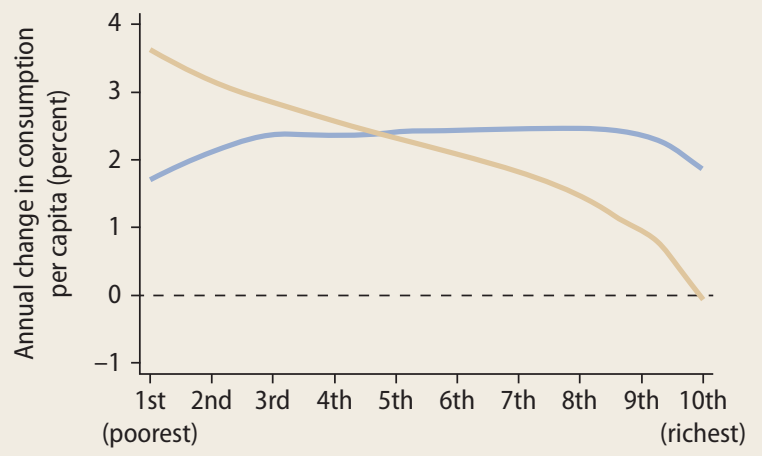

Consumption deciles

Nonanonymous

Source: Based on data from Dang and Lanjouw 2014 for this report.

the distribution in two years-the so-called anonymous distribution-simply because the households in a particular decile are unlikely to be the same in the two years. A more meaningful assessment involves comparing the consumption per capita of the same households in the initial year and in the final year. Based on this other approach-the socalled nonanonymous distribution-mobility has become particularly strong in more recent years.

Another way to assess mobility is to focus on the fraction of households that transit from one well-defined population group to another. For instance, the population can be classified into three mutually exclusive categories: the poor, the vulnerable, and the middle class. The poor are those whose consumption falls below the official poverty line. The vulnerable are households that are not poor in the initial year but that face a significant risk of falling into poverty in the final year. And the middle class is made up of the remaining households: those who are not poor in the initial year and for whom the risk of falling into poverty in the final year is low. Household transitions between these three groups reveal the extent of mobility-both upward and downward-in a particular society.

To distinguish between the vulnerable and the middle class, the concept of a vulnerability line needs to be introduced. For each nonpoor household in the initial year, one can compute a vulnerability index, defined as the probability that the household will have fallen into poverty by the final year. For any level of the vulnerability index, a vulnerability line can be identified (Dang and Lanjouw 2014). The synthetic panel data sets constructed for South Asia allow studying household transitions between 2005 and 2010 in Bangladesh and between 2004-05 and 2009-10 in India using this approach. If the vulnerability index is set at 20 percent, the vulnerability line for Bangladesh is 1,582 taka per person per month at 2005 prices, and the corresponding line for India is 998 rupees per person per month at 2004 prices.

The analysis of household transitions using these vulnerability lines shows that upward mobility was considerable for both the poor and the vulnerable (table 4.2). In India, the share of the population living below the poverty line (the poor group) declined from almost 37 percent in 
TABLE 4.2 Upward mobility is considerable among the poor and the vulnerable

\begin{tabular}{|c|c|c|c|c|c|}
\hline & & \multicolumn{4}{|c|}{ Five years later (percent) } \\
\hline & & Poor & Vulnerable & Middle class & Total \\
\hline \multicolumn{6}{|c|}{ Bangladesh } \\
\hline \multirow[t]{4}{*}{2005} & Poor & 19.5 & $1 \overline{16.2}$ & 128 & 38.5 \\
\hline & Vulnerable & 11.2 & 22.4 & 19.7 & 43.3 \\
\hline & Middle class & 1.5 & 7.3 & 9.4 & 18.1 \\
\hline & Total & 32.1 & 45.9 & 22.0 & 100.0 \\
\hline \multicolumn{6}{|l|}{ India } \\
\hline \multirow[t]{4}{*}{ 2004-05 } & Poor & 22.2 & '13.9, & 10, & 36.8 \\
\hline & Vulnerable & 8.9 & 28.8 & $(8.5$, & 46.3 \\
\hline & Middle class & 0.3 & 5.8 & 10.7 & 16.8 \\
\hline & Total & 31.5 & 48.5 & 20.0 & 100.0 \\
\hline
\end{tabular}

Sources: Based on data from Dang and Lanjouw 2014 for this report and Dang, Lanjouw, and Khandker 2014 for this report.

Note: The household head's age is restricted to between 25 and 55 years of age for the first survey and adjusted accordingly for the second survey. All cell numbers are significantly different from zero. The circled cells show the shares of the total population who experienced upward mobility. Percentages may not total to 100 because of rounding.

2004-05 to about 32 percent in 2009-10. Although some households fell into poverty between the two periods, more of themabout 15 percent of the total population, or about 40 percent of the poor-moved above the poverty line. Meanwhile a sizable proportion of the poor and the vulnerable-over 9 percent of the total population, or about 11 percent of the poor and vulnerable-moved into the middle class. Downward mobility was also considerable, however.

The pattern is similar in Bangladesh, where both upward and downward mobility were strong over the period considered. Between 2005 and 2010, about 19 percent of the total population, or half the poor, moved above the poverty line, and about 13 percent of the total population, or over 15 percent of the poor and vulnerable, moved into the middle class.

By these measures, upward mobility in Bangladesh and India was comparable to that of dynamic societies such as the United States and Vietnam (figure 4.4). Per capita consumption is higher and poverty incidence is lower in the United States and Vietnam than in South Asian countries, but over a comparable period, the four countries saw similar fractions of the poor moving above the poverty line and a considerable fraction of the poor and vulnerable moving into the middle class. Downward mobility was much bigger in the two South Asian countries, however, revealing the greater risks faced by the vulnerable and even the middle class.

In India, the expectation is that households from Scheduled Castes and Scheduled Tribes would experience less upward mobility than the rest of the population. However, this is not true when considering the fraction of these population groups moving up in the distribution (figure 4.5). Between 2004-05 and 2009-10, their poverty rate fell from 51 percent to 44 percent, following the same trend as the rest of the population. Taking downward mobility into account, about 35 percent of the poor from Scheduled Castes and Scheduled Tribes moved out of poverty in five years. And 7 percent of poor and vulnerable households from these disadvantaged population groups moved into the middle class. This figure is lower than for the rest of the population because Scheduled Castes and Scheduled Tribes have more poor and vulnerable members, thus the denominator of the ratio is bigger. But it suggests that 


\section{FIGURE 4.4 Upward mobility in South Asian countries is similar to that of the United States and Vietnam}

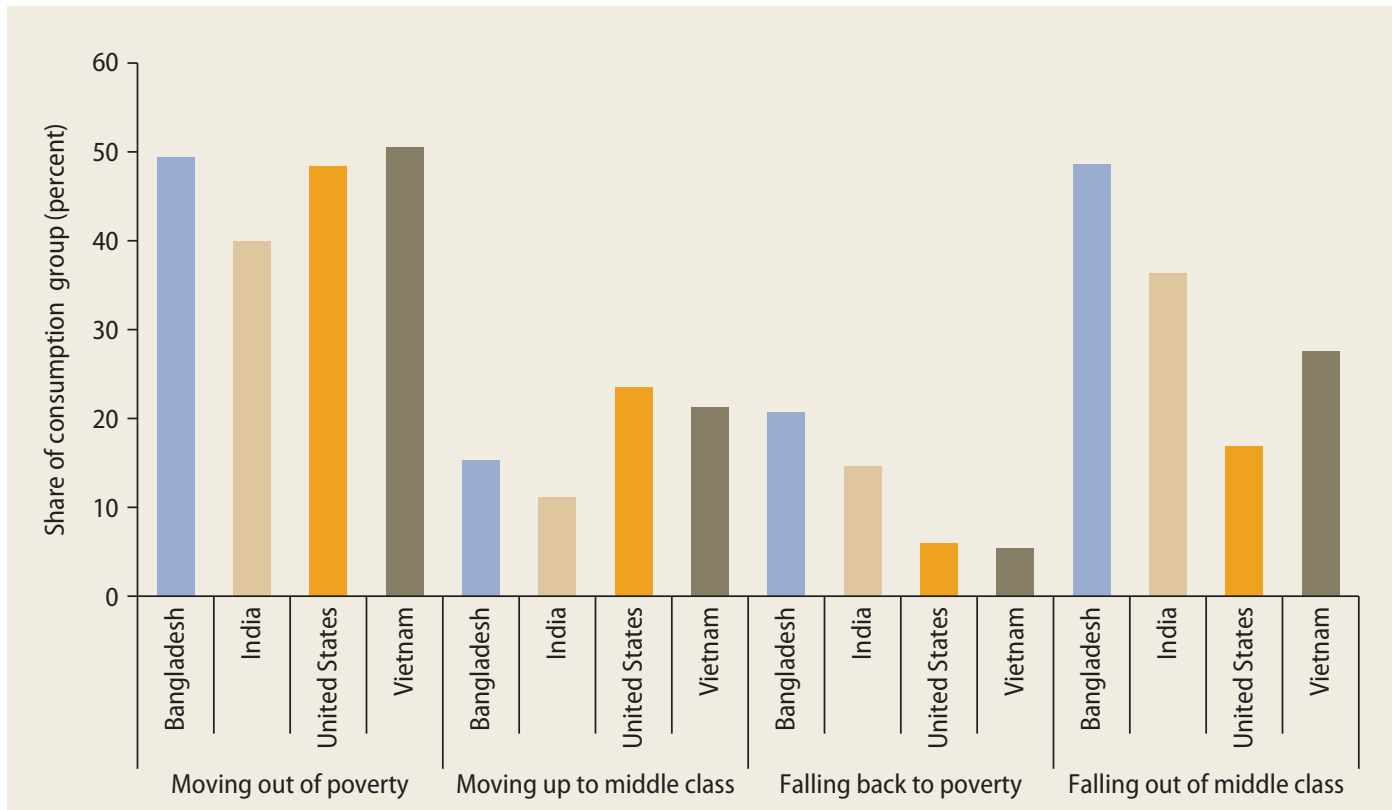

Sources: Based on data from Dang and Lanjouw 2014 for this report and Dang, Lanjouw, and Khandker 2014 for this report.

Note: The groups considered are the poor for moving out of poverty, the poor and the vulnerable for moving up to middle class, the nonpoor for falling back to poverty, and the middle class for falling out of middle class.

\section{FIGURE 4.5 Upward mobility in India is strong for the Scheduled Castes and Scheduled Tribes}

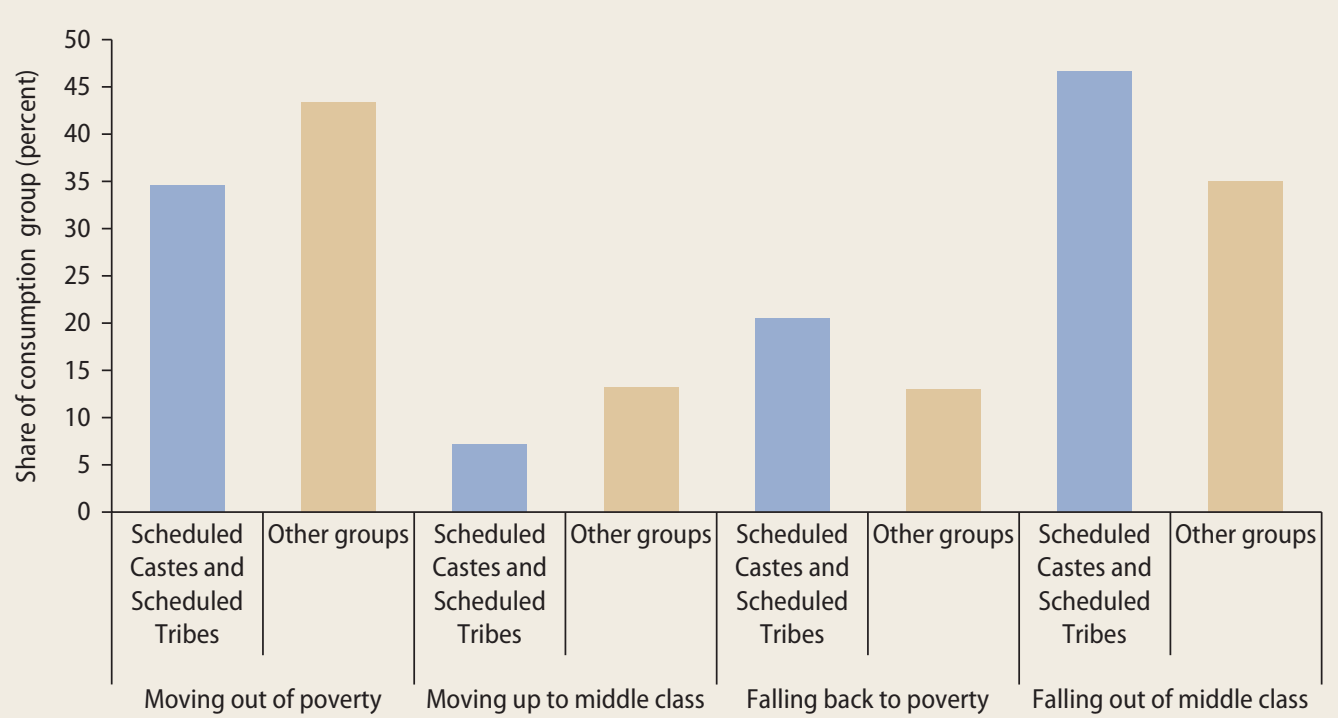

Source: Based on data from Dang and Lanjouw 2014 for this report.

Note: The groups considered are the poor for moving out of poverty, the poor and the vulnerable for moving up to middle class, the nonpoor for falling back to poverty, and the middle class for falling out of middle class. 
upward mobility for these socially disadvantaged groups is not taking place only at the bottom of the distribution.

\section{Nonfarm jobs drive mobility in villages}

Mobility is taking place even at the level of villages, where most South Asians still live, and it is largely associated with an occupational shift from farm to nonfarm activities. Casual employment in services and construction has driven this transition in most rural areas, in parallel with higher agricultural productivity. Employment in manufacturing, most often casual, has risen rapidly in the vicinity of major urban centers. Modernization of agricultural production, growing integration with urban economies, expanding markets, and migration opportunities are shaking up centuriesold social structures and offering a chance for the most disadvantaged to prosper.
Rural households in Bangladesh and India have experienced strong upward and downward mobility, consistent with the national trend. But upward mobility was slightly higher and downward mobility slightly lower among households primarily engaging in nonfarm activities (figure 4.6).

In South Asia's rural areas, many of the new jobs come from the expansion of nonfarm activities. This change in the structure of rural employment was underpinned by the modernization of agricultural production. In Bangladesh, for instance, the modernization process started with the adoption of new high-yielding rice varieties. Land productivity increased as a result; together with higher food prices, this led to an upswing in real agricultural wages, especially in the second half of the 2000s. Agricultural wages grew faster in villages experiencing larger increases in land productivity. Higher real agricultural wages, in turn, contributed to income growth and

\section{FIGURE 4.6 Upward mobility is substantial in rural Bangladesh and rural India}

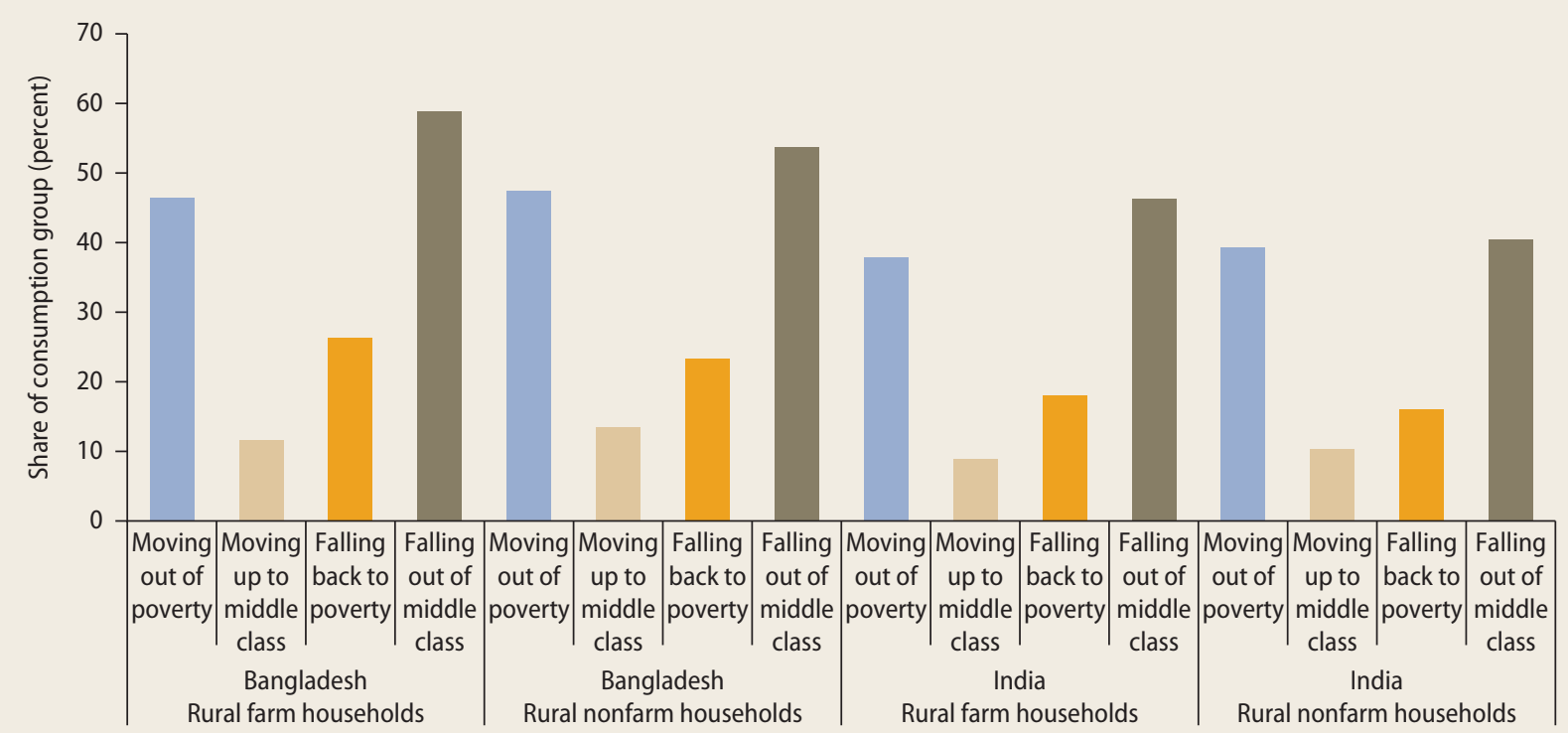

Sources: Based on data from Dang and Lanjouw 2014 for this report and Dang, Lanjouw, and Khandker 2014 for this report. Note: The groups considered are the poor for moving out of poverty, the poor and the vulnerable for moving up to middle class, the nonpoor for falling back to poverty, and the middle class for falling out of middle class. 
growing demand for nonfood products among the rural poor. They also encouraged the adoption of labor-saving techniques. For instance, machines currently do over 80 percent of tillage operations (Hossain and Bayes 2009; Hossain, Sen, and Sawada 2014; Narayan and Zaman 2008; World Bank 2013a).

The occupational shift from farm to nonfarm activities has been common across the region. In rural India, between 1993-94 and 2004-05, nonfarm employment grew more rapidly than agricultural employment. The trend accelerated after 2004-05, as agricultural employment started declining in absolute levels. In net terms, nonfarm activities accounted for all the expansion of employment in rural areas between 2004-05 and 2009-10 (figure 4.7, panel a). In rural Pakistan, the shift of employment from farm to nonfarm activities has taken a strong hold since 2001. The drought in 2000-02, one of the most severe weather-related shocks in decades, partly triggered the shift, but more fundamental trends consolidated it. Nonfarm employment increased more rapidly than farm employment in rural areas between 1999 and 2001, and the sectoral distribution of employment remained stable afterward (figure 4.7, panel b). Bhutan, Maldives, and Sri Lanka also experienced strong expansion of nonfarm employment in rural areas in the past decade.

The timing and the pace of the shift from farm to nonfarm activities have varied across countries, however. In Bangladesh, the expansion of nonfarm employment dominated from the late 1980s to the first half of the 2000s. Among rural households, the average number of adults working in nonagricultural activities increased from 0.65 in 1988 to 0.92 in 2004 , whereas the number working in agricultural activities decreased from 1.17 to 0.97 (Nargis and Hossain 2006). The expansion of nonfarm employment has stopped since 2005, however. Returns to farm activities have risen ever since, largely because food price increases have affected the dynamics between the two sectors. As for Nepal, it has seen only the nonfarm sector share of rural employment increase by about 1 percentage point over the last decade (World Bank 2011c, 2013a).

Rural nonfarm employment is almost exclusively casual. In India, nearly 40 percent of the rural nonfarm employment was in casual work in 2009-10, and another 40 percent was in self-employment. In Bangladesh, the

\section{FIGURE 4.7 Rural India and rural Pakistan have seen a consistent expansion of nonfarm employment}

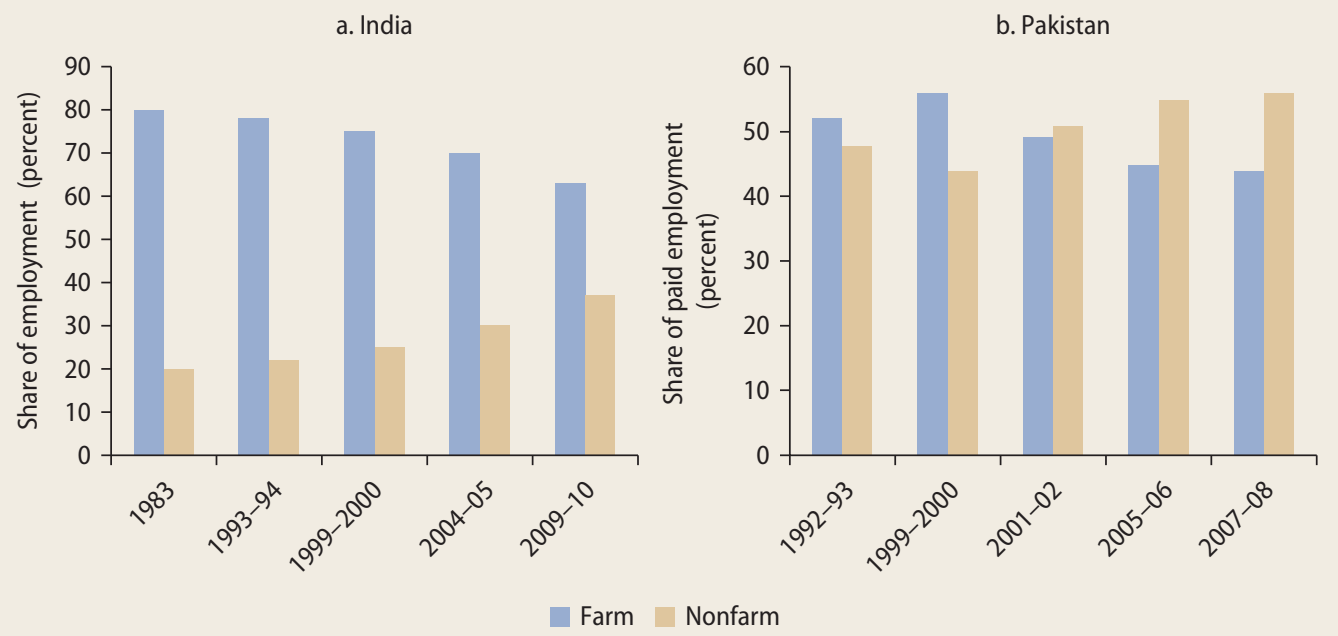

Sources: Himanshu and others 2013 and World Bank 2010 
share of casual labor within the rural nonfarm sectors increased considerably in the first half of the 2000s. In rural Pakistan, casual employment in manufacturing and construction increased significantly between 2000 and 2008. The increase accounted for almost all net wage employment creation for unskilled rural workers during that period (Himanshu and others 2013; World Bank 2010, 2011c).

However, casual employment is not inconsistent with upward economic mobility. Wages of casual nonfarm workers were 30 percent to 50 percent higher than agricultural wages in rural India, Nepal, and Pakistan in the 2000s; they were 10 percent higher in rural Bangladesh during the first half of the 2000s (World Bank 2011c). Although regular jobs tend to pay better, the earnings gap between regular and casual nonfarm jobs has narrowed over time in rural India, whereas the earnings gap between casual nonfarm jobs and agricultural jobs has increased (figure 4.8).

The shift in the structure of employment created new earning opportunities for rural households. Even after controlling for other characteristics such as education or asset ownership, this shift in occupations has been identified as a major contributor to income growth among the poor (Himanshu and others 2013; Nargis and Hossain 2006). Unskilled workers benefited from these transformations as well, even if they did so to a lesser extent than their skilled counterparts. Nonfarm jobs are better paid partly because they are higher-skilled jobs, and nonfarm workers have higher average levels of education than agricultural workers. However, the majority of industry and service jobs pay more than agricultural casual labor even after accounting for levels of education and other individual characteristics. Thus, unskilled workers achieved a reallocation gain even without additional investment in education (World Bank 2010, 2011c).

Socially disadvantaged population groups have been among the beneficiaries of the transformation of rural areas. A survey of households from Scheduled Castes in two rural blocks in the state of Uttar Pradesh,
FIGURE 4.8 Casual rural jobs provide increasingly higher earnings in India

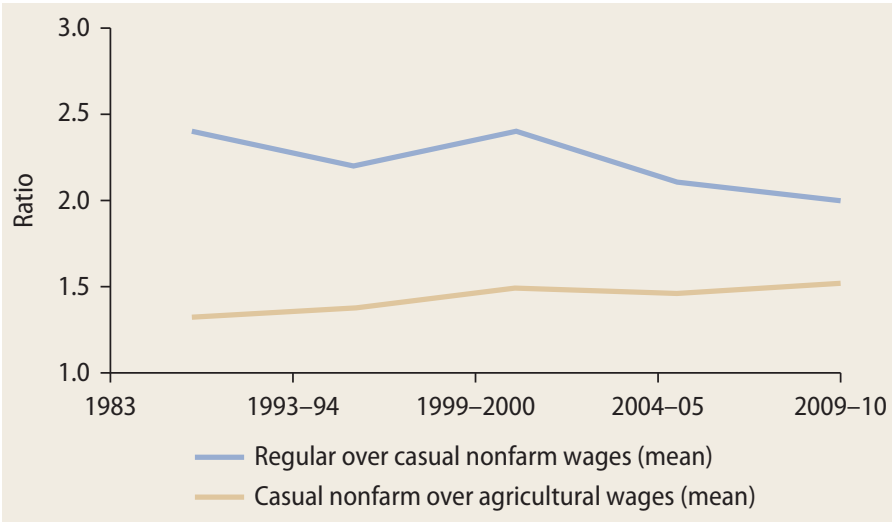

Source: Himanshu and others 2013

India, assessed the extent of the change in their economic activities between 1990 and 2007. In one of the blocks, 30 percent of the households had shifted their occupation toward nonfarm employment; in the other, the figure was 60 percent (Kapur and others 2010). In parallel, agricultural production has seen changes altering traditional economic and social relations. By 2007, almost no household from Scheduled Castes in these two rural blocks was subject to forms of bonded labor, such as halwaha, and very few worked on land owned by households from the upper castes. Conversely, sharecropping has risen considerably by households from Scheduled Castes, which are also more likely to rent in plowing services, a manual task usually performed by upper-caste men.

The experience of Palanpur, a village in western Uttar Pradesh that has been the focus of sustained research attention for several decades, could well mirror broader trends across northern India. In Palanpur, the expansion of nonfarm employment has translated into upward mobility for a significant number of households that had previously appeared mired in absolute poverty. Economic mobility has increased among the poor, and especially for households from Scheduled Castes. The flip side of this greater occupational change has been a clear trend 
toward rising income inequality in the village (Himanshu and others 2013).

The transformation of rural areas has also led to a change in the structure of female employment. Perhaps the best-known and most-often-told story is that of Bangladesh, where the rapid growth of the garment industry created wage employment opportunities for young women from the villages. But in Pakistan, too, women benefited more than men from the expansion of nonfarm activities. The number of unskilled women working as agricultural laborers fell by a third between 2000 and 2008, whereas the number of those working in manufacturing and construction tripled. This shift is more significant than that among rural unskilled male workers, for whom employment in manufacturing and construction increased by about 60 percent. The new employment opportunities have resulted in labor force participation by women who were less likely to work before. The manufacturing sector does not require a high level of education, but it offers significantly higher wages compared to agricultural work. Its expansion in rural areas particularly attracted semieducated women (with class 1 to 8 education), who usually participated in the labor market far less than those with no formal education and those with class 9 or higher education (World Bank 2010).

\section{Migration is a major source of mobility}

Internal migration has helped South Asian households find better jobs and investment opportunities and achieve significant and increasing economic mobility. Internal migration can be classified into two major types, depending on the length of migrants' stay in the area of destination: (a) permanent and semipermanent migration and (b) seasonal or circular migration. Permanent migration involves an openended change in location. Semipermanent migration-also called long-term circular migration-involves finding a foothold in the area of destination but with the intention of returning to the area of origin. Because of the time spells involved, permanent and semipermanent migrants share similar characteristics; importantly, they are also relatively well captured by official census or nationwide surveys. By contrast, most analyses of seasonal or circular migration need to rely on smaller-scale surveys and field studies.

In India, permanent migration accounted for about 30 percent of the population in 2001, a share that has remained roughly stable since then (NSSO 2010; RGCC 2012). But rural-to-urban and urban-to-urban migration flows have increased, especially among men. The share of rural-to-urban migrants in total male migrants increased from 34 percent in 1999-2000 to 39 percent in 2007-08; over the same period, the share of urban-to-urban migrants increased from 23 percent to 25 percent (Bhagat 2010; Kundu and Saraswati 2012; NSSO 2010; Srivastava 2011, 2012).

In Pakistan, permanent migrants account for 12 percent to 15 percent of the population 10 years of age and older. The shares of rural-to-urban and urban-to-urban migration within this aggregate are similar (Hamid 2010; Khan, Shehnaz, and Ahmed 2000; Narayan and Zaman 2008). But these figures are underestimates because they do not take into account migration within the same district. In Bangladesh, the number of permanent migrants was estimated to be 12.7 million in 2004-about 9 percent of the total population-increasing from 6.6 million in 1982 (BBS 2011). By the early 2000s, rural-to-urban transitions were the dominant form of migration, especially among men. Since then, the share of urbanto-urban migrants in total male migrants has increased more rapidly (BBS 2011). In Nepal, permanent migration stands at about 19 percent of the population 15 years of age and older (CBS 2012). At 18 percent, the figure is similar for Sri Lanka (DCS 2012).

Among men, permanent migration is primarily a strategy to fulfill aspirations for employment and investment opportunities (figure 4.9). The economic motivation is 


\section{FIGURE 4.9 Among men, permanent migration is driven by job aspirations}

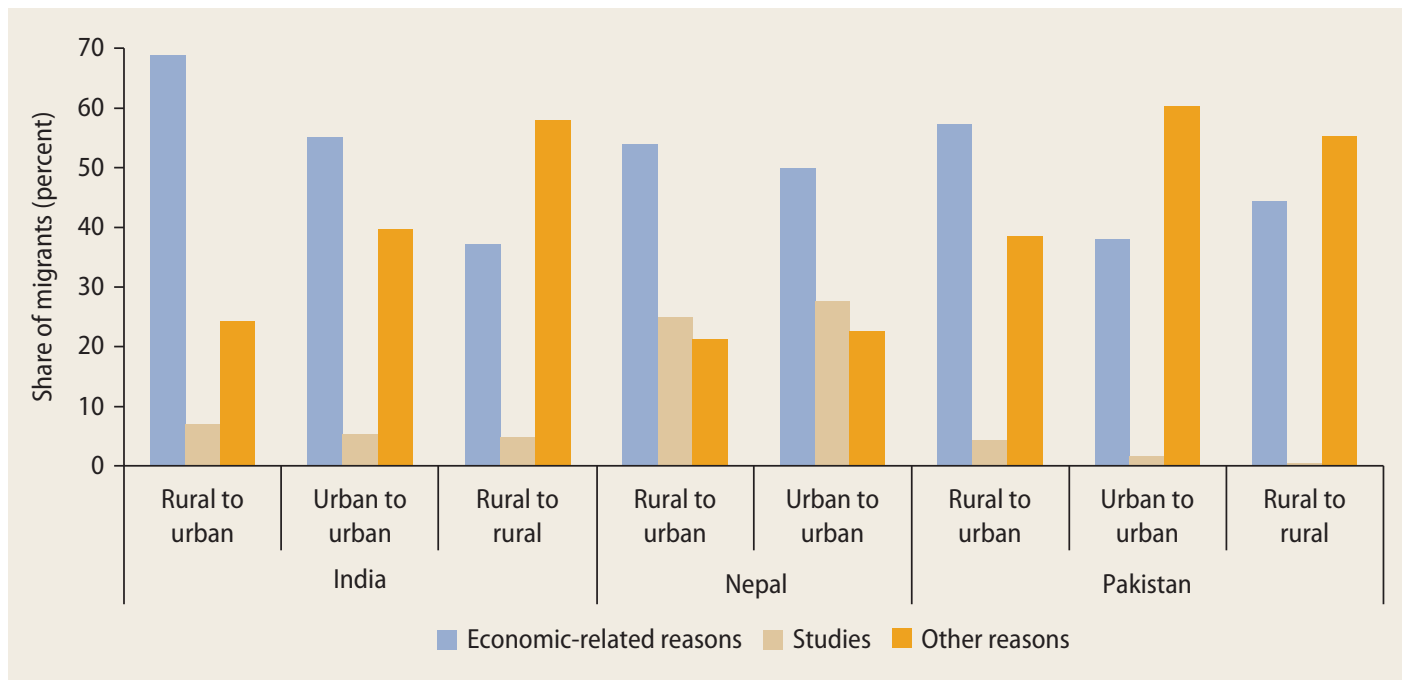

Sources: Based on NSS 2007-08 for India, Labour Force Survey 2009-10 for Pakistan, and CBS 2012 for Nepal.

Note: Economic-related reasons refer to employment and business. The migrants considered are adult males 15 years of age and older. Urban-to-rura migration is omitted because the sample sizes are too small.

stronger among those who migrated to urban areas. In India, economic-related reasons account for about 70 percent of adult male migrants who moved from rural to urban areas and 55 percent of those who moved between urban areas. The pattern is similar in Nepal and Pakistan. For women, migration is generally associated to a greater extent with marriage and social reasons. In countries such as Bangladesh, migration has also been an important response to natural hazards and conflicts (Afsar 2003; Marshall and Rahman 2013).

For India, a comparison of the occupations held before and after migration shows considerable upward occupational mobility. Regular wageworkers account for almost 40 percent of employment among permanent adult male migrants, compared with about 20 percent before migration. This increase in regular wage employment is particularly pronounced among rural-to-urban migrants (from 10 percent to 45 percent). The occupational transition matrix elucidates the composition of regular wage workers after migration (table 4.3). About 18 percent of those who were self-employed and 28 percent of those who were in casual employment before migrating had become regular wageworkers. A similar pattern was observed among those who were unemployed or not in the labor force before migration.

Evidence also suggests greater economic mobility among migrants than among nonmigrants. In both India and Pakistan, migrants to urban areas are more likely to work as wage employees (54 percent to 58 percent) than nonmigrants (about 46 percent); in rural areas, they are more likely to work in self-employment than nonmigrants. In the case of Dhaka, Bangladesh, which attracted the lion's share of migrants to urban areas, the unemployment rate was estimated to be 4 percent among workingage members of migrant households, half the rate found among nonmigrant households (Afsar 2000, 2003).

Substantial upward mobility is also found among migrants who ended up in urban slums. According to a slum survey in Delhi, many of the migrants living there had moved from casual jobs to regular wage jobs (Mitra 2010). Another survey for the Indian cities of Jaipur, Ludhiana, Mathura, 
TABLE 4.3 Changes in employment status reveal substantial mobility among migrant men in India

\begin{tabular}{|c|c|c|c|c|c|}
\hline \multirow[b]{2}{*}{ Before permanent migration } & \multicolumn{5}{|c|}{ After permanent migration (percent) } \\
\hline & Self-employed & $\begin{array}{l}\text { Regular } \\
\text { employee }\end{array}$ & Casual labor & $\begin{array}{l}\text { Unemployed or not } \\
\text { in labor force }\end{array}$ & Total \\
\hline Self-employed & 70.6 & '18.1' & 8.7 & 2.6 & 100 \\
\hline Regular employee & 9.9 & 83.8 & 2.6 & 3.7 & 100 \\
\hline Casual labor & 20.3 & '르. & 49.6 & 1.6 & 100 \\
\hline Unemployed or not in labor force & 17.3 & 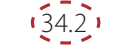 & 14.4 & 34.1 & 100 \\
\hline Total & 24.1 & '39.7,' & 19.2 & 17.0 & 100 \\
\hline
\end{tabular}

Source: Based on NSS 2007-08.

Note: The migrants considered are adult males 15 years of age and older. The circled cells show the shares of migrants who became regular wageworkers after migration.

and Ujjain reached a similar conclusion. For example, among the Jaipur workers engaged as semiprofessionals at the time of the survey, about 19 percent had worked earlier in sales and trade (Gupta and Mitra 2002). This pattern is also evident in other cities.

Permanent migrants tend to have higher economic status than nonmigrants. In India, when the total population is classified based on monthly per capita expenditure, permanent migrants turn out to be overrepresented at the top of the distribution-and underrepresented at the bottom-relative to nonmigrants (Bhagat 2010; Kundu and Sarangi 2007; Srivastava 2012). The contrast is sharper in the case of permanent migrants who moved for economic-related reasons, and even more so in the case of urban-to-urban permanent migrants (figure 4.10).

Permanent migrants-especially those migrating to urban areas-are relatively better educated than nonmigrants. In India, almost half the adult rural-to-urban migrants have at least secondary education, and the figure is even higher among urban-to-urban migrants. In contrast, only 30 percent of urban nonmigrants have at least secondary education. In Pakistan, 40 percent to 50 percent of adult permanent migrants to urban areas have at least secondary education in comparison with about 30 percent of urban nonmigrants. In Nepal, 45 percent of rural-to-urban adult permanent migrants and 64 percent of urban-to-urban permanent migrants have more than secondary education (CBS 2012). In Bangladesh, data covering 62 villages between 2000 and 2008 show that education correlates positively with permanent internal migration (Hossain, Sen, and Sawada 2014).

In contrast, seasonal migration is more frequent among poorer and more socially marginalized groups. In India, seasonal migrants are characterized by lower economic and educational attainment than the neighbors; they also tend to come from households with smaller landholdings (Keshri and Bhagat 2012). The rate of seasonal migration is much higher among the worse-off and among the socially marginalized populations, especially in rural areas (figure 4.11). Among the poorest population in rural areas, of 1,000 people, 52 migrated to urban areas and 22 migrated to other rural areas, whereas the figures are 12 and 6, respectively, among the richest population. Similarly, rural residents from the Scheduled Tribes have a much higher tendency to engage in seasonal migration to both urban and other rural areas than other groups. For rural-to-rural migration, village-level surveys in Andhra Pradesh and Madhya Pradesh confirm the general patterns. 
FIGURE 4.10 Permanent migrants have higher economic status in India

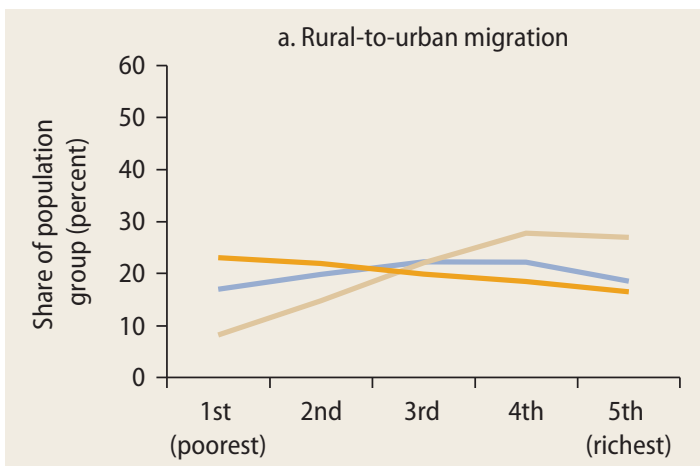

Consumption quintiles at place of destination

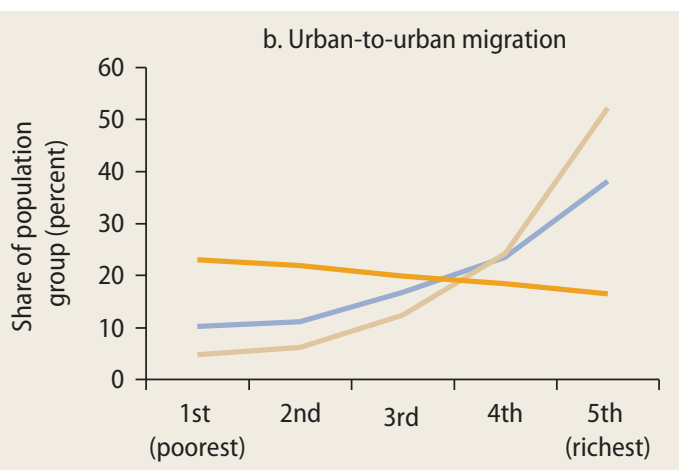

Consumption quintiles at place of destination

— Permanent migrants _- Economic-related permanent migrants _ Urban nonmigrants

\section{FIGURE 4.11 Seasonal migration is more common among poor and socially disadvantaged groups} in India

a. By expenditure quintile

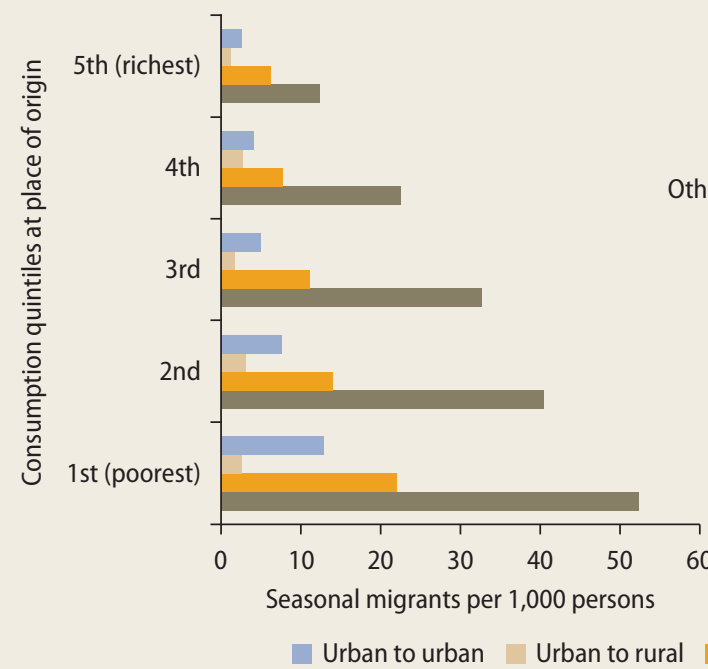

Source: Based on NSS 2007-08.

Note: The population considered are adult males 15 years of age and older.

These villages have hardly any permanent migrants among Scheduled Tribes and only a few among Scheduled Castes, but seasonal migration is common among both groups (Deshingkar and Akter 2009; Deshingkar and others 2008).
Seasonal migration is much more difficult to quantify than permanent migration, and numbers are often subject to heated debates. In India, official surveys suggested about 13.6 million people were seasonal migrants; of these, 13.1 million 
were of working age (Keshri and Bhagat 2012; NSSO 2010). But a number of scholars argue that these figures are gross underestimates (Deshingkar and Akter 2009; Deshingkar and Farrington 2009; Deshingkar and others 2008).

Village-level surveys provide complementary information. A village-level survey in Madhya Pradesh, India, suggests that 52 percent of households were involved in seasonal migration, mainly to work in the construction sector (Deshingkar and others 2008). In 42 villages in central-western India, about 65 percent of households and 48 percent of the adult population were involved in seasonal migration, overwhelmingly for urban construction work (Mosse, Gupta, and Shah 2005). But a large survey of 1,460 villages in 31 states finds that only about 58 percent of the villages reported having any seasonal migrants (Shah 2005, 2010).

For Bangladesh, regional household surveys offer some insights on the scale of seasonal migration. A survey of 1,600 rural households in the northwest region of Bangladesh suggests that 19 percent of total households and 25 percent of chronically poor households were involved in seasonal migration (Afsar 2003; Hossain, Khan, and Seeley 2003). A more recent survey of more than 480,000 poor households in the same region suggests that about 36 percent of these households engaged in seasonal migration in 2006-07 (Khandker, Khalily, and Samad 2012).

Seasonal migration is not only a coping strategy for the poorest; arguably, it is also an accumulation strategy. According to a village-level survey in Madhya Pradesh, India, earnings from seasonal migration account for over 30 percent or the largest share of total income among households with at least one migrant (Deshingkar and others 2008). The share is even higher among socially marginalized groups. Resurveys of the same villages suggest that seasonal migration has become more prevalent over time. This may be the result of new opportunities in urban areas having reduced the uncertainty of finding work, urban wages having increased, and dependence on contractors having declined over time. Seasonal migration has reduced borrowing for consumption, improved debt repayment capacity, and given migrants greater confidence and bargaining power (Deshingkar and Akter 2009; Deshingkar and others 2008; Mosse and others 2002).

As such, seasonal migration offers the Scheduled Castes and Scheduled Tribes an escape route from social discrimination. For instance, in Jharkhand, migration to work in brick kilns has given youth the opportunity to pursue romantic relationships away from the social restrictions they face in the villages. Similarly, migrant workers belonging to Scheduled Castes and Scheduled Tribes in Bihar reported that working outside the village had given them dignity and freedom (Deshingkar and Akter 2009; Shah 2005, 2010). This finding is consistent with the findings from village surveys of Scheduled Caste households in Uttar Pradesh (Kapur and others 2010).

In Bangladesh, seasonal migration stands out as an effective strategy to reduce seasonal distress. The northwest region, also known as the greater Rangpur region, is characterized by an acute lean season of agricultural activities (monga). Over a third of the poor rural households in the region use seasonal migration as a mechanism to cope with seasonal deprivation caused by monga. Indeed, seasonal migration is associated with significant reductions in the starvation rate and the general food deprivation rate (Khandker, Khalily, and Samad 2012). Another case in point is the workers of the brick-making industry in areas adjacent to Dhaka. Most of the workers come from the disaster-prone areas of both the southern (coastal belt) and northern (river erosion belt) parts of the country. Most of these migrant workers were engaged in agriculture and nonagricultural wage labor as their main occupation before their migration. Seasonal work significantly increases the average monthly income of migrant workers and reduces 
the extreme food deprivation rate among the migrant households (Hossain, Sen, and Sawada 2014).

Migration is an especially important avenue for upward mobility in the case of women. Special microsurveys conducted by the Centre for Women's Development Studies in 20 Indian states shed some light on the links between female migration and female occupational mobility (Mazumdar, Neetha, and Agnihotri 2011, 2013). Results point to a higher incidence of seasonal migration among women from Scheduled Castes and Scheduled Tribes, as well as a higher incidence of permanent migration among women from upper castes and more affluent families. In addition, a significant proportion of unemployed or housebound women are found to enter into paid employment through migration (figure 4.12). Among female migrants to urban areas, about 13 percent reported as engaging only in unpaid family work before migration while the share for this category is zero after migration. The fraction of female migrants to urban areas working as low-skilled manufacturing workers-such as tailors or textile spinning and weaving workers-almost tripled after migration (12 percent). The fraction of them working in low- and medium-skilled occupations in services-such as beauticians, nurses, teachers, call center employees, and technical employees-increased from 3 percent to 17 percent after migration.

In Bangladesh, the scale of female rural migration is such that it has changed social norms. Whereas initially more men than women migrated to cities, over time the gender ratio became more balanced, largely because of the boom in the garment industry since the mid-1980s. This rebalancing took place despite a socio-religious seclusion of women that could have reduced their freedom of movement. About 90 percent of the female workers in urban garment sectors in the 1990 s and early 2000 s were estimated to be migrants from rural areas; three-quarters of them came from landless or very poor households (Afsar 2000, 2003;
FIGURE 4.12 Migration provides opportunities for occupational mobility to women in India

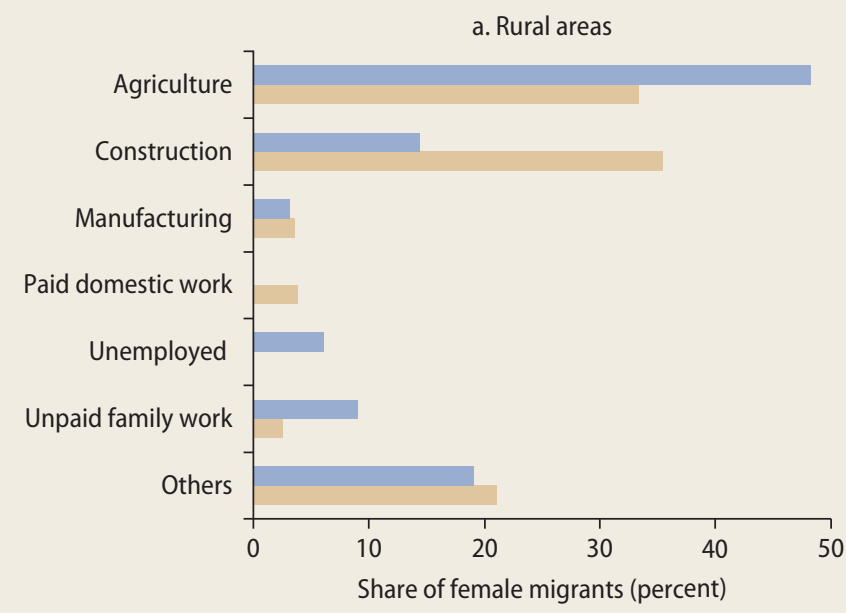

b. Urban areas

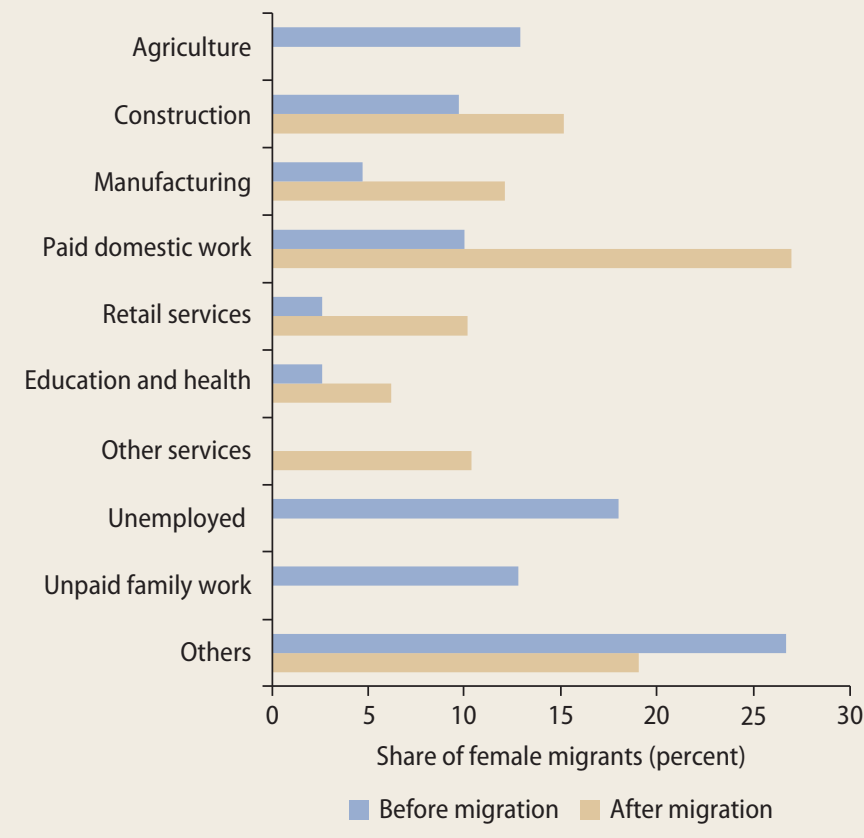

Source: Mazumdar, Neetha, and Agnihotri 2011

Note: The migrants considered are female adults 15 years of age and older.

Deshingkar and Grimm 2005). Although a socially negative image of the garment workers as "fallen women" prevailed in the early 1990s, these migrants effectively defied and redefined their place in society. 


\section{BOX 4.4 International migration supports upward mobility in Bangladesh and Nepal}

Every year Bangladesh and Nepal send abroad scores of migrant workers and receive substantial flows of remittances in exchange. Between 2000 and 2012, 5.5 million Bangladeshis and 2.4 million Nepalese migrated abroad. The Gulf region and other Southeast Asian countries are their most important destinations. These migrants typically have limited education. In Bangladesh, the share of unskilled or semiskilled labor migrants increased from 50 percent in 2000 to 76 percent in 2010. In Nepal, only 5 percent of international migrants can be considered skilled (World Bank 2011b). International migrants from these two countries also tend to be overwhelmingly male.

Remittances have become a major source of household income for the two countries over the last decade. Flows to Bangladesh increased from US $\$ 1.9$ billion in 2000 to US\$14.1 billion in 2012, while flows to Nepal surged from US\$0.1 billion to US $\$ 4.7$ billion over the same period.
By now, remittances account for 12 percent and 25 percent of GDP, respectively, for Bangladesh and Nepal. The picture is similar when seen from a household perspective. In 2010, remittances represented 14 percent of household income in Bangladesh and 20 percent in Nepal.

International migration is behind massive transitions out of poverty in both countries. One-fifth of the poverty reduction observed in Nepal between 1996 and 2004 can be attributed to remittances, and the share is presumably much higher in recent years. Similarly, 18 percent of the poverty reduction experienced by Bangladesh between 2000 and 2005, or 11 percent of the decline in poverty observed between 2000 and 2010 , is attributable to remittances. International migration also makes households less vulnerable to downward mobility. In Bangladesh, households receiving remittances are 6 percent less likely to fall into poverty.

Sources: Based on BBS 2010; BMET 2014; DOFE 2013; Inchauste and others 2012; Lokshin, Bontch-Osmolovski, and Glinskaya 2010; Raihan and others 2009; and Migration and Remittances Data (database), Development Prospects Group, World Bank, Washington, DC, http://go.worldbank.org/092X1CHHDO.

Although they often wear hijab in public places, they are also increasingly assertive on gender rights (Hossain, Sen, and Sawada 2014).

International migration is another important avenue for South Asian households to fulfill their aspiration for jobs and upward economic mobility (box 4.4). Between 2000 and 2012, 5.5 million Bangladesh workers migrated overseas and 2.4 million Nepalese workers migrated (BMET 2014; DOFE 2013). Migration of low-skilled workers has become a significant feature for both countries. Over the last decade, international remittance flows to Bangladesh and Nepal have been on the rise. In 2012, remittances accounted for 12 percent of the gross domestic product (GDP) in Bangladesh and 25 percent in Nepal.

\section{Urban mobility is shaped by city characteristics}

City dynamism is another driver of the increasing mobility observed in South Asia. Mobility both across and within generations is greater in urban areas than in rural areas, despite the existence of a large urban informal sector. Urban wage employment, regardless of whether it is formal or informal, offers better prospects of economic mobility for a massive number of households in South Asia. Urbanization is taking place through diversified processes, however. People move to cities through migration, but cities also "move" to people through the transformation of economic activity in formerly rural areas. These diverse processes have created cities with different characteristics. 
The availability and nature of jobs vary across cities of different types.

Solid evidence indicates that cities are associated with greater mobility than rural areas. In India, for instance, the sons of unskilled fathers in urban areas face a lower probability of staying in the same occupational category than their rural counterparts; they also face a much higher probability of taking on better jobs. Sons of farmers also face better prospects in urban areas than in rural areas (figure 4.13).

In both Bangladesh and India, within the same generation a larger fraction of the population manages to move above the poverty line in rural areas than in urban areas. Conversely, a larger fraction of the population achieves middle-class status in urban areas than in rural areas (table 4.4). And downward mobility in the form of falling below the poverty line is considerably smaller in urban areas than in rural areas.

Upward mobility is higher, and downward mobility lower, among households whose members are employed as regular wage or salaried workers. But selfemployment and casual employment also support substantial improvements in living standards (figure 4.14). In both Bangladesh and India, urban households whose members are self-employed or who work as casual labor experience stronger upward mobility and smaller downward mobility than rural households.

This dynamism, including substantive transitions into the middle class, is taking place despite the prevalence of informality in South Asia's urban areas. This is because the urban informal sector includes a considerable number of wage jobs, and they could be the main driver of upward mobility (Mukhopadhyay 2011). For instance, about 18 percent of total urban employment in India is accounted for by men who are regular wageworkers in the informal sector and another 16 percent by men who are casual workers in the informal sector (figure 4.15). If both men and women are considered, about 57 percent of the informal workforce in urban areas earns wages.

The sectoral distribution of informal employment further confirms that the informal sector is an integral part of the urban economy. In India, about half the informal urban male workers can be found in manufacturing, construction, and transport,

FIGURE 4.13 Upward mobility is much stronger in cities than in rural areas

a. Urban India

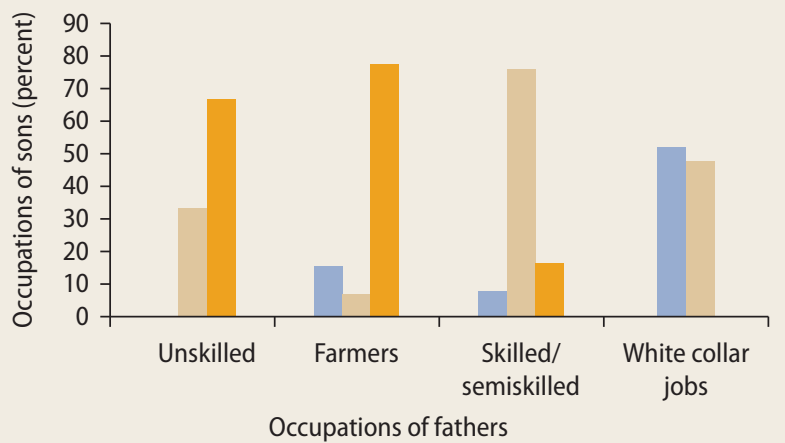

Downward mobility $\square$ Persistence Upward mobility b. Rural India

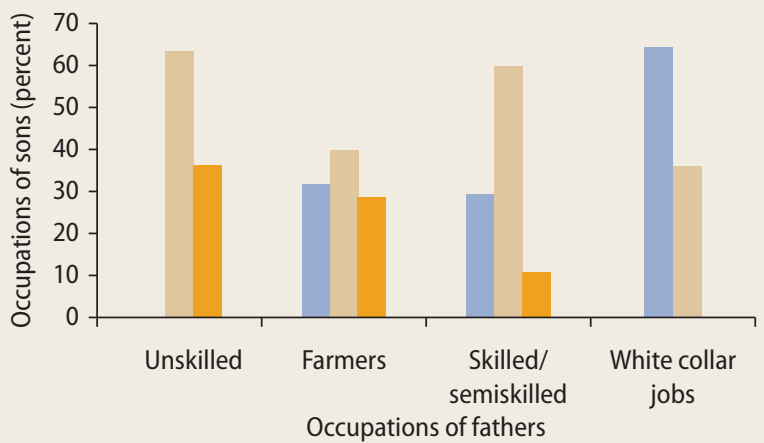

upations of fathers

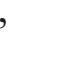


TABLE 4.4 Rural jobs allow people to escape poverty; urban jobs are a ticket to the middle class

\begin{tabular}{|c|c|c|c|c|c|}
\hline & & \multicolumn{4}{|c|}{ Five years later (percent) } \\
\hline & & Poor & Vulnerable & Middle class & Total \\
\hline \multicolumn{6}{|c|}{ Bangladesh } \\
\hline \multicolumn{6}{|c|}{ Rural households } \\
\hline \multirow[t]{4}{*}{2005} & Poor & 23.0 & ' $\overline{17} \bar{\delta}$, & $(2.8$ & 43.6 \\
\hline & Vulnerable & 12.4 & 22.3 & 18.2 & 42.9 \\
\hline & Middle class & 1.5 & 6.2 & 5.9 & 13.5 \\
\hline & Total & 36.9 & 46.3 & 16.9 & 100.0 \\
\hline \multicolumn{6}{|c|}{ Urban households } \\
\hline \multirow[t]{4}{*}{2005} & Poor & 9.9 & '1َ̄os, & 2.9 & 24.7 \\
\hline & Vulnerable & 7.9 & 22.5 & '14. & 44.5 \\
\hline & Middle class & 1.4 & 10.2 & 19.1 & 30.8 \\
\hline & Total & 19.2 & 44.6 & 36.1 & 100.0 \\
\hline \multicolumn{6}{|l|}{ India } \\
\hline \multicolumn{6}{|c|}{ Rural households } \\
\hline \multirow[t]{4}{*}{ 2004-05 } & Poor & 26.3 & 115.5, & 10,8 & 42.7 \\
\hline & Vulnerable & 9.6 & 28.7 & -7.5 & 45.8 \\
\hline & Middle class & 0.3 & 4.7 & 6.5 & 11.5 \\
\hline & Total & 36.2 & 48.9 & 14.8 & 100.0 \\
\hline \multicolumn{6}{|c|}{ Urban households } \\
\hline \multirow[t]{4}{*}{ 2004-05 } & Poor & 11.2 & 99 & 10 & 21.3 \\
\hline & Vulnerable & 7.1 & 29.3 & '11.3.; & 47.7 \\
\hline & Middle class & 0.4 & 8.8 & 21.8 & 31.0 \\
\hline & Total & 18.7 & 47.5 & 33.8 & 100.0 \\
\hline
\end{tabular}

Sources: Based on data from Dang and Lanjouw 2014 for this report and Dang, Lanjouw, and Khandker 2014 for this report.

Note: The household head's age is restricted to between 25 and 55 years on the first survey and adjusted accordingly for the second survey. The circled cells show the shares of the total population who experienced upward mobility. Percentages may not total to 100 because of rounding.

whereas 56 percent of the informal urban female workers are in manufacturing, construction, education, and health. Thus, rather than being segregated into low-productivity activities, households in the informal sector can be somewhat integrated with the more modern parts of the urban economy.

In Bangladesh, the urban formal sector has been expanding because of the rapid growth of labor-intensive manufacturingin particular, garments and textiles. Together, these activities account for nearly 75 percent of total manufacturing employment. Although their expansion has been sustained on low labor costs, real wages have grown more rapidly in manufacturing industries than in agriculture. Women, and especially migrants from rural areas, gained from the expansion of these industries.
Around 60 percent of garment workers were female in 2009; the share might have climbed to about 80 percent by 2012 . Because the demand for female workers in the manufacturing sector has increased faster than that of male workers, female wages have increased more rapidly than male wages in recent years (Ahmed, Bakht, and Yunus 2011; Hossain, Sen, and Sawada 2014; Lopez-Acevedo and Robertson 2012; Narayan and Zaman 2008; World Bank 2012a; Zhang and others 2013).

While urban areas present better prospects of economic mobility than rural areas, both the pace and the pattern of urbanization in South Asia are reasons for concern. In absolute terms, the urban population is massive, and the rate of urbanization is impressive. India had 388 million people residing in urban areas at the end of the 


\section{FIGURE 4.14 Even self-employment and casual work support upward mobility in urban areas}

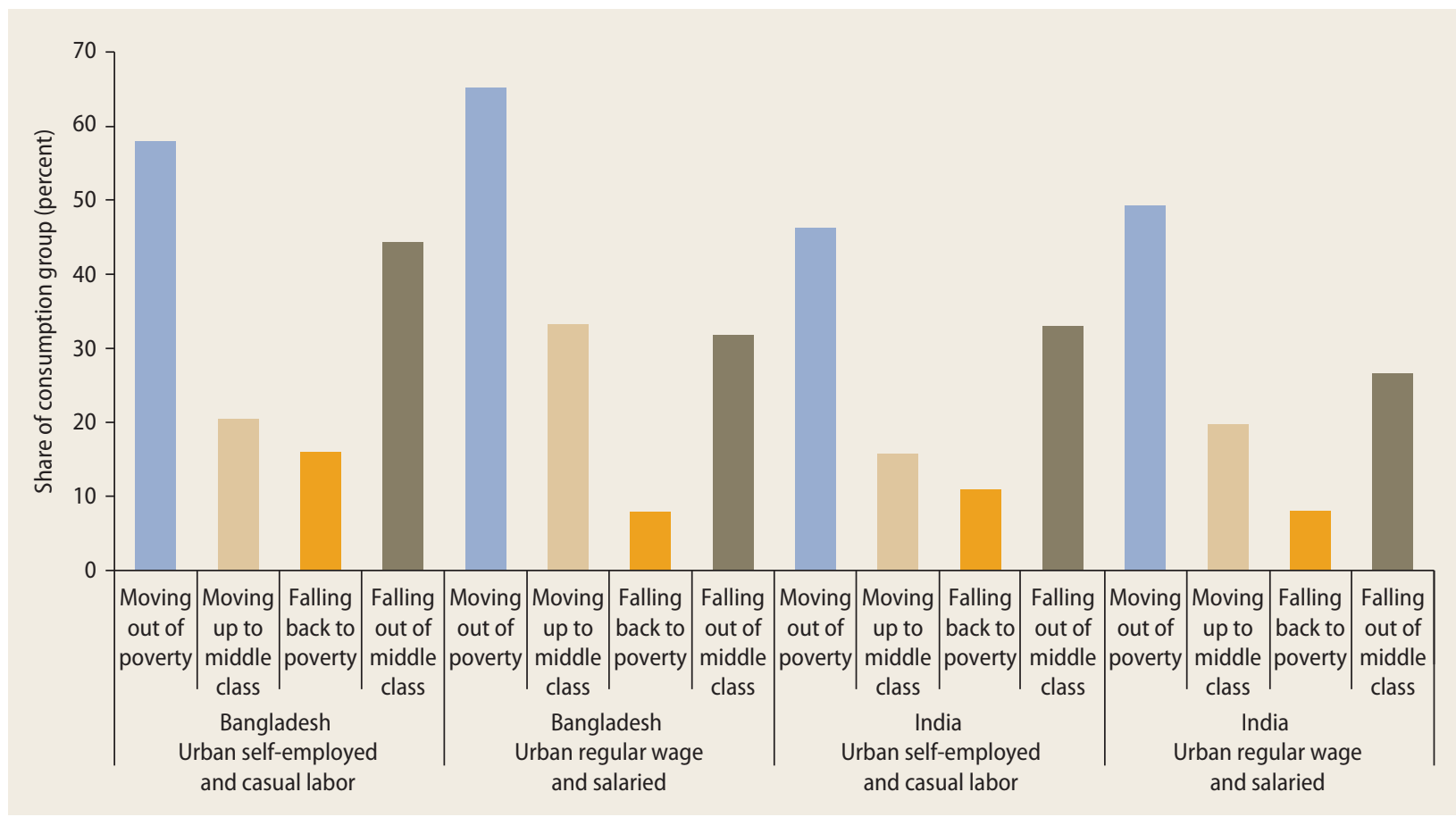

Sources: Based on data from Dang and Lanjouw 2014 for this report and Dang, Lanjouw, and Khandker 2014 for this report.

Note: The groups considered are the poor for moving out of poverty, the poor and vulnerable for moving up to middle class, the nonpoor for falling back to poverty, and the middle class for falling out of middle class.

\section{FIGURE 4.15 Many informal sector workers are wage earners in urban India}

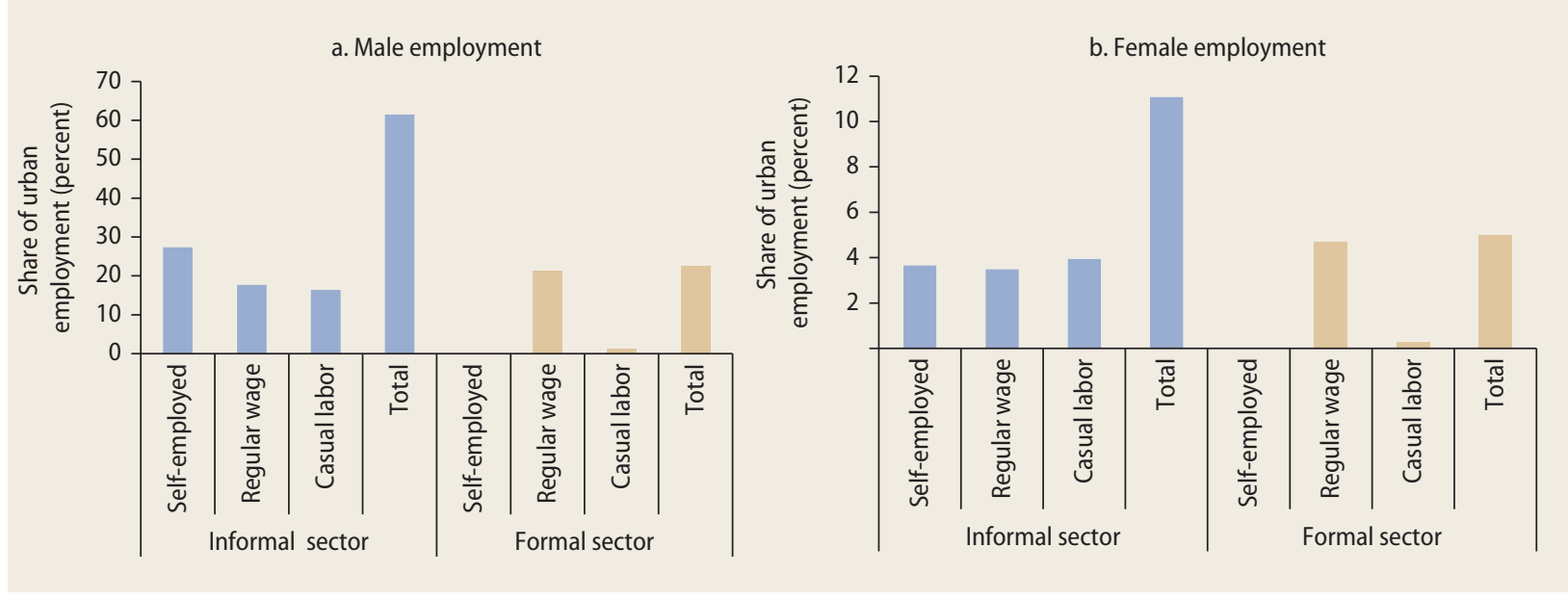

Source: Based on NSS 2009-10.

Note: The workers considered are adults 15 years of age and older. 


\section{FIGURE 4.16 South Asian countries are less urban than their peers}

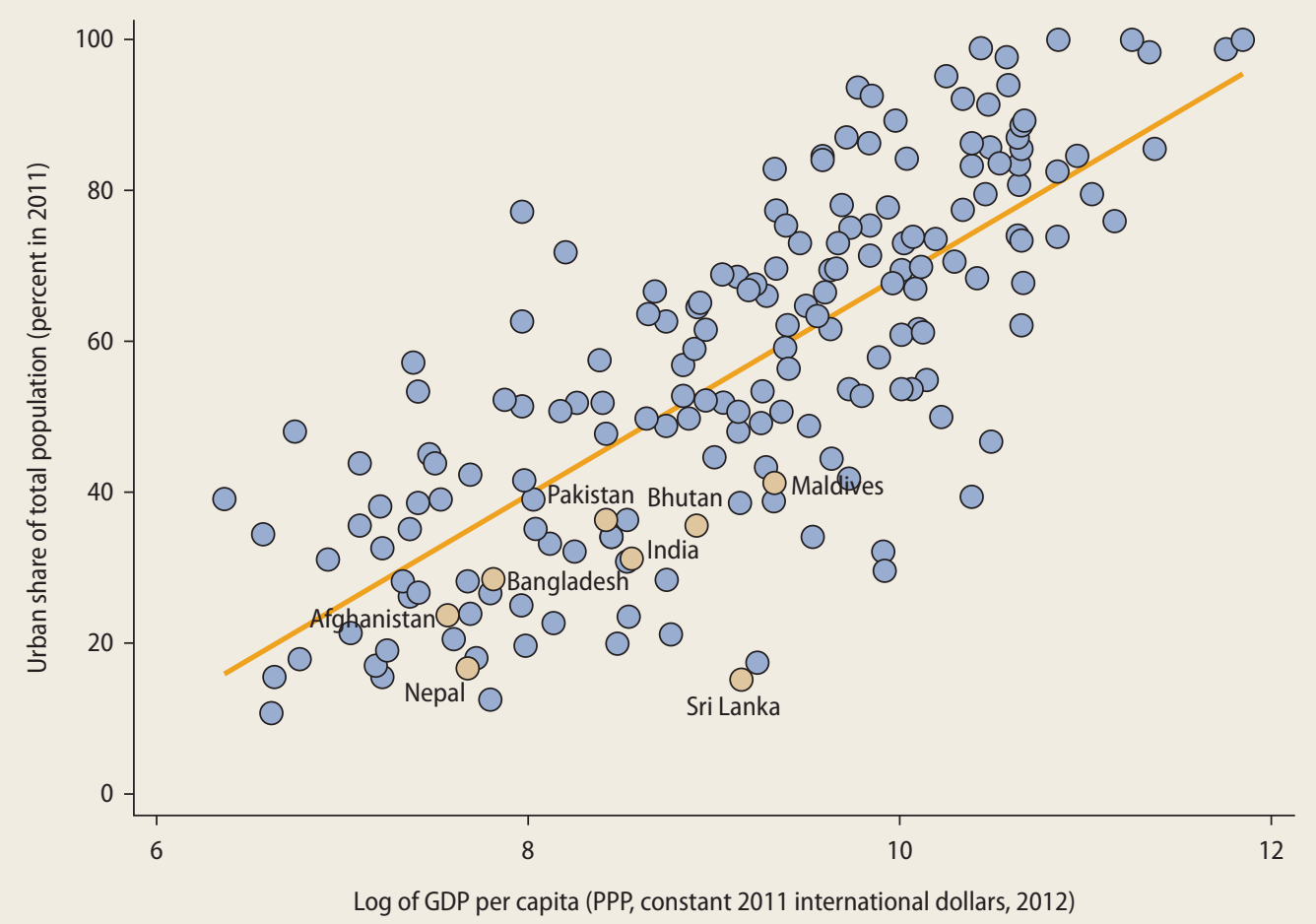

Sources: Based on UN 2012 and World Bank's World Development Indicators database, http://data.worldbank.org/data-catalog/world-development-indicators. Note: $\mathrm{PPP}=$ purchasing power parity.

century's first decade, Pakistan 64 million, and Bangladesh 43 million. Overall, 563 million people could be considered urban residents in South Asia in 2011, according to the countries' official definitions (UN 2012). India saw its urban population grow at about 3 percent a year in the 2000s, double the rural population growth rate. And Bangladesh has one of the world's fastestgrowing urbanization rates. However, countries in South Asia are still less urban than other countries at a similar level of development (figure 4.16). From a mobility perspective, this amounts to a missed opportunity.

Urbanization is not only slower in South Asia, but it also appears to be more organic. Whereas people come to cities in the form of migration, cities also "come" to people through the densification of population and the transformation of economic activity in rural areas. In India, for example, areas that are administratively rural but economically urban are called census towns. Between 2000 and 2011, a total of 2,553 administratively rural areas were reclassified as census towns, accounting for an estimated 30 percent of the urbanization recorded during that period (Pradhan 2013; RGCC 2012). Satellite imagery of contiguously built areas suggests that urban extent has expanded beyond officially defined urban boundaries, even when taking census towns into account (Denis and Marius-Gnanou 2011).

These diverse urbanization mechanisms have led to a range of cities with different characteristics, not just in terms of their size but also in terms of their governance structure. With more than 7,900 cities and towns, India spans the entire urban spectrum. 
The eight largest metropolitan areas have more than 4 million people. Another 38 cities have a population between 1 million and 4 million, 46 cities have a population between 500,000 and 1 million, and so on (RGCC 2012; UN 2012). Large cities are governed by municipal corporations, smaller ones are governed by municipalities and various types of town councils, and some are still administratively rural.

In other countries in the region, one or two metropolitan areas dominate the urban hierarchy. In Bangladesh, Dhaka and Chittagong account for over 48 percent of the urban population. In contrast, over 60 percent of other cities have populations of 50,000 or less. Similarly, in Pakistan, Karachi and Lahore account for about 32 percent of the urban population, whereas 40 percent of other towns have populations of 50,000 or less. About 20 percent of Nepal's urban population resides in Kathmandu, but areas around Birgunj and Biratnagar, which are close to the Indian border, are also dynamic. In Sri Lanka, about 28 percent of the total population lives in the Colombo Metropolitan Region, whereas many small cities cluster along the coast (Lall and Astrup 2009; Muzzini and Aparicio 2013a, 2013b; Narayan and Zaman 2008; UN 2012; World Bank 2012a, 2013a).

These differences in size and governance matter for mobility because they shape the types of jobs available across different types of cities. In India, districts can be classified depending on the size of their biggest city. This information, in turn, can be used to analyze the structure of urban employment at the district level. Districts with larger cities have a higher proportion of urban regular wageworkers than do districts with smaller cities (figure 4.17). For districts with cities of more than 4 million people, regular wage jobs account for 54 percent of urban employment, and the share still exceeds 40 percent for those with cities having a population between 1 million and 4 million. In contrast, for districts whose biggest city has fewer than 100,000 people, the share of regular wageworkers in urban employment is significantly smaller. Districts with larger cities also have a higher proportion of urban jobs in manufacturing and services, relative to districts with smaller cities. Construction, manufacturing, mining, and service activities account for over 80 percent of total employment in districts with cities of more than 4 million people, whereas the share is below 66 percent in districts whose biggest city hosts fewer than 100,000 people.

More disaggregated city-level analysis finds that the largest metropolitan areas offer more job opportunities in business services and sophisticated manufacturing industries than other cities do (World Bank 2013b). In particular, sophisticated manufacturing activities show a noticeable concentration in the largest metropolitan areas, compared with other urban areas. For example, only 17 percent of total employment in these metropolitan areas is in low-tech manufacturing industries, but the proportion reaches almost 36 percent for high-tech industries. The pattern is similar for business services.

In addition to size, the governance of cities matters for urban economic mobility. In India, population censuses provide detailed information on the administrative arrangements applying to each city or town. Using this information, one can classify urban areas into six categories: state capitals, other cities with municipal corporations, municipalities, notified areas, nagar panchayat (including census towns), and industrial townships. The first five are in a broadly descending order in terms of administrative autonomy, capacity, and financial resources. The last category, industrial townships, covers areas designated for industrial development that have some of the characteristics of special economic zones in other countries. Again, this information can be used to assess how the composition of urban employment varies across city characteristics at the district level.

The share of regular wage jobs in urban employment broadly declines with the autonomy, capacity, and financial resources of city authorities (figure 4.18). By contrast, the 


\section{FIGURE 4.17 The composition of urban employment varies with city size in India}

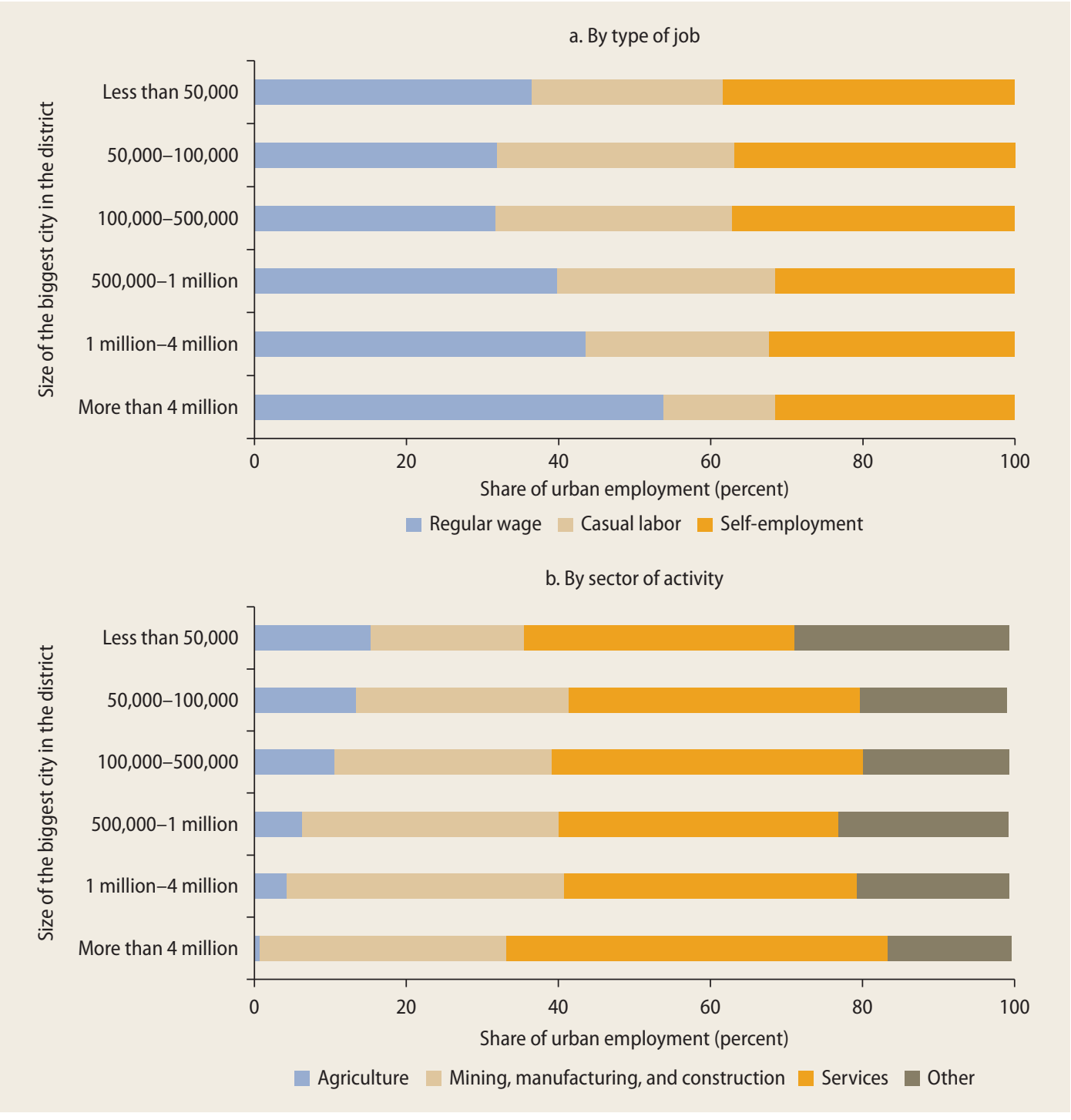

Sources: Based on NSS 2009-10 and RGCC 2012.

Note: The workers considered are adults 15 years of age and older.

share of self-employment increases. The composition of employment in districts with industrial townships resembles that of districts with municipal corporations. Overall, districts with state capitals, municipal corporations, or industrial townships are associated with significantly greater shares of regular wage jobs. Similarly, districts with a state capital or a municipal corporation have a smaller share of urban employment in agriculture; the same holds true for districts in which an industrial township exists. One could argue that urban governance improves as city size increases, thus making the observed relationships misleading. However, the relationships hold even after controlling for the size category of the biggest city in the district. 


\section{FIGURE 4.18 The composition of urban employment also varies with city governance in India}

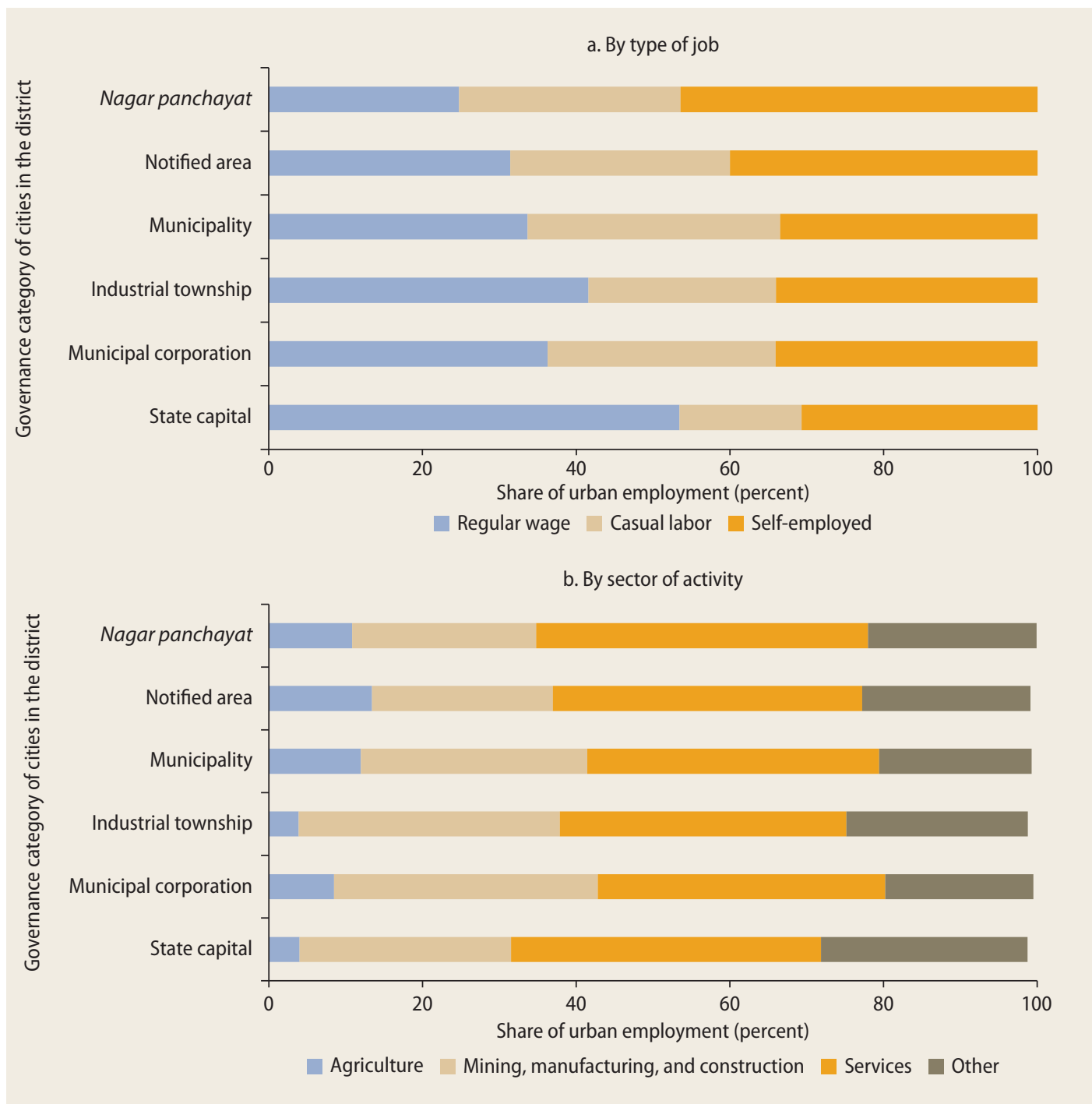

Sources: Based on NSS 2009-10 and RGCC 2012.

Note: The workers considered are adults 15 years of age and older. 


\section{Substantial mobility: Main messages and policy implications}

Mobility is an avenue to long-term equality and a source of economic efficiency. At any point in time, differences exist in household well-being, and these differences are amplified in the absence of equality of opportunity. But they can be partially offset if the choices households make on where to live and what kind of work to do are more rewarding, in relative terms, for the most disadvantaged. Through migration and changes in occupation, a rapidly urbanizing society offers to rural households-typically the poorest in society-a chance to improve their condition.

Assessing the actual extent of mobility is demanding, because it requires data for the same individuals or households at different-and ideally distant-points in time. Few data sources of this sort, including a matched father-son data set are available in South Asia. This chapter supplemented those sources with the construction of synthetic panels for Bangladesh and India, allowing the comparison of household expenditures per capita with an interval of several years. These data sources are admittedly partial, but they yield a consistent picture. Moreover, they provide information on both expenditures and occupations, which is valuable because occupational change is arguably the most powerful driver of mobility.

Contrary to expectations, the extent of mobility in South Asia turns out to be substantial. The occupations held by sons are increasingly independent from those their parents used to have, and the movement is in the direction of leaving unskilled jobs and farming. In India, mobility across generations is greater for households belonging to the Scheduled Castes and Scheduled Tribes and to Other Backward Castes than it is for higher-caste Hindus. When population is classified into three groups-the poor, the vulnerable, and the middle class-upward mobility within a generation is considerable for both the poor and the vulnerable. A large fraction of the poor moves above the poverty line while some of the vulnerable make solid progress into the middle class. The upward mobility of households belonging to the Scheduled Castes and Scheduled Tribes is similar to that of the rest of the population.

A spatial perspective sheds light on the drivers of mobility in South Asia. At the village level, mobility is associated with the development of nonfarm employment in rural areas and with the migration of household members to urban areas, whether permanent or temporary. Migration, not just from rural to urban areas but also between urban areas, emerges from the analysis as a powerful source of mobility. But overall, mobility is higher in urban than in rural areas, and this is so even though a vast majority of urban jobs in South Asia are informal. Regular wage and salaried jobs, formal or informal, appear to be the households' ticket to the middle class.

Recognizing the importance of mobility in adulthood-and not just of equality of opportunity in childhood-has important policy implications. The focus on human opportunity that has characterized much recent work on inequality focuses policy attention on the provision of basic health, education, and infrastructure services. A focus on mobility calls for attention to issues such as jobs and urbanization. Even the kind of infrastructure development to emphasize is different in both cases. And from the mobility perspective, the structure of cities, hence their capacity to support the creation of regular wage and salaried jobs, becomes crucial. 


\section{References}

Afsar, Rita. 2000. Rural-Urban Migration in Bangladesh: Causes, Consequences, and Challenges. Dhaka: University Press.

—. 2003. "Internal Migration and the Development Nexus: The Case of Bangladesh." Paper presented at the Regional Conference on Migration, Development and Pro-Poor Policy Choices in Asia, Dhaka, Bangladesh, June 22-24.

Ahmed, Nazneen, Zaid Bakht, and Md. Yunus. 2011. "Size Structure of Manufacturing Industry and Implications for Growth and Poverty." Bangladesh Country Paper, Bangladesh Institute of Development Studies, Dhaka.

Akerlof, George A., and Rachel E. Kranton. 2010. Identity Economics: How Our Identities Shape Our Work, Wages, and Well-Being. Princeton, NJ: Princeton University Press.

BBS (Bangladesh Bureau of Statistics). 2010. Report of the Household Income and Expenditure Survey 2010. Dhaka: Bangladesh Bureau of Statistics, Statistics Division, Ministry of Planning.

- 2011. Report on Sample Vital Registration System-2010. Dhaka: Bangladesh Bureau of Statistics, Statistics Division, Ministry of Planning.

Bhagat, Ram B. 2010. "Internal Migration in India: Are the Underprivileged Migrating More?" Asia-Pacific Population Journal 25 (1): 27-45.

Björklund, Anders, and Markus Jäntti. 2000. "Intergenerational Mobility of SocioEconomic Status in Comparative Perspective." Nordic Journal of Political Economy 26 (1): 3-32.

BMET (Bureau of Manpower, Employment and Training). 2014. Statistical Reports. Dhaka: Bureau of Manpower, Employment and Training, Ministry of Expatriate Welfare and Overseas Employment, Government of Bangladesh.

CBS (Central Bureau of Statistics). 2012. National Population and Housing Census 2011. Kathmandu: Central Bureau of Statistics, National Planning Commission Secretariat, Government of Nepal.

Dang, Hai-Anh, and Peter Lanjouw. 2013. "Measuring Poverty Dynamics with Synthetic Panels Based on Cross-Sections." Policy Research Working Paper 6504, World Bank, Washington, DC.
2014. "Welfare Dynamics Measurement: Two Definitions of a Vulnerability Line and Their Applications." Background paper for this report and Policy Research Working Paper 6944, World Bank, Washington, DC.

Dang, Hai-Anh, Peter Lanjouw, and Shahidur Khandker. 2014. "Poverty Dynamics in Bangladesh: Recent Trends and Insights from Synthetic Panel Data.” Background paper for this report, World Bank, Washington, DC.

DCS (Department of Census and Statistics). 2012. Census of Population and Housing, 2011. Colombo: Department of Census and Statistics, Government of Sri Lanka.

Denis, Eric, and Kamala Marius-Gnanou. 2011. "Toward a Better Appraisal of Urbanization in India: A Fresh Look at the Landscape of Morphological Agglomerates." Cybergeo: European Journal of Geography [Online], Systems, Modelling, Geostatistics, Document 569. http://cybergeo.revues.org/24798. doi: 10.4000/cybergeo.24798.

Deshingkar, Priya, and Shaheen Akter. 2009. "Migration and Human Development in India." Human Development Research Paper HDRP 2009-13, United Nations Development Programme, New York.

Deshingkar, Priya, and John Farrington. 2009. Circular Migration and Multilocational Livelihood Strategies in Rural India. New York and Oxford: Oxford University Press.

Deshingkar, Priya, and Sven Grimm. 2005. Internal Migration and Development: A Global Perspective. IOM Migration Research Series No. 19. Geneva: International Organization for Migration.

Deshingkar, Priya, Pramod Sharma, Sushil Kumar, Shaheen Akter, and John Farrington. 2008. "Circular Migration in Madhya Pradesh: Changing Patterns and Social Protection Needs." European Journal of Development Research 20 (4): 612-28.

Deshpande, Ashwini. 2000. "Does Caste Still Define Disparity? A Look at Inequality in Kerala, India." American Economic Review 90 (2): 322-25.

DOFE (Department of Foreign Employment). 2013. Annual Report. Kathmandu: Ministry of Labour Employment, Department of Foreign Employment, Government of Nepal.

Erikson, Robert, and John H. Goldthorpe. 1992. The Constant Flux: A Study of Class Mobility in Industrial Societies. Oxford, U.K.: Oxford University Press. 
Ferreira, Francisco H. G., Julian Messina, Jamele Rigolini, Luis-Felipe López-Calva, Maria Ana Lugo, and Renos Vakis. 2012. Economic Mobility and the Rise of the Latin American Middle Class. Washington, DC: World Bank.

Ferrie, Joseph P. 2005. "History Lessons: The End of American Exceptionalism? Mobility in the United States since 1850." Journal of Economic Perspectives 19 (3): 199-215.

Fields, Gary S. 2008. "A Brief Review of the Literature on Earnings Mobility in Developing Countries." Working Papers, Cornell University, ILR School site. http://digitalcommons.ilr.cornell.edu/workingpapers/101.

— . 2010. "Does Income Mobility Equalize Longer-Term Incomes? New Measures of an Old Concept." Journal of Economic Inequality 8 (4): 409-27.

Fields, Gary S., and Efe A. Ok. 1996. "The Meaning and Measurement of Income Mobility." Journal of Economic Theory 71 (2): 349-77.

—. 2000. "Income Mobility: Concepts and Measures." In New Markets, New Opportunities? Economic and Social Mobility in a Changing World, edited by Nancy Birdsall and Carol Graham, 101-33. Washington, DC: Brookings Institution and Carnegie Endowment Press.

Ganzeboom, Harry B. G., and Donald J. Treiman. 1996. "Internationally Comparable Measures of Occupational Status for the 1988 International Standard Classification of Occupations." Social Science Research 25 (3): 201-39.

Giddens, Anthony. 2009. Sociology. 6th ed. Cambridge, U.K.: Polity Press.

Gupta, Indrani, and Arup Mitra. 2002. "Rural Migrants and Labour Segmentation: MicroLevel Evidence from Delhi Slums." Economic and Political Weekly 37 (2): 163-68.

Hamid, Shahnaz. 2010. "Rural to Urban Migration in Pakistan: The Gender Perspective." Working Papers and Research Reports 2010, Pakistan Institute of Development Economics, Islamabad.

Himanshu, Peter Lanjouw, Rinku Murgai, and Nicholas Stern. 2013. "Non-farm Diversification, Poverty, Economic Mobility and Income Inequality: A Case Study in Village India.” Policy Research Working Paper 6451, World Bank, Washington DC.

Hnatkovska, Viktoria, Amartya Lahiri, and Sourabh B. Paul. 2013. "Breaking the Caste Barrier Intergenerational Mobility in
India." Journal of Human Resources 48 (2): 435-73.

Hossain, Mahabub, and Abdul Bayes. 2009. Rural Economy and Livelihoods: Insights from Bangladesh. Dhaka: A H Development Publishing House.

Hossain, Mahabub, Binayak Sen, and Yasuyuki Sawada. 2014. "Jobs, Growth and Development: Making of the 'Other' Bangladesh.” Background Paper for the World Development Report 2013, World Bank, Washington, DC.

Hossain, Munshi I., Iqbal A. Khan, and Janet Seeley. 2003. "Surviving on Their Feet: Charting the Mobile Livelihoods of the Poor in Rural Bangladesh." Paper presented at the conference Staying Poor: Chronic Poverty and Development Policy, Institute for Development Policy and Management, University of Manchester, U.K., April 7-9.

Inchauste, Gabriela, Sergio Olivieri, Jaime Saavedra, and Hernan Winkler. 2012. "What Is Behind the Decline in Poverty since 2000? Evidence from Bangladesh, Peru and Thailand." Policy Research Working Paper 6199, World Bank, Washington, DC.

Kapur, Devesh, Chandra Bhan Prasad, Lant Pritchett, and D. Shyam Babu. 2010. "Rethinking Inequality: Dalits in Uttar Pradesh in the Market Reform Era." Economic and Political Weekly 45 (35): 39-49.

Keshri, Kunal, and Ram B. Bhagat. 2012. "Temporary and Seasonal Migration: Regional Pattern, Characteristics and Associated Factors." Economic and Political Weekly 47 (4): 81-88.

Khan, Aliya H., Lubna Shehnaz, and Ather Maqsood Ahmed. 2000. "Determinants of Internal Migration in Pakistan: Evidence from the Labour Force Survey, 1996-97." Pakistan Development Review 39 (4) Part II: 695-712.

Khandker, Shahidur R., M. A. Baqui Khalily, and Hussain A. Samad. 2012. "Seasonal Migration to Mitigate Income Seasonality: Evidence from Bangladesh." Journal of Development Studies 48 (8): 1063-83.

Kundu, Amitabh, and Niranjan Sarangi. 2007. "Migration, Employment Status and Poverty: An Analysis across Urban Centres." Economic and Political Weekly 47 (26): 219-27.

Kundu, Amitabh, and Lopamudra Ray Saraswati. 2012. "Migration and Exclusionary Urbanisation in India." Economic and Political Weekly 42 (4): 299-306. 
Lall, Somik V., and Claus Astrup. 2009. Sri Lanka: Reshaping Economic Geography: Connecting People to Prosperity. Washington, DC: World Bank.

Lokshin, Michael, Mikhail Bontch-Osmolovski, and Elena Glinskaya. 2010. "Work-Related Migration and Poverty Reduction in Nepal." Review of Development Economics 14 (2): 323-32.

Long, Jason, and Joseph Ferrie. 2007. “The Path to Convergence: Intergenerational Occupational Mobility in Britain and the US in Three Eras." Economic Journal 117 (519): C61-71.

-. 2013. "Intergenerational Occupational Mobility in Great Britain and the United States since 1850." American Economic Review 103 (4): 1109-37.

Lopez-Acevedo, Gladys, and Raymond Robertson, eds. 2012. Sewing Success? Employment, Wages, and Poverty Following the End of the Multi-fibre Arrangement. Washington, DC: World Bank.

Marshall, Richard, and Shibaab Rahman. 2013. "Internal Migration in Bangladesh: Character, Drivers and Policy Issues." Paper by the United Nations Development Programme, Bangladesh.

Mazumdar, Indrani, N. Neetha, and Indu Agnihotri. 2011. "Gender and Migration in India." National Workshop on Internal Migration and Human Development in India: Workshop Compendium, Vol. II. New Delhi: UNESCO and UNICEF.

- 2013. "Migration and Gender in India." Economic and Political Weekly 48 (10): 54-64.

Mitra, Arup. 2010. "Migration, Livelihood and Well-Being: Evidence from Indian City Slums." Urban Studies 47 (7): 1371-90.

Mosse, David, Sanjeev Gupta, Mona Mehta, Vidya Shah, Julia Rees, and the KRIBP Project Team. 2002. "Brokered Livelihoods: Debt, Labour Migration and Development in Tribal Western India." Journal of Development Studies 38 (5): 59-88.

Mosse, David, Sanjeev Gupta, and Vidya Shah. 2005. "On the Margins in the City: Adivasi Seasonal Labour Migration in Western India." Economic and Political Weekly 40 (28): 3025-38.

Mukhopadhyay, Partha. 2011. "Formality and Functionality in Indian Cities, Op-Ed." Seminar Web edition (January), New Delhi.

Muzzini, Elisa, and Gabriela Aparicio. 2013a. Bangladesh: The Path to Middle-Income
Status from an Urban Perspective. Washington, DC: World Bank.

- 2013b. Urban Growth and Spatial Transition in Nepal: An Initial Assessment. Washington, DC: World Bank.

Narayan, Ambar, and Hassan Zaman. 2008. Poverty Assessment for Bangladesh: Creating Opportunities and Bridging the East-West Divide. Bangladesh Development Series Paper no. 26. Washington, DC: World Bank.

Nargis, Nigar, and Mahabub Hossain. 2006. Income Dynamics and Pathways out of Rural Poverty in Bangladesh, 1988-2004." Agricultural Economics 35 (Suppl. s3): 425-35.

NSSO (National Sample Survey Office). 2010. Migration in India 2007-2008: NSS 64th Round (July 2007-June 2008). NSS Report No. 533 (64/10.2/2). New Delhi: National Sample Survey Office, Ministry of Statistics and Programme Implementation, Government of India.

Pradhan, Kanhu Charan. 2013. "Unacknowledged Urbanisation: The New Census Towns of India." Economic and Political Weekly 47 (36): 43-51.

Raihan, Selim, Bazlul H. Khondker, Guntur Sugiyarto, and Shikha Jha. 2009. "Remittances and Household Welfare: A Case Study of Bangladesh.” Working Paper Series No. 189, Asian Development Bank, Manila, Philippines.

RGCC (Registrar General and Census Commissioner). 2012. Census of India, 2011. New Delhi: Registrar General and Census Commissioner, India, under Ministry of Home Affairs, Government of India.

Salverda, Wiemer, Brian Nolan, and Timothy M. Smeeding, eds. 2011. The Oxford Handbook of Economic Inequality. Oxford, U.K.: Oxford University Press.

Schumpeter, Joseph Alois. 1955. Imperialism [and] Social Classes: Two Essays. New York: Meridian.

Shah, Amita. 2005. "Land Degradation and Migration in a Dry Land Region in India." SANDEE Working Paper No. 10, South Asian Network for Development and Environmental Economics, Kathmandu, Nepal.

- 2010. "Migration as an Exit Route: How Does It Work for the Chronic Poor in India?" Paper presented at International Conference on Ten Years of War against Poverty: What Have We Learned since 2000; What Should We Do 2010-2020, Manchester, U.K., September 8-10. 
Singh, Ashish, and Sripad Motiram. 2012. "How Close Does the Apple Fall to the Tree?" Economic and Political Weekly 47 (40): 56-65.

Srivastava, Ravi. 2011. "Labour Migration in India: Recent Trends, Patterns and Policy Issues." Indian Journal of Labour Economics 54 (3): 411-40.

. 2012. "Internal Migration in India: An Overview of its Features, Trends, and Policy Challenges." National Workshop on Internal Migration and Human Development in India: Workshop Compendium, Vol. II. New Delhi: UNESCO and UNICEF.

UN (United Nations Department of Economic and Social Affairs/Population Division). 2012. World Urbanization Prospects: The 2011 Revision. New York: United Nations.

World Bank. 2010. "Pakistan Poverty Assessment.” World Bank, Washington, DC. Unpublished.

- 2011b. Large-Scale Migration and Remittance in Nepal: Issues, Challenges, and Opportunities. Report No. 55390-NP. Washington, DC: World Bank.
. 2011c. More and Better Jobs in South Asia. Washington, DC: World Bank.

.2012a. Bangladesh: Towards Accelerated, Inclusive and Sustainable Growth: Opportunities and Challenges. Washington, DC: World Bank.

2012b. World Development Report 2013: Jobs. Washington, DC: World Bank.

- 2013a. Bangladesh Poverty Assessment: Assessing a Decade of Progress in Reducing Poverty, 2000-2010. Washington, DC: World Bank.

. 2013b. Urbanization beyond Municipal Boundaries: Nurturing Metropolitan Economies and Connecting Peri-Urban Areas in India. Washington, DC: World Bank.

Zhang, Xiaobo, Shahidur Rashid, Kaikaus Ahmad, Valerie Mueller, Hak Lim Lee, Solomon Lemma, Saika Belal, and Akhter Ahmed. 2013. "Rising Wages in Bangladesh." IFPRI Discussion Paper 1249, International Food Policy Research Institute, Washington, DC. 


\section{Inadequate Support}

H ouseholds in every country suffer from shocks. Most are minor and can be cushioned relatively easily, but some can have long-lasting impacts, adversely affecting nutrition, human capital, and asset accumulation. The vulnerability of households to shocks is determined partly by the types of risks they face. For instance, urban and rural populations are exposed in different degrees to the same natural disasters. The vulnerability of households also depends on their own ability to manage those risks. Typically, the poor have a relatively weak capacity to self-insure or to pool risks beyond extended families. Informal mechanisms tend to be costly and inefficient, often breaking down when shocks affect entire communities.

Bad luck can hit even before birth. Individuals differ in their inherited wealth, in their talent, in the value they attach to future well-being relative to present well-being, and in their willingness to work hard. Even children of the same parents can differ in these respects. In an ideal society with equality of opportunity and perfect mobility, these inherited differences would result in inequality of outcomes. Given that no society fully meets the ideal, the inequality of outcomes caused by inherited wealth, talent, and other innate characteristics is often amplified by the legacy of inequities accumulating through life. Parents' support for their less fortunate offspring can go some way toward redressing disparities within a household, whereas charity inspired by the generosity of those who do well can reduce disparities more broadly. But private transfers are unlikely to be sufficient to offset the consequences of these other forms of randomness.

To what extent inequality of outcomes resulting from these different forms of bad luck is tolerable-or even desirable-is a question to which different societies give different answers. But most-if not allhave developed mechanisms for redress (box 5.1).

Government-sponsored mechanisms to cope with shocks are known as social protection; they typically comprise social assistance and social insurance programs. They are designed to prevent households that are affected by an adverse shock from experiencing too dramatic a fall in their living standards. Mechanisms to redress deeper differences in the fate of individuals and households fall under the broader heading of redistribution; the instruments used in this case are taxes, subsidies, and transfers. 


\section{BOX 5.1 Support aims at offsetting inequality of outcomes stemming from bad luck}

Consider a society with equality of opportunity and perfect mobility. In such society, inequality of outcomes is still possible because individuals differ in their inherited wealth, their talent, their foresightedness, or their aversion to effort. In the absence of any government intervention, differences in well-being are unlikely to be resorbed as people age. Imagine now that all individuals experience an adverse shock at some point in their adult life, but the magnitude of the shock varies. In the figure, for example, poorer individuals are affected to a greater extent-in relative terms-than richer ones.

The level of final well-being crucially depends on the support received from the government. If social protection programs are indeed targeted to the poor, and if taxes and subsidies are progressive, then the actual inequality of outcomes could be even lower than the initial one. In most countries, after-tax inequality of outcomes is indeed lower than pretax inequality.

However, as the figure shows, some inequality of outcomes would still occur. People who had the same opportunity in childhood and the same chances to prosper through mobility in adult life

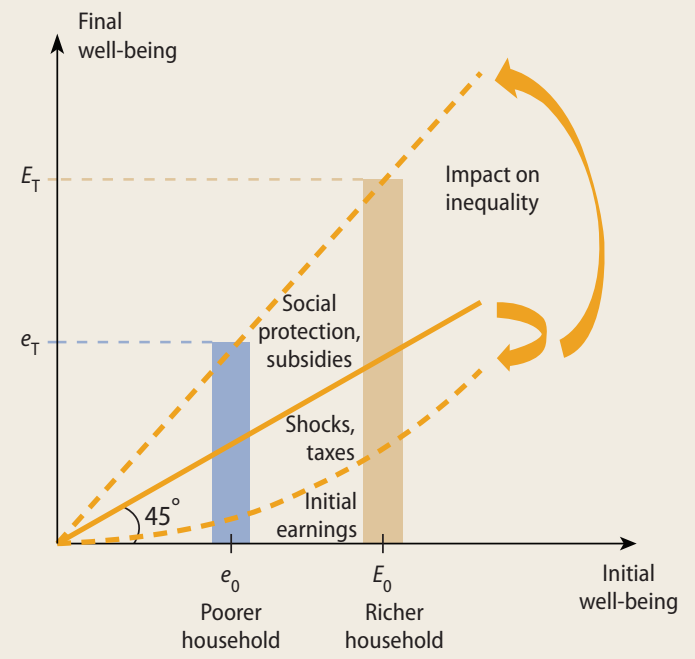

can be taken in different directions, depending on their talent and the shocks they experience. And government support, although partially mitigating the effects of this randomness, is unlikely to fully offset it. The policy challenge is not how to ensure equality of outcomes but rather how to provide support in an efficient manner.
This type of support aims at bringing disadvantaged households to a higher level of welfare than they could attain on their own. The reach, generosity, and efficiency of social protection and redistribution mechanisms vary from one society to another and, as a result, the extent of inequality of outcomes varies as well.

South Asian countries have a mixed record on both fronts. Public spending on social protection programs has expanded over time. Measured as a fraction of GDP, it is in line with other countries at roughly the same development level. The design of these programs also shows important strengths. Thus, the Benazir Income Support Programme (BISP) of Pakistan is remarkably well targeted to poorer households and has helped them become more resilient to natural disasters such as floods and earthquakes. Similarly, the Mahatma Gandhi National Rural Employment Guarantee (MGNREG) Act of India-the largest public works program in the world-has dramatically reduced distress sales of land in years of drought.

But the social protection programs of the region also have distinct features that make them less than ideal. Compared with other regions, a much higher proportion of resources goes into direct subsidies for households to purchase items such as food, fuel, and electricity. The justification for some of these subsidies may be conceptually strong, as 
in the case of food, where the aim is to reduce the risk of hunger, but weak implementation results in high leakage and substantial waste. Subsidies for fuel and electricity tend to be regressive in that they benefit betteroff households. Because of these features, social protection programs in the region are less well geared to reducing inequality than they could be. Their coverage is partial, their targeting is generally poor, and the amount of resources they make available to those who need them the most is often too modest.

The record is arguably more questionable in the case of redistribution. One of South Asia's salient characteristics is the low level of its tax revenue relative to GDP, which implies that the potential for the government to make a dent in inequality of outcomes is more limited than elsewhere. Tax revenue is low not because South Asian countries rely on unusual tax instruments but rather because the revenue "productivity" of those instruments is unusually low. Tax avoidance, tax evasion, and the underreporting of taxable amounts are widespread, as are exemptions and special regimes favoring the businesses with more clout. All of this results in a tax system of relatively low progressivity.

A positive note comes from spatial transfers to poorer administrative units, such as provinces and districts. Several countries in the region are large enough for these transfers to be a very important component of local budgets. Transfers designed on a spatial basis also have the advantage of not directly distorting the incentives faced by households and firms. Transfers of this sort are clearly progressive in South Asia, but they are still modest in relation to the needs of poorer areas.

\section{Shocks and how households cope}

South Asian households are periodically exposed both to individual shocks and to economy-wide shocks, such as natural disasters, food price spikes, and armed conflict. The region's frequent exposure to shocks relates to geographic, historical, and socioeconomic factors. South Asia has a high population density; 23.8 percent of world's population lives on 3.6 percent of the world's land-and approximately 68 percent of the region's population lives in poverty. South Asia's economy is strongly oriented toward agriculture, which makes countries more vulnerable to natural disasters and weather-related shocks. Indeed, roughly 70 percent of the South Asian population lives in rural areas and about half relies on agriculture for its livelihood. In addition, the region experiences frequent conflicts, including guerrilla warfare, riots, and antigovernment demonstrations.

Health shocks affect households and communities through births, deaths, disability, illness, accidents, and other adverse individual health events. Shocks emanating from noncommunicable diseases such as cardiovascular problems, cancer, diabetes, and the like affect individual households, whereas shocks from communicable diseases such as tuberculosis, HIV and AIDS, hepatitis, and the like threaten entire communities. In addition to the impact on health, shocks of this sort often result in catastrophic household expenditures, thus undermining the wellbeing of all household members.

Many natural disasters, such as tidal waves and earthquakes, occur with little warning and have widespread, devastating effects. Other weather-related events are recurrent annual or periodic problems. More than 900 disasters have been reported in South Asia since 1970, with floods constituting almost half the events. Floods and changes in traditional agricultural patterns can severely affect households. An example is the Rangpur region of Bangladesh, where hunger is prevalent during the monga season (Khandker 2012; World Bank 2013a).

Natural disasters affected more than 750 million people in the region between 1990 and 2008, resulting in approximately 230,000 deaths and US\$45 billion in damages (World Bank 2009b). Bangladesh stands out as one of the countries that have experienced the largest losses of human lives 
TABLE 5.1 Bangladesh suffered 2 of the 10 most deadly natural disasters of recent times

\begin{tabular}{llll}
\hline Victims & Date & \multicolumn{1}{c}{ Type of disaster } & \multicolumn{1}{c}{ Area } \\
\hline 300,000 & 1970 & Drought & Ethiopia \\
300,000 & 1970 & Storm and flood catastrophe & Bangladesh \\
255,000 & 1976 & Earthquake & China \\
220,000 & 2004 & Earthquake, tsunami in Indian Ocean & Indonesia, Thailand \\
150,000 & 1983 & Drought & Sudan \\
138,000 & 1991 & Tropical cyclone Gorky & Bangladesh \\
133,655 & 2008 & Cyclone Nargis & Myanmar \\
87,476 & 2008 & Earthquake & China, India, Pakistan \\
73,300 & 2005 & Earthquake & Afghanistan \\
66,000 & 1970 & Earthquake & Peru \\
\hline
\end{tabular}

Source: Based on EM-DAT, the International Disaster Database, Centre for Research on the Epidemiology of Disasters, Brussels, Belgium, http://www.emdat.be/.

worldwide (table 5.1). Moreover, the frequency and magnitude of natural disasters are increasing, mainly because of climate change and accelerated snow melting in the Himalayas (Memon 2012).

Economic crises that start in industrial countries can quickly affect developing countries in today's interconnected global economy. Compared with the rest of the world, the effect of the most recent global financial crisis on South Asia was relatively modest. But Bangladesh was hit especially hard by the reduction in global demand for apparel, which is the country's leading industry. Another important transmission channel for economic shocks is remittances. In relative terms, remittances are particularly important for Nepal, Bangladesh, and Sri Lanka; in 2009 they accounted for 23, 12, and 8 percent of GDP, respectively. The global crisis reduced the average growth rate of remittances to South Asia from 33 percent in 2008 to less than 6 percent in 2009 (Migration and Remittances Data, World Bank n.d.).

Food price inflation has been the main driver of headline inflation throughout most of South Asia. The effects of the widespread food price inflation of 2007-08 varied significantly among countries in the region. Inflation ranged from relatively moderate in India (approximately 7 percent) to high in Nepal and Bangladesh (approximately 15 percent), to very high in Pakistan (approximately 20 percent). Sri Lanka and Afghanistan experienced food price inflation of more than 30 percent.

South Asia is also prone to conflict and violence. Over the past decade, the number of terrorist incidents increased significantly in South Asia (Global Terrorism Database 2009-14). The region accounted for more than 30 percent of the world's terrorist incidents between 2004 and 2008 and at least 40 percent in 2009 and 2010.

A sizable number of households in parts of South Asia are directly affected by conflict. For example, in a World Food Programme survey carried out in parts of Khyber Pakhtunkhwa and federally administered tribal areas in Pakistan during 2010, 16 percent of households reported high levels of insecurity from strict rules imposed by militants, curfews or bans on freedom of movement, military operation against militants, displacement, and property damage (Pop 2010).

Households are affected differently by these various kinds of shocks, however (Glewwe and Hall 1998; Heltberg and Lund 2009). In Pakistan, almost two-thirds of respondents had experienced one or more shocks over the three-year study period. Slightly more than half the shocks were 
related to health events, including disease, death, accident, and disability (figure 5.1). Interestingly, the wealthiest quintile was the most likely to face a large decrease in consumption.

Studies focusing on specific shocks shed additional light on who is most affected. For instance, natural disasters significantly affect poor children who cannot continue their education because of lost family income and housing as well as delays in matriculation (UN/ISDR 2008). In India, natural disasters are strongly correlated with more working hours devoted to nonfarm activities at lower wages, especially when child labor is involved (Kochar 1995, 1999; Rosenzweig and Stark 1989). As a consequence of the destructive 1988 floods in Bangladesh, the nutrition of children from landless households in affected areas significantly worsened (Foster 1995). Within the flood-exposed households in Bangladesh, the percentage of stunted children in households at the bottom 40th percentile of the consumption distribution remained much higher than that for households in the top 20th percentile a year after the flood (Del Ninno and Lundberg 2005).

Countries adjust to economic shocks in different ways, with potentially different implications for workers. One study found that adjustments for 41 developing countries occurred through the quality of jobs rather than through the number of jobs (Khanna, Newhouse, and Paci 2010). Growth in earnings slowed much more than employment growth, unemployment changed little, and hourly wage growth did not collapse. Adjustments came mainly through large reductions in the number of hours worked.

Because poorer households in the region spend a considerable amount of their household budget on food (half of it, on average, in 2011), even minor changes in food prices can profoundly affect their well-being. Short-term declines in food security can have serious implications. In particular, low levels of dietary diversity have been statistically linked to inadequate nutrient intake
FIGURE 5.1 Health-related events and disasters are the most common shocks in Pakistan

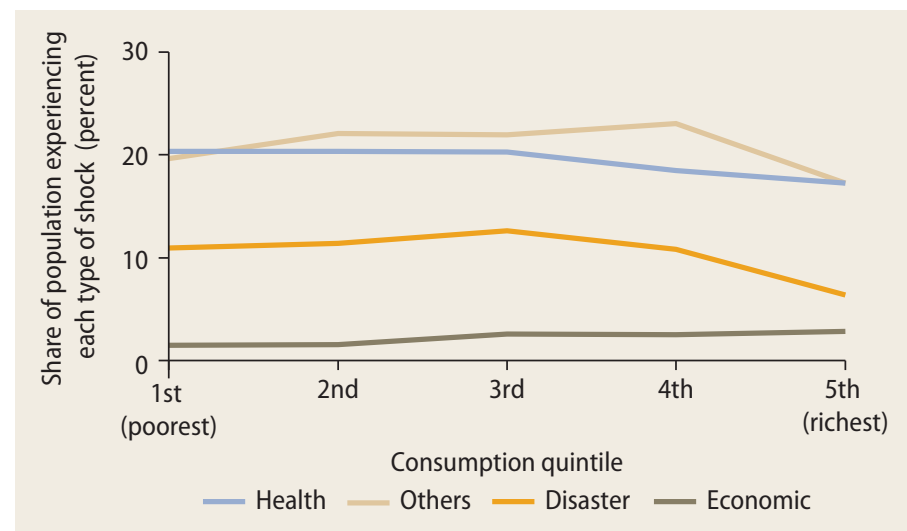

Sources: Based on PSLM 2007-08 to 2009-10

(Arimond and Ruel 2004). Micronutrient deficiencies and early childhood malnutrition, in particular chronic malnutrition, have been linked to impaired cognitive development, physical and mental disabilities, child and maternal deaths, and lower productivity (Alderman, Hoddinott, and Kinsey 2006; Glewwe and Jacoby 1995; Glewwe and King 2001; Micronutrient Initiative and others 2009).

It seems natural to expect conflict and violence to negatively influence all households within the affected regions, but even then, wealth can make a difference. In two conflict-affected regions of Pakistan, poor households were more likely to incur debts, to sustain house damage during fighting, to be displaced, to become victims of crime and theft, and to be affected by drought than wealthier households (Pop 2010). Because of attacks by militants, many households did not send children to school, especially their girls, suggesting a gender effect. In Nepal, the conflict adversely affected female education, but overall it did not significantly reduce the number of years of education for either sex (Valente 2011).

Households can mitigate the effects of shocks by reducing consumption, altering expenditure patterns, and changing the allocation of their time (Frankenberg, Smith, and Thomas 2003). Their strategies include 
depleting savings and selling physical assets (Deaton 1990), increasing labor force participation, finding new jobs or producing goods for home consumption, accessing interhousehold transfers (Cox 1987), borrowing, and altering consumption patterns (World Bank 1990). But coping strategies can lead to persistent negative effects on human capital, such as removing children from school and putting them to work (Jacoby and Skoufias 1997; Kochar 1995; Moser 1998).

In Pakistan, shocks negatively affected household consumption regardless of the indicator considered and regardless of the number of shocks experienced. But the impact was not always statistically significant. Among households that reported natural disasters, rural households were more likely to experience a drop in consumption than those in urban areas (figure 5.2). Conversely, among households that reported economic shocks, those in urban areas were likely to experience a drop in consumption, which was not the case in rural areas. Health shocks are also significantly related to a drop in household consumption in urban areas.
Employment diversification within households is a usual way to mitigate risk, akin in spirit to portfolio diversification in finance. Employment diversification includes having household members who take other jobs in the same location or who migrate for jobs elsewhere (Banerjee and Duflo 2007). In India, rural areas with higher rainfall variability or those affected by the severe flood of 1998 exhibited a significantly higher level of intrahousehold employment diversification. But this excessive diversification negatively affected household welfare and increased the probability of falling into poverty (Bandyopadhyay and Skoufias 2012).

South Asian countries exhibit high rates of informal sector employment (World Bank 2012c). That could seem an advantage in dealing with economic shocks, because flexibility is higher in the informal sector. Indeed, the formal sector tends to adjust more through the number of jobs, whereas in the informal sector the burden of the adjustment falls on earnings, with fewer people being left totally out of employment. In the case of aggregate

\section{FIGURE 5.2 Disasters in Pakistan affect rural populations much more than urban populations}

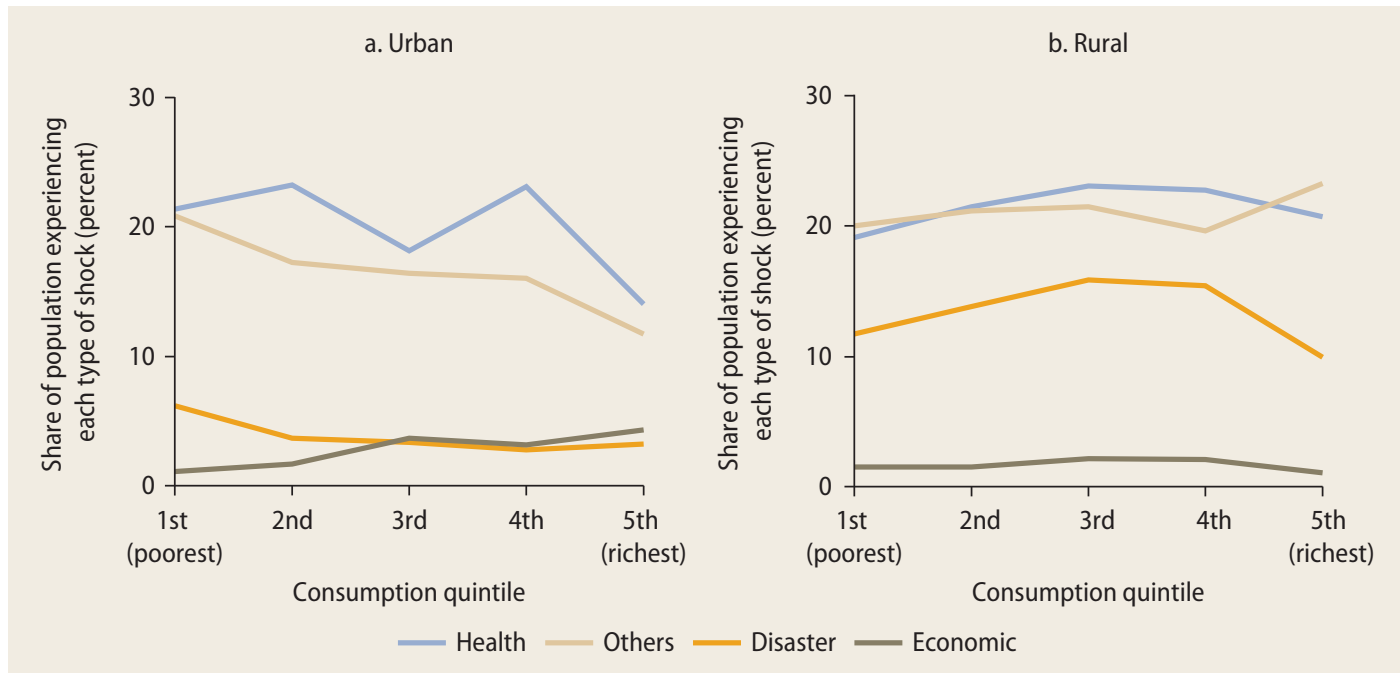

Source: Based on PSLM 2007-08 to 2009-10. 
shocks, however, self-employment does not always provide a safety net, and the number of hours of work may fall short of the desired level (McKenzie 2004).

Without formal social safety nets and with limited or no access to formal credit and insurance markets, households in the developing world often resort to selfhelp and mutual insurance mechanisms. Self-insurance strategies include accumulating assets - stored grain or small and large livestock in rural areas or jewelry and durables in urban areas-that can be sold during hard times. Informal insurance mechanisms comprise local borrowing schemes with friends and neighbors as well as private transfers originating from relatives. The most common informal mechanisms of lending in the rural economy are informal group loans, microfinance programs, and rotating savings and credit associations. Borrowing can be costly in imperfect markets, especially for poor households (Banerjee and Duflo 2007; Behrman 1988). Mitigating risks through production choices can be costly, too, because expected profits must be sacrificed to achieve a lower risk (Morduch 1995).

Poor households in some South Asian countries also rely significantly on remittances. For example, more than 50 percent of the poorest two deciles of the population in Bangladesh report receiving remittances, for an average amount corresponding to 142 percent of their pretransfer consumption. Similarly, about 50 percent of Pakistani households in the poorest two deciles report receiving remittances, the amount received corresponding to 76 percent of their average consumption.

Households have developed informal strategies to cope with food price inflation. In Afghanistan, poor households demonstrate large negative price elasticities of food consumption but much smaller price elasticities of caloric intake, suggesting that households trade quality of food for quantity of calories in response to declining purchasing power and relative price changes (D'Souza and Jolliffe 2010).

Recent data on the whole set of coping mechanisms are available for Pakistan (figure 5.3). When faced with a shock, a large majority of households in the poorest quintile borrow money, reduced expenditures, switched to lower-quality food, or reduced the quantity of food they consumed. Equally important, 11.5 percent of the poorest households reported selling agricultural assets to cope with the shock-a strategy that compromises their long-term ability to earn an income. In contrast, the wealthiest groups are much less likely to use these mechanisms.

The full welfare impact of shocks depends on whether they are individual or aggregate. Food price fluctuations are a case in point. For an individual household that is a net buyer of food, the individual shock is clearly negative. But higher prices also encourage food production and tend to result in a higher demand for rural labor. Some of the poorest households work as rural laborers, so they benefit from this indirect effect, and the net outcome may be positive in their case.

The significant price fluctuations that took place during 2000-10 make measurement of the impact of food price inflation on the poor possible. In Bangladesh, the poor bore the brunt of higher food prices in the short term. Once wages adjusted to the price shock, however, the impact was largely equalized across population groups. In the longer term, as the price shock permeated other sectors, the negative short-term impact on the poor was reversed. Because Bangladesh is still to a large extent an agrarian country, in the end all groups benefited from higher food prices (Jacoby and Dasgupta 2012).

Regardless of the origin of the shock, the impact on household well-being depends on the nature of the social protection programs in place. Health shocks illustrate the trade-offs (figure 5.4). On one hand, in countries without well-developed 


\section{FIGURE 5.3 In Pakistan, poorer and richer households cope with shocks in different ways}

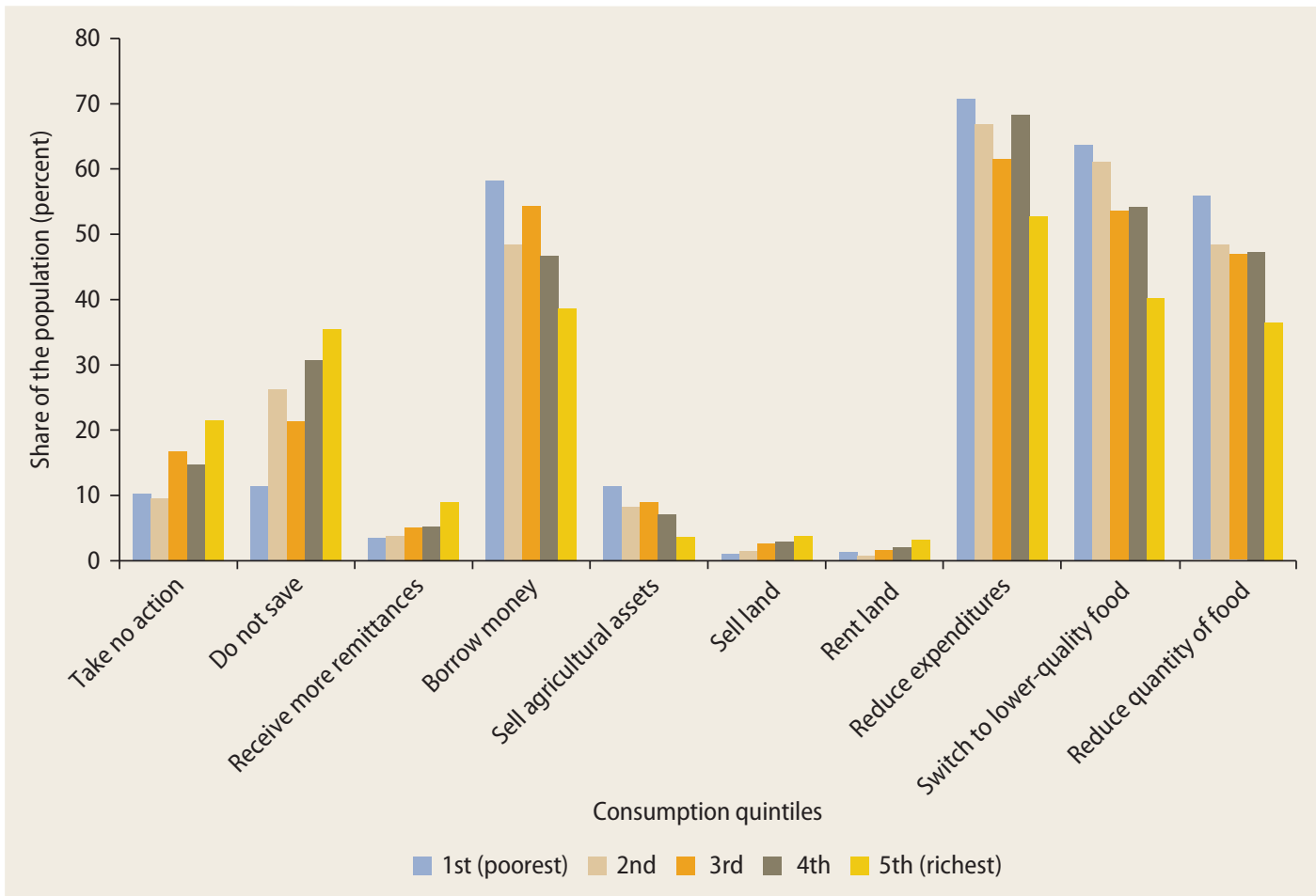

Sources: Based on PSLM 2007-08 to 2009-10.

\section{FIGURE 5.4 Spending on health is mainly out of households' pockets}

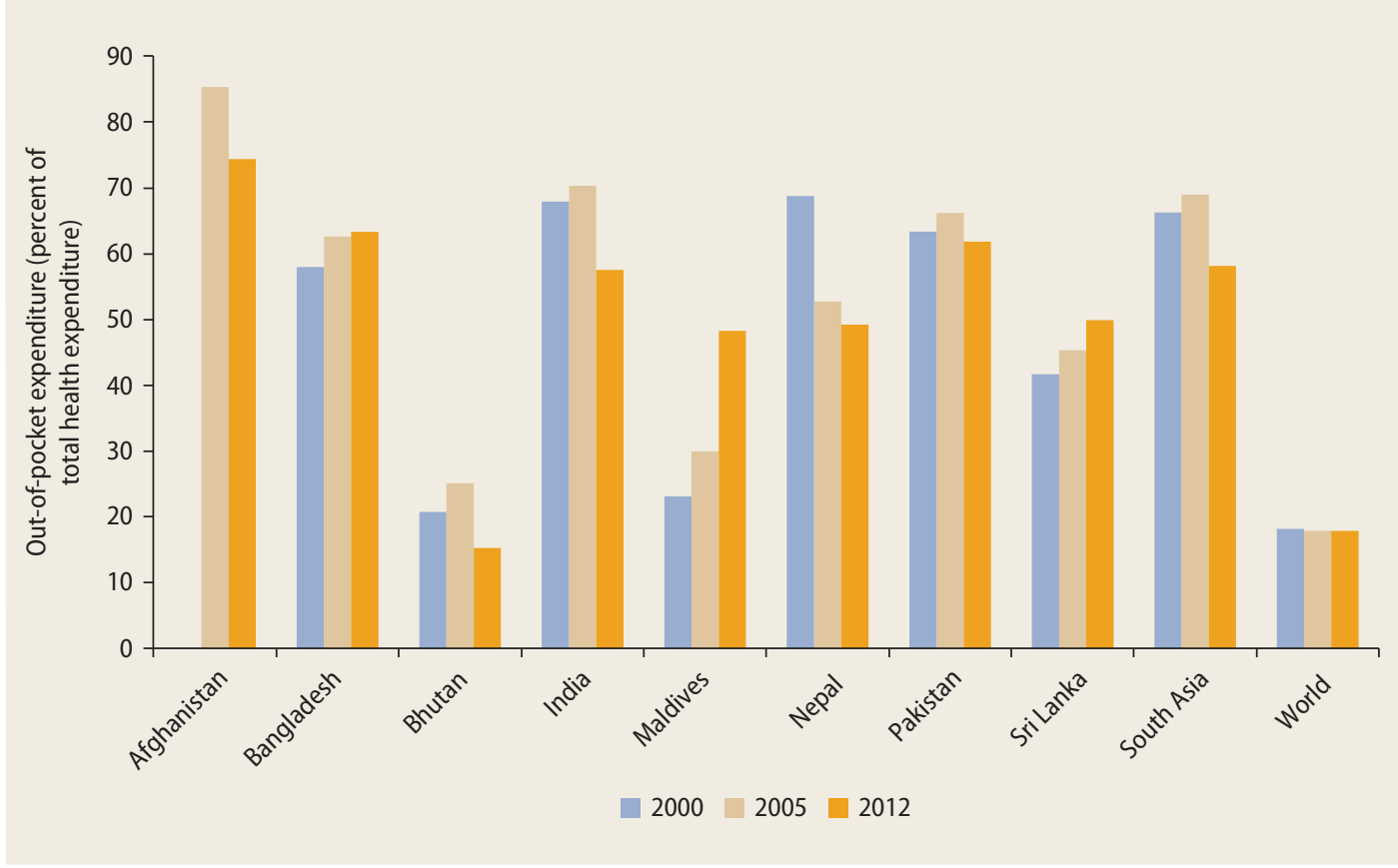


social protection architecture, such as Afghanistan and India, catastrophic health shocks confront households with massive out-of-pocket expenditures. On the other hand, in Maldives and especially Bhutan, the public sector bears most of the cost through the corresponding social security agencies.

\section{A scorecard for social protection programs}

Social protection helps individuals, households, and communities create assets, cope with risk and volatility, and cushion the impact of crisis, structural transformations, and other shocks. By targeting the poor and the most vulnerable, spending on social protection programs should be progressive and thus reduce inequality. By reducing the variability of earnings, expenditures, and well-being more generally, social protection programs also cushion individual household transitions for a given level of aggregate inequality. However, the impact of social protection on inequality can be undermined by low coverage, poor targeting, administrative leakage, and inadequacy of benefits.

On average, developing countries spend 1.53 percent of their GDP on safety nets, and with the exception of Sri Lanka, most South Asian countries fall within the 0.25 percent to 2 percent range (figure 5.5). This, in itself, reflects the recent strides countries in the region have made. Bangladesh provides a clear example (box 5.2). Among its public safety net programs, the Female Secondary Schools Stipends Program-the precursor of modern conditional cash transfers-is known worldwide. But Bangladesh is not alone. In India, the MGNREG Act represents a significant milestone in the design and execution of public works, supported by massive government resources. The Rashtriya Swasthya Bima Yojana health insurance program for the poor is also pathbreaking in its design though still in an early stage of development. In Pakistan the
FIGURE 5.5 Spending on social protection in South Asia is lower than in other developing countries

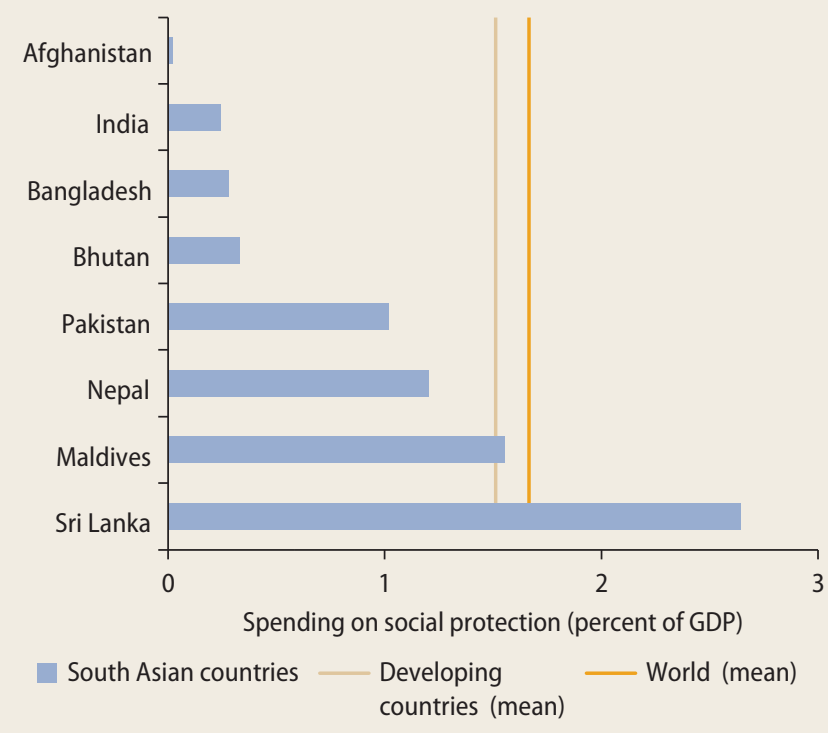

Source: Based on World Bank 2014.

BISP, introduced in 2008, helped increase spending on social safety net programs from 0.3 percent of GDP in 2003-04 to over 0.7 percent of GDP in 2010.

When assessed on the basis of absolute spending per person, social protection programs are progressive in Bangladesh, Pakistan, and Sri Lanka (figure 5.6). Bangladesh is the most effective in directing social protection resources to the poor. In 2010, the poorest 40 percent of households received a little over half the social assistance and over 75 percent of the social insurance, whereas the wealthiest 20 percent of households received about 12 percent of both types of assistance. In contrast, resources are more tilted toward the better-off in Afghanistan, Maldives, and Nepal.

However, because poorer households consume less, the same level of public spending makes a greater difference in their case. When assessed relative to the consumption level of the beneficiaries, social protection spending turns out to be largely progressive across the entire region. 


\section{BOX 5.2 Bangladesh has a rich and complex social protection architecture}

The social protection architecture of Bangladesh builds on a long history of efforts emanating from the need to roll out emergency relief measures in response to a cyclone or a famine. These efforts instilled a culture of experimentation and innovation, depending on the nature of the crisis, the instruments available, and the actors involved. Large numbers of nongovernmental organizations, which provide an extensive safety net system for the poor in Bangladesh, were part of these relief efforts. The many programs in place and the relatively poor coordination and harmonization between them are largely the result of this long and rich history of efforts.

Until 2005, the bulk of public transfers in Bangladesh were allocated to expensive and "leaky" food transfer programs. However, since then, the government boosted its cash transfer programs and thereby their share of total program spending. The Food for Education program was transformed into a cash-based stipend program, and Cash for Work is gradually being incorporated into the Food for Work program. The increased emphasis on cash transfers reflects recognition of their greater cost-effectiveness and lower risk of misappropriation. Nevertheless, food transfer programs remain an important pillar of Bangladesh's food security strategy and serve a secondary role in turning over the country's emergency grain supplies.

Under the government-financed caption of "social protection and social empowerment," 99 social protection programs together account for 14 percent of the budget and 2.4 percent of GDP. These programs are of varying sizes and can be grouped under a number of broad categories: food-based emergency or seasonal relief and public works programs, pension programs, transfers linked to health and education, and cash allowance programs for special groups. Agricultural programs aimed at supporting farmers, microcredit and rural employment programs, and programs addressing climate change are also included in the social protection budget. Despite the varied mix of the programs, the largest 10 absorb over 70 percent of the total social assistance budget.
The progressivity of social safety net programs is partially explained by the location of the recipients. In Bangladesh, the vast majority of them reside in the countryside-7.2 million, about 10 times the number of recipient households in urban areas. Although the coverage of safety net programs varies significantly by region within Bangladesh, it is closely correlated with local poverty rates. For example, Barisal, with the highest poverty rate (39 percent), has the second-highest coverage of safety nets among all divisions (34 percent). In contrast, Chittagong and Dhaka, which have the lowest poverty rates in the country (respectively, 26 and 31 percent), have the lowest coverage
(19.4 and 18.8 percent). These figures represent a significant improvement over time: in 2005 , the coverage of safety nets was negatively correlated with regional level poverty rates.

Overall, the potential of a safety net program to reduce inequality depends on its coverage of the intended beneficiaries, the share of total resources spent on intended beneficiaries, the spillover to unintended beneficiaries, and the generosity of the benefits provided. In more technical terms, the four dimensions to assess are coverage, targeting, leakage, and adequacy. Household survey data from 2005 to 2010 can be used to conduct such an assessment for most of 


\section{FIGURE 5.6 Absolute spending on social protection is progressive in Bangladesh and Sri Lanka}
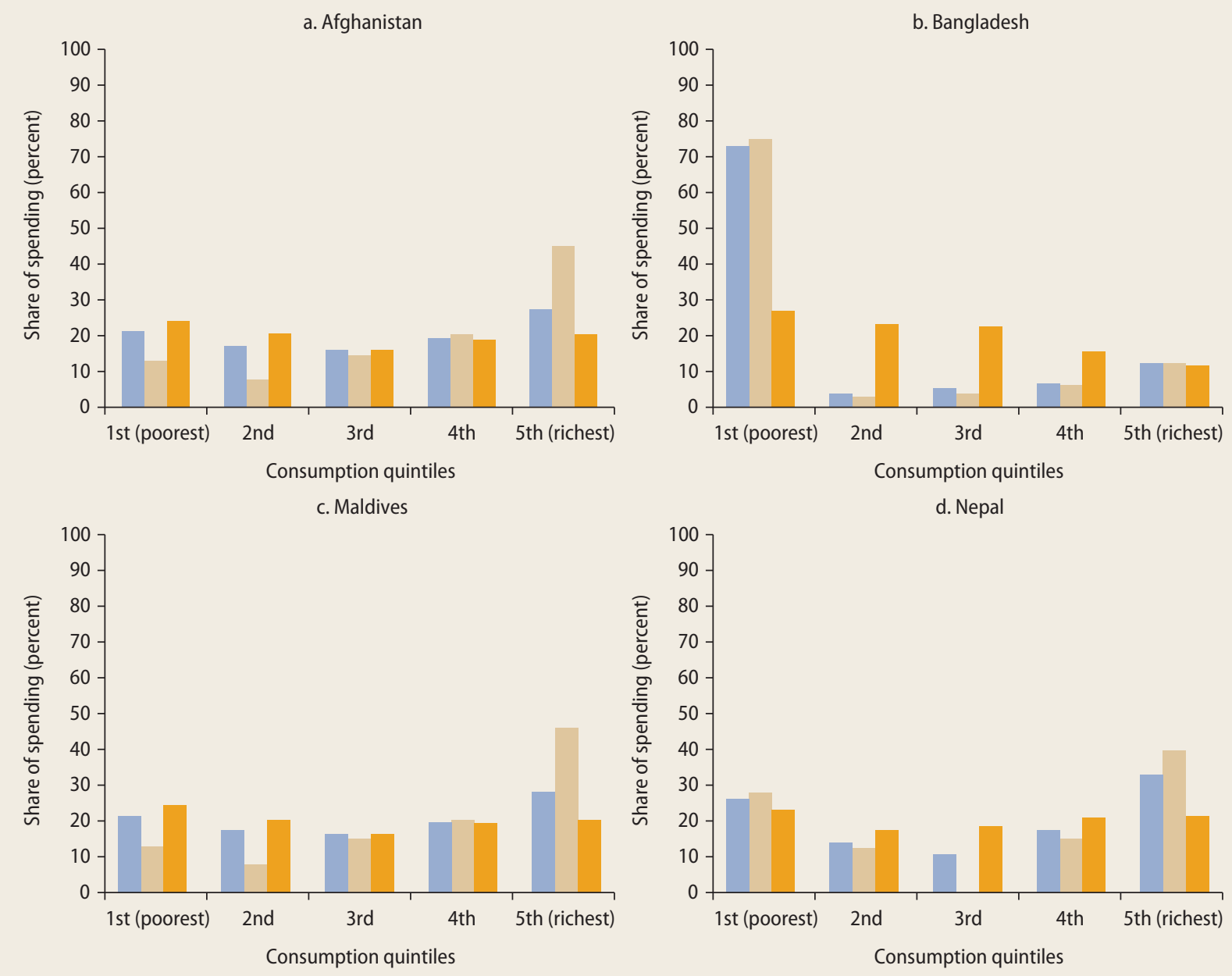

e. Pakistan

f. Sri Lanka
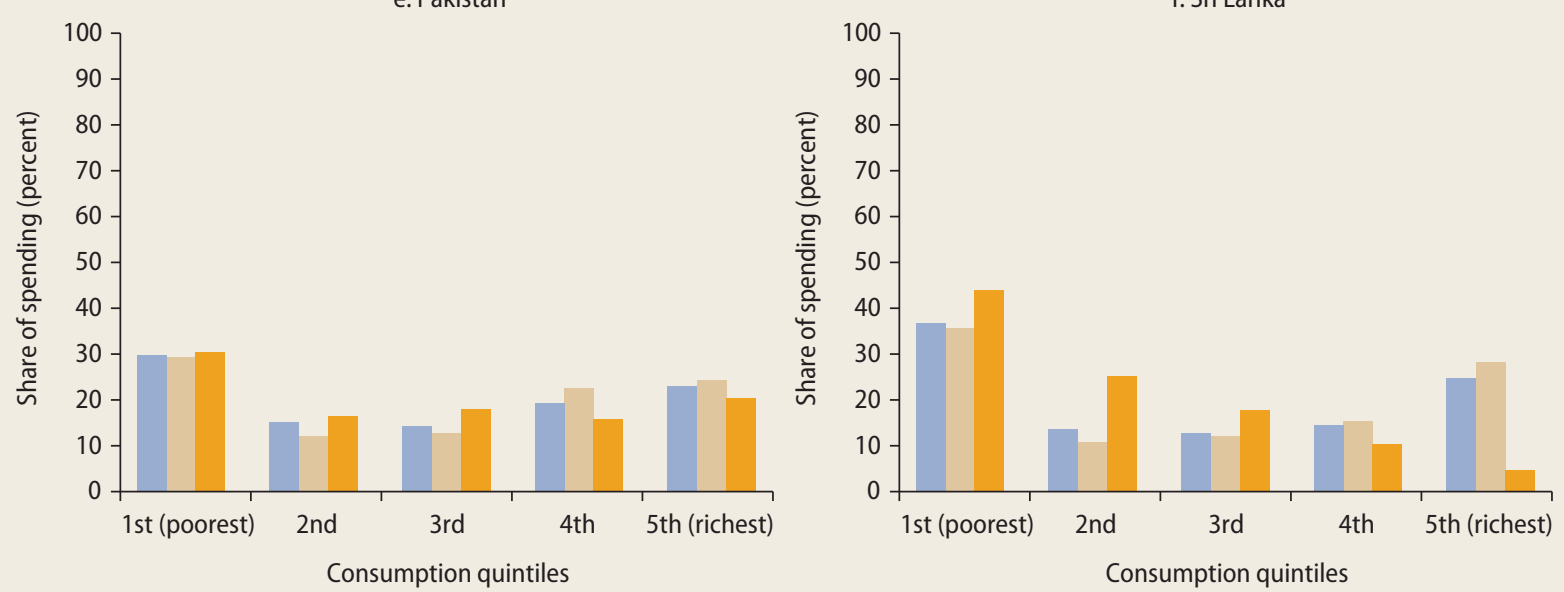

All social protection $\square$ All social insurance $\square$ All social assistance 
the countries in the region (data on benefit adequacy are unfortunately unavailable for India). Given the variation in program objectives and design, distinguishing between social assistance and social insurance is important (figure 5.7).

Social protection spending in South Asia is characterized by low to moderate coverage. In Nepal and Sri Lanka, a little more than half the poor receive support. In most other countries, the coverage rate of social assistance spending is between 20 and 30 percent. However, coverage has improved over time. In Bangladesh, for instance, 33 percent of the poor benefitted from at least one social assistance program in 2010, compared with 21 percent in 2005.

Generally, social assistance programs are not very well targeted. Across all countries in the region, 60 percent to 80 percent of the beneficiaries are not poor, and they receive between 50 percent and 80 percent of the funding. Although some of the nonpoor may stand just above the poverty line, a disproportionately large fraction of resources is captured by the better-off. This high rate of leakage significantly weakens the impact of social protection spending in South Asia. In Bangladesh, for example, the proportion of program recipients who are not poor increased from 44 percent in 2005 to almost 60 percent in 2010; in parallel, the share of total program spending accruing to the poor dropped from 52.6 percent to 35.3 percent. Pakistan is an exception, however, and the 2010 data even underestimate its actual performance, because the data only partially reflect recent improvements in targeting from the implementation of a proxy means test to identify the poor.

Finally, the benefit adequacy of social assistance programs remains low in most countries considered. In Nepal, the transfer amount represents less than 10 percent of the consumption of the poorest two deciles of the population. Average transfer adequacy is also low in Bangladesh, and it has actually declined over the years: as a share of the expenditure per capita of poor households, the real value of transfers has halved between 2005 and 2010, falling from 22 percent to 11 percent (box 5.3). Adequacy is higher in the case of social insurance programs.

Although countries in South Asia are spending more on social protection, a large proportion of that spending is in direct subsidies for households to purchase food, fertilizer, or electricity. These subsidies are justified on poverty reduction grounds, but they are not always progressive, and in some cases they end up being unambiguously regressive. Maldives and Sri Lanka rely more on contributory social insurance than on social safety nets (DNP 2013; MoFP 2012). With the exception of these two countries, spending on social insurance tends to be small because a majority of workers in South Asia are informal sector employees who are not eligible to participate in programs such as old-age pensions and health insurance.

The bias toward food and price subsidies is especially marked in India and Pakistan. In India, the Public Distribution System is responsible for the provision of subsidized food. In fiscal year 2003/04, it absorbed about 3 percent of GDP, almost triple the average spending on food security in advanced economies. Since then the share has declined, but in fiscal year 2008/09 it still absorbed about 1 percent of GDP. This is the largest share of resources among all social protection programs: 43 billion Indian rupees, compared to around 30 billion Indian rupees devoted to MGNREG funding (Union Budget of India 2013-14, http://indiabudget.nic.in /budget2013-2014/budget.asp). In Pakistan, part of the increase in social protection spending resulted from higher spending on fuel and food subsidies in response to the global financial crisis. Subsidies absorbed more than 230 billion Pakistani rupees, or 1.3 percent of GDP, in fiscal year 2010/11; in comparison, BISP consumed about 34 billion Pakistani rupees (Government of Pakistan 2010; World Bank 2013b). 


\section{FIGURE 5.7 Social assistance is less adequate than social insurance but has greater coverage}

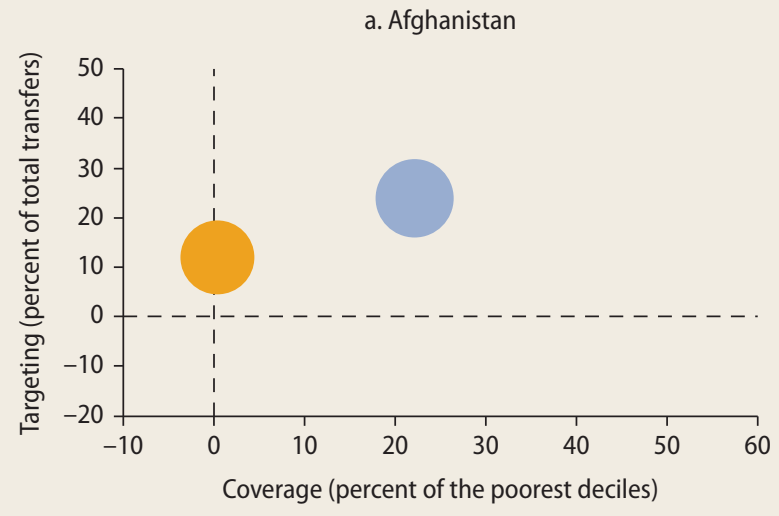

c. Maldives

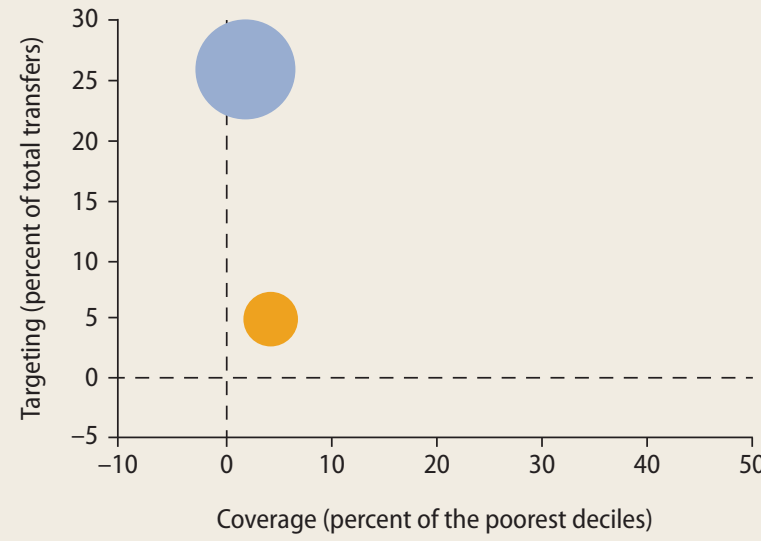

e. Pakistan

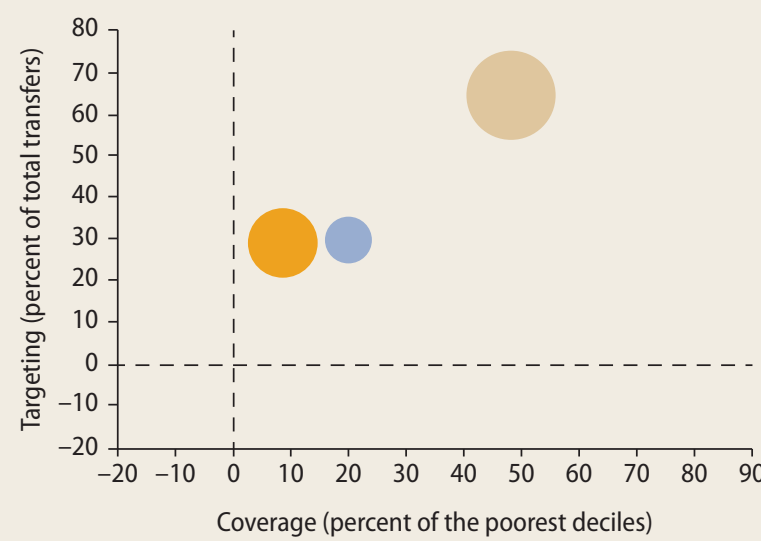

b. Bangladesh

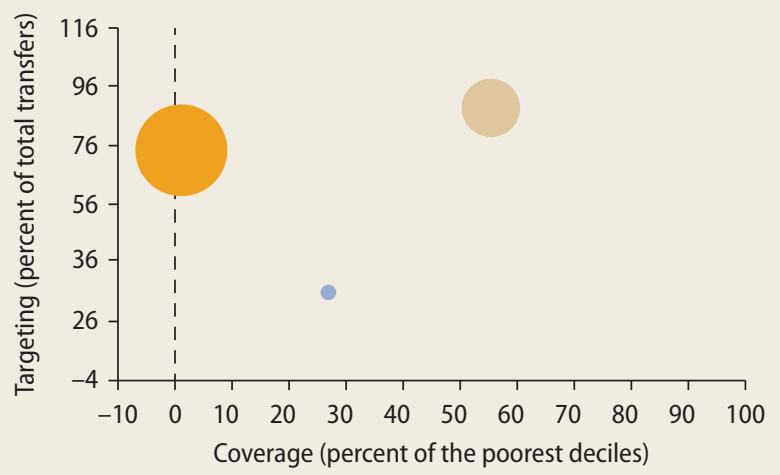

d. Nepal

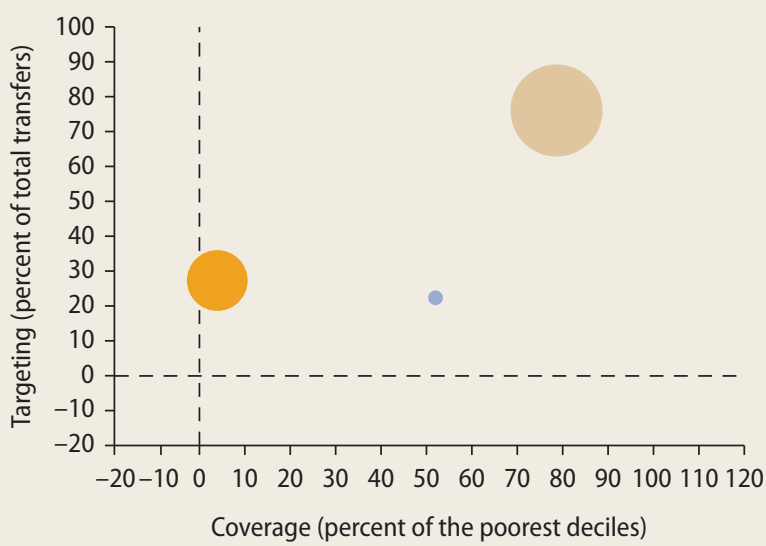

f. Sri Lanka

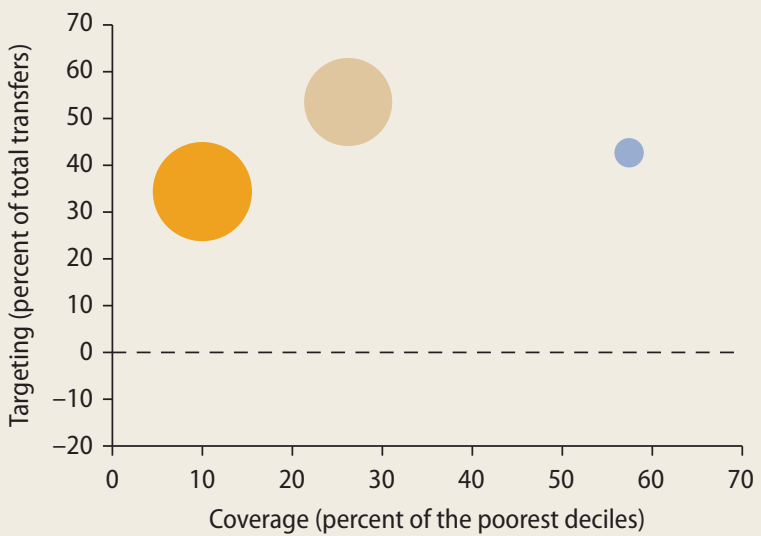

Social assistance programs Social insurance programs Remittances

Sources: Based on NRVA 2007 for Afghanistan, HIES 2010 for Bangladesh, VPA 2004 for Maldives, NLSS 2010 for Nepal, PSLM 2010-11 for Pakistan, and HIES 2006 -07 for Sri Lanka. Note: Coverage is the percentage of the population in the bottom two deciles that receives the benefits. Targeting is the sum of transfers received by the bottom two deciles in percent of total transfers. Adequacy, measured by the size of the bubble, is the mean value of the transfer amount received by beneficiaries in the bottom two quintiles in percent of mean expenditure per capita in that group. Deciles are defined based on expenditure per capita net of social protection transfers. The color blue is for social assistance programs and the color orange for social insurance programs. The color brown refers to remittances, used here as a benchmark for government-funded social protection programs 


\section{BOX 5.3 The adequacy of social assistance programs has declined in Bangladesh}

The success of Bangladesh's commendable social protection architecture is partially negated by implementation problems. Outcomes are encouraging in the case of the Vulnerable Group Feeding program: in 2010 beneficiaries received on average 88 percent of their expected cash transfer and 90 percent of the in-kind transfer they were entitled to. But substantial variation occurred across beneficiaries. Often program officials retain part of the benefits to recover the cost of bagging and transporting the food. In the case of public works, part of the allocation is frequently used to fund nonwage costs of small infrastructure projects.

More disturbing is the gap between actual and expected transfers in the Food for Education (FFE) program. Estimates based on the 2000 HIES suggest that an overwhelming 75 percent of program allocations did not reach any household, whether an intended or unintended beneficiary. Such disconnect between program allocations and survey estimates indicates substantial administrative leakage. Similar calculations using the earlier 1995-96 HIES showed a substantially lower discrepancy, suggesting that problems of leakage worsened over time.

Whether these support mechanisms make a difference to their intended beneficiaries is frequently debated. In Bangladesh, strong evidence from the mid-1990s suggests that the FFE program succeeds in attracting poor children to school. Specifically, estimates show that participation in the FFE program increases the probability of attending school by 20 percent on average. Evidence shows that these gains have been sustained. Furthermore, the presumption that recipients would misuse the benefits is not supported by the available evidence (Devereux 2002; Hanlon, Barrientos, and Hulme 2010).

Likewise, the size of the benefits received is small and has increased only marginally in recent years. The most generous transfer remains the old-age allowance, with an average transfer of Tk 501 a month, which represents only 28 percent to 44 percent of the poverty line. The average amount of rice given out by the Gratuitous Relief program is 15.7 kilograms per beneficiary, which represents 20 percent to 33 percent of the poverty line. Similarly, the benefit from the Vulnerable Group Feeding program is 17 percent to 26 percent of the poverty line. Thus, despite increased spending on safety net programs between 2005 and 2010 , the improvement on the ground has been limited.

\section{The distributional impact of taxes}

Whether deliberate policy or unintended effect, taxes alter the distribution of income or consumption. The distinction between pretax and after-tax inequality is common in advanced economies, where tax collection is more effective than elsewhere. Recent series of studies suggest that income tax is a major factor in explaining the evolution of income distribution in advanced economies in the post-World War II period (Atkinson, Piketty, and Saez 2011).
The government's capacity to redistribute income through taxes is more limited in developing countries, because the overall tax collection as a percentage of GDP tends to be significantly smaller (Chu, Davoodi, and Gupta 2000). It is even lower than the average in South Asian countries, where government revenue averages between 10 percent and 15 percent (map 5.1). The collection rates fall behind comparable developing countries or emerging economies, including Brazil, China, Mexico, and the 
Russian Federation, where revenue collections average about 20 percent. They are much lower than the collection rates in advanced economies.

Low rates of revenue collection in South Asia result in part from structural factors, notably lower income levels, higher agricultural shares of GDP, and lower international trade than most other regions experience (World Bank 2012a). Even after controlling for the main structural factors, however, revenue mobilization in most South Asian countries is still below the average for countries at similar income levels (figure 5.8).

\section{MAP 5.1 Government revenue in South Asia is low compared with the rest of the world}

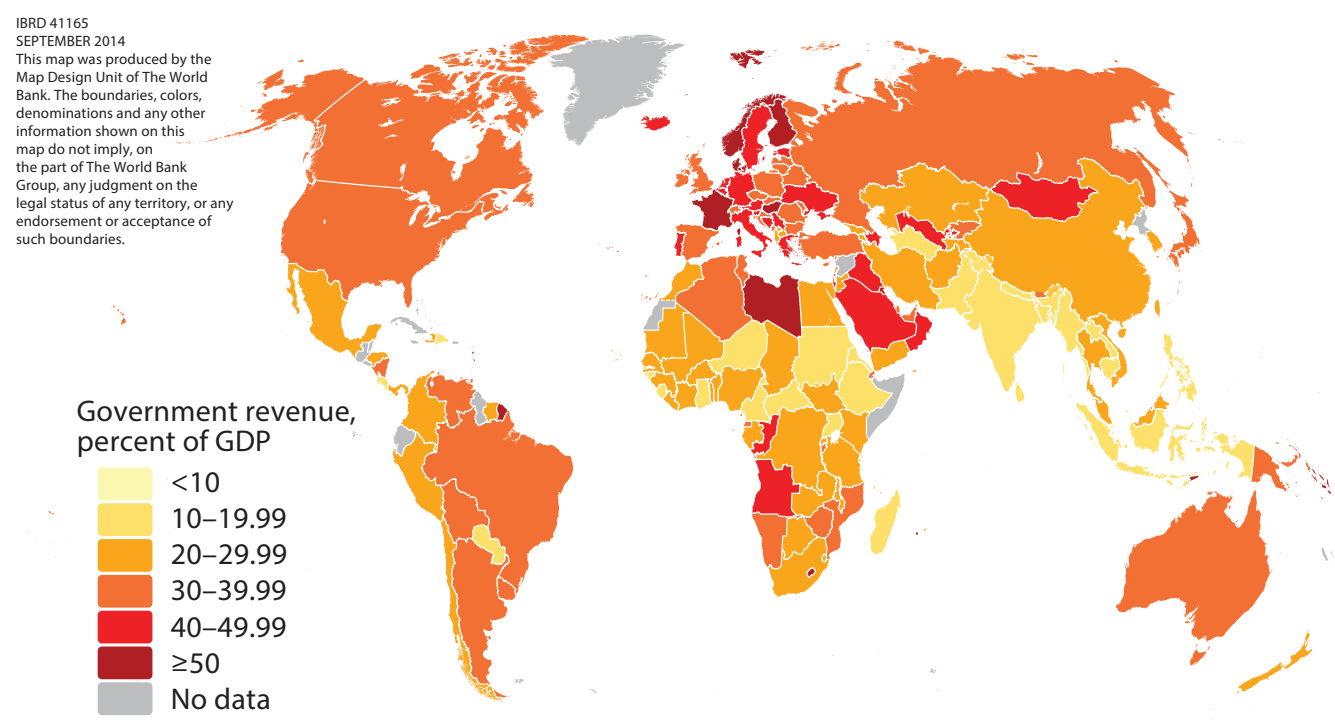

Source: Based on International Monetary Fund Data Mapper, http://www.imf.org/external/Datamapper/index.php.

\section{FIGURE 5.8 Tax revenue is lower than in other countries at a similar development level}

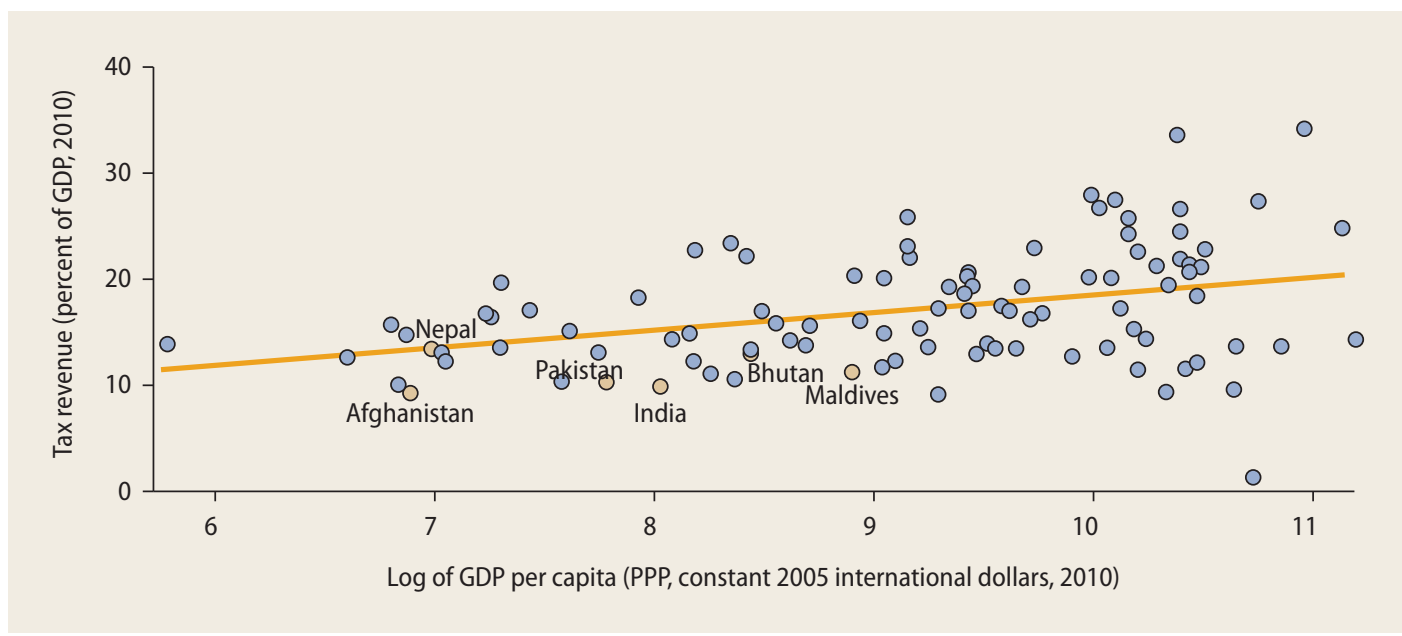

Source: Based on World Bank World Development Indicators database, http://databank.worldbank.org/data/views/reports/tableview.aspx. Note: PPP = purchasing power parity. 
Furthermore, the gaps have persisted in the 2000s.

These revenue gaps cannot be accounted for by the tax structures of South Asian countries, which resemble those of other low-income countries. The tax instruments used, and even the tax rates, are standard. Most countries in the region have introduced personal income tax, corporate income tax (CIT), some form of general services tax or value added tax (VAT), excise taxes, and trade taxes.

One important difference with other developing countries lies in the relative weight of each of these tax types in total revenue. Compared to their peers at a similar development level, South Asian countries rely less on income taxes and more on trade taxes (figure 5.9). Income tax collection, especially for personal income tax, is low, except in India. This situation is not unusual: revenues for personal income tax represent about 2 percent of GDP in developing countries compared with 11 percent of GDP in advanced economies (Zolt 2008). Although import tariffs have declined in the past decades, South Asian countries still see relatively high revenue collection from trade. In contrast, trade tax collection has fallen in many other regions because of trade liberalization. Moreover, some of the countries in the region depend heavily on nontax revenue to finance their public expenditures. That is the case of Afghanistan, whose budget is mostly funded by donors, and of Bhutan, which relies on revenue from electricity exports to India.

Exemptions, avoidance, and evasion account for low tax revenue in South Asian countries to a much greater extent than the formal tax structure does. In India, a meager 2.8 percent of the population pays personal income tax. Stepped-up efforts to increase tax collection by the ministry of finance include a unique online system for monitoring suspicious transactions through real-time coordination among revenue intelligence agencies. Yet these efforts concern a few thousand cases and less than 0.2 percent of GDP in lost tax revenue, showing that there is still some way to go (World Bank 2012a).

\section{FIGURE 5.9 South Asian countries rely less on income taxes and more on trade taxes}

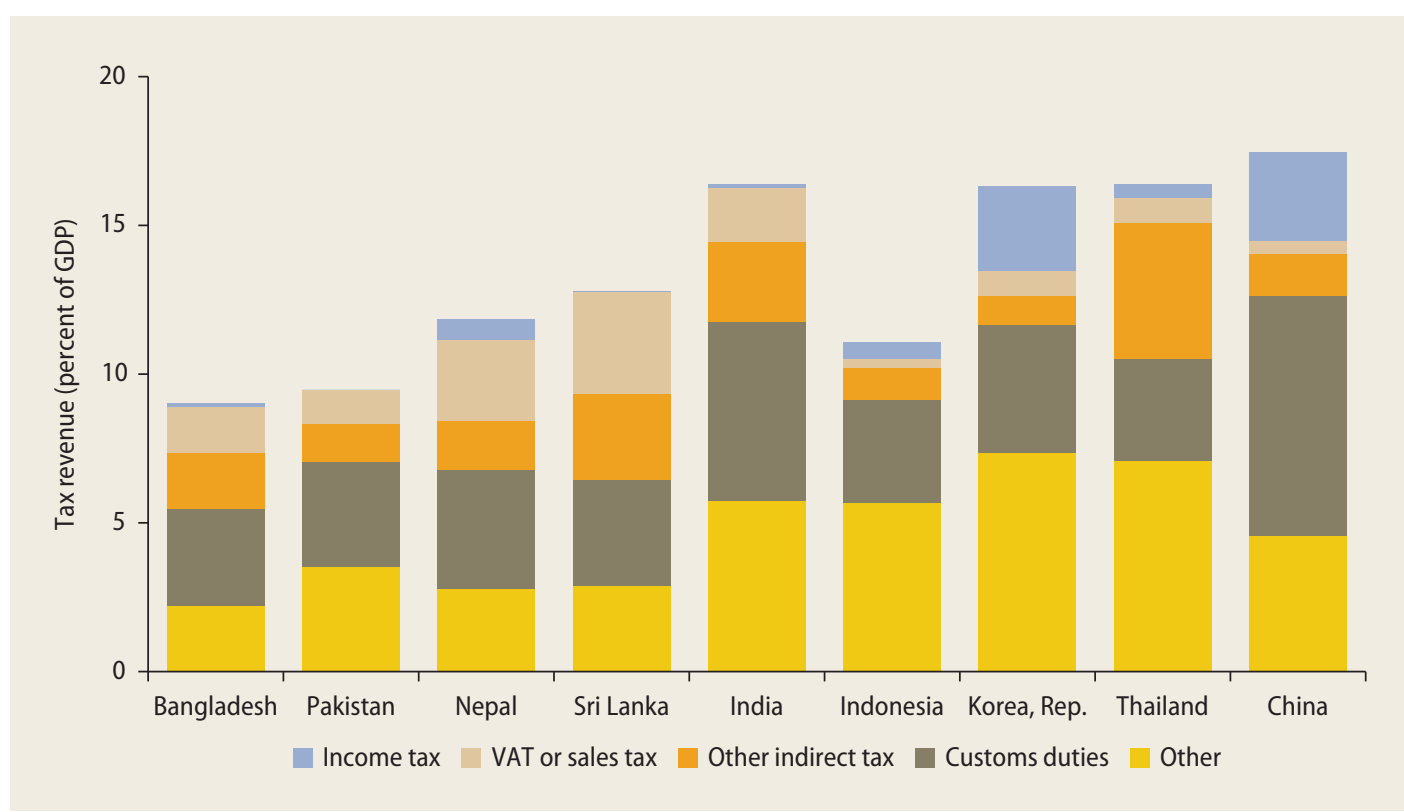

Source: World Bank 2012a. 
In Pakistan, actual tax receipts were estimated at only 21 percent of potential receipts in fiscal year 2007/08. This number is likely to be an underestimate because it does not include the workers welfare fund, the workers profit participation fund, the capital value tax, or the wealth tax (which together represent less than 2 percent of total federal tax receipts). Data limitations also rule out an analysis of provincial taxes, which account for about 4 percent of Pakistan's total tax collection (World Bank 2009a).

Another important difference with other developing countries concerns the "productivity" of taxes. A standard indicator of such productivity is the share of GDP in revenue collection for every percentage point of the basic tax rate. In countries such as Thailand or Vietnam, the productivity of VAT exceeds 50 percent and that of CIT reaches 30 percent. This means that a VAT rate of 10 percent, for example, brings in more than 5 percent of GDP to government coffers. In contrast, the productivity of VAT in South Asian countries varies between 20 and 40 percent, and that of CIT hovers around a meager 10 percent (World Bank 2012a).

Despite some improvements in tax administration, tax enforcement has remained weak, creating incentives for evasion. Currently, only 17 percent of taxpayers registered as an "association of persons" in Pakistan are systematically filing their income tax returns (figure 5.10). A large proportion of the taxpayers formally registered with regional tax offices, and even with large taxpayer units, fail to file tax returns. This situation clearly points to weak tax enforcement by the Federal Board of Revenue. Similarly, tax audits, discontinued because of weak Federal Board of Revenue capacity, have remained suspended for years, despite significant improvement in capacity.

The redistributive impact of taxes depends on tax scale and structure as well as on the effectiveness of tax administration. In developing countries, tax systems tend to
FIGURE 5.10 In Pakistan, even registered taxpayers fail to file tax returns

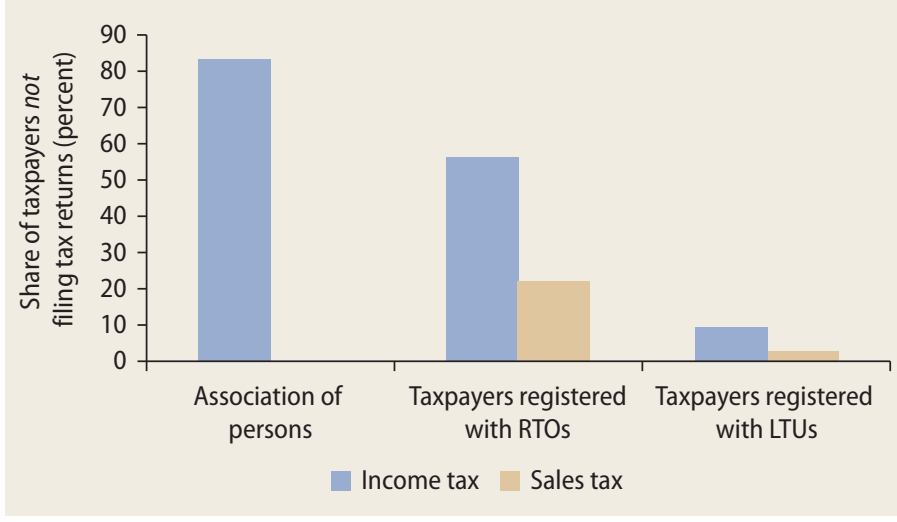

Source: World Bank 2012b.

Note: RTOs = regional tax offices; LTUs = large tax units.

be broadly or mildly progressive (MartinezVazquez 2008; Shah and Whalley 1991) even though many transactions take place in the informal sector. A weak tax administration combined with the ability of residents to shift assets outside the country also limits the collection of income tax. These limitations have forced developing countries to rely more on indirect taxes on consumption and less on direct taxation. However, consumption taxes, including VAT, are also found to be progressive in some developing countries (Sahn and Younger 2003; Younger and others 1999).

Evidence of the redistributive impact of taxes is scant for South Asian countries, as it is for most other developing countries. Several incidence analyses have been conducted for Pakistan, however, including for general services taxes and for federal taxes. Most recently, the incidence of direct and indirect taxes at both federal and provincial levels was assessed, making extensive use of microeconomic data. Although incidence assumptions and data sources differ, findings from these studies largely corroborate each other. Overall, the system is mildly progressive, with the progressivity coming mainly from direct taxes (MartinezVazquez 2006; Wahid and Wallace 2008). Households in the lowest deciles pay about 2.4 percent of total taxes, while they 
FIGURE 5.11 Relative to their means, the poor in Pakistan pay almost as much tax as the middle class

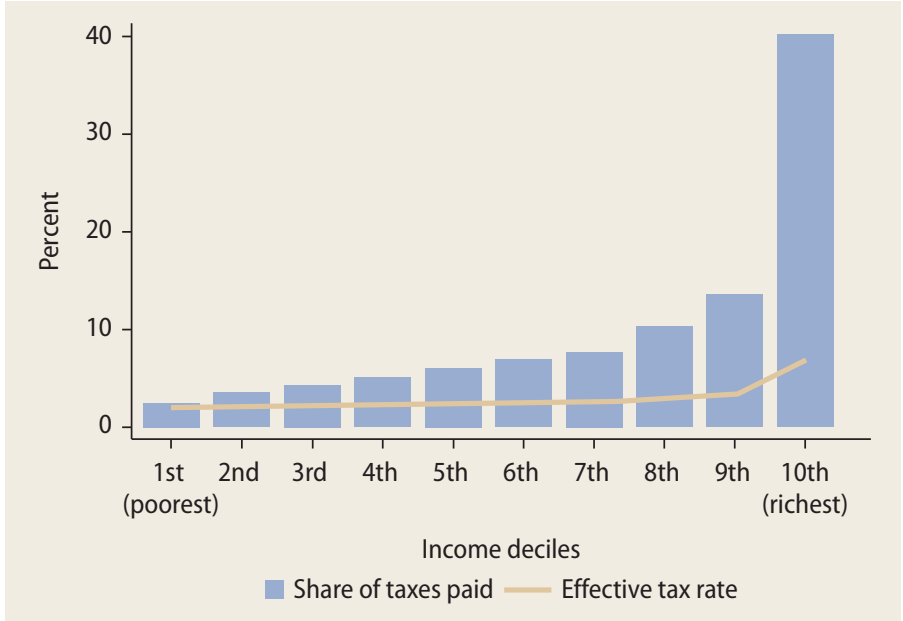

Source: Wahid and Wallace 2008

account for 3 percent of total consumption; households in the highest decile pay a little over 40 percent while accounting for about 32 percent of total consumption. Effective tax rates are basically flat across most of the population until the richest group is reached (figure 5.11).

Substantial differences exist between direct and indirect taxes, however. On one hand, indirect taxes are neutral or slightly progressive because the general services tax and customs duties are neutral to slightly progressive, whereas the excises are actually regressive (Refaqat 2003; Wahid and Wallace 2008). Direct taxes, on the other hand, are more progressive (Wahid and Wallace 2008). The top income group bears over 70 percent of the burden. The personal income tax paid by salaried workers is progressive, and that paid by the self-employed slightly so. The burden of the CIT also falls disproportionately on the top income group, because the effective tax of the top decile is more than triple that of the bottom decile. Because CIT accounts for the lion's share of direct taxes, it greatly contributes to the overall progressivity of direct taxes.

\section{Wasteful and often regressive subsidies}

Taxes are only one transfer mechanism through which the distribution of income or consumption can be modified. From an individual's point of view, taxes and public spending can have similar consequences on income or consumption (although they typically affect incentives differently). In developing countries, public expenditure policies are found to be more effective than tax policies in redistributing income or in modifying the distribution of consumption. However, expenditures that have intended equity goals may not be progressive in practice.

In South Asia, a substantial share of public spending goes into subsidies. Some of them are regressive and can crowd out the provision of essential public goods. An unusually large fraction of the typically low government revenue is often devoted to reducing the final price of food, fertilizer, gas, and electricity (figure 5.12). Equity concerns are among the justifications for this type of spending. And in some cases, as for food, the justification has merit. But in countries where the poor generally lack access to the grid and often cook using biomass, subsidizing electricity is bound to be regressive. Moreover, the delivery mechanisms for these subsidies can lend themselves to inefficiencies and leakages.

In India, the government spends more on subsidies (relative to GDP) than much richer countries do. For example, only 68 percent of fertilizer subsidies are estimated to reach farmers, with the bulk being paid to large farmers in irrigated areas (Herd and Leibfritz 2008).

The Public Distribution System is another example. It covers about 20 percent of the population, much more than any other social protection program. It was found to have strong poverty reduction impacts, accounting for a significant fraction of the poverty decline between 2004-05 and 2009-10. Several states have made 
substantial improvements in infrastructure and delivery systems to plug leakage. However, the coverage rates were around 53 percent in rural areas and 33 percent in urban areas in 2011-12. Take-up rates were progressive across quintiles, but coverage rates of the richest 20 percent in rural areas remained high. Because of the price difference between subsidized grain and grain sold through regular marketing channels, powerful incentives exist to arbitrage and make illegal profits. In fiscal year 2004/05, the level of leakage of Public Distribution System grains countrywide was estimated to reach above 50 percent. The situation improved later: the illegal diversion and leakages declined to about 44 percent by the end of 2007/08 and to around 35 percent in 2011/12 (Himanshu 2013; Jha and Ramaswami 2010; Khera 2011).

The story is similar in Pakistan. Both federal and provincial governments intervene in markets for food products through mechanisms such as the "Utility Store" arrangement. The complexity of these mechanisms makes quantifying the full extent of the inefficiencies difficult, but part of the subsidy is clearly appropriated by wheat flour millers and traders. The interventions have also resulted in a significant excess capacity-about 300 percent in the wheat milling industry-while crowding out the private sector. In addition, fertilizer subsidies create a large fiscal burden because the domestic price of fertilizer is almost 60 percent higher than it was before the crisis (World Bank 2013b).

Energy subsidies are arguably more regressive than food and fertilizer subsidies, suffering as they do from looser targeting and being more prone to capture by the rich than the subsidized grain programs. India's subsidies for liquefied petroleum gas (LPG) are a case in point. More than half the total cost of an LPG cylinder is paid for by the government through a direct price subsidy as well as through transfers to the oil marketing companies. In fiscal year 2010/11, this combined government spending

\section{FIGURE 5.12 Much public spending goes into energy subsidies}

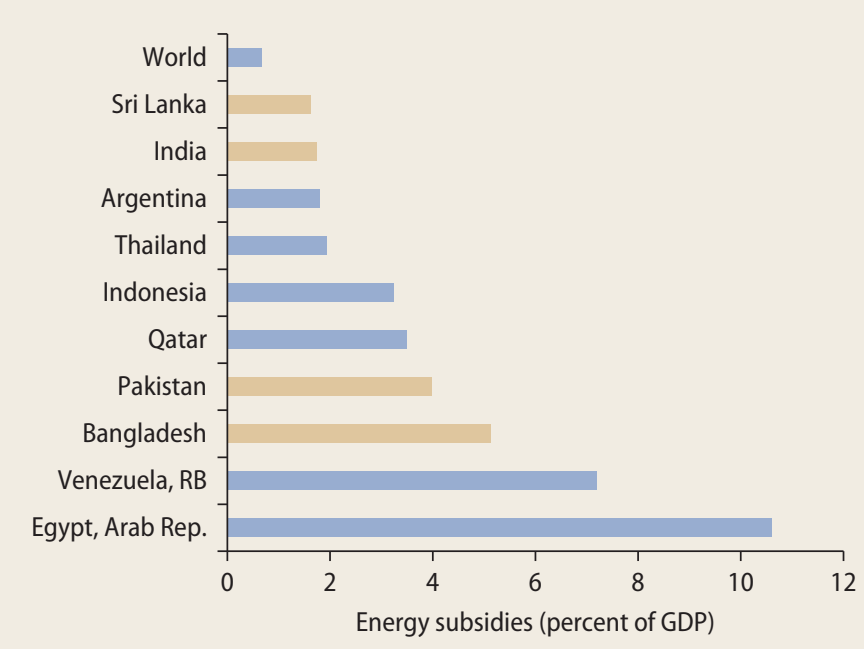

Source: Based on IMF 2013

amounted to more than 250 billion Indian rupees. According to one estimate, the average household in the poorest quintile has less than a 20 percent probability of using LPG; in contrast, the average probability for an urban household in the richest quintile is almost 100 percent (Goutam Lahoti, and Suchitra 2012).

Energy subsidies disproportionately benefit the better-off in Maldives and Pakistan as well. In the case of Pakistan, the poorest 40 percent of households used to receive less than 30 percent of total electricity subsidies, while the richest 20 percent received close to 40 percent of total subsidies. The distribution of benefits improved after the October 2013 tariff increase, but electricity subsidies remain regressive (figure 5.13).

In South Asia where the energy sector suffers from severe capacity or delivery shortfalls, subsidies exacerbate the effects of the shortages. Subsidized energy use stimulates demand by widening the supply and demand gaps. Cross-subsidies as a popular policy in South Asia raise another concern. Under cross-subsidies, households and especially agricultural users of electricity tend to pay well below the incremental 
FIGURE 5.13 Electricity subsidies favor the better-off
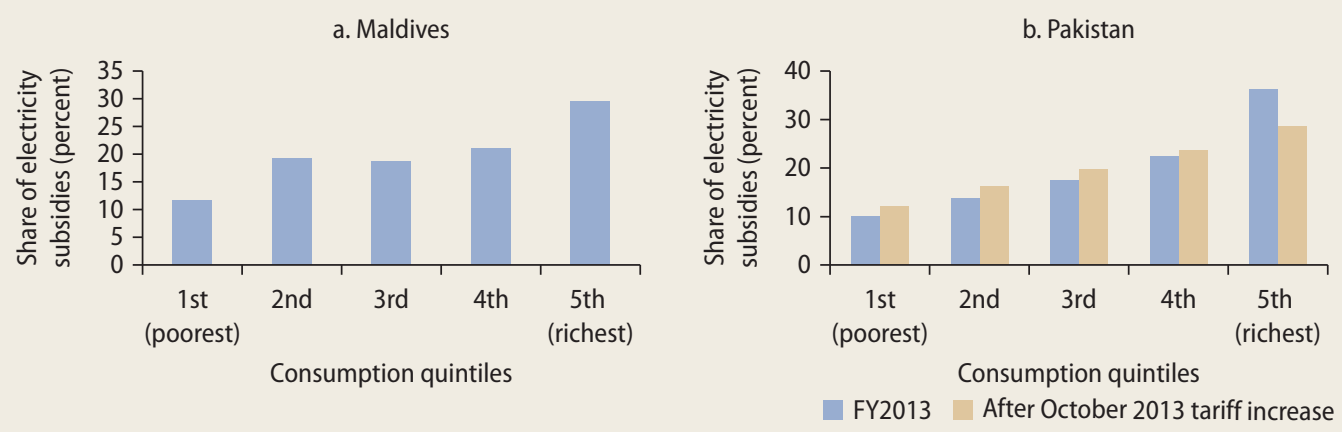

Sources: Redaelli 2013; Trimble, Yoshida, and Saqib 2011

Note: FY2013 = Fiscal Year 2013.

cost of supply, whereas rates are higher for industrial customers. These subsidies motivate industrial customers to turn to alternatives that make good economic sense for them but are societally inefficient. Endemic inefficiencies in the supply of energy services also increase the cost of energy production, in addition to constraining its overall supply (Chattopadhyay 2004; Toman 2014).

In Sri Lanka, total public expenditure in agriculture in 2011 increased by 64 percent over 2010, mainly because of increased spending on the fertilizer subsidy. The subsidy, which had been available for paddy since 2005, was extended to other crops in 2011. By providing a fertilizer subsidy to farmers, the government absorbed about 90 percent of the total fertilizer cost for paddy in 2011, while absorbing 65 percent of the fertilizer costs for other eligible crops (MoFP 2012).

Yet agricultural growth critically depends on investments in rural infrastructure, including irrigation, flood protection, rural roads, and power, as well as on investments in agricultural research and extension services. These investments have generally been found to provide high economic returns. Because the assets created by such investments have the characteristics of public goods and thus tend to be underprovided by the market, public expenditures are pivotal in their provision.
Fertilizer subsidies are crowding out these investments.

Similarly, in Bangladesh ever-growing subsidies have crowded out investments in core public goods such as research and development, extension services, and water and irrigation infrastructure. Investment in these sectors has fallen from 5.2 percent of total public agricultural expenditures to 2.7 percent over less than a decade. In particular, expenditures on research and development have contracted from 9.9 percent of total agricultural expenditures in 2000 to 2.8 percent in 2007. This is the equivalent of only 0.3 percent of agricultural GDP, compared with 0.62 percent for other developing countries and 2.80 percent for developed countries as a group (World Bank 2010).

Expenditures on core public goods in the agricultural sector have been declining as a proportion of total budgetary resources devoted to the sector. Discretionary resources, which fund research projects, have taken the biggest hit, while a large share of research and development expenditures is spent on overhead costs of the 10 research institutes under the umbrella of Bangladesh Agricultural Research Council. Although public expenditures on agricultural research as a percentage of agricultural GDP have remained at roughly the same levels (mainly as 
result of agricultural growth being slower than growth in overall public expenditure levels), they are low by international standards (World Bank 2010).

\section{The promise of intergovernmental transfers}

One can argue that in countries with high levels of informality and important spatial disparities, intergovernmental transfers are a more effective tool to reduce inequality than either taxes or transfers to individuals. When avoiding or evading rules is easy, taxes encourage individuals and firms to remain informal. And both taxes and transfers to individuals affect incentives to work and accumulate in ways that tend to be detrimental to efficiency. By contrast, intergovernmental transfers make resources available for the provision of public goods in places that would not be able to mobilize the resources to pay for them. The relevance of intergovernmental transfers is even greater in countries that are large and diverse, as is the case in Bangladesh, India, and Pakistan.

Intergovernmental transfers are defined by country-specific institutions. In federal nations such as India and Pakistan, intergovernmental transfers are typically enshrined in the constitution. The magnitude of these transfers and the rules and procedures that govern them are often controversial political questions. The controversies involve the magnitude of the transfers, their relationship to indicators of needs or performance, and the ability of local authorities to raise additional revenue. Recent debates around the 18th Constitutional Amendment in Pakistan is a case in point. But every country has an array of earmarked transfers around specific budget lines or government programs.

The specifics vary from country to country. In India, subnational governments receive transfers from the central government through tax shares and grants from the Finance Commission, through plan grants from the Planning Commission, and through discretionary grant transfers in the form of centrally sponsored schemes
(Chakraborty, Mukherjee, and Nath 2010). The other major component is the direct transfer of resources to districts and other implementing agencies, thereby bypassing the state budget. Most of this flow is through the Ministry of Rural Development (55 percent), the Ministry of Human Resource Development (29 percent), and the Ministry of Health and Family Welfare (11 percent). Transfers to fund Sarva Shiksha AbhiyanIndia's flagship program for universalizing elementary education-and the MGNREG together constituted almost half the total associated with these three ministries.

\section{FIGURE 5.14 Intergovernmental transfers benefit poorer states and provinces}
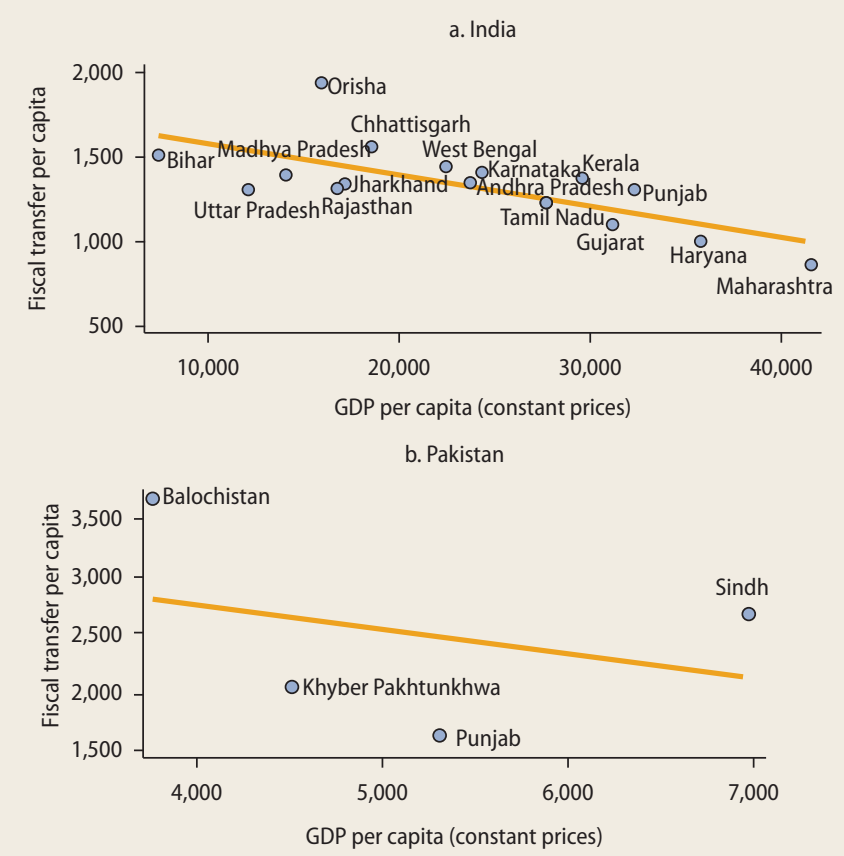

c. Sri Lanka

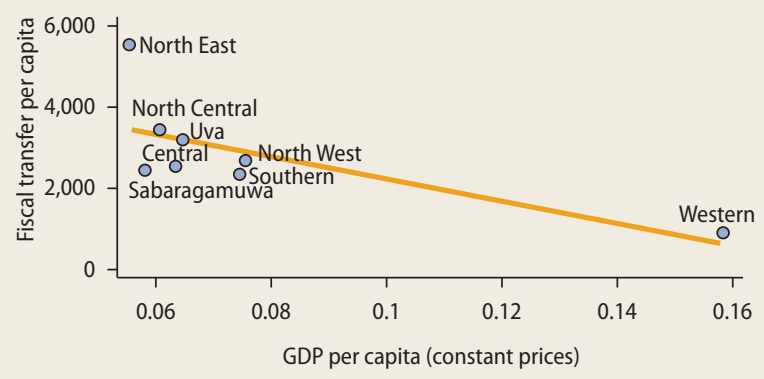

Source: Iyer, Ghani, and Mishra 2010 
In Pakistan, transfers occur through tax shares from the National Finance Commission and through development and nondevelopment grants allocated by the federal government (Cheema, Khwaja, and Qadir 2006). In Sri Lanka, fiscal transfers from the central government are based on the recommendation of the Finance Commission and come in four major ways: block grants, Provincial Service Development Grants, criteria-based grants, and matching grants. And in Bangladesh, a highly centralized country, fiscal transfers occur through earmarked sectoral grants, through grants for specific transfer programs, through block development grants, and through recurrent expenditure grants (Ghani 2010).

The largest component of fiscal transfers in India comes from tax-sharing schemes, but discretionary transfers and the subsidies together are almost as large as the tax shares. The subsidy component benefits richer states. For both food and fertilizer subsidies, the value of the transfers is indeed strongly correlated with the states' per capita income (Ghani, Iyer, and Misra 2013). However, the overall system of intergovernmental transfers in India is generally progressive and leads to a more equitable distribution of fiscal resources across constituencies. The same can be said of Pakistan and Sri Lanka, where poorer regions receive higher per capita fiscal transfers (figure 5.14).

The relatively progressive nature of intergovernmental transfers does not imply, however, that public development spending per person is progressive (figure 5.15). Subnational governments in poorer areas tend to have much less locally generated revenue than those in more affluent parts of the country. In addition, their capacity to spend their resources is more limited. For instance, a study covering 533 blocks in BiharIndia's poorest state-found that one-third of them did not have any block development officers. As a result, 20 percent of the funds allocated to the state had not been spent (World Bank 2005). Because of weak capacity, districts with lower revenues and poorer educational outcomes are found to be less capable of using Sarva Shiksha Abhiyan funds; in particular, they are found to be less able to implement programs that target disadvantaged groups (Jhingran and Sankar 2006, 2009). Weak capacity also undermines local monitoring of public spending, often leading to leakages or unspent funds (Murgai and Zaidi 2005).

\section{FIGURE 5.15 Development spending per person is lower in poorer states and districts}

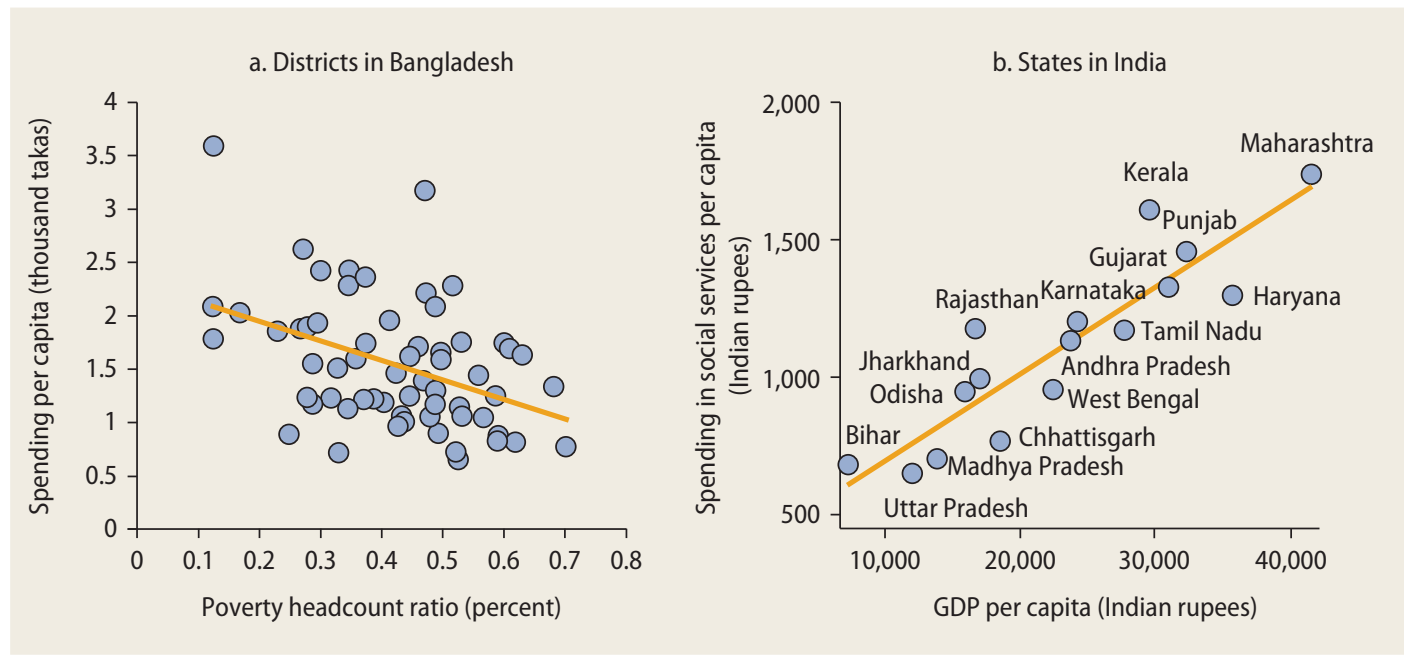

Sources: Iyer, Ghani, and Mishra 2010; World Bank 2010. 


\section{Inadequate support: Main messages and policy implications}

Individuals may be hit by shocks, some of which can have long-lasting impacts on well-being, at any time. Although self-insurance and reliance on extended families and communities can help them cope, informal mechanisms of this sort tend to be costly and inefficient and to break down when shocks are widespread. Randomness hits even before birth, because individuals differ in their inherited wealth, their talent, their preference for the present, and their willingness to work hard, all of which have lifelong implications for well-being. Care by parents for their less fortunate offspring and charity by more fortunate individuals can go some way toward redressing these gaps, but they are unlikely to offset them. Thus, even a society with equality of opportunity and perfect mobility is bound to experience inequality of outcomes. Social protection and redistribution are the usual instruments to address this type of inequality.

Seen from a household perspective, healthrelated events and disasters are the most common types of shocks in South Asia, with disasters affecting the rural populations most. Confronted with shocks, the poor more frequently reduce expenditures, including quantity and quality of food consumed; they are also more prone to borrow and sell agricultural assets.

Social protection programs are the standard instrument to address these shocks. By now South Asian countries' spending on social protection is roughly the same share of their GDP as other countries at a similar level of development. Absolute spending on social protection per person is progressive in some countries and generally not regressive in the rest; spending relative to expenditure per capita is clearly progressive. But social protection programs differ considerably in their strengths. Social assistance programs have broad coverage but offer modest support. The benefits provided by social insurance programs are more adequate, but the coverage of these programs is thin and favors the better-off. One of the striking features of South Asian countries is how much of the social protection spending goes into subsidies-especially for food, gas, and electricity. Subsidies under the form of food distribution are prone to leakage; subsidies for gas and electricity are clearly regressive.

Outright redistribution is the other typical instrument to address bad luck. But across most countries in the region the fiscal space for redistribution is constrained by low government revenue relative to GDP. This is not because of the nature of the tax instruments used, although South Asia relies more on trade taxes than other regions. Tax rates are not unusual either, but the "productivity" of taxes is abnormally low. This is caused by numerous exemptions and special regimes. It is also the result of massive tax avoidance and tax evasion. When considering the overall incidence of the tax system, including indirect taxation, the poor pay almost as much in taxes as the middle class.

In a region characterized by wide spatial disparities, transfers between levels of government bear much promise as a mechanism to redress inequality of outcomes. Intergovernment transfers can bridge the gap between assignment of responsibilities-including for social protection and disaster management-and assignment of revenue. Because they do not reach individuals and households directly, transfers are less likely to distort incentives to work, save, and invest. With poorer regions generally facing greater needs and fewer resources, intergovernment transfers are generally progressive. This is the case in South Asia, too, but they are often too small to make a difference. 


\section{References}

Alderman, Harold, John Hoddinott, and Bill Kinsey, 2006. "Long Term Consequences of Early Childhood Malnutrition." Oxford Economic Papers 58 (3): 450-74.

Arimond, Mary, and Marie T. Ruel. 2004. "Dietary Diversity Is Associated with Child Nutritional Status: Evidence from 11 Demographic and Health Surveys." Journal of Nutrition 134 (10): 2579-85.

Atkinson, Anthony B., Thomas Piketty, and Emmanuel Saez. 2011. "Top Incomes in the Long Run of History." Journal of Economic Literature 49 (1): 3-71.

Bandyopadhyay, Sushenjit, and Emmanuel Skoufias. 2012. "Rainfall Variability, Occupational Choice, and Welfare in Rural Bangladesh." Review of Economics of the Household: 1-46.

Banerjee, Abhijit V., and Esther Duflo. 2007. "The Economic Lives of the Poor." Journal of Economic Perspectives 21 (1): 141-68.

Behrman, Jere R. 1988. "Nutrition, Health, Birth Order and Seasonality: Intrahousehold Allocation among Children in Rural India." Journal of Development Economics 28 (1): 43-62.

Chakraborty, Pinaki, Anit N. Mukherjee, and H. K. Amar Nath. 2010. "Interstate Distribution of Central Expenditure and Subsidies." Working Paper No. 2010-66, National Institute of Public Finance and Policy, New Delhi, India.

Chattopadhyay, Pradip. 2004. "Cross-Subsidy in Electricity Tariffs: Evidence from India." Energy Policy 32 (5): 673-84.

Cheema, Ali, Asim I. Khwaja, and Adnan Qadir. 2006. "Local Government Reforms in Pakistan: Context, Content and Causes." In Decentralization and Local Governance in Developing Countries: A Comparative Perspective, edited by Pranab Bardhan and Dilip Mookherjee, 257-84. Cambridge, MA: MIT Press.

Chu, Ke-young, Hamid Reza Davoodi, and Sanjeev Gupta. 2000. "Income Distribution and Tax and Government Spending Policies in Developing Countries." IMF Working Paper WP/00/62, International Monetary Fund, Fiscal Affairs Department, Washington, DC.

Cox, Donald. 1987. "Motives for Private Income Transfers." Journal of Political Economy 95 (5): 957-76.

Deaton, Angus. 1990. "Saving in Developing Countries: Theory and Review." In Proceedings of the World Bank Annual Conference on
Development Economics 1989, vol. 1, 61-96. Washington, DC: World Bank.

Del Ninno, Carlo, and Mattias Lundberg. 2005. "Treading Water: The Long-Term Impact of the 1998 Flood on Nutrition in Bangladesh." Economics \& Human Biology 3 (1): 67-96.

Devereux, Stephen. 2002. "Can Social Safety Nets Reduce Chronic Poverty?” Development Policy Review 20 (5): 657-75.

DNP (Department of National Planning), Ministry of Finance and Treasury, Republic of Maldives. 2013. Statistical Yearbook of Maldives 2013. http://planning.gov.mv/yearbook2013 /yearbook.html.

D’Souza, Anna, and Dean Jolliffe. 2010. "Rising Food Prices and Coping Strategies: HouseholdLevel Evidence from Afghanistan." Policy Research Working Paper 5466, World Bank, Washington, DC.

Foster, Andrew D. 1995. "Prices, Credit Markets and Child Growth in Low-Income Rural Areas.” Economic Journal 105 (430): $551-70$.

Frankenberg, Elizabeth, James P. Smith, and Duncan Thomas. 2003. "Economic Shocks, Wealth, and Welfare." Journal of Human Resources 38 (2): 280-321.

Ghani, Ejaz, ed. 2010. The Poor Half Billion in South Asia: What Is Holding Back Lagging Regions? New Delhi: Oxford University Press and World Bank.

Ghani, Ejaz, Lakshmi Iyer, and Saurabh Misra. 2013. "Promoting Shared Prosperity in South Asia." Economic Premise 110 (March): 1-8.

Glewwe, Paul, and Gillette Hall. 1998. "Are Some Groups More Vulnerable to Macroeconomic Shocks Than Others? Hypothesis Tests Based on Panel Data from Peru." Journal of Development Economics 56 (1): 181-206.

Glewwe, Paul, and Hanan G. Jacoby. 1995. "An Economic Analysis of Delayed Primary School Enrollment in a Low Income Country: The Role of Early Childhood Nutrition." Review of Economics and Statistics 77 (1): 156-69.

Glewwe, Paul, and Elizabeth M. King. 2001. "The Impact of Early Childhood Nutritional Status on Cognitive Development: Does the Timing of Malnutrition Matter?” World Bank Economic Review 15 (1): 81-113.

Global Terrorism Database. 2009-14. National Consortium for the Study of Terrorism and Responses to Terrorism, START: A Center of Excellence of the U.S. Department of Homeland Security, University of Maryland, College Park, MD. http://www.start.umd.edu/gtd/. 
Goutam, Prodyumna, Rahul Lahoti, and J. Y. Suchitra. 2012. "Subsidies for Whom? The Case of LPG in India." Economic and Political Weekly 47 (44).

Government of Pakistan. 2010. Poverty Reduction Strategy Paper. Islamabad: Finance Division, Government of Pakistan.

Hanlon, Joseph, Armando Barrientos, and David Hulme. 2010. Just Give Money to the Poor: The Development Revolution from the Global South. Sterling, VA: Kumarian Press.

Heltberg, Rasmus, and Niels Lund. 2009. "Shocks, Coping, and Outcomes for Pakistan's Poor: Health Risks Predominate." Journal of Development Studies 45 (6): 889-910.

Herd, Richard, and Willi Leibfritz. 2008. "Fiscal Policy in India: Past Reforms and Future Challenges." Economics Department Working Paper No. 595, Organisation for Economic Co-operation and Development, Paris.

Himanshu, Abhijit Sen. 2013. "In-Kind Food Transfers-I: Impact on Poverty." Economic and Political Weekly.

IMF (International Monetary Fund). 2013. "Energy Subsidy Reform: Lessons and Implications.” IMF, Washington, DC, January 2.

Iyer, Lakshmi, Ejaz Ghani, and Saurabh Mishra. 2010. "Is Decentralization Helping the Lagging Regions?" In The Poor Half Billion in South Asia: What Is Holding Back Lagging Regions? ed. Ejaz Ghani, New Delhi: Oxford University Press and World Bank.

Jacoby, Hanan G., and Basab Dasgupta. 2012. "Household Exposure to Food Price Increase in Rural Bangladesh." World Bank, Washington, DC.

Jacoby, Hanan G., and Emmanuel Skoufias. 1997. "Risk, Financial Markets, and Human Capital in a Developing Country." Review of Economic Studies 64 (3): 311-35.

Jha, Shikha, and Bharat Ramaswami. 2010. "How Can Food Subsidies Work Better? Answers from India and the Philippines." ADB Economics Working Paper 221, Asian Development Bank, Manila, Philippines.

Jhingran, Dhir, and Deepa Sankar. 2006. “Orienting Outlays toward Needs: An EvidenceBased, Equity-Focused Approach for Sarva Shiksha Abhiyan." Working paper, World Bank, Washington, DC.

- 2009. "Addressing Educational Disparity: Using District Level Education Development Indices for Equitable Resource Allocations in India.” Policy Research Working Paper 4955, World Bank, Washington, DC.
Khandker, Shahidur R. 2012. "Seasonality of Income and Poverty in Bangladesh.” Journal of Development Economics 97 (2): 244-56.

Khanna, Gaurav, David Newhouse, and Pierella Paci. 2010. "Fewer Jobs or Smaller Paychecks? Labor Market Impacts of the Recent Crisis in Middle-Income Countries." Economic Premise 11 (April): 1-4.

Khera, Reetika. 2011. "Trends in Diversion of PDS Grain.” Working Paper No. 198, Centre for Development Economics, Delhi School of Economics, Delhi, India.

Kochar, Anjini. 1995. "Explaining Household Vulnerability to Idiosyncratic Income Shocks." American Economic Review 85 (2): 159-64.

—. 1999. "Smoothing Consumption by Smoothing Income: Hours-of-Work Responses to Idiosyncratic Agricultural Shocks in Rural India." Review of Economics and Statistics 81 (1): 50-61.

Martinez-Vazquez, Jorge. 2006. "Pakistan: A Preliminary Assessment of the Federal Tax System.” International Studies Program Working Paper 06-24, Andrew Young School of Policy Studies, Georgia State University, Atlanta, GA.

— 2008. "The Impact of Budgets on the Poor: Tax and Expenditure Benefit Incidence Analysis." In Public Finance for Poverty Reduction: Concepts and Case Studies from Africa and Latin America, edited by Blanca Moreno-Dodson and Quentin Wodon, 113-62. Washington, DC: World Bank.

McKenzie, David J. 2004. “Aggregate Shocks and Urban Labor Market Responses: Evidence from Argentina's Financial Crisis." Economic Development and Cultural Change 52 (4): 719-58.

Memon, Naseer. 2012. "Disasters in South Asia: A Regional Perspective.” Karachi: Pakistan Institute of Labour Education and Research.

Micronutrient Initiative, Flour Fortification Initiative, USAID, GAIN, WHO, World Bank, and UNICEF. 2009. Investing in the Future: A United Call to Action on Vitamin and Mineral Deficiencies; Global Report 2009. Ottawa, Canada: Micronutrient Initiative.

MoFP (Ministry of Finance and Planning, Sri Lanka). 2012. Annual Report 2011. Colombo: Treasury of Sri Lanka.

Morduch, Jonathan. 1995. "Income Smoothing and Consumption Smoothing." Journal of Economic Perspectives 9 (3): 103-14.

Moser, Caroline. 1998. "The Asset Vulnerability Framework: Reassessing Urban Poverty Reduction Strategies." World Development 26 (1): 1-19. 
Murgai, Rinku, and Salman Zaidi. 2005. "Effectiveness of Food Assistance Programs in Bangladesh." Journal of Developing Societies 21 (1-2): 121-42.

Pop, Luana. 2010. "Covariate Shocks and Vulnerabilities in KP and FATA.” Processed, World Bank, Washington, DC.

Redaelli, Silvia. 2013. "Sustainability, Efficiency and Equity of Electricity Subsidies in Maldives: Where Do We Stand and Options Moving Forward." Processed, World Bank, Washington, DC.

Refaqat, Saadia. 2003. "Social Incidence of General Sales Tax in Pakistan." IMF Working Paper WP/03/216, International Monetary Fund, Washington, DC.

Rosenzweig, Mark R., and Oded Stark. 1989. "Consumption Smoothing, Migration, and Marriage: Evidence from Rural India.” Journal of Political Economy 93 (4): 905-26.

Sahn, David E., and Stephen D. Younger. 2003. "Estimating the Incidence of Indirect Taxes in Developing Countries." In The Impact of Economic Policies on Poverty and Income Distribution: Evaluation Techniques and Tools, edited by François Bourguignon and Luiz A. Pereira da Silva, 27-40. New York: World Bank and Oxford University Press.

Shah, Anwar, and John Whalley. 1991. "Tax Incidence Analysis of Developing Countries: An Alternative View." World Bank Economic Review 5 (3): 535-52.

Toman, Michael. 2014. "Energy and Sustainable Economic Development in South Asia: Assessment of Knowledge and Identification of Key Issues for Further Investigation.” World Bank, Washington, DC.

Trimble, Chris, Nobuo Yoshida, and Mohammad Saqib. 2011. "Rethinking Electricity Tariffs and Subsidies in Pakistan." Policy Note, World Bank Report 62971-PK, World Bank, Washington, DC.

UN/ISDR (United Nations Office for Disaster Risk Reduction), 2008. Linking Disaster Risk Reduction and Poverty Reduction: Good Practices and Lessons Learned. Geneva: United Nations.

Valente, Christine. 2011. "What Did the Maoists Ever Do for Us? Education and Marriage of Women Exposed to Civil Conflict in Nepal." Policy Research Working Paper 5741, World Bank, Washington, DC.
Wahid, Umar, and Sally Wallace. 2008. "Incidence of Taxes in Pakistan: Primer and Estimates." International Studies Program Working Paper 08-13, Andrew Young School of Policy Studies, Georgia State University, Atlanta, GA.

World Bank. n.d. Migration and Remittances Data [database]. World Bank, Washington, DC. http://go.worldbank.org/092X1CHHD0). 1990. World Development Report 1990: Poverty. New York: Oxford University Press.

- 2005. Bihar: Towards a Development Strategy. Washington, DC: World Bank.

- 2009a. Pakistan: Tax Policy Report: Tapping Tax Bases for Development. Vol 2. Washington, DC: World Bank.

- 2009b. South Asia: Shared Views on Development and Climate Change. Washington, DC: World Bank.

. 2010. Bangladesh: Public Expenditure and Institutional Review: Towards a Better Quality of Public Expenditure. Report No. 47767BD. Dhaka and Washington, DC: World Bank. - 2012a. Creating Fiscal Space through Revenue Mobilization. South Asia Economic Focus. Washington, DC: World Bank.

— . 2012b. "Pakistan: From Raising Spending to Spending for Results: A Review of Public Expenditure, Procurement and Financial Management Practices." Processed, World Bank, Washington, DC.

2012c. More and Better Jobs in South Asia. Washington, DC: World Bank.

_. 2013a. Bangladesh Poverty Assessment: Assessing a Decade of Progress in Reducing Poverty, 2000-2010. Dhaka and Washington, DC: World Bank.

- 2013b. Pakistan-Towards an Integrated National Safety Net System: Assisting Poor and Vulnerable Households, an Analysis of Pakistan's Main Cash Transfer Program. Washington, DC: World Bank.

- 2014. The State of Social Safety Nets 2014. Washington, DC: World Bank.

Younger, Stephen D., David E. Sahn, Steven Haggblade, and Paul A. Dorosh. 1999. "Tax Incidence in Madagascar: An Analysis Using Household Data." World Bank Economic Review 13 (2): 303-31.

Zolt, Eric M. 2008. "Inequality, Collective Action, and Taxing and Spending Patterns of State and Local Governments." Tax Law Review 62 (4): 445. 



\section{ECO-AUDIT \\ Environmental Benefits Statement}

The World Bank is committed to preserving endangered forests and natural resources. Addressing Inequality in South Asia was printed on recycled paper with 30 percent postconsumer fiber in accordance with the recommended standards for paper usage set by the Green Press Initiative, a nonprofit program supporting publishers in using fiber that is not sourced from endangered forests. For more information, visit www.greenpressinitiative .org.

Saved:

- 25 trees

- 11 million BTU of total energy

- 2,164 pounds of net greenhouse gases $\left(\mathrm{CO}_{2}\right.$ equivalent)

- 11,735 gallons of waste water

- 785 pounds of solid waste 
South Asia Development Matters

Inequality in South Asia appears to be moderate when looking at standard indicators, such as the Gin index, that are based on consumption expenditures per capita. But other pieces of evidence reveal enormous gaps, from extravagant wealth at one end to appalling human development outcomes at the other. Which prompts the question: How bad is inequality in South Asia? And why would that matter?

Addressing Inequality in South Asia takes a comprehensive look at the extent, nature, and drivers of inequality in this very dynamic region of the world. It discusses how some dimensions of inequality, such as high returns to investments in human capital, contribute to economic growth while others, such as high payoffs to rent-seeking, or broken aspirations, undermine it. Drawing on a variety of data sources, it disentangles the contribution that opportunity in young age, mobility in adult years, and support throughout life make to inequality at any point in time.

The analysis shows that South Asia performs poorly in terms of opportunity. Access to basic services is partial at best, and can be traced to characteristics at birth, including gender, location, and caste. Conversely, despite its cluttered urbanization and widespread informality, the region has had a robust performance in terms of mobility, both across generations and within the same generation. Migration and jobs have served disadvantaged groups well, highlighting the importance of the urbanization and private sector development agendas. Finally, support falls somewhere in between.

Poverty alleviation programs are pervasive, but the mobilization of public resources is limited and much of it is wasted in regressive subsidies, while intergovernmental transfers do not do enough to mitigate spatial inequalities.

ISBN 978-1-4648-0022-1

WORLD BANK GROUP

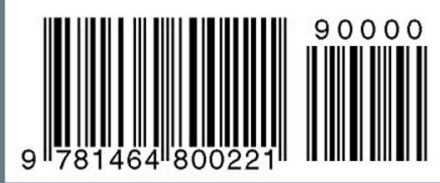

SKY 210022 